\title{
Distributive Justice and Transportation Equity: Inequality in accessibility in Rio de Janeiro
}

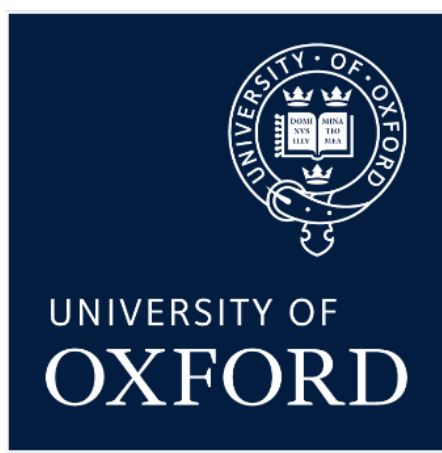

\section{Rafael Henrique Moraes Pereira}

Transport Studies Unit, School of Geography and the Environment

St Edmund Hall College

University of Oxford

Thesis presented for the degree of Doctor of Philosophy at the University of Oxford Oxford, June 2018 
"The natural distribution is neither just nor unjust; nor is it unjust that persons are born into society at some particular position. These are simply natural facts. What is just and unjust is the way that institutions deal with these facts."

John Rawls 


\section{Abstract}

Public transport policies play a key role in shaping the social and spatial structure of cities. These policies influence how easily people can access opportunities, including health and educational services and job positions. The accessibility impacts of transport policies thus have important implications for social inequalities and for the promotion of just and inclusive cities. However, in the transportation literature, there is still little theoretically informed understanding of justice and what it means in the context of transport policies. Moreover, few studies have moved beyond descriptive analyses of accessibility inequalities to evaluate how much those inequalities result from transport policies themselves. This is particularly true in cities from the global South, where accessibility and equity have so far remained marginal concerns in the policy realm.

This thesis builds on theories of distributive justice and examines how they can guide the evaluation of transport policies and plans. It points to pathways for rigorous assessment of the accessibility impacts of transport policies and it contributes to current discussions on transportation equity. A justice framework is developed to assess the distributional effects of transport policies. This framework is then applied to evaluate recent transport policies developed in Rio de Janeiro (Brazil) in preparation to host sports mega-events, such as the 2014 FIFA World Cup and the 2016 Olympic Games, which included substantial expansion of the rail and Bus Rapid Transit (BRT) infrastructure. This research presents ex-post analyses of the policies implemented between 2014 and 2017 and ex-ante analysis of an as yet unfinished BRT project. It evaluates how the planned transport legacy of those megaevents impacted accessibility to sports venues, healthcare facilities, public schools and job opportunities for different income groups.

The results show that there were overall accessibility benefits from the expansion in transport infrastructure between 2014 and 2017, but these were generally offset by the reduction in bus service levels that followed an economic crisis that hit the city after the Olympics. Quasi-counterfactual analysis suggests that, even if the city had not been hit by the economic crisis, recent transport investments related to mega-events would have led to higher accessibility gains for wealthier groups and increased inequalities in access to 
opportunities. Results suggest that those investments had, or would have had, greater impact on inequalities of access to jobs than in access to schools and healthcare facilities. The evaluation of the future accessibility impacts of the unfinished BRT corridor, nonetheless, indicates that such project could significantly improve access to job opportunities for a large share of Rio's population, particularly lower-income groups. Spatial analysis techniques show that the magnitude and statistical significance of these results depend on the spatial scale and travel time threshold selected for cumulative opportunity accessibility analysis. These results demonstrate that the ad-hoc methodological choices of accessibility analysis commonly used in the academic and policy literature can change the conclusions of equity assessments of transportation projects.

Key words: Accessibility; transportation equity; distributive justice; ethics; equality of opportunity; Rio de Janeiro; Brazil; legacy; Mega-events; Olympic games; transport policy; public transportation 


\section{Acknowledgements}

I would like to thank my supervisors David Banister and Tim Schwanen for their constant support and advice. Their meticulous attention to my drafts, thoughtful provocations and rich discussions provided invaluable guidance to my research. It has been a real privilege to learn from them and I know their influence on my work will extend much beyond this thesis. This thesis was written in memory of two mentors, Daniel Joseph Hogan and Brasilmar Ferreira Nunes, who were incredible advisors in my early career steps at the State University of Campinas (Unicamp) and at the University of Brasilia (UnB).

I am grateful to the European research network on Transport Equity Analysis - TEA COST Action. Being able to join the group has given me a unique opportunity to discuss transport justice with some great researchers and expand my collaboration network. These researchers include Karen Lucas, Karst Geurs, Karel Martens, Anders Wretstrand, Jean Ryan, Koos Fransen, Beatriz Mella, Thiago Guimarães and John Pritchard. I would like to thank Andherson Ojeda (Fetranspor) for his support with the data of Rio's transport system, and Nate Wessel (Toronto University) for the good time we spent together trying to crack the GPS data of Rio. I am also in debt to Thiago Hérick de Sá and Renato Arbex for the enthusiastic discussions. I would like to thank the support I received from my colleagues at TSU - Sally, Andre, Ersilia, Heuishil, Anna, Kirsty, Denver, Debbie and Christian - and at Ipea - Vanessa Nadalin, Bernardo Furtado, Pedro Souza, Leonardo Monasterio, Marcelo Medeiros, Daniel da Mata and Lucas Mation.

I am grateful to the WRI Ross Center for Sustainable Cities, for awarding me the 2017 Lee Schipper Memorial Scholarship. My PhD was funded by Capes Foundation, Ministry of Education, Brazil [Grant Number BEX 1397/13-3] and the Institute for Applied Economic Research (Ipea), to whom I am very grateful.

My journey in the UK could not have been completed without the support of some of the wonderful friends I have made along the way. These include my closest Teddy Hall community - Lucía, Julia, Gaurav, Sudi, Aashique and Nassima - and the geography crew, whose important presence has been felt in some of the most joyful movements and also in 
the difficult ones, when we lost our friend Claudia Comberti: Emma, Edo, Anna Davidson, Victoria, Nico, Franzi, Kevin, Jakob, Kelsi, Pablo, YannicK, John Mittermeier, Negar, Maria Luisa, Gonzalo, Jose Luiz, Jerome, Homero, Christine, Filipa, Sisi, Johanna, Alice and Ben. My warm thanks to the Brazilian community in Oxford (Deia, Rosana, Luana, Sergio, Karen, Malu, Kathi, Rodolfo, Erick, Rodrigo, Steff, Mauricio, Anita, Thais e Juca) and at "the other place" (Matheus, Maria, Josie e Livia). You brought sunshine when there was none. Special thanks to my family, for the unconditional love and support: Maria Cristina Moraes Pereira, Eduardo Pereira, Flavio Eduardo Moraes Pereira, Stella Cristina Moraes Pereira, Leandro Garcia, Cleusa Maria Ramos de Freitas and Lucio Carneiro de Freitas.

My final thanks go to Fá (Fabiana Ramos de Freitas). My deepest gratitude for your persistent support, companionship, and for constantly pushing me to become a better person. Thank you for being by my side in this journey, for helping keep me sane and reminding me of the things that matter the most in life. You are the best third-supervisor I could have ever wanted. Love. 


\section{Publications}

The work presented in Chapters 2 to 5 has appeared or has been submitted to the following peer-reviewed journals:

1. Pereira, R. H. M., Schwanen, T., \& Banister, D. (2017). Distributive justice and equity in transportation. Transport Reviews, 37(2), 170-191. (Chapter 2).

https://doi.org/10.1080/01441647.2016.1257660

2. Pereira, R. H. M. (2018). Transport legacy of mega-events and the redistribution of accessibility to urban destinations. Cities, 81, 45-60. (Chapter 3).

https://doi.org/10.1016/j.cities.2018.03.013

3. Pereira, R. H. M., Banister, D., Schwanen, T., \& Wessel, N. (under review) Distributional effects of transport policies on inequalities in access to opportunities in Rio de Janeiro. Submitted to Transportation Research Part A: Policy and Practice. (Chapter 4).

4. Pereira, R. H. M. (under review) Future accessibility impacts of transport policy scenarios: equity and sensitivity to travel time thresholds for Bus Rapid Transit expansion in Rio de Janeiro. Journal of Transport Geography. (Chapter 5) 


\section{Contents}

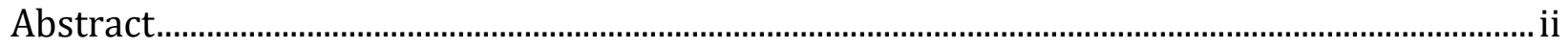

Acknowledgements ..............................................................................................................

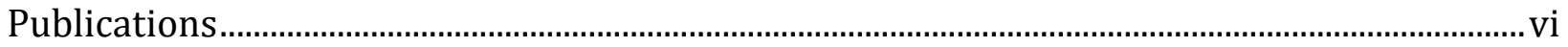

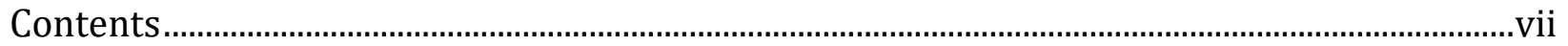

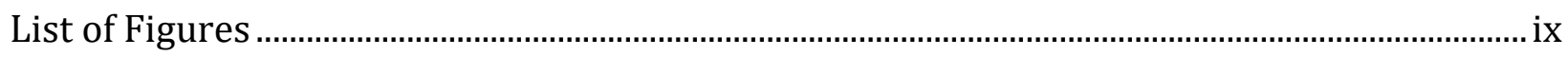

List of Tables .........................................................................................................................................

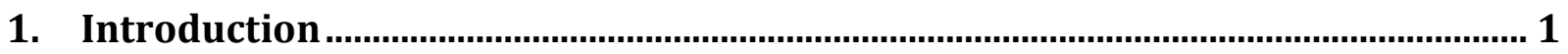

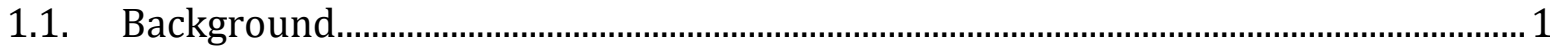

1.2. Nexus of justice and transportation................................................................................ 4

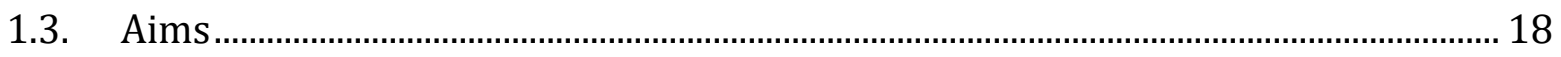

1.4. The case study choice: Rio de Janeiro, Brazil .............................................................. 18

1.5. Methodological overview...................................................................................... 25

1.6. Chapters Outline ................................................................................................... 31

2. Distributive justice and equity in transportation ....................................................36

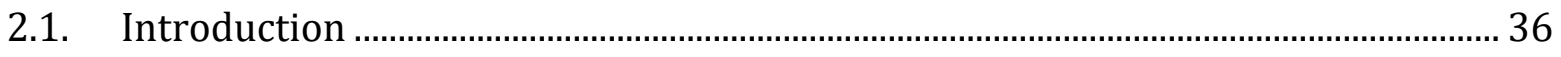

2.2. An overview of theories of justice in political philosophy ……………………........ 39

2.3. Transport disadvantage, social exclusion and equity in transportation ................ 48

2.4. Insights from political philosophy for transport policy and accessibility ............. 53

2.5. Conclusions ................................................................................................................... 63

\section{Transport legacy of mega-events and the redistribution of accessibility to}

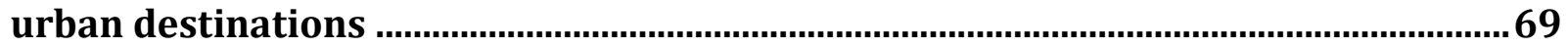

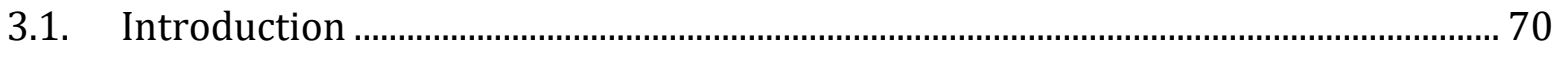

3.2. Mega-events, urban development and transport legacy ………………………........ 74

3.3. The transport legacy of Mega-events in Rio de Janeiro............................................ 80

3.4. Data and Methodology ……………………………................................................... 87

3.5. Results .................................................................................................................... 94

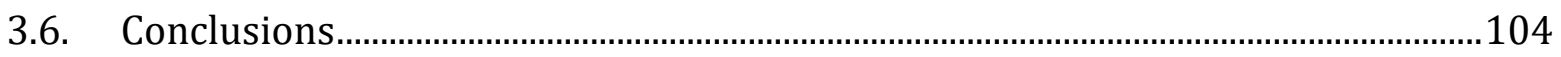




\section{Distributional effects of transport policies on inequalities in access to}

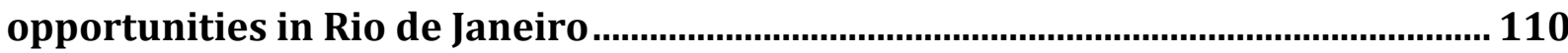

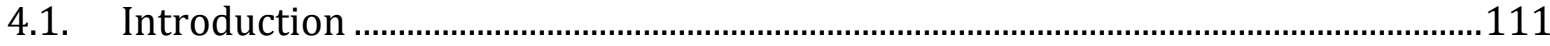

4.2. Literature Review - Transportation Equity...............................................................113

4.3. Study Area: Rio de Janeiro …………………............................................................116

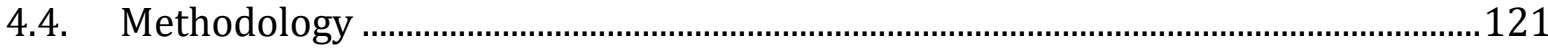

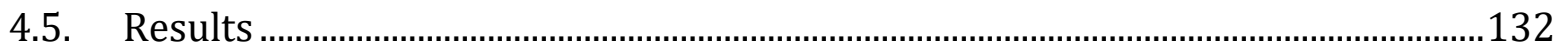

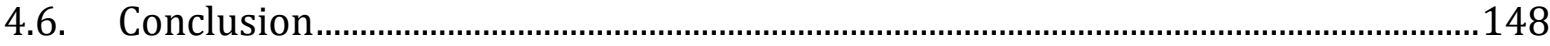

5. Future accessibility impacts of transport policy scenarios: equity and sensitivity to travel time thresholds for Bus Rapid Transit expansion in Rio de

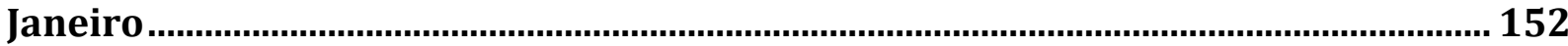

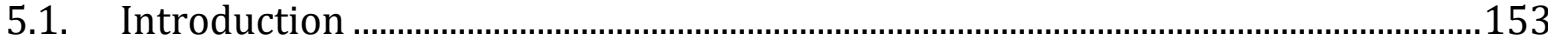

5.2. Transportation equity and accessibility..................................................................155

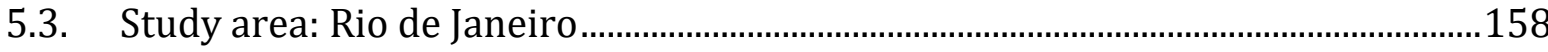

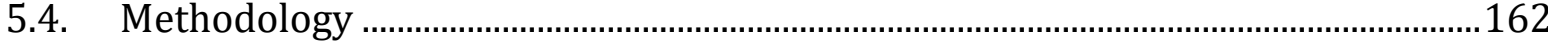

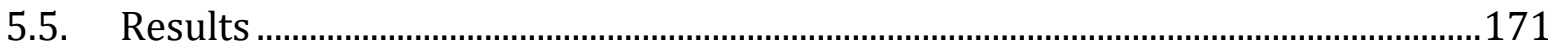

5.6. Conclusions ...............................................................................................................184

Appendix I - Stop sequence of the services planned to run in the TransBrasil BRT corridor

Appendix II - Operational information of the services planned to run in the TransBrasil BRT corridor ……………………………………………………………………………....190

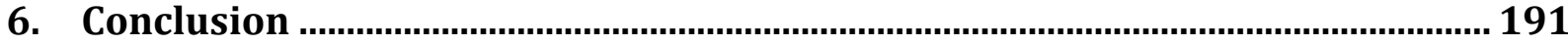

6.1. Thesis Summary ……………………………………………………………………191

6.2. Reflections on emerging issues...............................................................................203

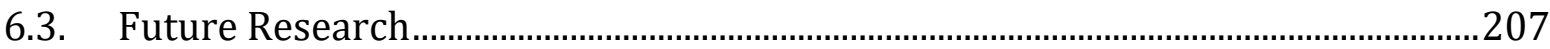

6.4. Policy recommendations......................................................................................215

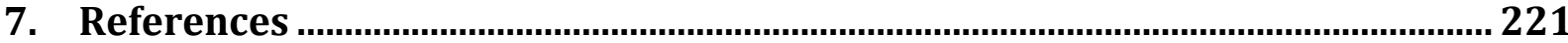




\section{List of Figures}

Figure 1.1 Municipality of Rio de Janeiro (dashed line), Brazil................................................... 20

Figure 1.2 Spatial distribution of population density and medium and large capacity transport corridors of Rio de Janeiro, 2017........................................................ 20

Figure 1.3 Spatial distribution of population classified by deciles of household income per capita and medium and large capacity transport corridors of Rio de Janeiro, 2017. 22

Figure 1.4 Medium and large capacity transport corridors. Rio de Janeiro, December 2017. 24

Figure 1.5 Typology of accessibility indicators........................................................................... 26

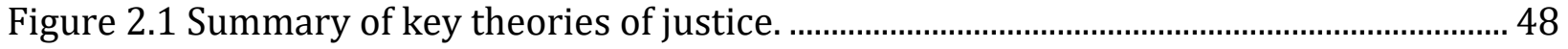

Figure 3.1 Spatial distribution of population, Olympic Sports Venues and high capacity transport corridors. Rio de Janeiro, 2010 …………………………………………... 81

Figure 3.2 Evictions in the city of Rio de Janeiro between 2009 and 2012............................... 86

Figure 3.3 Spatial distribution of healthcare facilities by level of service complexity. Rio de

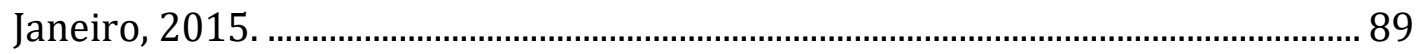

Figure 3.4 Spatial distribution of Olympic Sports Venues. Rio de Janeiro, 2016 ..................... 90

Figure 3.5 Proportion of the city population within the catchment area of 60 minutes by public transport and walking. Rio de Janeiro, 2014 and 2017. ........................... 95

Figure 3.6 Variation in percentage points of the city population within the catchment area of 60 minutes by public transport and walking in implemented and counterfactual scenarios. Rio de Janeiro, 2014 and 2017. 96

Figure 3.7 Population size and income composition within the catchment area of 60 minutes by public transport and walking of Olympic Sports Venues. Rio de Janeiro, 20142017. 98

Figure 3.8 Variation in the population size (by income groups) of the catchment areas of 60 minutes by public transport and walking of Olympic Sports Venues between 2014 and 2017. Rio de Janeiro. 99 
Figure 3.9 Population size and income composition within a 30 min catchment area of healthcare facilities by service complexity. Rio de Janeiro, 2014-2017............101

Figure 3.10 Variation in the population size (by income) within a 30 min catchment area of healthcare facilities (by service complexity) between 2014 and 2017. Rio de Janeiro. 103

Figure 4.1 Spatial distribution of the population and new public transport infrastructure. Rio de Janeiro, 2017.

Figure 4.2 Spatial distribution of population classified by deciles of household income per capita. Rio de Janeiro, 2010. 133

Figure 4.3 Median proportion of formal jobs accessible within 1 hour by public transport and walking between 7am and 7pm. Rio de Janeiro, 2017. 134

Figure 4.4 Median proportion of public high-schools accessible within 1 hour by public transport and walking between 7am and 7pm. Rio de Janeiro, 2017. 135

Figure 4.5 Proportion of formal jobs accessible from each grid cell via public transport and walking under 1 hour in the years 2014 ( $\mathrm{X}$ axis) and 2017 (Y axis) in implemented and counterfactual scenarios. Rio de Janeiro. 138

Figure 4.6 Proportion of public high-schools accessible from each grid cell via public transport and walking under 1 hour in the years 2014 (X axis) and 2017 (Y axis) in implemented and counterfactual scenarios. Rio de Janeiro.

Figure 4.7 Bivariate LISA based spatial clusters showing the local association between average household income per capita and gains in access to formal job opportunities by public transport between 2014 and 2017. Rio de Janeiro...146

Figure 4.8 Bivariate LISA based spatial clusters showing the local association between average household income per capita and gains in access to public high-schools by public transport between 2014 and 2017. Rio de Janeiro 147

Figure 5.1 Medium and large capacity transport corridors. Rio de Janeiro, 2017. 159

Figure 5.2 Detail of the TransBrasil BRT corridor. Rio de Janeiro, 2017. 161

Figure 5.3 Figure 5.3 Variation in the proportion of formal jobs accessible within various travel time thresholds via public transport and walking under full (A) and partial (B) operation scenarios of the TransBrasil BRT project. Rio de Janeiro. 
Figure 5.4 Detail of the variation in the proportion of formal jobs accessible within various travel time thresholds via public transport and walking under full (A) and partial (B) operation scenarios of the TransBrasil BRT project. Rio de Janeiro.

Figure 5.5 Distribution of gains in job accessibility via public transport and walking by income groups under partial and full operation scenarios given various travel time thresholds. Rio de Janeiro. 180 


\section{List of Tables}

Table 3.1 Summary of new public transport investments. Rio de Janeiro, 2012-2016 ......... 84

Table 3.2 Data sources used in the empirical analysis................................................................ 88

Table 4.1 Affordability index of public transportation by income decile. Rio de Janeiro....117

Table 4.2 Total effects of spatial Durbin model showing association with gains in access to public high-schools under various spatial scales and zoning schemes................141

Table 4.3 Total effects of spatial Durbin model showing association with gains in access to formal jobs under various spatial scales and zoning schemes.

Table 4.4 Total effects of spatial Durbin model showing association with gains in access to public high-schools in quasi-counterfactual scenario under various spatial scales and zoning schemes. 143

Table 4.5 Total effects of spatial Durbin model showing association with gains in access to formal jobs in quasi-counterfactual scenario under various spatial scales and zoning schemes. 144

Table 5.1 Summary of the impact of the TransBrasil BRT project on people's access to job opportunities within various travel time thresholds under partial and full operation scenarios. Rio de Janeiro.

Table 5.2 Total effects of spatial Durbin model showing association with gains in access to formal jobs given various travel time thresholds under full operation scenario of TransBrasil BRT.

Table 5.3 Total effects of spatial Durbin model showing association with gains in access to formal jobs given various travel time thresholds under partial operation scenario of TransBrasil BRT. 183 


\section{Introduction}

\subsection{Background}

Geographers and other social scientists have long studied the complex relationship between transport conditions, social exclusion and spatial inequalities (Currie et al., 2010; Lucas, 2012; Preston \& Rajé, 2007). Public transport infrastructure and services have the potential to significantly impact people's social and economic well-being by shaping their ability to access opportunities that are essential to human development, such as employment, healthcare and education (Farrington, 2007; Foth et al., 2013; van Wee \& Geurs, 2011). Nonetheless, different studies have shown that certain groups such as low-income families, elderly and disabled people, women and ethnic minorities often suffer disproportionately from transport disadvantages such as the lack of adequate public and private transport options and other travel difficulties related to affordability, health and safety issues (Akyelken, 2017; Lucas et al., 2016; Preston \& Rajé, 2007; Sanchez et al., 2003). These disadvantages are particularly acute in low-income and marginalized areas, where poor transport combined with the lack of economic opportunities and basic services can potentially lead to spatial poverty traps and deepen socio-spatial inequalities (Cervero et al., 2002; Lucas et al., 2016; Porter, 2014). In this sense, accessibility constraints are at the same time a reflection of, and a force acting to deepen broader social and spatial inequalities in society.

In recent years, transport researchers and practitioners have become increasingly interested in understanding the differential impacts of transport policies on different social 
groups, and particularly on the potential role of transport and land use policies in tackling issues of social exclusion and inequalities (Banister, 2008, 2018; Boschmann \& Kwan, 2008). In 2015, the member countries of the United Nations signed a resolution on Sustainable Development Goals with 169 targets, five of which aim at promoting equitable access to infrastructure and urban services, sustainable transport systems and equality of opportunities (United Nations, 2015).

Nevertheless, the idea of justice has received little theoretical consideration in the transportation literature, which has been primarily based on empirical approaches describing socio-spatial inequalities in people's travel behavior and access to urban services and to the labor market (Welch, 2013; Vasconcellos, 2005; Kawabata \& Shen, 2007). Some notable exceptions, discussed below, include a small but expanding number of studies which explore how different ethical theories and principles can be used to incorporate equity concerns in transport planning and appraisal (e.g. Lucas et al., 2015; Martens, 2016; van Wee \& Roeser, 2013). A more consistent engagement with ethical theories of justice can help provide conceptual clarity about what justice means in the context of transport policies (Davoudi \& Brooks, 2014; van Wee, 2011). From a theoretical point of view, this conceptual clarity also allows for a more nuanced understanding of the relationship between transport disadvantages and social inequalities. From a practical standpoint, in-depth engagement with theories of justice can have relevant implications for the conceptualization and measurement of transport disadvantages and accessibility and on decisions about transport policy priorities to tackle such inequalities (Lucas et al., 2015; Martens, 2011; Neutens, 2015). 
A prominent feature of Geography as a discipline has been its contribution to the development of a critical theoretical understanding of the spatial dimension of social justice. Alongside other social scientists and philosophers, geographers have extensively studied the social, economic and political processes that shape social and spatial inequalities in cities by mobilizing theories and concepts related to democratic governance, diversity, power and the right to the city, among others (Fainstein, 2010; Harvey, 2009; Purcell, 2014; Soja, 2010; Young, 1990). Questions of distributive justice, however, have received less theoretical attention in transport geography but provide a valuable moral compass that help assess the fairness of how the distribution of the benefits and burdens of transport policies shapes social and spatial inequalities in access to opportunities. The call for distributive justice does not exhaust a broader conception of justice, and yet justice cannot be achieved without it.

This thesis focuses on distributive justice to address questions of how transportation policies fundamentally affect people's lives by shaping the geographies of access to opportunities. Accessibility can be broadly conceptualized as the ease with which people can reach places and opportunities, or conversely, a characteristic of places and opportunities in terms of how easily they can be reached by the population (Kwan, 1998; Neutens et al., 2010). Accessibility is a central concern in transportation equity for various reasons. In the transportation equity literature, inequalities in transport accessibility have been widely associated with the idea of inequality of opportunities, one of the most central concerns of distributive justice (Chetty et al., 2014; Delbosc \& Currie, 2011; Delmelle \& Casas, 2012; Neutens et al., 2010). As such, the concern with inequality of opportunities places the geographical concept of accessibility at the heart of distributive justice in the transport context. Moreover, transport accessibility is critical to the satisfaction of individual and 
social needs and a necessary, though not sufficient, condition for the expansion of people's freedom of choice and promotion of equality of access to opportunities such as employment, healthcare and education (Church et al., 2000; Delmelle \& Casas, 2012; Kaplan et al., 2014). The idea of accessibility thus unpacks the spatial dimension of social injustices and helps to explicitly incorporate the notion of space into the design of policies intended to address those injustices (Farrington \& Farrington, 2005). For these reasons, accessibility can be considered a key concept to critically evaluate transport policies from a distributive justice perspective.

\subsection{Nexus of justice and transportation}

The idea of justice has been addressed from a variety of different theoretical approaches (Kymlicka, 2002; Young, 1990). It broadly involves moral and political concerns related to (1) the rights and entitlements which should be recognized and enforced, (2) the fairness of the political processes of participation in decision making and distribution; and (3) how benefits and burdens are distributed in society. In the urban studies and planning literature, the work of Susan Fainstein (2010) has made a valuable contribution by articulating that the idea of a "just city" encompasses a balance between those three types of justice concerns, what she refers to as diversity, democracy and equity (or distributive justice). As noted by Fainstein (2010, p.42), these are analytically separable but necessary and complementary components of a just society.

The concern with distributive justice relates to how the institutions and rules that govern society shape social and economic inequalities among its members. It focuses on the 
evaluative standards used to judge the outcomes of policies, asking who benefits from them and to what extent. Meanwhile, the concern with democracy relates to the challenge of moving beyond periodic voting and overcoming technocratic top-down planning practices. It involves the ideal that everyone's opinion should be equally heard in the decision-making processes that form institutions and the public policies that shape the built environment. Finally, the concern with diversity involves facing the fact that participatory democracy is constantly marked by structural imbalances of wealth and power that marginalize certain groups and favor others in their ability to influence policy decisions. It requires the recognition of group-based differences and identities, and the promotion of diversity in decision-making processes in order to fight injustices caused by oppression in its various forms (Young, 1990, 2001). Related to the concerns with democracy and diversity is the idea of the "right to the city", which received little attention from Fainstein in her work on the just city, but which has occupied a central place in critical theories of justice (Harvey, 2009; Purcell, 2014; Soja, 2010). Originally proposed by Henri Lefebvre in the late 1960s, the idea of right to the city revolves around the political struggles over who has the power to influence and shape urbanized space. It is broadly understood as a claim for people to reshape the processes of urbanization through collective action and self-management and to overcome the uneven geography of power and privilege in cities (Soja, 2010). According to Purcell (2002), the idea of the right to the city is an aspiration for "a radical restructuring of social, political, and economic relations" that reorients decision-making in cities away from the state and that advocates decentralizing decisions and production of urban space.

Much of the critical literature on justice that developed from the perspectives of democracy, diversity and the right to the city was initially motivated by reactions to liberal 
theories of distributive justice and their limitations (Kymlicka, 2002). These theories of distributive justice have been criticized for holding fundamentally aspatial and ahistorical notions of justice that abstract distributional inequalities from geographical space and social context (Harvey, 2009; Soja, 2010). According to Soji (2010), theories of distributive justice like the one proposed by Rawls (2001) are also incomplete because they narrowly delimit the scope of justice within the formal and legal institutions of the state. Other authors, including Fraser (1995) and Young $(1990,2001)$, argue that a key limitation of a distributive justice perspective is that it focuses only on distributional outcomes while ignoring that the root causes of such distributions are structural issues of power and oppression that shape production and public policy formation.

Even though a distributive justice perspective does not exhaust all issues of a broad understanding of justice, it can bring an important complementary perspective on justice concerns. Although it assesses the justice of social arrangements from the standpoint of distribution, it need not mean that remedies for injustices should be limited to redistributional measures (Fraser, 1995). Instead, the study of social and spatial inequalities can help make visible the underlying structurally unjust aspects of how society and government institutions are organized. According to Soja (2010), distributional inequalities are "the most basic and obvious expression of spatial injustice." Furthermore, despite various struggles for justice that happen outside formal institutional settings, government policies still have a crucial role to play in social democracies through the provision of public goods and services. This is particularly true in the provision of mass transportation, which often involves the mobilization of substantial resources and construction of large infrastructure projects which cannot be easily provided in a decentralized manner through 
local communities. In this sense, public transport services and investments will remain one of the key drivers that can shape spatial inequalities of development and opportunities in cities (Tonkiss, 2013), making the study of the distributional effects of transport policies particularly important. Moreover, even a genuinely diverse, democratic and inclusive participatory planning process is not a sufficient condition to ensure that the outcomes of transport policies are distributed equitably in a way that help promote equality of opportunities.

Finally, although liberal theories of distributive justice may not necessarily be universally applicable to all societies and historical periods, they bring valuable contributions to the reflection on justice in western liberal democratic societies at the beginning of the twenty-first century (Fainstein, 2010). These societies are founded on fundamental values and principles that form the shared basis of those theories. These principles include, among others, the belief that all individuals have equal moral worth, the idea of equality of opportunities and the respect for people's autonomy and their basic rights and liberties, such as the physical and psychological integrity of the person, political liberties and the rights and liberties covered by the rule of law. The fact that these principles are broad makes them useful to guide the assessment of injustices in a wide and diverse range of concrete cases while considering the particularities of each context, as it will be argued in the following chapters.

Concerns about justice are not new in urban and transport studies. In the late 1960s, a growing number of researchers started to investigate transport inequalities related to access to job opportunities (Kain, 1968; Wachs \& Kumagai, 1973), distribution of transport 
subsidies (Abe, 1975; Hefner, 1972) and differential levels of exposure to environmental externalities (Appleyard \& Lintell, 1972). Since then, the idea of justice has been addressed from various perspectives in the literature. Previous research has discussed, for example, the importance of democratic approaches to participatory planning in transportation (Booth \& Richardson, 2001; Hodgson \& Turner, 2003), the struggles over the recognition of mobility rights (Cresswell, 2006; Prytherch, 2012) as well as the role of transport and mobilities in promoting the right to the city (Attoh, 2012; Verlinghieri \& Venturini, 2017). Nevertheless, the bulk of this literature has focused on questions of distributive justice. While various studies have focused on the equitable distribution of transportation costs and subsidies (Levinson, 2010; Serebrisky et al., 2009) and on environmental justice issues (Feitelson, 2002; Schweitzer \& Valenzuela, 2004), questions of social exclusion and social inequalities have received the most attention in the literature (Ciommo \& Shiftan, 2017; Lucas, 2018; Preston \& Rajé, 2007).

Over the past decades, the literature on transportation equity that discusses questions of social exclusion and social inequalities has been largely empirical in nature (Ciommo \& Shiftan, 2017; Lucas, 2012). Within this empirical literature, the emphasis is usually on distributional justice rather than other forms of justice. The use of descriptive analysis of differences in travel-behavior or accessibility across social groups is commonplace and the idea of equity is often conflated with equality. The idea of equity is not to be confused with equality, however. While the idea of equity always implies a moral judgement, equality does not have to imply a normative stance if the term is used in a descriptive sense to indicate full equality or sameness (van Wee \& Geurs, 2011). The studies in transportation equity generally look at differences in the levels of accessibility to 
opportunities or daily travel behavior patterns of various social groups as proxies to reflect different levels of well-being or how those groups are more or less integrated into society (Akyelken, 2017; Fransen et al., 2018; Vasconcellos, 2005).

Looking at the city of Melbourne in Australia, for example, Delbosc and Currie (2011) used Lorenz curve and Gini coefficient to measure inequalities in the supply of (proximity to) public transport services. The authors found that $70 \%$ of the population shares only $19 \%$ of the transport supply, and that there was relatively higher supply of services for youth and low-income groups in inner Melbourne compared to the city average. Using a similar method to that of Delbosc and Currie, Ricciardi et al (2015) found that overall inequality in proximity to public transport services was smaller in the city of Perth than in Melbourne (Gini of 0.52 and 0.68 , respectively). Yet, Ricciardi and colleagues also found that three socially disadvantaged groups in Perth (elderly, low-income and households with no cars) had poorer access to public transport services than the overall population, what should raise questions about the limits of Lorenz curve and Gini coefficient to inform transport equity analysis. Using a different type of analysis, the study of Kawabata and Shen (2007) found that public transport users had considerably lower job accessibility than car users and that such inequalities remained fairly large across different areas of the San Francisco Bay area. Similar results were also found in other urban areas, such as in New York State (Hess, 2005), Tel Aviv (Benenson et al., 2011), and Hong Kong (Kwok \& Yeh, 2004). Most of these studies are based on cross-sectional analysis that does not allow capturing the effects of transport policies on the shaping of those inequalities. Moreover, much of this literature is based on data on differences in travel behavior, for example, in terms trip frequency or commute time. Nonetheless, observational data on inequalities of mobility outcomes offer limited insights 
into questions of transportation equity. Among other reasons, this is because these data cannot tell alone how much of those inequalities result from individuals' tastes and preferences (voluntary choice) and how much result from contextual constraints or systematic discrimination outside individual of control. From the perspective of transportation equity, it is crucial to differentiate the places people actually go to from the range of places they are able to access if they so choose.

Growing attention has been dedicated to understanding the differential effects of public transport investments and services on different social groups in terms of how they improve people's access to social and economic opportunities. The work of Foth et al. (2013), for example, analyzed the relationship between social disadvantage and accessibility to jobs in Toronto (Canada) before and after the implementation of several transport projects in the city between 1996 and 2006. The authors found that the policies implemented in the period improved accessibility significantly more for socially disadvantaged census tracts than for the rest of the region. A contrasting result was found by Delmelle and Casas (2012), who analyzed the impact of the construction of a Bus Rapid Transit (BRT) system in Cali (Colombia) on people's access to hospitals, libraries, and recreation facilities. Delmelle and Casas found that accessibility gains due to the new BRT were generally skewed in favor of the middle and upper-middle classes. These types of ex-post evaluations of the accessibility impacts of transport projects are increasingly being adopted by transport authorities, particularly in Western European and North American cities (Boisjoly \& El-Geneidy, 2017; Papa et al., 2015), to evaluate the different impacts of projects on different population groups (Karner \& Niemeier, 2013; Manaugh et al., 2015). Nonetheless, the use of ex-ante accessibility analysis has been much less explored as a useful tool to anticipate the likely 
impacts of different transport project scenarios in their early planning stages (Farber \& Grandez, 2017; Guthrie et al., 2017). Moreover, the research methods used in these studies are often based on statistical analysis that disregards spatial dependence in the data, which violates basic assumptions of standard regression analysis and leads to possibly flawed conclusions and policy prescriptions (Páez \& Scott, 2005).

Additionally, previous evaluations of the distributive impacts of transport policies have largely overlooked whether their results are robust to ad-hoc methodological decisions related, for instance, to the temporal and spatial scale of accessibility analysis. Much of the academic and policy research on transport accessibility, for example, measure accessibility levels using cumulative opportunity measures based on a single travel-time threshold defined ad-hoc and using transport and land use data aggregated in space according to arbitrary geographical scales and zonal schemes - such as census tracts or administrative boundaries (Boisjoly \& El-Geneidy, 2017; Manaugh et al., 2015). This question relates to what is known as the modifiable area unit problem (MAUP) and the modifiable temporal unit problem (MTUP) (Cheng \& Adepeju, 2014; Kwan \& Weber, 2008). These problems are a source of statistical bias that can significantly influence the results of spatial-temporal data analysis because of the different ways in which data can be organized/aggregated in space and time. While the MTUP has received little attention in the urban and transport literature in general (Huang \& Wong, 2015), previous studies have documented how MAUP can importantly influence the estimation of both transport accessibility levels and inequality, and subsequent policy recommendations (Horner \& Murray, 2004; Kwan \& Weber, 2008; Tan \& Samsudin, 2017). These problems of MAUP and MTUP raise important issues of spatial and temporal uncertainties that are receiving growing attention in geographic research 
(Kwan \& Schwanen, 2018), but which have not been dealt with in the transportation equity literature.

As a rule, the literature on transportation equity is predominantly empirical and it shows little engagement with political theories of justice. Some of the small number of studies in the transportation literature that address the topic of distributive justice from a conceptual point of view were published in the late 1970s by Rosenbloom and Altshuler (1977), whereas others appeared in the 1990s (Banister, 1994; Hay \& Trinder, 1991; Khisty, 1996; Langmyhr, 1997; Trinder et al., 1991). Drawing on the works of various philosophers from Aristotle to Barry (1965) and Rawls (1999) among others, these studies generally present an intuitionist approach whereby they discuss a series of competing moral principles which should guide transport policy decisions. These principles include, for example, the idea of basic needs, so that the allocation of transport services in each society should be guided to sustain what is acceptable as a minimum standard of living for the population in that society (sufficientarianism). Other principles include the ideas of formal equality, which requires that individuals who are alike in a relevant manner and belong to the same social group should be treated equally, and the principle of substantive equality, according to which people from different groups can be treated differently in order to promote equality of opportunities or outcomes. These principles of formal and substantive equality are often referred to as the principles of horizontal and vertical equity and have become the most common conceptual basis used in the transport equity literature in recent decades (Delbosc \& Currie, 2011; Levinson, 2002; Litman, 2002; Manaugh \& El-Geneidy, 2012; Sanchez et al., 2003; Venter et al., 2017). 
Only a few studies have tried to move beyond intuitive competing principles to engage with full-fledged theories of justice. Authors like Martens (2011) and van Wee (2011, 2012), for example, have argued strongly against a utilitarian view of justice. They criticize that the utilitarian moral reasoning that underlies cost-benefit analysis (CBA), conventionally used in transport project appraisal, does not seriously take into account how costs and benefits of transport policies are distributed across the population. In various studies, van Wee and colleagues also discussed how the interpretation of different ethical perspectives ranging from consequentialism, egalitarianism and sufficientarianism can inform the ex-ante evaluation of transport policies regarding issues of social exclusion and accessibility (Lucas et al., 2015; van Wee, 2012; van Wee \& Geurs, 2011; van Wee \& Roeser, 2013), intergenerational equity (van Wee, 2011), and environmental and safety considerations (van Wee et al., 2014; van Wee \& Rietveld, 2013). When it comes to the accessibility benefits of transport policies, in particular, the authors discuss how different theories of distributive justice including utilitarianism and Rawls's egalitarianism can provide different evaluative standards against which to evaluate the distribution of transport policy outcomes. Van Wee and colleagues $(2011 ; 2013)$ suggest, for example, that accessibility to some basic destinations can be interpreted as a Rawlsian primary social good and which also relates to the idea of human capabilities to perform activities, as developed in the capability approach (Nussbaum, 2011; Sen, 2009). Ultimately, van Wee and colleagues argue that the equity assessment of transport policies should ideally consider not only how such policies impact the absolute levels of people's accessibility but also how they change inequalities in the relative distribution of accessibility, incorporating both sufficientarian and egalitarian concerns. This work is revised with more detail in the next chapter of this 
thesis. For now, it suffices to say that these studies do not fully articulate Rawls's theory or the capabilities approach and, consequently, overlook some of the conceptual implications and practical challenges that these theories raise in relation to how the idea of accessibility should be operationalized to guide policy decisions. These issues are discussed in chapter 2 and later in chapter 6 of the thesis.

Another notable attempt to bring transport studies in dialogue with theories of justice can be found in the work of Martens $(2012,2016$; Martens et al., 2012), who focuses on the role of transport policies in tackling transport disadvantages and social exclusion. Martens selectively draws on elements of different theories to propose a distributive justice framework. Drawing on Walzer' theory of spheres of justice (Walzer, 1983), Martens proposes that because transportation has a distinct social meaning, the distribution of transportation "goods" should not be determined by market exchange, but rather should follow principles of justice. According to Martens, the social meaning of transportation and transport policies ultimately relies on the accessibility they confer to people. Martens then draws partially on the difference principle of Rawls's theory of justice (Rawls, 1999) to argue for a view that policies should prioritize disadvantaged groups, and on Dworkin's idea of compensatory insurance schemes (Dworkin, 1981b) to argue that transport policies should guarantee minimum accessibility levels. Given some fundamental disagreements between the theories of Walzer, Rawls and Dworkin (Kymlicka, 2002), however, it is not clear whether 
this approach of selectively engaging with parts of these theories of justice can provide a consistent framework ${ }^{1}$.

Furthermore, the framework proposed by Martens (2016) reduces the understanding of transportation equity to a sufficientarian problem related to an absolute minimum level of accessibility. He does not justify why questions of relative distribution of accessibility should be excluded from transportation equity concerns, even though situations in which transport policies increase accessibility inequalities by favoring well-off groups after the minimum standard has been satisfied for all individuals can be considered morally questionable (Lucas et al., 2015; Tyler, 2006). Martens is thus silent about problems of inequality of opportunities, a concern that is crucial across various theories of justice, including the ones developed by Walzer, Rawls and Dworkin upon which Martens' framework is based. Moreover, a narrow focus on sufficientarian concerns alone overlooks critical questions of environmental justice that arise from transport related inequalities. It overlooks, for example, how the excessive (auto)mobility of some have particularly negative effects on others. At a more local space-time scale, hegemonic automobility generates

\footnotetext{
${ }^{1}$ In the communitarian theory developed by Walzer, justice is a feature of a community, a collective project. In this view, any conception of justice cannot be universal because moral reasoning appeals to meanings internal to a community and not to abstract principles (Sandel, 1984). This is what Walzer means when he says that "every substantive account of distributive justice is a local account" (Walzer, 1983). Moreover, for Walzer, a separate distributive sphere emerges when a community shares a common understanding of the distinct social meaning of a good. The meaning of each sphere of justice and its distributive principle are intrinsically context specific; they are not compatible with, and cannot be deducted from, views of justice that arise from moral imperatives or logical axioms like Rawls's difference principle and Dworkin's insurance scheme (Armstrong, 2000; Sandel, 1984). In its turn, Dworkin's theory of justice rejects Rawls's difference principle for different reasons, including its focus on disadvantaged groups. For the individualistic theory espoused by Dworkin, Rawls's difference principle is too much focused on group comparisons and ends up overlooking the heterogeneity in individuals' preferences, ambitions and endowments within groups (Dworkin, 2000; Kymlicka, 2002).
} 
negative externalities such as road congestion, air pollution and traffic accidents that harm other people's health conditions and undermine accessibility of other transport modes like public transport, walking and cycling. On larger space-time scales, greenhouse gas emissions from widespread automobility contribute to sea level rise and climate change more generally, adversely affecting future generations across the world and their abilities to satisfy their mobility and other needs ${ }^{2}$. In other words, second and higher order effects are rendered invisible when justice is narrowed down to sufficientarianism.

Finally, there is also a growing theoretical work on "mobility justice" emerging in the sociological literature (Cook \& Butz, 2015; Sheller, 2013). There are important differences between the ways in which justice is addressed in the mobilities literature and in transportation studies. One of these differences is that the mobilities scholarship looks beyond urban and regional transport to incorporate a broader range of questions on differentiated mobilities at international and global scales related, for example, to tourism, migration and refugees (Sager, 2006; Sheller, 2016; Uteng \& Cresswell, 2008). Moreover, the mobilities literature also pays more attention to the insights from critical social theory (Marxism, feminism, post-colonialism) to draw attention to the politics of mobility involved in how institutional contexts and structural social conditions shape mobility systems and capacities (Cresswell, 2006, 2010; Manderscheid et al., 2014). This is the case, for example, of the work of Cook and Butz (2015), who engage with Young's critical theory of justice (Young, 1990). The authors conceptualize mobility justice as "not only as the equitable

\footnotetext{
${ }^{2}$ For a version of this latter argument, see Nixon \& Schwanen (2018) and Sheller's work on mobility justice (Sheller, 2016).
} 
distribution of motility throughout a social system, but also as just institutional actions and decision-making processes about mobility issues that promote just mobility outcomes" (Cook \& Butz, 2015, p.17). Nevertheless, there is still little clarity in the mobilities literature about what constitutes a just mobility outcome, and this literature has received little attention from scholars in transport studies. This thesis does not cover the mobilities literature in depth because the latter focuses more on questions of justice related to diversity and democracy (Fainstein, 2010), which goes beyond the scope of distributive justice of the thesis.

In summary, the literature on transportation equity exhibits several gaps which this thesis seeks to address. This literature generally lacks a more theoretically informed understanding of the idea of justice and how it translates into the context of transport policies. This literature is also largely based on empirical cross-sectional analysis of differences in accessibility levels between different social groups, but studies have paid less attention to ex-post and ex-ante evaluations of transport investments to investigate how much of those inequalities are determined by government policy. This is particularly true for cities in the Global South, which have received far less attention in the transportation equity literature with a few notable exceptions (Hernandez, 2017; Maia et al., 2016; Oviedo \& Dávila, 2016; Vermeiren et al., 2015). Finally, the studies that evaluate the distributional and accessibility impacts of transport projects are often based on simple or standard descriptive statistical analysis and, as a rule, do not question whether their results are robust to ad-hoc methodological choices regarding the temporal and spatial scale of accessibility analysis. This thesis advances previous research by proposing a distributive justice framework to guide the equity assessment of transportation policies. It also addresses some of the gaps in 
the literature by applying the proposed framework to the evaluation of the transport policies implemented in Rio de Janeiro (Brazil) in the mid-2010s, and using state of art methods of accessibility modeling and spatial analysis to evaluate how the accessibility benefits of those policies are distributed across space and income groups.

\subsection{Aims}

The aim of this thesis is threefold. The first is to develop a theoretical framework that can help guide the assessment of the distributive effects of transportation policies and that can nurture research on transportation equity more broadly. The second aim is to apply this framework in the evaluation of recent policies that were implemented in Rio de Janeiro (Brazil) in preparation to host sports mega-events, and examine the extent to which those policies have reshaped social and spatial inequalities in people's access to opportunities. Finally, the third aim of this thesis is to investigate whether the equity assessment of transport projects and their impacts on people's accessibility are sensitive to the temporal and spatial scales of accessibility analysis. The first aim is addressed in chapter 2 , while the second and third aims are addressed in the empirical chapters 3, 4 and 5.

\subsection{The case study choice: Rio de Janeiro, Brazil}

There are divergent views in the literature about the extent of urban development in the world and how much of the world population lives in urban areas today (Brenner \& Schmid, 2014). It is less controversial, though, that most of the population growth expected in urban 
areas in the next decades will happen in developing countries (Seto et al., 2012). It is also widely accepted that cities concentrate some of the most pressing challenges of transportation (Hickman et al., 2015). These challenges will likely intensify as the world becomes more urbanized, particularly in major cities of the Global South that face high population density and poor infrastructure (UN-HABITAT, 2010). In different ways, Rio de Janeiro shares many of the characteristics of cities in the Global South today and presents many of the challenges that other cities will increasingly face in the future, with high levels of social inequality, large and dense population and increasing automobile use.

Rio de Janeiro is the second largest city in Brazil, located in the southeast region of the country (Figure 1.1). In 2010, the municipality of Rio de Janeiro housed more than half of the population of the metropolitan area of over 12 million inhabitants and it had an average population density similar to that of Greater London, with approximately 5.5 thousand inhabitants per $\mathrm{km}^{2}$. Most of the city's population resides in the eastern half of the city, where large concentrations of population are found in the northeast and along the coast in the southeast of the city (Figure 1.2). 
Figure 1.1 Municipality of Rio de Janeiro (dashed line), Brazil.

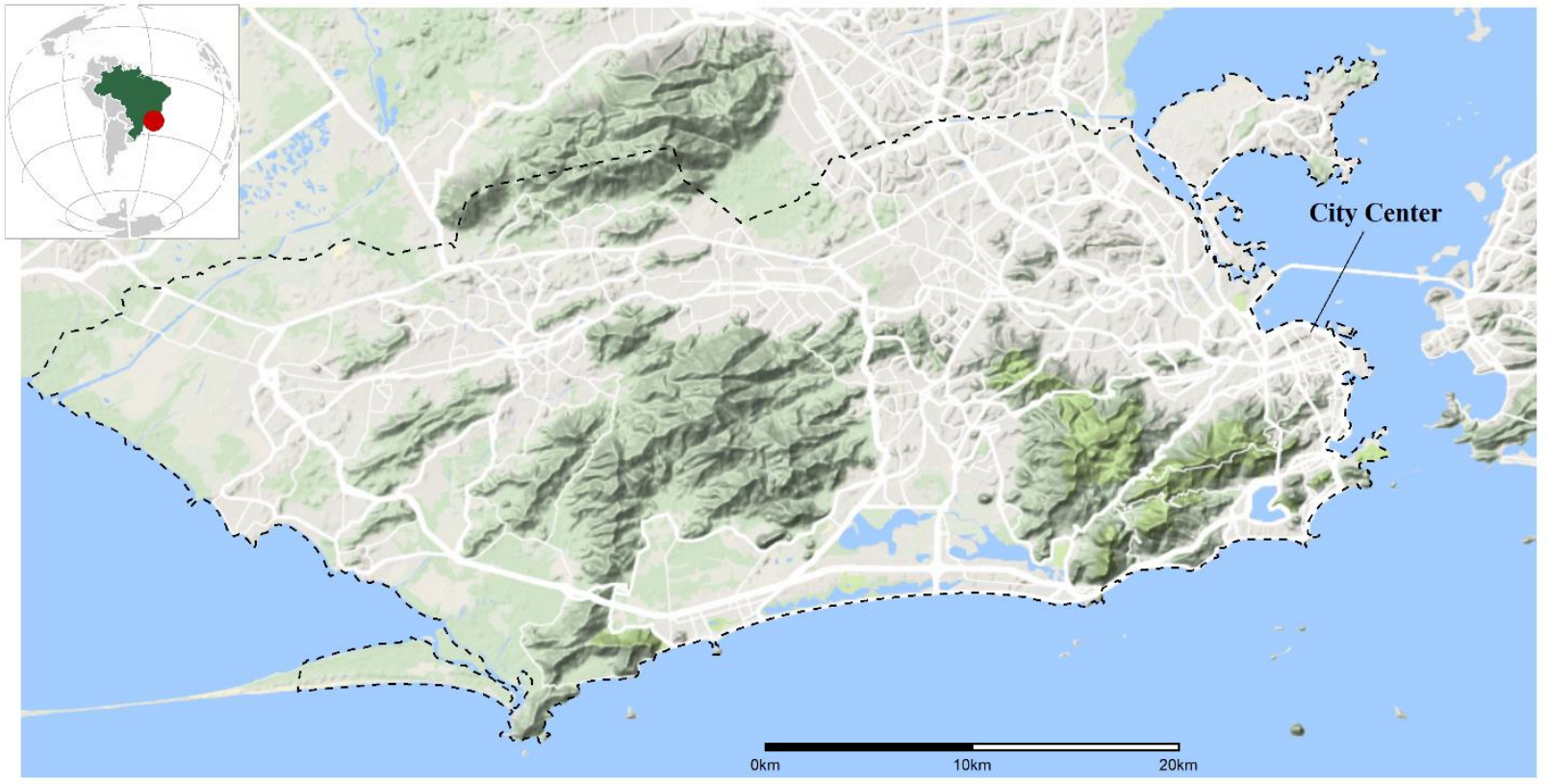

Figure 1.2 Spatial distribution of population density and medium and large capacity transport corridors of Rio de Janeiro, 2017.

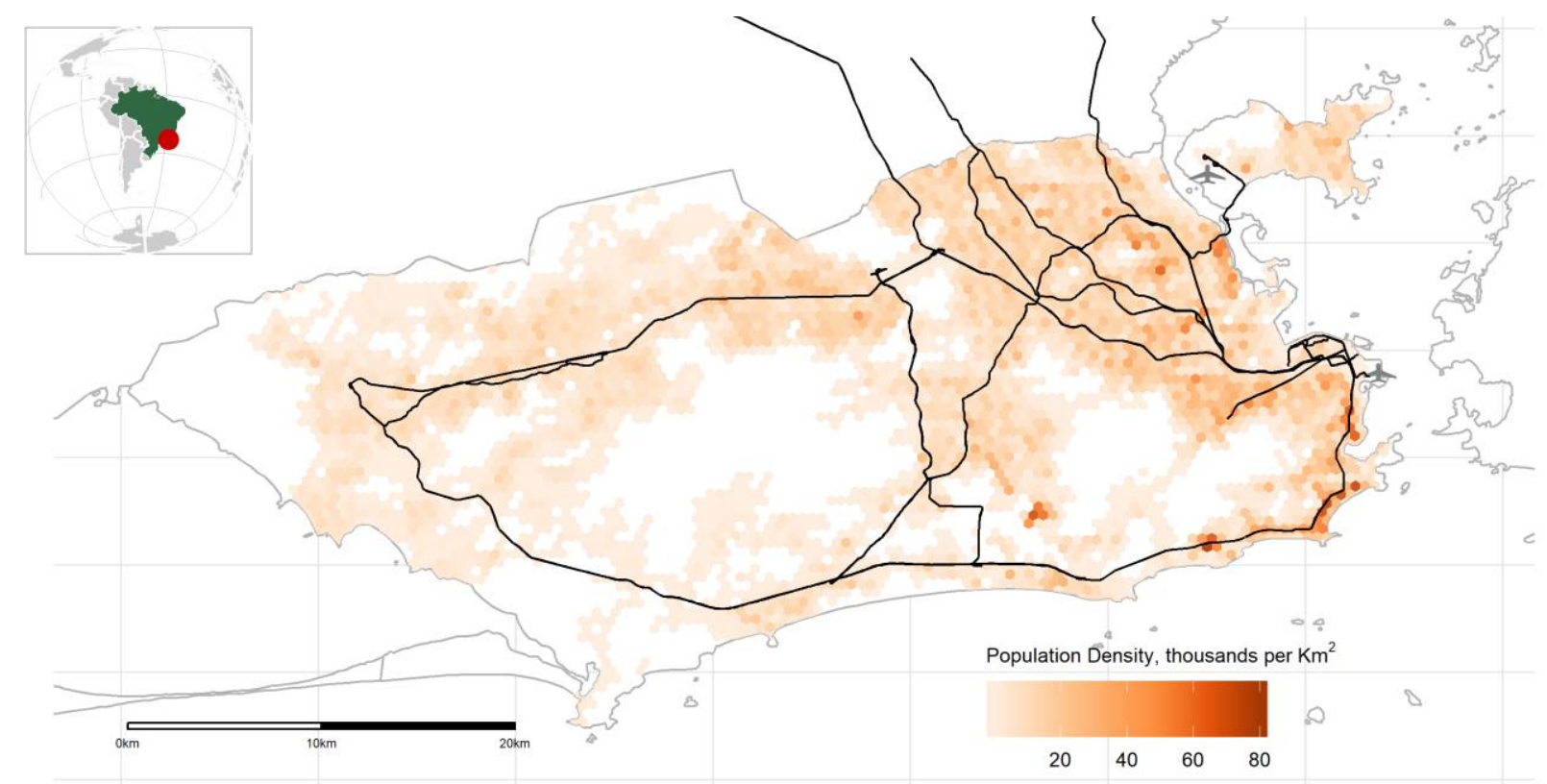

Note: Population data comes from the 2010 Population Census (IBGE, 2016). 
Rio is one of the richest cities in the Global South and yet also stands out as one of the most unequal cities in the world in terms of income distribution, with a Gini coefficient of 0.62 (PNUD et al., 2013). Compared to other major cities included in the UN-HABITAT report (2010), the level of income inequality in Rio de Janeiro is close to that observed in Cape Town, Bogotá or Lagos (Gini between 0.61 and 0.67) and higher than in cities like Santiago, Mexico City, Nairobi and Hong Kong (Gini between 0.53 and 0.55). A territorial expression of this income inequality in Rio de Janeiro is its socially fragmented urban space and the uneven provision of transport infrastructure. The research of Villaça (1998) and Lago (2000) have documented the spatial separation between social classes since the 1940s, largely shaped by urban development policies. Housing policies and housing costs near the city center have generally pushed lower-income families towards regions poorly served by urban infrastructure, particularly in the north and west areas of Rio, while higher income classes have historically benefited from the provision of transport services and better access to urban amenities and economic opportunities, concentrated along the coastal area and the city center (Barat, 1990; Câmara \& Banister, 1993; Rodrigues, 2013).

These inequalities are largely reflected nowadays in the spatial distribution of income groups in the city (Figure 1.3). A characteristic that distinguishes the spatial pattern of urban segregation in Rio from other cities is the presence of shantytowns (favelas), which occupy cheaper land in hilly areas across the city, not only in the periphery. Because of topographical conditions and vulnerability to hazards like mud slides, these hilly areas were not attractive to the formal housing market and were thus historically occupied by low income population. Some of the poor people living in the central favelas are in a relatively advantageous position from an accessibility standpoint because they face relatively shorter physical distances to 
some of the core areas of employment (Ribeiro et al., 2010; Ribeiro, 2017). Some of these central favelas can be seen in Figure 1.3, with pockets of low-income population (red colors) surrounded by higher-income (blue colors) in the south and east regions of Rio.

Figure 1.3 Spatial distribution of population classified by deciles of household income per capita and medium and large capacity transport corridors of Rio de Janeiro, 2017.

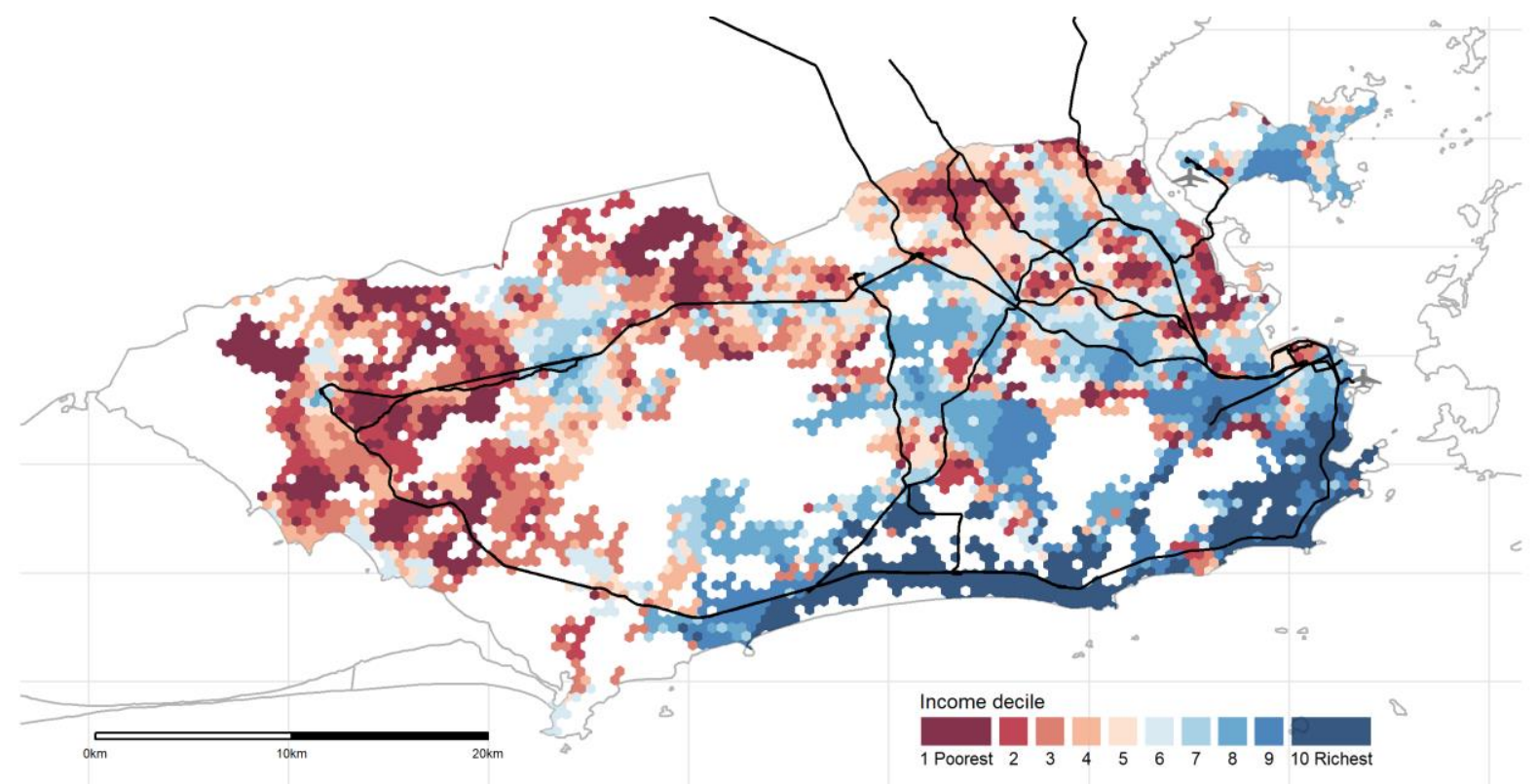

Note: Income data comes from the 2010 Population Census (IBGE, 2016).

Like many other cities in the Global South, transport conditions in Rio are extremely poor. In the past two decades, Rio has witnessed increasing congestion levels coupled with a substantial increase in car traffic, giving it one of the highest average commute times among global cities (Pereira \& Schwanen, 2013). The city's public transport system stands out as one of the most expensive in the world (UN HABITAT, 2013), and its governance structure has been widely criticized for being fragmented and lacking transparency (Costa et al., 2015; Matela, 2017). Urban mobility conditions in Rio are particularly poor in 
peripheral areas towards the northwest of the city, where the public transport network has limited connectivity (Rodrigues, 2013), and where low-income communities present significantly lower levels of participation in out-of-home activities (Motte-Baumvol \& Nassi, 2012). A peculiar characteristic of Rio's transport landscape is the way the city's marked topography has strongly shaped where urban infrastructure, including large-capacity transport corridors, can and cannot be built.

In recent years, however, the city of Rio has undergone major urban transformations in the run-up to host mega-events including the FIFA World Cup in 2014 and the Olympic Games in 2016. These events fast-tracked considerable investments in the city's public transport system (Gaffney, 2010; Rodrigues \& Legroux, 2015). Between 2012 and 2017, approximately $\mathrm{U} \$ 5.5$ billion was invested to build a new light rail system in the city center, a subway extension and four new bus rapid transit (BRT) corridors, one of which is still in construction phase (Figure 1.4). This expansion in public transport infrastructure was advertised as one of the main legacies of the recent sports mega-events, and according to local authorities, it would help the city overcome its socially fragmented urban development and improve transport conditions particularly for poor marginalized neighborhoods (BOC, 2009; Brazil, 2009; Rio de Janeiro, 2008). Shortly after the Olympics, though, the city was hit by a severe economic crisis, followed by rising unemployment rates and a drop in the number of passengers in the public transport system (França, 2016; Rodrigues, 2017). This led the government to adopt austerity measures, including substantial cuts in the budget of the Transportation Secretariat (Magalhães \& Rodrigues, 2017), and some bus companies went bankrupt (Borges, 2016; Zarur, 2017; Zuazo et al., 2017), affecting transport service levels in various parts of the city. The austerity measures adopted in Rio's public transport 
systems resonate well with the experience of many local authorities around the globe, but particularly in developing countries, which often need to invest and manage their transport systems under severe budgetary constraints.

Figure 1.4 Medium and large capacity transport corridors. Rio de Janeiro, December 2017.

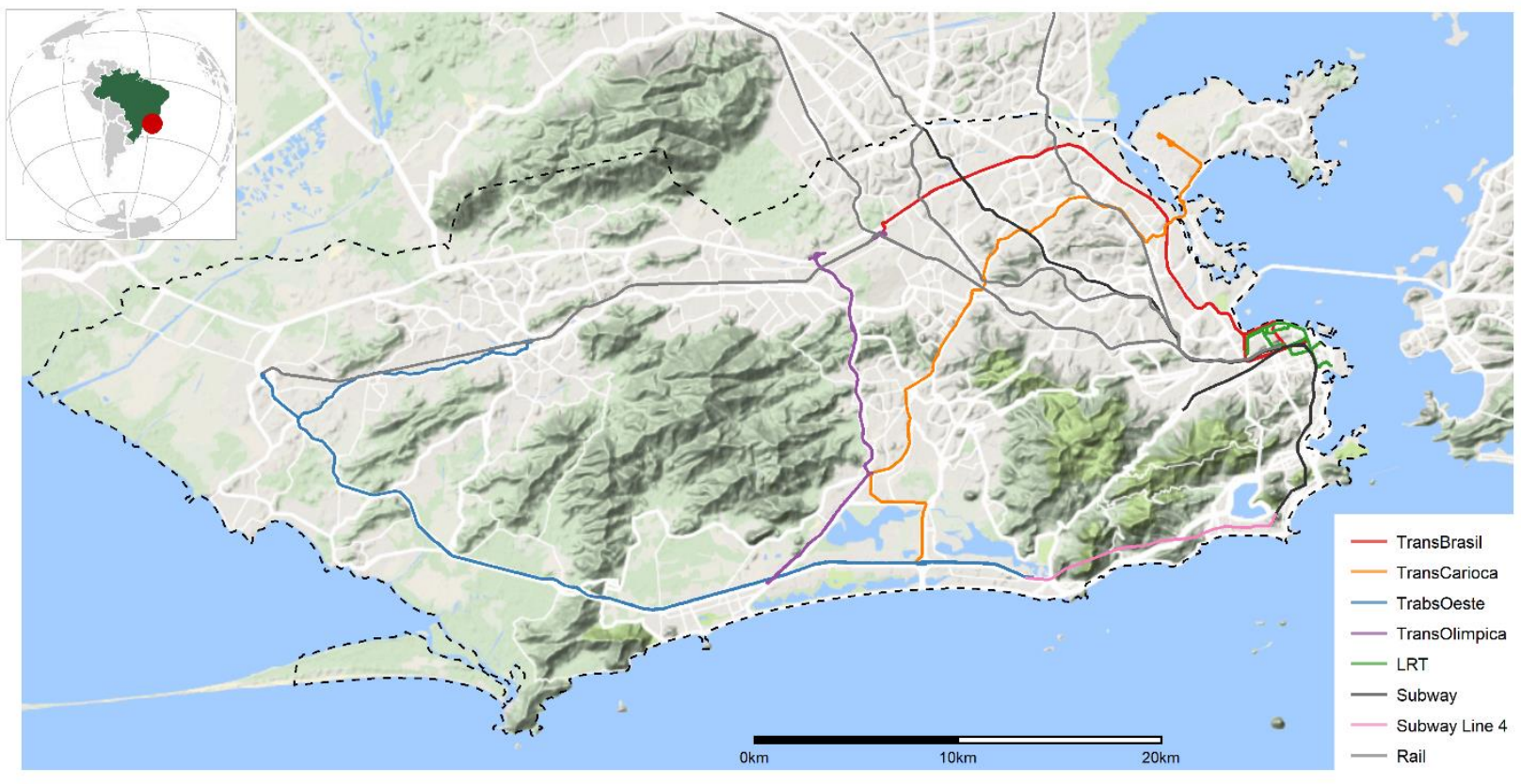

Note: As of June 2018, the TransBrasil BRT was still under construction.

In summary, Rio's public transport network has undergone both significant network expansion and service contraction in a relatively short period of time, giving a unique opportunity to assess its equity impacts on urban accessibility to various types of activities for populations of different income levels. The choice of focusing on inequalities in access to opportunities by income is motivated because of the extremely high levels of income inequality observed in Rio Janeiro and because low-income people are typically dependent on public transport services. Given the urban characteristics of Rio de Janeiro and these recent transformations in its transportation system, Rio is a timely case study to investigate 
the distributive effects of transportation policies and from which to draw lessons for other cities, particularly in the Global South.

\subsection{Methodological overview}

The research methods used in this thesis as well as its advantages and limitations are discussed in more detail in the empirical chapters 3, 4 and 5. For now, this section provides a brief overview of the methods used in the accessibility analyses that comprise the core element of the empirical research in those chapters.

\subsubsection{Accessibility metric}

Following the typology of accessibility indicators proposed by Dijst et al (2002), the concept of accessibility can be conceived from the perspective of individuals or from the perspective of the activity places (e.g. schools, companies and hospitals). From the individual perspective, accessibility is understood in relation to the area or opportunities a person can reach from her departure point, say her residential location for example. From the perspective of an activity place, on the other hand, accessibility is defined as "the space within which a set of people can choose a certain activity place as a destination, at acceptable (times) costs, from their departure locations" (Dijst et al., 2002). Furthermore, Dijst and colleagues propose that indicators used to operationalize the concept of accessibility can be classified either as place-based or person-based accessibility measures. Metrics in the first category reflect accessibility levels as characteristics of locations and include for example 
gravity and cumulative opportunity measures. In its turn, person-based accessibility measures not only relate to location characteristics but also take into account how personal characteristics such as age, gender and physical disabilities affect accessibility levels of a person. This category includes, for example, logsum and space-time accessibility measures. Figure 1.5 below shows how the empirical chapters of this thesis are positioned in relation to the $2 \times 2$ matrix typology of accessibility proposed by Dijst et al (2002).

Figure 1.5 Typology of accessibility indicators.

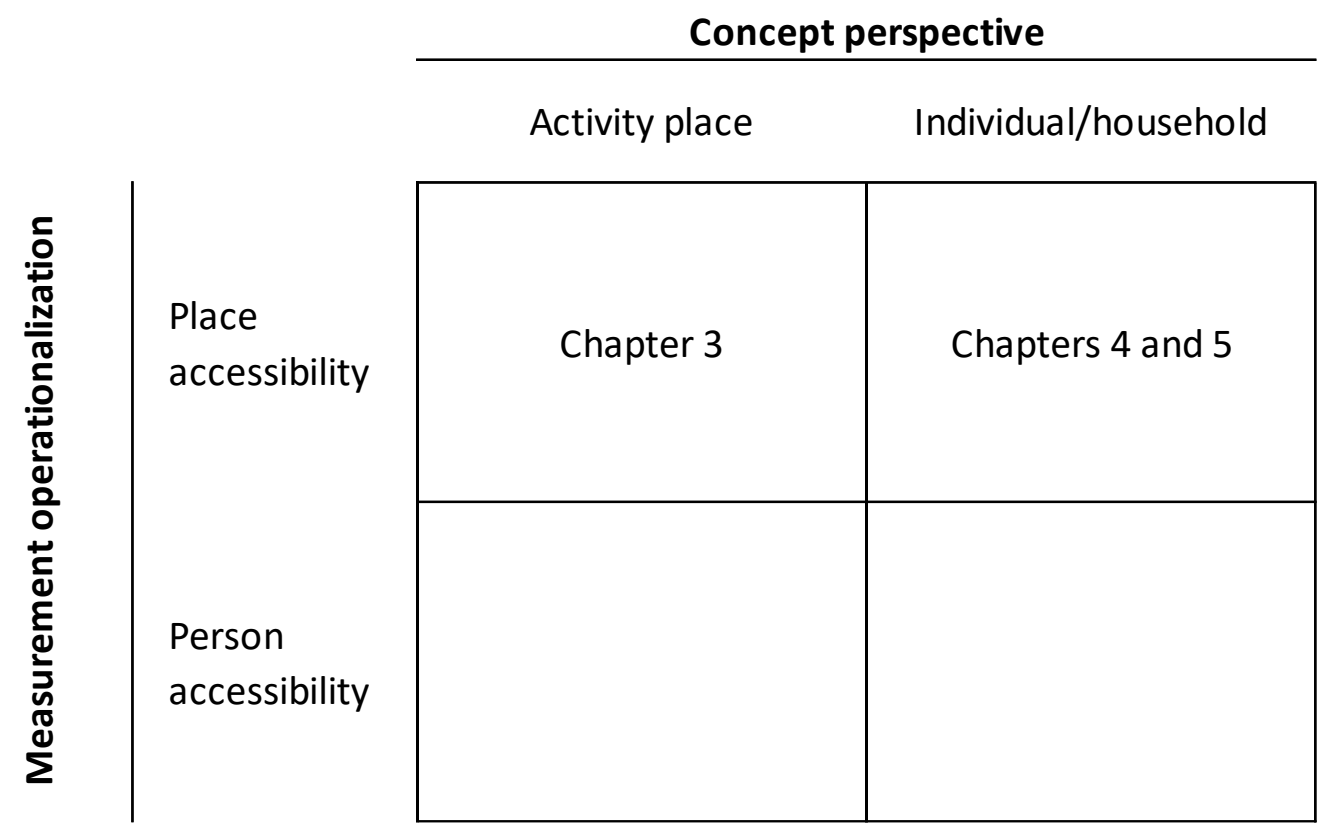

Source: adapted from Dijst et al (2002).

This thesis works with the concept of accessibility from both activity place and individual perspectives. Accessibility here is broadly understood as the ease with which people can reach places and opportunities, or conversely, a characteristic of places and 
opportunities in terms of how easily they can be reached by the population. Transport accessibility levels in Rio de Janeiro are measured using place-based cumulative-opportunity measures that take into account the complex spatial and temporal connectivity of a multimodal transport network and its interaction with land use patterns. The accessibility metrics used in the thesis do not capture the influence of personal characteristics on accessibility estimates (Geurs \& van Wee, 2004; van Wee \& Geurs, 2011), and may generally underestimate inequality levels (Kwan, 1998; Neutens et al., 2010). As will be discussed in chapter 2, transportation equity analyses should ideally be based on more comprehensive accessibility measures that consider how personal and cultural factors also influence people's capability to use transport systems and move around the city. However, detailed information on the influence that personal factors exercise on people's capability to use public transportation is rarely available in conventional transport surveys, and this type of data would have been extremely costly to collect at the individual level for a large city such as Rio de Janeiro. Given this data constraint, the accessibility analyses conducted in this thesis deploy place-based accessibility measures which relate to the characteristics of locations and their relative position in relation to transport networks and land use activities (Dijst et al., 2002). The accessibility calculations, statistical analysis and data visualizations presented in this thesis were conducted using R version 3.5 (R Core Team, 2018). The code is available on GitHub (https://github.com/rafapereirabr/thesis).

Cumulative-opportunity measures of accessibility (COMs) have been chosen for different reasons. In this thesis, accessibility measurements are used as indicators of the impact of transport policies on the organization of spatial inequalities in cities. COMs are particularly suited to examining how interventions in transport networks and land use 
patterns change the relative proximity between homes and social and economic opportunities. Moreover, because COMs are not based on information or assumptions about people's actual travel behavior, in contrast to gravitational or logsum measures (Neutens et al., 2010), cumulative opportunity measures can represent the places and opportunities people can potentially reach without replicating biases in past travel behavior patterns, and thus align better with the purposes of this thesis. In this sense, COMs can better embody concerns with equality of opportunities than equality of outcomes. This research is also particularly focused on the equity implications of transport policies and plans. In this context, there are clear advantages of using accessibility metrics like COMs, which produce results that are relatively easy to communicate to policymakers and stakeholders and that are computationally less expensive and can be more easily integrated into policymaking processes than gravitational or space-time accessibility metrics, for example. Finally, COMs have been chosen because there has as yet been no exploration of the extent to which transport equity appraisals based on this metric are sensitive to methodological choices regarding temporal and spatial scales of accessibility modeling. This is despite COMs being the most common metric used by researchers and transport agencies when assessing the accessibility impacts of transport policies (Boisjoly \& El-Geneidy, 2017; Manaugh et al., 2015).

\subsubsection{Data sources}

Accessibility levels in Rio de Janeiro have been estimated using a combination of various data sources that are mostly publicly available or that use standardized data formats that can be 
found for other cities, so that the methods used here can be replicated by other researchers or applied to other urban contexts. The latest Brazilian population census (2010) has been used to extract information on the spatial distribution of Rio's resident population by income levels at fine spatial scale (IBGE, 2016; Ipea et al., 2015). Land use information, including geolocated data of Olympic sports venues and healthcare facilities, has been downloaded from Rio's open data portal (www.data.rio). In turn, data on the spatial distribution of public high schools and jobs come, respectively, from the School Census conducted by the Brazilian Ministry of Education and from RAIS, a national register organized by the Ministry of Labor and Employment with information on all public and private establishments and the socioeconomic characteristics of their employees working in the formal labor market. Data on Rio de Janeiro's road networks and pedestrian infrastructure come from OpenStreetMap. Finally, data on Rio's public transport system have been provided by Fetranspor, the Federation of Passenger Transport Companies in Rio de Janeiro. These data included detailed geolocated information of routes, stops and timetables of the public transport system organized in General Transit Feed Specification (GTFS) format. The accessibility analysis conducted in this thesis is thus based on the level of public transport services officially planned by transport authorities. The available GTFS data is limited to the city of Rio de Janeiro and it does not cover the entire metropolitan area. Moreover, the data provided by Fetranspor only go back as far as April 2014 and do not cover the previous years, which limits the time horizon of the before-and-after analyses presented in chapters 3 and 4. These and other limitations of the data sources used in this research are discussed in more detail in the next chapters. 


\subsubsection{Travel-time estimates}

One of the first steps to conduct the accessibility analyses presented in chapters 3,4 and 5 was to generate travel-time estimates via public transport and walking. These estimates have been obtained using OpenTripPlanner, an open-source tool developed by the consultancy Conveyal for conducting detailed multimodal transport network modeling at high spatial and temporal scales (www.opentripplanner.org). This tool combines data on road networks and pedestrian infrastructure from OpenStreetMap and public transport network data in General Transit Feed Specification (GTFS) format to create a graph representation of a transport system. It yields travel-time estimates at point-level of doorto-door trips that consider walking time from the point of departure to a public transport stop, waiting time for the vehicle, actual travel time through the transport network including any transfers, and the walking time from the transport stop to the destination. It also takes into account trip departure times and how the temporal variations in the availability of public transport services influence travel-times estimates. These travel-time estimates obtained with OpenTripPlanner have been combined with land use and socioeconomic data to calculate accessibility levels using cumulative opportunity measures. Chapters 3,4 and 5 use slightly different versions of the cumulative opportunity measure, which will be discussed in detail in each chapter.

The use of OpenTripPlanner to estimate travel times have been documented in a public repository using a general example. This tutorial is available on GitHub and can be consulted at this link: https://github.com/rafapereirabr/otp-travel-time-matrix. One of the advantages of using OpenTripPlanner is that it relies on datasets that are organized in 
standardized formats and commonly available for different cities in the world, allowing for replicability of this research method to transport projects in other urban contexts. A caveat of using GTFS data, though, is that they are based on information on scheduled services. Consequently, accessibility analyses based on this type of dataset do not consider the variability of travel-time estimates due to unplanned factors such as traffic accidents or nonrecurrent congestion levels. Recurrent congestion, nonetheless, is normally taken into account by transport authorities in the planning of timetables so this should not be a critical problem. Over the course of this research, an effort was made to use GPS data of buses in Rio de Janeiro to update the GTFS feeds with more accurate timetables, as developed in other studies (Wessel et al., 2017). Unfortunately, the GPS data of Rio had very poor quality, which precluded the use of the updated GTFS data for the empirical analyses in chapters 3, 4 and 5.

\subsection{Chapters Outline}

This thesis is organized into six chapters, the first being this Introduction. Chapter 2 provides the general theoretical framework of the thesis. It presents an extensive review of various theories of justice from modern political philosophy and the literature on transport disadvantage, social exclusion, and equity in transportation. Drawing on these two bodies of scholarship, the chapter puts forward a distributive justice framework to support the assessment of transport policies and their accessibility impacts. This framework builds on a dialogue between the theoretical works of John Rawls $(1999,2001)$ and capability approaches (Nussbaum, 2011; Sen, 2009) in the transport context to provide broader conceptualizations of transportation equity and accessibility that bring practical insights to 
transport policies. When evaluating the impacts of a transport project, for example, this framework entails examining the extent to which the implementation of that project (1) respects the basic rights and liberties of individuals, and (2) contributes to reduce inequalities of opportunities by prioritizing the accessibility improvements of disadvantaged groups. It also calls for a more nuanced understanding of accessibility as a human capability, which ideally requires the use of comprehensive accessibility measures that go beyond the limits imposed by the data conventionally used in transport surveys.

The following chapters (3, 4 and 5) develop the empirical analysis of Rio de Janeiro and illustrate how the theoretical framework developed in chapter 2 can be used to assess the distributional effects of transportation policies on accessibility inequalities in both expost evaluations of implemented projects and in ex-ante scenario analysis of projects in their early planning stages. These chapters analyze major transport policies implemented in Rio de Janeiro in preparation for the 2014 World Cup and the 2016 Olympic Games, both of which involved substantial expansion in the city's public transport infrastructure followed by rationalization of bus routes and cuts in service levels. Each chapter examines those policies from a different angle, assessing how they changed social and spatial inequalities in people's access to sports and healthcare facilities, schools and job opportunities. Together, the analyses presented in these studies complement each other, building a robust evaluation of the transport legacy of mega-events in Rio. The combination of these studies also shows how some methodological choices regarding the temporal and spatial scales of accessibility analysis can have important but little discussed implications for policy evaluation. 
Chapter 3 engages with the literature on mega-events and urban development to understand the particularities of transport planning in Rio de Janeiro, conducted for almost two decades under a context of mega-event planning. It is argued that evaluations of the social impacts of mega-events on urban infrastructure should take into account the distributional effects of the transport legacies created by those events, looking particularly at how such transport developments reshape socio-spatial inequalities in access to opportunities. The chapter looks at transport accessibility from the perspective of activity places and estimates how the transport policies implemented in Rio between 2014 and 2017 changed the number of people from different income levels that could access Olympic sports venues and healthcare facilities via public transport. The estimates are calculated using a before-and-after comparison of Rio's transport network (2014-2017) and a quasicounterfactual scenario that allows separating the effects of newly added infrastructure from the reorganization and cuts of transport services. The analysis shows that the accessibility benefits from Rio's transport legacy generally accrued to middle- and higher-income groups, reinforcing existing patterns of urban inequality.

In chapter 4, the recent investments and disinvestments in Rio de Janeiro's public transport system between 2014 and 2017 are also examined using a before-and-after comparison and quasi-counterfactual analysis. Looking at accessibility from the individual/household perspective, though, the study estimates how recent transport policies in the city have impacted people from different income groups in terms of the number of schools and job opportunities they could reach from their homes via public transport. A spatial regression model and cluster analysis are used to estimate the distributive effects of those transport policies on accessibility inequalities and to test whether these effects are 
robust when analysis is conducted using different geographical scales and zoning schemes. The results of this study show that recent cuts in service levels have offset the potential benefits of newly added public transport infrastructure in Rio, confirming the findings from the previous chapter. The results also indicate that wealthier areas have had on average small but statistically significant greater gains in access to schools and job opportunities than poorer areas, contrary to the official discourses on transport legacy. Finally, the chapter shows that the association between accessibility gains and income levels can be sensitive to the spatial scale and zoning scheme of choice, which could potentially have important implications for the evaluation of policy impacts.

While chapters 3 and 4 present ex-post assessments of policies that have already been implemented in Rio, chapter 5 illustrates how ex-ante accessibility analysis can be used to anticipate the likely accessibility impacts of transportation project scenarios in their early planning stages. This chapter evaluates the scenarios of full and partial construction of the TransBrasil BRT corridor, currently under development in Rio de Janeiro. It looks more specifically at how these two scenarios can impact the number of jobs that are accessible to the population of different income levels under various travel-time thresholds $[30,60,90$ and 120 minutes). The results suggest that, when compared to the other policies recently implemented in Rio analyzed in chapters 3 and 4, the TransBrasil corridor stands out as a far more equitable investment, with the potential to promote larger accessibility gains for lower-income groups due to the way this route is inserted in the urban landscape and to how it is connected to the wider transport network. The results also indicate that this BRT project would have greater and more progressive accessibility impacts under shorter travel-time thresholds of 30 and 60 minutes, while it would bring smaller and more neutral accessibility 
gains for longer travel times of 90 and 120 minutes. These results indicate that the equity assessment of transport projects as well as the size of their accessibility impacts can significantly vary according to the time threshold used in the accessibility analysis.

Finally, chapter 6 gives a summary of the thesis and provides an outlook for future research. This conclusion chapter articulates the main contributions of this thesis in terms of advancing both theoretical debates about justice in urban transportation and methodological insights into equity assessment of transport policies. It sums up the ways in which a distributive justice perspective can shed light on important policy questions in a concrete case study like the one in Rio to discuss how the differential impacts of transport policies shape social and spatial inequalities in access to opportunities. The chapter closes the thesis by drawing from the case study of Rio some general lessons and policy recommendations for other cities. 


\title{
2. Distributive justice and equity in transportation
}

\begin{abstract}
Over the past decades, transport researchers and policymakers have devoted increasing attention to questions about justice and equity. Nonetheless, there is still little engagement with theories in political philosophy to frame what justice means in the context of transport policies. This chapter reviews key theories of justice (utilitarianism, libertarianism, intuitionism, Rawls's egalitarianism, and Capability Approaches), and critically evaluates the insights they generate when applied to transport. Based on a dialogue between Rawlsian and Capability Approaches, we propose that distributive justice concerns over transport disadvantage and social exclusion should focus primarily on accessibility as a human capability. This means that, in policy evaluation, a detailed analysis of distributional effects of transport policies should consider minimum standards of accessibility to key destinations and the extent of which these policies respect individuals' rights and prioritize disadvantaged groups, reduce inequalities of opportunities and mitigate transport externalities. A full account of justice in transportation requires a more complete understanding of accessibility than traditional approaches have been able to deliver to date.
\end{abstract}

\subsection{Introduction}

The number of studies concerned with justice and equity in transportation has dramatically increased in recent decades. This literature addresses multiple questions including: which neighborhoods of a city benefit from transport infrastructure projects and service provision (Currie, 2010; Foth et al., 2013); how policies impact the affordability of transport goods and services for different income classes (Levinson, 2010; Pucher, 1981), and which social groups are more exposed to transport-related externalities, such as pollution and traffic 
accidents (Feitelson, 2002; Forkenbrock \& Schweitzer, 1999). Despite the centrality of these and related questions to transport planning, there is little conceptual clarity about what justice means in the transport context. This lack of conceptual clarity makes it difficult to compare the findings from different studies and to obtain insights that could inform policy decisions.

The purpose of this chapter is to engage with the political philosophy of justice and to explore some of its contributions and limitations in providing a distributive justice perspective on transport research and policy. We review key theories of justice (utilitarianism, libertarianism, intuitionism, Rawls's egalitarianism and Capability Approaches), and discuss some of their insights and limitations when applied to issues of transport disadvantage, social exclusion and accessibility. We focus on these issues because they are the most widely discussed issues in studies on equity in transportation (Geurs et al., 2009; Lucas, 2012). In this literature, concepts are also used to denote different things and sometimes without rigorous definitions. Moreover, there is often limited engagement with the philosophical literature on justice, even if a small but expanding number of publications explore how different ethical theories and principles can be used to incorporate equity concerns in transport planning and appraisal (Davoudi \& Brooks, 2014; Khisty, 1996; Lucas et al., 2015; Martens, 2012, 2016; Mullen et al., 2014; van Wee \& Roeser, 2013). Such works tend to advocate pluralistic perspectives on justice, drawing on different moral principles that need to be balanced in each situation, and argue for a focus on accessibility when addressing questions over distributive justice and transport disadvantage. 
The current chapter differs from previous research by proposing a distributive justice perspective that stages a dialogue between theoretical works of John Rawls and Capability Approaches, two of the most prominent theories in political philosophy. It accommodates universalist concerns about inequality of opportunities and basic needs regarding transport and considers context-specific issues regarding how people's transport choices are bounded by both personal and contextual factors. This perspective also holds that a full account of justice in transportation demands a more complete understanding of accessibility as a human capability.

There is no single overarching definition of justice. As an initial approximation and based on different theoretical traditions (Fraser, 1995; Kymlicka, 2002; Young, 1990), justice can be understood as a broad moral and political ideal that relates to: (1) how benefits and burdens are distributed in society (distributive justice); (2) the fairness of processes and procedures of decision and distribution (procedural justice); and (3) the rights and entitlements which should be recognized and enforced. Similarly, the concept of equity has been understood in various ways, including a demand for impartiality (Sen, 2009), proportionality between an individual's reward and cost/effort (Schweitzer \& Valenzuela, 2004), treatment of people according to their differences (Rawls, 1999), and the consideration of particular circumstances in ethical judgments (Barry, 1965). Even if the word equity is used to refer to particular aspects of a broader idea of justice, the academic literature tends not to draw a clear distinction between the two concepts. We therefore use the terms equity and justice interchangeably. While equity always implies a moral judgment, equality does not have to imply a normative stance if the term is used in a descriptive sense to indicate full equality or sameness (van Wee \& Geurs, 2011). Nevertheless, perfect equality 
is not a sufficient condition for achieving fairness (Rawls, 1999). Some authors recognize not all inequality is unfair and, in fact, fairness comes sometimes at the price of treating people differently according to their differences and even limiting some individual liberties (Dworkin, 1981a; Rawls, 1999; Sen, 2009).

\subsection{An overview of theories of justice in political philosophy}

The political philosophy literature has long discussed the idea of justice, with liberal philosophers dedicating special attention to questions regarding the fair distribution of material and non-material goods in society. The liberal understanding of justice is characterized by two fundamental principles: respect for individuals' autonomy and moral equality, according to which all people deserve equal respect and consideration (Kymlicka, 2002). Yet, liberal thinkers have different conceptions of liberty and moral equality, offering different answers to three interrelated central questions about distributive justice that cannot be addressed in isolation from each other: (i) what - that is, which benefits and burdens - should be distributed?; (ii) on which moral principles should distribution patterns be based?; and (iii) what is the fairest distribution pattern? We discuss five justice theories that provide distinctive answers to these questions (see also Figure 2.1 at the end of this section $)^{3}$.

\footnotetext{
${ }^{3}$ Questions of how distributive policy is decided and by whom have attracted much less attention in the political philosophy literature (Young, 1990). Similarly, this chapter does not cover the concept "right to the city" (Fincher \& Iveson, 2012) nor feminist theories of justice because they go beyond the scope of distributive justice.
} 


\subsubsection{Utilitarianism}

Originally proposed by Jeremy Bentham and John Stuart Mill, utilitarianism is among the most influential theories of justice, not least because it provides the ethical foundation of cost-benefit analysis (Hausman \& McPherson, 2006). Utilitarianism is based on three key assumptions, which structure its understanding of justice. Firstly, utilitarianism is premised on the view that human well-being ('utility') is the only thing with intrinsic value and therefore is the core of justice concerns (Kymlicka, 2002). Secondly, utilitarians interpret the principle of equal respect as giving equal weight to everyone's welfare and interests, "regardless of the content of the preferences or the material situation of the person" (ibid.). Finally, utilitarianism holds a strictly consequentialist view: the moral judgment of an action or policy should be based exclusively on its consequences, particularly in how it maximizes well-being (ibid). Accordingly, the policy that best aggregates people's conflicting preferences becomes simply a matter of efficient administration, where the best alternative is the one which maximizes aggregate net welfare for the greatest number of people (ibid.).

Despite its attractive simplicity, the utilitarian approach is contested as a moral theory. Three criticisms are particularly important in the transportation context. Firstly, there is no particular concern with how well-being is distributed between individuals; this can be especially problematic when the promotion of aggregate welfare comes at the expense of the least well-off (Sen, 2009). Secondly, utilitarians overlook how some people's preferences may be illegitimate as they violate rights and reduce the liberties of others (Kymlicka, 2002). Finally, the combination of strict consequentialism and emphasis on maximizing aggregate well-being conflicts with the idea of respecting individuals' rights 
(ibid.). From a utilitarian perspective, for example, it is perfectly acceptable to override individual rights of minorities if this promotes a greater good for a greater number of people. Underlying this perspective is the Kaldor-Hicks compensation principle, according to which a project is worthwhile and equitable if its benefits are large enough so that winners could hypothetically compensate the losers, even if no compensation is provided (Hausman \& McPherson, 2006). Although all theories of justice take consequences into account in evaluating the rightness of actions (Kymlicka, 2002), the traditions discussed below take a deontological approach to ethics, i.e. they understand certain actions to be categorically wrong, even if they promote an increase in overall welfare (Sandel, 2009).

\subsubsection{Libertarianism}

The idea of self-ownership is at the heart of the libertarian conception of justice presented by Nozick (2003). It recognizes that all individuals equally share some fundamental rights (e.g., to one's own life and property) and the freedom to choose how to lead one's life according to one's values and goals, without interference by the state or others, provided the rights of others to do the same are respected (Hausman \& McPherson, 2006). Accordingly, libertarians claim free markets are inherently just and work as the primary instrument to promote justice, inasmuch as they result from voluntary choices by consenting adults, and are the best mechanism for efficiently maximizing social wealth (Kymlicka, 2002). State interventions such as regulation, taxes and subsidies should be limited as they tend to distort market functioning (ibid.). 
Criticisms to libertarian conception of justice abound (Kymlicka, 2002; Sandel, 2009; Sen, 2009); suffice it to note that its understanding of individual freedom overlooks the fact that a person's preferences and achievements are never solely dependent on her individual choices, which cannot be fully separated from the natural and social contingencies of her context (ibid). When it comes to an individual's actions (e.g., travel behavior) with secondorder effects on other members of the community (e.g., vehicle emissions, traffic accidents, congestion), libertarians believe self-regulated markets can provide adequate solutions to unfair or inefficient outcomes that emerge from collective action. However, free markets are not efficient or, arguably, fair in the presence of market failures (Hausman \& McPherson, 2006). Additionally, consent in market transactions is not a sufficient condition for justice, particularly when contracts involve large power imbalances, as is often the case in free markets (Sandel, 2009). In the end, while utilitarianism gives priority to aggregate wellbeing over individual rights, libertarianism gives priority to individuals' liberties, even if they come at the expense of human welfare (Kymlicka, 2002).

\subsubsection{Intuitionism}

Intuitionism is not a single theory of justice, but rather refers to the perspectives shared by authors for whom moral propositions are self-evident and basic moral knowledge is acquired through intuition (Rawls, 1999). Intuitionist authors such as Barry (1965) and Miller (1999) share the belief that moral problems in real life situations are so complex and diverse that only a pluralistic conception of justice can properly deal with them. 
In contrast to utilitarianism and libertarianism, which put forward universal theories about justice, intuitionism argues for a more context-dependent and pluralistic approach. The decision of what is the right thing to do depends on the particularities of each moral dilemma, and may demand the consideration of different moral values, such as merit, basic needs, rights, formal equality, compensation, non-discrimination or procedural fairness (Barry, 1965). In transport planning processes, for example, procedural fairness demands all affected communities should be equally heard. When it comes to setting public transport fares, one could evoke the principle of compensation, so people receive transport subsidies according to their financial constraints.

This context-dependent nature of intuitionism, however, is also a main source of criticism. From (universalist) theoretical perspectives, intuitionism is unsatisfying since it proposes a series of ultimately arbitrary moral principles not specified by any consistent logical argument (Kymlicka, 2002; Rawls, 1999). From a practical viewpoint, intuitionism is of little help because it is unclear when each principle would be the right one to choose or how one should proceed to reconcile or prioritize competing moral principles (ibid.).

\subsubsection{Rawls's egalitarianism}

Rawls's theory of justice is essentially concerned with the role played by institutions in promoting justice (Rawls, 1999, 2001). His theory is comprised of two overarching principles, ordered by priority. The first principle has absolute priority and applies 
particularly to basic rights and liberties. ${ }^{4}$ It holds that the rules defining individuals' basic rights and liberties ought to apply equally to everyone and that individuals should have as much freedom as possible as long as this does not infringe the freedom of others (ibid.). The second principle applies to the distribution of primary goods, which are various social conditions and all-purpose means that are necessary to enable citizens to pursuit their life plans (whatever they may be); they include in broad categories income and wealth, opportunities, powers and prerogatives of authority and the social bases of self-respect. This second principle contends that social and economic inequalities can only be considered fair if they simultaneously (a) derive from a situation of fair equality of opportunity, and (b) work to the benefit of the least advantaged members of society (ibid.).

The idea of equality of opportunity stresses the importance of individual freedom of choice. It implies that in a society with genuine equality of opportunity inequalities are legitimate, provided they result from people's choices and efforts; inequalities are unfair if they result from morally arbitrary circumstances that result from natural and social contingencies beyond a person's control, such as being born in a poor family or ethnic group (Kymlicka, 2002). Rawls (1999) nonetheless acknowledges that some level of inequality is inescapable and that it is not possible to achieve genuine equality of opportunity because individuals' innate or trained abilities, freedom of choice and even effort cannot be completely separated from their social conditions. Since no one can claim credit for their innate capacities, nor for the initial position in society in which they were born, it is unfair for individuals to be penalized or privileged by such arbitrary circumstances. This leads

\footnotetext{
${ }^{4}$ These include freedom of thought and of association, political liberties, the rights and liberties covered by the rule of law and the physical and psychological liberty and integrity of the person (Rawls, 2001).
} 
Rawls to argue in the second part of his second principle - known as 'difference principle; that inequalities can only be considered fair if they work to the benefit of the least well-off, thereby mitigating inequalities of opportunities and the morally arbitrary effects of social and natural lotteries (ibid). In practical terms, the difference principle points to a distributive rule based on the maximin criterion, suggesting one should choose the policy alternative that maximizes the minimum level of primary goods of the people in the worst-off position (ibid.). Furthermore, Rawls's theory of justice does not require inequality levels to be restricted to a maximum gap, except in those cases where the increase of primary goods at the top of the distribution would begin to have negative effects on those at the bottom. In such circumstances the notions of fraternity and mutual benefit embedded in the difference principle give moral justification for institutions to limit the upper part of the distribution (Rawls, 1999, 2001).

Two criticisms of the difference principle should be noted. Although Rawls acknowledges the difference between inequalities that emerge from personal choices and those that emerge from morally arbitrary circumstances, the difference principle does not make such a distinction (Kymlicka, 2002). Consequently, this principle mitigates not only the unfair effects of morally arbitrary circumstances but also the legitimate effects of personal choices and effort (ibid.). This issue extends beyond Rawls's difference principle and is a crucial problem for any policy design seeking to distinguish between choice and circumstances in real life settings (Dworkin, 1981a). 


\subsubsection{Capability Approaches}

Another important criticism of Rawls's theory comes from Amartya Sen who endorses Rawls's overall scheme but proposes that the focus of the difference principle should shift from primary goods to human capabilities (Sen, 1979, 2005, 2009). Capabilities are sets of freedoms and opportunities available for individuals to choose and to act, resulting from "[...] a combination of personal abilities and the political, social and economic environment" (Nussbaum, 2011). Although the Capability Approach (CA) is not intended to be a full theory of justice, human capabilities are at the heart of justice concerns, which essentially deal with the opportunities and substantive freedoms that enable individuals to achieve things they have reason to value (Sen, 2009).

For Sen (ibid), the focus on the distribution of resources or primary goods is incapable of recognizing the diversity of human needs and preferences. This is because goods, services or income are not ends in themselves, but merely means to valued ends. Most of the time, a car or a bicycle is not something we value for its own sake, but only to the extent it helps us achieve our aspirations in symbolic, aesthetic or practical terms. Additionally, the capacity of each person to convert a particular resource into pursued ends depends heavily on her social context, preferences, skills, etc. Hence, what matters from the moral point of view is not so much the distribution of resources, but people's capacities to convert such resources into a good life made up of 'functionings' (practices) according to their own preferences.

The CA recognizes the influence that a person's environment has in enhancing or restricting the set of opportunities that are available for her to choose (Nussbaum, 2011; Robeyns, 2005). It takes into account not only the diversity of individuals' characteristics 
(e.g. preferences, values, needs, abilities), but also the societal structures and constraints affecting individuals' capacities to convert resources and opportunities into functionings. This interaction between internal capabilities and external environment is what Nussbaum (2011) refers to as 'combined capabilities'. Accordingly, assessments of justice and social life conditions ought to differentiate the possibilities of what a person is able to do (her capability set) from what the person ends up doing - her functionings (Sen, 2009).

Sen acknowledges the importance of reducing capability inequalities to promote equality of opportunities (Sen, 1999, 2009) . However, the CA is primarily concerned with promoting basic capability equality by guaranteeing minimum levels of basic capabilities (Sen, 1979). These basic capabilities refer to the freedom to do things that are essential for survival and later development, and include, for example, being able to move around, participate in the social life of the community, and meet one's nutritional requirements (Nussbaum, 2011; Robeyns, 2005). In this sense, the CA share both egalitarian and sufficientarian concerns discussed by van Wee and Geurs (2011) and Lucas et al (2015). For Sen, the definition of a list of basic capabilities and minimum thresholds must be culturedependent. It ought to take into account each society's particular values and material conditions, and may even change across time as societies develop and reassess their political positions (Sen, 2005, 2009). Others, following Nussbaum, argue that even if the definition of acceptable minimum thresholds is context-dependent, a universal list of central capabilities that any state would need to guarantee to all citizens can be identified. These include, among others, the capabilities of being able to participate effectively in political decisions that affect one's life, to move freely from place to place and having good health (Nussbaum, 2011). 
Figure 2.1 Summary of key theories of justice.

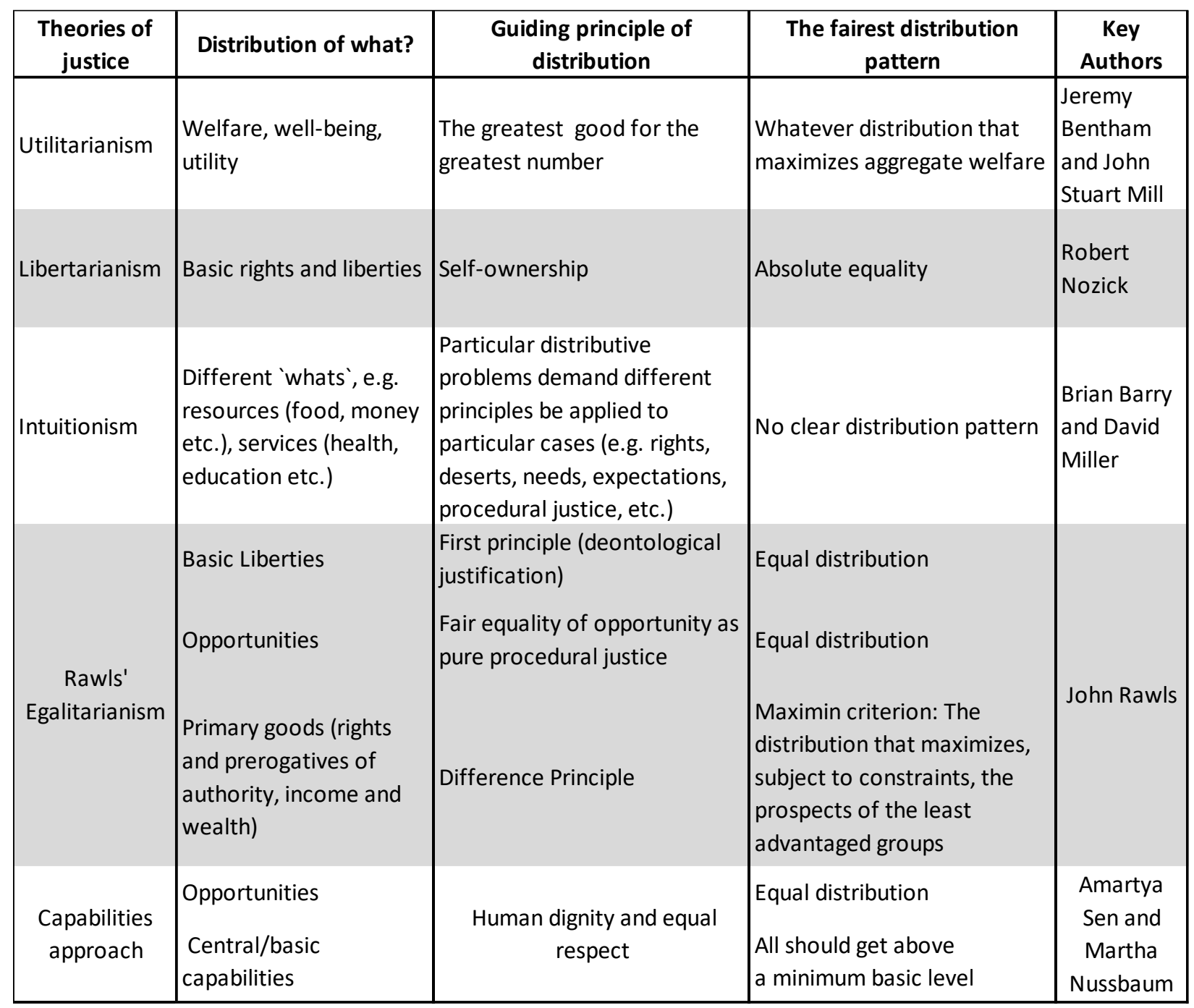

\subsection{Transport disadvantage, social exclusion and equity in}

\section{transportation}

At least since the 1960s, transportation scholars have investigated how transport disadvantages can lead to social exclusion and compromise the well-being of individuals (Kain, 1968; Wachs \& Kumagai, 1973). This literature is also fundamentally concerned with 
issues of distributive justice, and this section reviews how this literature addresses the three questions raised in the introduction section.

Regarding the first question (distribution of what), the literature emphasizes three types of transport-related inequalities that are interconnected and have key influence on people's well-being: inequalities of transport-related resources, observed daily travel behavior and transport accessibility levels. Many studies focus on the unequal distribution of transport-related resources, such as car ownership and proximity to transport services and infrastructure (Murray \& Davis, 2001; Ong, 2002; Thomopoulos et al., 2009). One insight from the Capabilities Approaches is that this focus on resources can be misleading. Because people's needs, preferences and abilities/skills are so heterogeneous, this focus provides only a partial account of individuals' capacity to use such resources to move around the city and to reach desired activities. For example, proximity to transit services is of little use if they are not affordable, if the transport system is not adequately adapted to disabled people, or if that system does not connect the places between which individuals need to travel. Even bicycle use for daily transportation demands, apart from an appropriate built environment and safe cycling infrastructure, some level of bodily fitness and health that is not equally available to all individuals.

Meanwhile, other researchers focus on inequalities in daily travel behavior, including differences in trip frequency, traveled distances and travel time - the idea being that such travel patterns reflect different levels of well-being and participation in society (Bills et al., 2012; Karlström \& Franklin, 2009; Vasconcellos, 2005). As a general rule, the academic literature assumes transport decisions to be primarily a matter of individual choice and 
personal responsibility (Mullen, 2012). However, it is not always possible to tease out how much inequality in travel behavior arises from individuals' tastes and preferences (voluntary choice) and from contextual constraints outside individual control. Longer commutes, for example, can arise due to affordable housing only being available in more distant locations, but also reflect preferences for suburban living. While this differentiation is difficult to deduce from data on observed travel behavior, such information is crucial to determine, for instance, whether certain behaviors are entitled to public subsidy.

Furthermore, the focus on observed travel behavior overlooks the unfulfilled needs of less mobile groups, ignoring the suppressed demand for those trips that would have been taken were it not for constraints imposed by the transport system or by other economic and social reasons (Nordbakke \& Schwanen, 2015). Similarly, this type of analysis does not capture what range of places the transport system actually makes accessible to the population. From the perspective of expanding people's potential mobility and freedom of choice, it is crucial to differentiate the places people actually go to from the range of places they are able to reach. From a social justice and environmental perspective, there are considerable differences between policies that increase people's actual mobility and those that enhance people's capability to access desired destinations if they so choose (Banister, 1994).

A more promising approach than considering travel behavior is to focus on inequalities in accessibility levels. Accessibility is conceptualized and measured in many different ways, and some conceptualizations and methods are more compatible with certain ethical perspectives than others (Martens \& Golub, 2012; Neutens et al., 2010; van Wee \& 
Geurs, 2011). From a justice perspective, accessibility can usefully be conceptualized as the ease with which persons can reach places and opportunities from a given location and be understood as the outcome of the interplay of characteristics of individuals, the transport system and land use (Kwan, 1998; Neutens et al., 2010). A substantial literature on inequalities in transport accessibility (Church et al., 2000; Delmelle \& Casas, 2012; Welch, 2013) considers accessibility as a necessary, though not sufficient, condition for the expansion of people's freedom of choice and promotion of equality of opportunities in terms of employment, healthcare, education services, etc. The focus on accessibility is also justified since a primary purpose of transport policy is to improve access to places, activities and opportunities people have reason to value (Martens et al., 2012; van Wee \& Geurs, 2011).

The second question regarding distributive justice concerns the moral principles that should guide and justify redistribution. This is perhaps the most overlooked question in the transport literature: most existing studies neither justify why observed inequalities in transport-related benefits and burdens should be considered unfair, nor offer any moral reasoning to guide us towards a fairer distribution. There are some exceptions which apply a broad conception of political and social equality to walking and cycling policies (Mullen et al., 2014) and which propose a non-market-based distribution of transport accessibility (Martens, 2012). Others studies examine the link between accessibility and general principles of equality and basic needs (Lucas et al., 2015) and raise a variety of ethical principles to guide transport policies (Litman, 2002; Trinder et al., 1991) but without committing to any specific theory of justice. 
The third question about how benefits and burdens can be distributed in the fairest way has been addressed from two different perspectives. The first - egalitarian - approach frames this as a question of relative distribution and focuses on inequality between social groups or geographical areas, asking why certain groups/areas have higher or lower accessibility levels or transport goods/services than others (Benenson et al., 2011; Kawabata \& Shen, 2007; Meijers et al., 2012). The second - sufficientarian - approach is framed in terms of transport poverty and basic needs, considering why some groups/areas simply do not have/offer enough access to those goods and services (Delbosc \& Currie, 2011; Jaramillo et al., 2012). The first approach implicitly assumes there is an ideal or acceptable level of inequality considered to be fair. The idea underlying the second approach is that there are minimum levels of transport goods, services and accessibility to essential activities that should be available to everybody. Elaborations of both approaches to date can be criticized. Studies in the first category tend not to make clear statements about acceptable levels of inequality, what an ideal distribution pattern looks like, or how far transport policies should go in reducing inequalities. Research in the second group suffers from the conundrum that no minimum thresholds can be established without paternalistic assumptions that overlook the diversity of people's preferences and needs (Cass et al., 2005; Preston \& Rajé, 2007).

In summary, studies on distributive justice in relation to transportation are primarily descriptive, containing little or no explicit theoretical reflection on justice. The literature gives diverse answers to key questions regarding distributive justice, and rarely addresses such questions in a systematic way (Martens, 2011), often leaving some of these questions unanswered. Transport accessibility, rather than resources or travel behavior, stands out as 
the most promising focal variable of distributive justice. In whatever way accessibility is conceptualized and measured, the ethical perspective should be made explicit because different theories of justice give different answers to how policies should address inequalities in accessibility. In what follows, we present our interpretation of what insights the theories analyzed in section 2.2 could bring to policies focused on accessibility.

\subsection{Insights from political philosophy for transport policy and accessibility}

\subsubsection{Utilitarians}

Utilitarians are not interested in accessibility in itself, but only in the instrumental value of actual trips for the promotion of those activities from which people derive utility. From this perspective, urban and transport policies should be designed to facilitate trips to those activities that maximize aggregate utility. However, since the utility derived from an activity is commonly measured by people's willingness to pay, and because benefits derived from transport projects have traditionally been evaluated in terms of the monetary value of travel time savings, an unintended consequence of utilitarian evaluations is that they implicitly prioritize accessibility gains to more profitable activities and people with higher incomes and hence higher values of time. This and other criticisms to utilitarian reasoning in traditional transport planning have been raised by critics of cost-benefit analysis (Martens, 2011; van Wee, 2012; van Wee \& Roeser, 2013). 
Because the well-being of everyone is seen as equally important, a utilitarian approach focuses on aggregate measures of transport performance, paying no particular attention to how accessibility is distributed among individual members of society (ibid). In such evaluations it would not matter if, for example, the promotion of transport accessibility for higher income classes and car drivers came at the expense of reducing the accessibility of lower classes and public transport users. Although this issue can be addressed partially by project evaluations using utility-based weights to capture variations of benefits/costs between affected groups/individuals (Lucas et al., 2015), the utilitarian approach still faces serious shortcomings regarding the measurement and interpersonal comparison of the utility people derive from transport improvements (Rietveld et al., 2007). Additionally, the strict consequentialism espoused by utilitarians means that situations in which transport policies violate the rights of minorities are not seen as a moral problem, as long as such policies bring about net benefits to a larger number of people. From a utilitarian perspective, the eviction of, say, hundreds of families in order to expand a road would be perfectly acceptable, even if those families were not compensated in an appropriate manner.

\subsubsection{Libertarianism}

The libertarian approach would also have no particular concern about how accessibility is distributed among members of society, but for a different reason. According to libertarians, the fairest distribution of transport accessibility would be whatever distribution resulted from free market transactions between consenting adults. According to this view, the free market is the best instrument to expand people's choices about how to better satisfy their 
transport needs, and to make individuals fully responsible for their own choices. The state should play no role in terms of taxes and subsidies, and state regulation should be limited to the minimum necessary to establish clear property rights and due compensation when contracts are broken (Klein et al., 2003; Winston, 2000). This view resonates with the emergence of unregulated on-demand ridesharing companies such as Uber and Lyft, whose services could be considered somewhat closer to a pure market solution to urban transportation, despite being heavily dependent on government-provided road infrastructure.

However, this idea that free market and its price system can work as the sole device to promote just and efficient transport solutions disregards the possibility of conflict between markets and distributive fairness. It overlooks how efficiency might be in conflict with equity and how these two goals are often jeopardized by market failures that typically occur in urban transportation (Estache \& Gómez-Lobo, 2005; Glaister et al., 1990; Santos et al., 2010). Because mass transportation services work under a regime of natural monopoly, unregulated competition of transport companies is often inefficient and sub-optimal. Under such conditions, private companies have no economic incentives to consider the special needs of minority groups such as people with disabilities, to provide public goods such as urban roads, and to provide transport services to distant and impoverished neighborhoods where services are less profitable. The emphasis on individual transport decisions coupled with unregulated use of public goods such as urban roads can lead to overuse of road space, aggravating negative externalities, including congestion, air pollution and traffic accidents (ibid.). 


\subsubsection{Intuitionism}

An intuitionist approach to transport policies is context sensitive, and the allocation of transport investments and services to improve people's accessibility may be guided by different moral justifications (e.g., basic needs, formal equality, horizontal and vertical equity) across individual cases (Hay, 1993; Hay \& Trinder, 1991; Khisty, 1996; Litman, 2002). For example, the need to access essential activities (e.g., education and health services) could be used to justify allocation of subsidies and services for certain groups (e.g., students, low-income classes, deprived neighborhoods) to guarantee they have minimum levels of accessibility to those activities. As often happens in the policy context, however, allocation dilemmas usually involve a plurality of competing principles of justice leading to different policy alternatives and it is not straightforward to decide which principle and distribution rules should prevail on specific occasions. For example, while formal equality would support transit services being equally distributed in all areas of a city and all passengers paying equal transport fares, compensation would justify prioritizing services in poorer neighborhoods and would allow for the provision of fare concessions to vulnerable groups such as the elderly or disabled. There is, moreover, little consistency across transport studies using this intuitionist approach (ibid.). Different lists of intuitions deemed relevant for project evaluation have been put forward, often without consistent definitions of what each intuition means.

The risk of an intuitionist approach lies in its evaluation of distributive conflicts becoming too context specific. It provides only limited guidance to policy decisions inasmuch as it does not offer any consistent moral scheme to balance various competing claims of 
justice. Under such approach, policy decisions may well be taken on an ad-hoc basis or following opportunistic claims that are electorally appealing at specific moments in time. Such decisions may also lead to incoherent and conflicting policies, with benefits of one policy potentially increasing the undesired effects of other policies.

\subsubsection{Rawlsian egalitarianism}

From a Rawlsian perspective (or rather, our interpretation of it), any transport project should be guided by respect for individuals' basic rights; no policy would be acceptable if it violated such rights, even if it improved people's accessibility. For example, even though Rawls $(1999,2001)$ acknowledges freedom of movement as a crucial liberty, arguing people should be free to move from place to place, this liberty should be exercised within the limit of not harming the basic rights including that of physical integrity of others. This position offers an important moral argument in favor of policies that discourage individual motorized transport in congested areas, because such transport disproportionately generates negative externalities that harm other people's health conditions through road congestion, air pollution and traffic accidents (Viegas, 2001).

In a more recent reassessment of his original theory, Rawls (2001, p.172) has broadened his understanding of primary goods to include personal goods and services provided by the state: "primary goods of income and wealth are not to be identified only with personal income and private wealth. [...] As citizens we are also the beneficiaries of the government's providing various personal goods and services to which we are entitled, as in the case of health care, or of its providing public goods (in the economist's sense), as in the 
case of measures ensuring public health (clean air and unpolluted water, and the like). All of these items can (if necessary) be included in the index of primary goods". This broadening is consistent with his idea that government services and public goods should be guided by the difference principle (Rawls, 1999, p.175, 246-267). Along with other authors (van Wee \& Geurs, 2011; van Wee \& Roeser, 2013), we believe transport accessibility as well as governmental investments and services aimed at improving people's accessibility can be understood as primary goods to which the difference principle is applicable. This does not mean everybody should experience the same level of transport accessibility. In fact, from our interpretation of Rawls's theory, justice is not about whether some people enjoy greater accessibility than others but about how institutions and policies deal with such inequalities in order to minimize inequality of opportunities (Rawls, 1999). This interpretation may seem compatible with transport policies that aim to advance the common good by improving overall or average levels of accessibility. However, the application of Rawls's difference principle to transport entails that interventions such as infrastructure investments, subsidies and service provision can only be considered fair if they give priority to improving accessibility levels of the least advantaged groups. This is the case with policies that focus on improving accessibility of low-income classes living in deprived areas or policies that prioritize those transport modes most commonly used by low-income people (van Wee \& Geurs, 2011). While in dense urban areas this can be done through policies that prioritize public transport, walking and cycling over private cars (e.g., exclusive bus lanes, congestion charging schemes, cycle paths), policies that facilitate car use for low-income people would likely be more appropriate in low-density and rural areas. Moreover, the difference principle would also provide ethical support for policies to limit the highest levels of car accessibility 
in circumstances where further increases in car use and concomitant negative externalities undermine the accessibility of public transport users and impose health burdens on vulnerable groups.

Rawls $(1999$, sections 43,$44 ; 2001$, sections 38,39$)$ argues that at a certain point justice would also demand setting a minimum level of primary goods. In practice, governments should guarantee minimum levels of primary goods for all individuals so that at least the basic needs essential to a decent life - the definition of which differs across societies - are met; the allocation of primary goods above minimum thresholds can be allocated via regulated markets. Thus, Rawls's concept of appropriate social minimum goes beyond basic individuals' physiological needs and is dependent on a given society's wealth and public political culture, among other factors (ibid.). A similar idea has been proposed on the setting of minimum transport access to basic destinations such as food stores, schools and medical services (Delbosc \& Currie, 2011; van Wee \& Geurs, 2011), although the definition of minimum accessibility thresholds still presents great challenges (see next section).

\subsubsection{Capability Approaches}

To date, various authors have argued that mobility in the sense of being able to move should be considered as a basic capability because of its central role in enabling people to satisfy basic needs (Beyazit, 2011; Kronlid, 2008; Robeyns, 2003; Sen, 2005; Tyler, 2006; van Wee, 2012). While usefully highlighting mobility's instrumental importance to the development 
of other human capabilities, the idea of mobility as capability should be expanded into an understanding of accessibility as a combined capability.

According to our interpretation of the Capability Approaches, urban and transport policies should not only aim at increasing overall accessibility levels in society, so that individuals become better able to develop other capabilities and conduct the activities they have reason to value. Policies should also, and primarily, guarantee individuals a minimum level of access to those key activities that are essential for meeting basic needs, such as food stores, education, health services and employment opportunities. However, this does not imply that, as a necessary condition of justice, everybody must enjoy exactly the same transport conditions. This belief would amount to resource fetishism (Nussbaum, 2011) and overlook how people's ability to convert transport resources into capability and quality of life is affected by contingencies such as personal characteristics, physical environment and cultural norms (Ryan et al., 2015).

The application of Capability Approach to transport policy raises at least two challenges. The first is that understanding accessibility in capability terms couples accessibility needs with the idea of social rights insofar as some minimum level of accessibility is necessary for the satisfaction of individuals' basic needs and a necessary, though not sufficient, condition for people to exercise basic rights such as going to school, receiving health care and voting in elections. While this might go as far as raising a discussion on accessibility rights (Farrington, 2007), it certainly requires the identification of minimum acceptable thresholds of accessibility to key activities and demands government initiatives to guarantee the accessibility needs of people who fall below those thresholds. The 
identification of such minimum thresholds remains an unresolved challenge in the academic literature (Farrington \& Farrington, 2005; Hananel \& Berechman, 2016; Smith et al., 2012). It is nonetheless evident that their identification is dependent on a given society's history and values, and would require a political decision reached through a legitimate political and democratic process.

A second challenge is that understanding accessibility as a combined capability requires one to address accessibility as a result from a combination of personal abilities and the social, economic, and built environment, which is a more complex and multidimensional concept of accessibility than often used in transport studies (Tyler, 2006). For policy reasons, it is important to frame accessibility as a combined capability in respect of two analytically separable but interconnected accessibility components:

a) One component is the person's capability to access and use mobility technologies and transport systems/vehicles, which depends on the interplay of personal and external factors. Relevant personal factors may include, for example, physical and mental fitness, the motor and cognitive skills to understand and interact with the transport system, accumulated experience, and sufficient financial resources. Meanwhile, the external factors may refer to the social environment (e.g., whether a person is able to use the transport system without being harassed or discriminated), as well as to a transport system's physical design, provisions for disabled individuals, price levels, quality and availability of travel information, and so forth. 
b) The other component of accessibility refers to how the interactions between the transport system and land use patterns enhance people's capabilities: given that a person is able to use a transport system/vehicle, does that system/vehicle actually improve her capacity to access desired places and opportunities? Even if a person is able to access and use a transport system, she may not necessarily be able to reach the destinations she wants to access. This is because accessibility as a combined capability also depends on time-budget restrictions of individuals and additional external factors related to land use patterns, how the transport network is distributed and connected across the city vis-à-vis the distribution of desired opportunities and activities, in addition to the transport system performance, including service frequency, reliability, speed, etc. This capability can also be extended beyond the spatial domain through information/communications technologies that allow people to access opportunities without having to move physically (Banister \& Hickman, 2006; Kenyon et al., 2002) 5 .

The understanding of accessibility as capability is not easily compatible with placebased conceptualizations that understand accessibility exclusively as an attribute of locations. Because the CA is fundamentally concerned about individual freedom of choice

\footnotetext{
${ }^{5}$ This integral notion of accessibility is encompassed and further developed by the concept of motility (Flamm \& Kaufmann, 2006; Kaufmann et al., 2004). Motility incorporates how personal, social and environmental factors interact to form the processes that shape the relation between an individual's spatial and social mobility. The complex relation between the concepts of motility, accessibility and capability deserves more attention in future research on equity in transportation. We should note, though, these concepts generally overlook issues of externality from societal perspective.
} 
and human agency, this approach requires that accessibility be understood as an attribute of individuals in their interaction with their environment, taking into account how personal characteristics (such as gender, age, social class, disabilities, time budget) shape interpersonal differences in accessibility levels.

Even if one focuses on person-based accessibility, there is still a substantial variety of metrics which can be used to measure accessibility (e.g., utility-based and space-time measures). The choice of metric is significant and strongly shapes which conclusions can be drawn from accessibility analysis (Kwan, 1998; Neutens et al., 2010). Further research is needed to discuss which accessibility measures are conceptually consistent with different ethical frameworks (Martens \& Golub, 2012), and to discuss the challenges of building more comprehensive accessibility measures that go beyond the limits imposed by data conventionally used in transport surveys.

\subsection{Conclusions}

Given the strengths and limitations of the theories reviewed in previous sections, the overarching conclusion of this chapter is that future studies addressing distributive issues in transportation equity would benefit from an ethical perspective that builds a dialogue between Rawls's egalitarianism and the Capability Approaches, which we only briefly sketch here $^{6}$. When it comes to the question "distribution of what" under this perspective, accessibility is understood as a combined capability and should be the primary focus of

\footnotetext{
${ }^{6}$ For a discussion on the integration of Rawls's theory and the capability approach applied to planning theory more broadly, see Fainstein (2010) and Basta (2015).
} 
transport researchers and policy makers addressing questions over distributive justice and transport disadvantage. This focus emphasizes the social and economic opportunities available for individuals to access if they so choose. This perspective thus stresses the link between accessibility and the ideas of agency and freedom of choice, while demanding a more nuanced and multidimensional understanding of accessibility that acknowledges the diversity of people's needs and constraints when they make their transport decisions.

With respect to the second question, the concern with accessibility is morally justified for different reasons. First, some minimum level of accessibility to key destinations is a basic capability that is necessary for people to satisfy their basic needs. Moreover, the concept of accessibility draws out the spatial dimension in moral concerns over equality of opportunities, which is a central concern of distributive justice but has thus far only been treated as a non-spatial idea by political philosophers. In this sense, accessibility works as a necessary, though not sufficient, condition for promoting equality of opportunity. It also has instrumental importance for the development of further capabilities and freedom of choice that allow people to flourish and pursue the life they have reason to value.

With regard to the question of what a fair distribution of accessibility should look like, this perspective contends, firstly, that individuals' basic rights and liberties should never be violated or sacrificed on the grounds of improving accessibility levels of others. Secondly, a transport policy is fair if it distributes transport investments and services in ways that reduces inequality of opportunity. While aiming to enhance overall levels of accessibility, policies should prioritize vulnerable groups and thereby mitigate morally arbitrary disadvantages that systematically reduce their accessibility levels, such as being elderly, 
disabled or born in an ethnic minority or poor family (Lucas, 2012; Páez et al., 2010). Finally, this proposed framework gives support to the ideas of setting minimum standards of accessibility to key destinations which should be guaranteed by the government through social or transport policies if necessary, and limiting the highest levels of accessibility of social groups and transport modes only in those circumstances when a marginal improvement of accessibility at the upper levels would harm those groups at the bottom.

Some of the practical implications of this perspective can be illustrated with issues that commonly arise in cities with investments in public transport (e.g., metro and bus rapid transit developments) and cycling/walking. These types of investments can be good ways to prioritize transport modes which are more widely used by low-income classes. To be considered fair, however, these investments should not override the social rights of families threatened with eviction due to the infrastructure projects. The distributional effects of such investments should be evaluated in terms of the extent to which they reduce inequalities in transport accessibility, particularly by improving accessibility levels of low-income public transport-dependent groups to key destinations such as employment opportunities, healthcare and education services. According to this approach, the design of those transport projects (including design of vehicles, stations, cycle paths, etc.) must be inclusive towards social groups such as the elderly and disabled in order to minimize the impact that nonchosen disadvantages have on people's capacity to access activities. Moreover, this perspective also calls for complementary policies that discourage car use (e.g., congestion/parking charge, fuel tax) in highly congested and polluted areas to mitigate the 
negative externalities imposed by drivers on everyone else, particularly on vulnerable populations ${ }^{7}$.

One important advantage of this ethical perspective in addressing distributive justice is its ability to strike a balance between a universalist approach to justice and contextsensitivity. It offers a universalist perspective by providing a strong protection of individuals' rights and liberties. It also accommodates universalist concerns with the protection of basic capabilities that are necessary for individuals to satisfy their basic needs, for the promotion of equality of opportunities, and for ensuring a pluralistic society where individuals can lead the lives they value while respecting the rights of others. At the same time, this ethical perspective is contextualist by acknowledging that the identification of disadvantaged groups and appropriate policies to improve their accessibility are context-specific and that acceptable minimum thresholds of accessibility ought to be defined by each society according to its particular values and material conditions following due political process. Moreover, it acknowledges that evaluations of transport inequalities should hold people responsible for their choices but also recognizes how such choices are often constrained by people's needs, and by their social and built environments.

We believe this provisional and tentative dialogue between Rawls's theory and the Capability Approaches addresses both sufficientarian and egalitarian concerns about the economic, social and health prospects of disadvantaged groups. It is also flexible enough to apply to different dimensions of transport exclusion and inequalities related to gender,

\footnotetext{
${ }^{7}$ To both Rawls and the capabilities approach, people's health/physical integrity should be protected inasmuch as it is understood either as an individual basic right or as a basic capability.
} 
race/ethnicity, disability, segregated and impoverished neighborhoods, etc. We hope it will bring valuable insights to other aspects of equity related to transportation pricing and finance (Pucher, 1982; Santos \& Rojey, 2004), civil rights and spatial discrimination (Karner \& Niemeier, 2013; Sanchez et al., 2003) and environmental justice (Chakraborty, 2006; Schweitzer \& Valenzuela, 2004).

The ideas proposed here go in line with a broader concept of "just city" and how it seeks to build a dialogue between Rawls and Capabilities (Fainstein, 2010). For future studies, further exploration of synergies and divergences between Rawls's theory and the Capability Approaches is needed. A crucial challenge for this framework would be to prove its value in the evaluation of case studies of transport projects and policies in different spatial settings and at local and regional scales. Ideally, this would require more comprehensive accessibility measures that are consistent with the Capability Approach and go beyond conventional transport surveys to capture other factors that shape interpersonal differences in individuals' accessibility, including people's cognitive and embodied competencies, cultural norms, time constraints or whether the social environment is free from any kind of harassment and discrimination. While time-geographers have advanced many of these issues (Kwan, 1998; Miller, 2006), further research is required to discuss how the concept of motility can offer further insights into transportation equity and social exclusion (Kellerman, 2012).

A distributive justice approach does not, however, exhaust all relevant concerns about equity in transportation. As Rawls and Sen themselves recognize, there is more to justice than fair distributions, which cannot be judged in isolation from the process of which 
they are an outcome (Rawls, 1999; Sen, 1999, 2005, 2009). This requires recognizing both the role of participatory planning as a crucial part of transport justice (Booth \& Richardson, 2001; Hodgson \& Turner, 2003), and that current policies and rights one might take for granted today are themselves result of historical processes and political disputes marked by power imbalances between social groups (Fincher \& Iveson, 2012). This is important because the way in which society understands the nature and role of transport accessibility will ultimately shape what a fair transport policy is. The conclusion that justice entails more than questions of distribution calls for a deeper engagement with critical philosophy and social science, which would help situate distributive justice in the broader context of participatory planning, democratic citizenship, the right to the city and spatial justice (Fainstein, 2010; Soja, 2010; Young, 1990).

Transportation equity studies unavoidably deal with normative discussions about what is fair. To grapple this political challenge, a theoretically grounded understanding of distributive justice allows us to go beyond descriptive studies of transport inequalities and to advance justice in transport policies. 


\title{
3. Transport legacy of mega-events and the redistribution of accessibility to urban destinations
}

\begin{abstract}
Local governments increasingly justify the hosting of mega-events because of their legacy value, assuming that all local residents benefit from those events. Yet, little attention has been paid to the distributive question of who benefits from the transport legacy left by those events. This chapter reflects on the delimitation of transport legacies and its social impacts in terms of how such developments can reshape urban accessibility to opportunities. It analyses the transformation in the transport system of Rio de Janeiro (Brazil) in preparation for the 2014 World Cup and the 2016 Olympic Games. That transformation involved substantial expansion in public transport infrastructure, followed by cuts in service levels and a reorganization of many bus lines to streamline the transport system. The chapter examines whether those recent changes have increased the number of people from different income levels who could access Olympic sports venues and healthcare facilities by public transport within 15, 30, 60 and 90 minutes. The analysis uses a before-and-after comparison of Rio's transport network (2014-2017) and a quasi-counterfactual scenario to separate the effects of newly added infrastructure from the reorganization and cuts of transport services. The results show that the infrastructure expansion alone would have increased the number of people who could access the Olympic sports venues, but it would have only marginally improved people's access to healthcare facilities. Nonetheless, the findings indicate that the streamlined bus system have offset the benefits of infrastructure investments in a way that particularly penalizes the poor. The analysis of both the implemented changes to the public transport network and the counterfactual scenario show that the accessibility benefits from the recent cycle of investments and disinvestments in Rio generally accrued to middle- and higher-income groups, reinforcing existing patterns of urban inequality.
\end{abstract}




\subsection{Introduction}

There is a growing debate about whether sports mega-events, such as the FIFA World Cup and the Olympic Games, can foster urban development in host cities by boosting their local economies and leveraging investments in infrastructure (Chalkley \& Essex, 1999; Gratton et al., 2005; Hiller, 2000). The infrastructure projects associated with such events and its promised legacy usually play a key part in the justification used by local and national governments in bids for hosting mega-events (Paddison, 1993; Rubalcaba-Bermejo \& Cuadrado-Roura, 1995; Zhang \& Zhao, 2009).

The strategy of using mega-events to fast-track urban development is commonly backed by pro-growth discourses (Burbank et al., 2002), which rely on the assumption that all local residents invariably benefit from the trickle-down effects of economic growth and improvements to urban infrastructure (Baade, 1996; Baade \& Matheson, 2004; Jones, 2001; Kasimati, 2003; Müller, 2015). Yet, this assumption has been questioned by several studies, which claim that the evaluation of the legacy of sports mega-events should incorporate an equity perspective of how the benefits and burdens of their purported legacies are distributed (Horne \& Manzenreiter, 2006; Smith, 2009). Various studies, for example, have also noted how the organization of mega-events often leads to negative impacts on local communities. In many occasions, thousands of families have had to be evicted from their homes to make room for new infrastructure (Armstrong et al., 2011; Shin \& Li, 2013; Vanwynsberghe et al., 2013), mega-events have caused significant environmental impacts (Collins et al., 2007, 2009; Death, 2011; Gaffney, 2013), they have bypassed democratic decision-making processes (Andranovich et al., 2001; Gold \& Gold, 2011; Raco, 2014; Roche, 
1994) and they have concentrated economic and political power in the hands of small interest groups attempting to rewrite urban planning priorities (Broudehoux, 2007; Sánchez \& Broudehoux, 2013).

However, scholars have devoted much less attention to the equity implications of the transport legacies of mega-events, overlooking the distributive aspects of who benefits from these new transport developments ${ }^{8}$. Most of the literature on mega-events and urban transport has focused on the short-term challenges of delivering transport services during the actual events - in terms of traffic management and contingency plans to address peak demand and congestion (Currie \& Shalaby, 2012; Hensher \& Brewer, 2002; Liu et al., 2008; Mao, 2008; Minis \& Tsamboulas, 2008; Robbins et al., 2007; Silva \& Portugal, 2016; Xu \& Gonzalez, 2016). Only a handful of studies have focused on the lasting transport benefits derived from mega-events (Kassens-Noor, 2012), and little attention has been paid to how these transport legacies subsequently change the daily transport conditions of local residents from different social groups (see next section).

This chapter focuses on the distributional effects of the transport legacies of megaevents looking at how such investments affect different income groups' access to Olympic sports sites and health-care facilities in host cities. It analyzes the city of Rio de Janeiro (Brazil), where transport planning has been largely driven by mega-events for almost two decades (Kassens-Noor et al., 2016). In particular, the study looks at the transformations

\footnotetext{
${ }^{8}$ The terms equity and distributive justice are used interchangeably throughout this chapter. The idea of justice is a broader concept that encompasses moral and political concerns related to (1) how benefits and burdens are distributed in society (distributive justice); (2) the fairness of processes and procedures of decision (procedural justice); and (3) the recognition of rights and entitlements (Fainstein, 2010; Pereira et al., 2017).
} 
implemented in the city's public transport system in preparation for the 2014 World Cup and the 2016 Olympic Games, which included two new high-capacity Bus Rapid Transit (BRT) corridors, a new light-rail system, and a subway extension. These investments were also followed by a reorganization of bus lines to streamline the transport network and, more recently, by cuts in service levels in response to a drop in passenger demand (see section 3.3).

In the empirical analysis, a before-and-after comparison of Rio's transport system between 2014 and 2017 were conducted to calculate how the newly implemented transport investments and subsequent reorganization of the transport system have changed the number of people from different income groups who could access Olympic sports venues and healthcare facilities in the city. A quasi-counterfactual analysis was also conducted to investigate how these results would have been different had the expansion of public transport infra-structure in Rio had not been followed by a reorganization of bus lines. Census data and geolocated timetables of public transport services were combined to calculate the catchment areas of sports venues and healthcare facilities in terms of how many people from different income groups can reach those locations from their homes within 15, 30, 60 and 90 minutes using only public transport and walking. This allowed to estimate how recent modifications in Rio's public transport system have changed the size and income composition of the catchment areas of those facilities and to compare how accessibility gains vary across different income groups and areas of the city.

Olympic sports facilities have been chosen because they have immediate connection to the new transport projects in the city and because improving people's access to such 
venues is a key condition to promote sports participation and leave a sports legacy (Weed et al., 2015), which was one of the main goals purported by local authorities in their bids to host the Olympics (Rio de Janeiro, 2016). Health services were chosen for the analysis in this chapter because they play an important role in the satisfaction of people's basic needs. Health services are considered in Brazil to be a basic constitutional right that should be accessible to all, regardless of personal income. Assessing the impacts of Rio' transport legacy on people's access to educational and employment opportunities would be equally important and this investigation is presented in the next chapters.

A distributive justice discussion on who benefits from the transport legacies of megaevents is important for several reasons. These events require substantial public funds be directed to infrastructure investments, but the local population generally has little involvement in the relevant decision-making processes. Project evaluations of mega-events and transport investments are traditionally conducted using a cost-benefit analysis framework (Flyvbjerg \& Stewart, 2012), which has been widely criticized for not taking into account the distributive aspects of who reaps the benefits and who bears the costs of such investments (van Wee, 2012). Moreover, the transport legacies of such events can substantially change the organization of urban space, making it crucial to evaluate whether local governments mobilize these events in a way that redresses or reinforces existing patterns of urban inequality and segregation.

The remainder of this chapter is divided into five parts. The next section reviews the concept of legacy as it is used in the mega-events literature and discusses how it translates into transport legacy and connects to transportation equity. Section 3.3 presents the context 
of Rio de Janeiro and the changes implemented to its transport system in the context of recent sports mega-events. Sections 3.4 and 3.5, respectively, present the data sources and methods used in the analysis and discuss the results. Section 3.6 presents the chapter's conclusions.

\subsection{Mega-events, urban development and transport legacy}

The idea of leveraging mega-events to fast-track urban development and create lasting benefits for host cities has gradually been incorporated into the mega-events agenda and governments' discourse over the past decades (Gold \& Gold, 2008; Leopkey \& Parent, 2012; Tomlinson, 2014). In 2003, the International Olympic Committee (IOC) started officially requesting that candidate cities include legacy concerns in their bid proposals. The word legacy, however, often lacks conceptual consistency in bidding documents and across the academic literature (Andranovich \& Burbank, 2011; Cornelissen et al., 2011; Preuss, 2007). Perhaps the most comprehensive definition of legacy embraces "the material and nonmaterial effects produced directly or indirectly by the sport event, whether planned or not, that durably transform the host region in an objectively and subjectively positive or negative way." (Chappelet \& Junod, 2006).

Different authors generally recognize that legacy impacts tend to be greater in areas that are physically closer to the event sites and that they are more difficult to identify in the long term (Cornelissen et al., 2011; Preuss, 2007). The durable nature of legacies is the most prominent feature emphasized in the literature (Cornelissen et al., 2011; Gratton et al., 2005). Nonetheless, the definition of what qualifies as short or long term is often vaguely 
defined in cities' bids and in the literature, and yet this issue of temporal scale is crucial when assessing legacy impacts (ibid.). Kassens-Noor $(2010,2013)$ notes, for example, that only a few of the transport measures adopted during the Olympic Games between 1992 and 2012 (Barcelona, Atlanta, Sydney, Athens and London) have been sustained beyond the immediate years following the Games. Consideration of the spatial dimension of mega-event legacies is also particularly important when addressing concerns about their equity implications. Specifically, how are the benefits and costs of mega-events distributed across groups and neighborhoods in host cities? Official pro-poor discourses surrounding the transport legacy of the 2010 FIFA World Cup in South Africa, for example, were challenged by Pillay and Bass (2008), who claimed that improvements to the transport system would be spatially concentrated and offer limited benefits to peripheral urban areas.

All too often there are discrepancies between the plans laid down in bid books and the legacies that are left after the events (Stewart \& Rayner, 2016). Müller (2015) points to a "mega-event syndrome" and its seven interrelated "symptoms" that affect the planning of mega-events and which help explain why delivered legacies fall short of the promises made to local communities. These problems involve the overpromising of benefits, the underestimation of costs, the displacement of local development priorities by the events' agenda, the suspension of regular rule of law, a naive belief that mega-events could work as quick fixes for major planning challenges, the use of public funds to cover the risks of projects with limited public benefits, and the capture of decision-making processes by economic and political elites. According to the Müller (2015), these issues are present to a greater or lesser degree in the organization of mega-events worldwide and commonly lead to the bypassing of regular planning processes and inequitable distributions of public funds and urban 
infrastructure. Together, these symptoms and their consequences raise serious questions about democratic accountability and call into question whether the logics of mega-event legacy planning are practically and functionally compatible with more egalitarian notions of urban policy.

Although mega-events are often justified with reference to their role in addressing urban inequity, these events have generally brought questionable benefits to socially disadvantaged groups (Hiller, 2006; Minnaert, 2012; Smith, 2009). Concerns over distributive justice focusing on who benefits from mega-event legacies have generally received little attention in assessments of the impacts of mega-events (Short, 2008; Whitson \& Horne, 2006). In part, this relates to a common practice of event promoters, who emphasize only the positive legacies of such events, despite the negative impacts they frequently have on local communities (Essex \& Chalkley, 2004; Hiller, 2006; Müller, 2015; Preuss, 2007). However, when assessing the equity impacts of mega-events, it is necessary to acknowledge that the benefits and costs arising from their legacies are rarely equally distributed among members of society and that the same legacy might have positive effects for some groups and negative effects for others (Chappelet, 2012). In the case of the 2016 Olympics in Rio de Janeiro, for example, public authorities used a utilitarian argument that the wider benefits of infrastructure investments would outweigh their social and environmental costs, thus justifying the evictions of more than two thousand families to create space for the new transport investments (Legroux, 2014). Before discussing the case of Rio de Janeiro, the next section outlines how the transport legacies and their equity implications can be framed within a distributive justice perspective. 


\subsubsection{Transport Legacy and accessibility}

Mega-event legacies affect different but interrelated aspects of urban development, such as the economy, knowledge and skill development, physical infrastructure, city image/reputation, and the environment (Andranovich \& Burbank, 2011; Gratton \& Preuss, 2008; Ritchie, 1984). Regarding urban transportation in particular, Kassens-Noor (2010) argues that transport legacies can be created either in the form physical and infrastructural changes to the transport systems of host cities or in the form of how these systems are governed and managed. In the first case, mega-events can create some form of transport legacy by driving changes in management practices, regulation and institutional policies, including, for example, the adoption of Intelligent Transport Systems (ITS), the creation of traffic management centers (TMC), the reorganization of transit routes and the integration of transport modes and tariff systems. In the second case, mega-events can lead to or fasttrack more tangible physical changes in the transport system, such as through the renovation of public transport fleets or the building or expansion of transport infrastructure such as roads, subway systems and airports (ibid.).

Most previous studies on transport legacy have focused on questions about the extent to which the short-term view of mega-events has influenced/dominated the long-term transport planning in host cities (Kassens-Noor, 2010, 2013; Kassens-Noor et al., 2016; Legroux, 2014; Rodrigues \& Legroux, 2015). Although there is a general consensus in the literature of the importance of aligning transport projects related to mega-events with the long-term developmental goals of host cities (Hiller, 2000; Müller, 2015; Pillay \& Bass, 2008; 
Steinbrink et al., 2011; Tomlinson, 2014), these projects should not be planned as ends in themselves. These projects only become valuable to the extent that they improve living conditions in the communities where they are implemented (Banister, 2002; Cervero, 2013). This can be achieved, for example, when these investments contribute to making transport systems more environmentally sustainable, safe, inclusive and efficient, thus improving the everyday transport conditions of local residents and their environment. A major component of transport legacy relies therefore on the effectiveness of transport projects in improving urban accessibility.

Accessibility can be broadly conceptualized as the ease with which people can reach places and opportunities, or, conversely, a characteristic of places and opportunities that describes how easily they can be reached by the population (Neutens et al., 2010). Transport accessibility is thus considered critical for individuals to reach out-of-home activities in order to satisfy basic needs; it is a necessary, although not sufficient, condition for expanding people's freedom of choice and promoting equality of access to opportunities such as employment, healthcare, education, etc. (Lucas, 2012). When evaluating the impact of transport legacy, it thus becomes critical to understand the impact of those investments in making essential services and daily life activities more easily accessible to people, and particularly whether those investments contribute to minimizing or exacerbating sociospatial inequalities in access to opportunities (Lucas et al., 2015; Pereira et al., 2017; van Wee \& Geurs, 2011).

The distributional effects of institutions and policies on social inequalities are the primary concern of one of the most influential theories of social justice, proposed by John 
Rawls (Rawls, 1999, 2001), and feature as a central aspect of justice in urban planning (Basta, 2015; Fainstein, 2010; McKay et al., 2012). In a recent paper, Pereira et al (2017) put forward an interpretation of how Rawls's two principles of justice can be applied to evaluate the fairness of transport policies, which can be extended to the transport legacy of megaevents. According to this interpretation, Rawls's first principle implies that transport projects can only be considered fair if they respect people's basic rights and liberties, such as the rights and liberties covered by the rule of law, and the physical and psychological liberty and integrity of the person. This means that the sacrifice of people's rights and liberties (for example, the forced eviction of families to create space for the implementation of transport projects) cannot be morally justified on the grounds of improving infrastructure development. Following Rawls's second principle of justice, Pereira et al (2017) argue that, while new transport investments have an important role in improving general transport conditions in cities, they should prioritize improving the accessibility of disadvantaged groups - such as low-income and transit-dependent people, the elderly and the disabled and thus contribute to the reduction of inequality of opportunities (ibid.).

Despite the universal character of Rawls's theory, its application to the assessment of urban planning (Fainstein, 2010; McKay et al., 2012) and transport policies (Pereira et al., 2017; van Wee \& Geurs, 2011) must account for the specificities of how new projects are implemented in each context. In the following sections, I discuss the equity implications of the new transport investments recently implemented in the city of Rio. 


\subsection{The transport legacy of Mega-events in Rio de Janeiro}

Rio de Janeiro is one of the largest and richest urban areas in the Global South, with over 12 million inhabitants. It is also among the most unequal cities in the world in terms of income distribution (UN-HABITAT, 2010), having experienced increasing income inequality in recent decades (Ipea, 2016) and historical spatial segregation (Préteceille \& Cardoso, 2008; Ribeiro et al., 2010). Most of the population of Rio also faces extremely poor transport conditions. The city's public transport system stands out as one of the most expensive in the world (UN HABITAT, 2013) and is coupled with a substantial increase in car traffic , giving Rio one of the highest average commute times among global cities (Pereira \& Schwanen, 2013). Urban mobility conditions in Rio are further aggravated by a complex institutional and governance context marked by fragmentation of responsibilities and jurisdiction regarding transport policies and data collection at the metropolitan scale (Costa et al., 2015). Because of the absence of detailed transport information for the whole of the metropolitan area, the current study considers the city of Rio only, which includes $53 \%$ of the metropolitan area's population.

Rio's history of bidding to host mega-events is characterized by heavy emphasis on using such events as opportunities to accelerate urban development and overcome persistent urban problems (Gaffney, 2010; Silvestre, 2012). The adoption of this mega-event strategy in Rio dates at least to the mid-1990s, with the elaboration of the city's strategic plan in 1996 and the 1997 bid to host the 2004 Olympic games (Rio de Janeiro, 1996; Santos, 2013). Since then, Rio won the bids to host the 2007 Pan-American Games, the 2014 FIFA football World Cup and the 2016 Summer Olympic Games (BOC, 2009; Brazil, 2009; Rio de 
Janeiro, 2008). Most of these sporting events have taken place in one of four areas of the city in which the Olympic sports venues were clustered (Figure 3.1).

Figure 3.1 Spatial distribution of population, Olympic Sports Venues and high capacity transport corridors. Rio de Janeiro, 2010

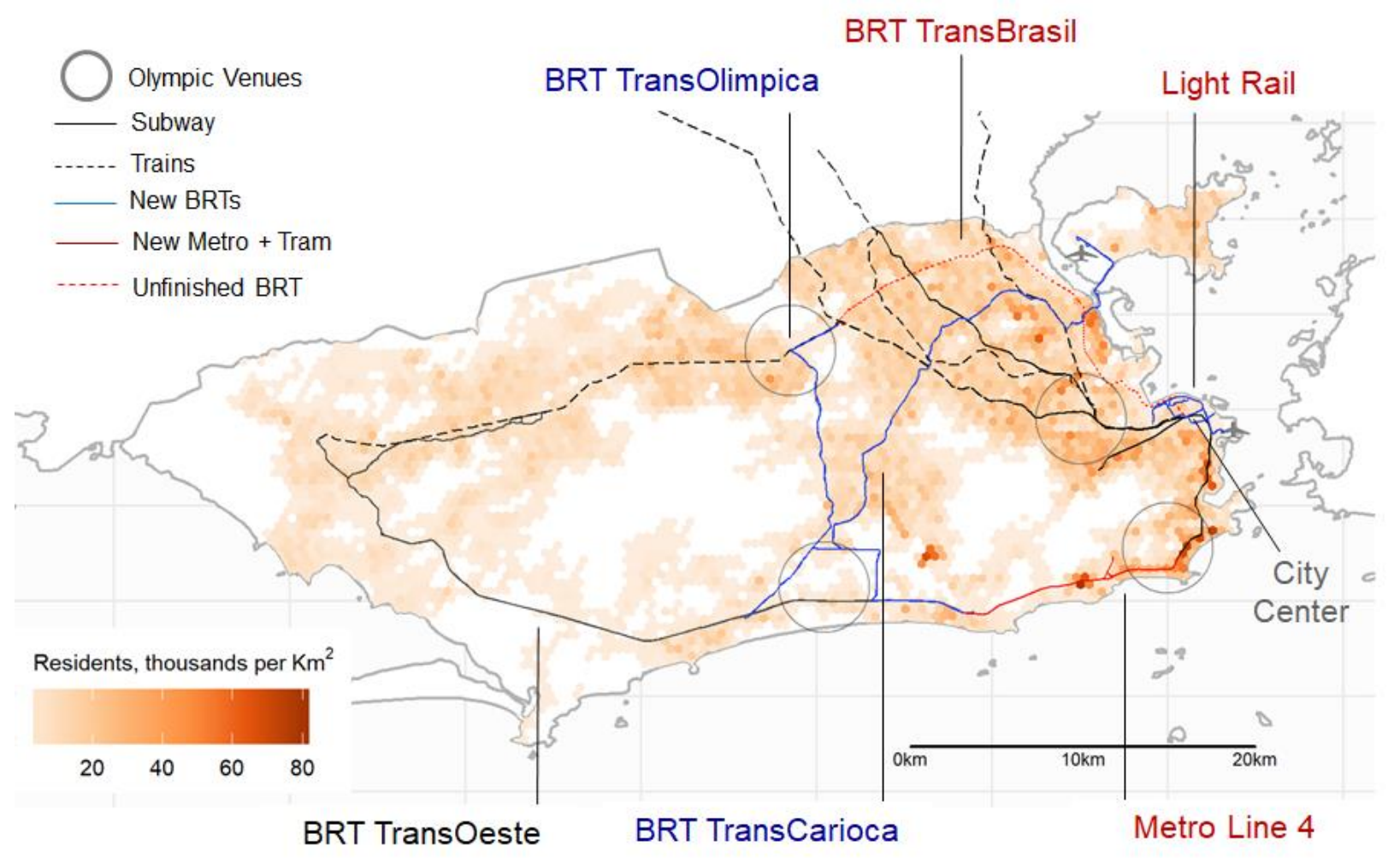

Note: The TransBrasil BRT corridor was originally included in the transportation plans for the 2016 Olympic Games. It was unfinished as of the writing of this chapter

These events mobilized an investment of approximately $\mathrm{U} \$ 5.7$ billion in the city's public transport system between 2010 and 2016. Some of the most significant transformations in Rio's transport network since 2014 include the construction of a lightrail system in the city center, two new BRT corridors and the expansion of a subway line that, 
combined, form a high-capacity transport ring connecting several neighborhoods across the city, two airports and the Olympic sports venues. Along with these investments, local authorities have also reorganized many bus lines to accommodate the newly added infrastructure and streamline the transport network. More recently, however, these changes have been followed by a severe economic crisis coupled with a drop in the number of passengers in the public transport system (França, 2016; Rodrigues, 2017). This has led the government to reorganize the transport network and reduce service levels. In total, 70 bus routes were withdrawn, 41 routes were rerouted or shortened, and 16 new routes were created (G1, 2017).

This subsequent reorganization of bus services raises serious concerns about what will be the actual impact of recent transport investments and who will benefit from them. Perhaps more importantly, it also raises the question of what should be considered as the transport legacy of mega-events. On one hand, a narrow understanding of legacy would only include the actual investments and infra-structure expansion related to the mega-events. From a broader perspective, however, the legacy of those investments cannot be separated from questions of opportunity costs and the wider evolution of the transport network in the city because some of the reorganization of bus services has been implemented in order to accommodate the newly added infrastructure. In the case of Rio, the answer to this question is not trivial particularly because it is not possible to disentangle how much of the reorganization of bus lines was a response to new infrastructure and how much responded to the economic crisis. I return to this question in section 3.5 where a quasi-counterfactual analysis was used to isolate the effects of the new infrastructure expansion. 
From a historical point of view, it is important to note that the transport investments included in Rio's 2009 Olympic bid file are not completely disconnected from the city's previous urban plans. The increasing investments in Barra da Tijuca can be considered part of a long historical process of decentralizing economic activities towards the western part of the city, a process that started in the late 1960s with the Barra Pilot Plan (Rezende \& Leitão, 2003). Most of the transport investments described in the bid are generally located in regions of the city that had already been identified as structural transport corridors in previous city plans since 1965 (Table 3.1), although more fragmented and with different choices of transport modes and routes (Herdy, 2012). The metropolitan transport plan of 2005 (Rio de Janeiro, 2005), for example, proposed that (in an ideal scenario) all structural transport corridors of the city would be covered by a subway system. According to Santos (2013) and Kassens-Noor et al (2016), who interviewed different managers from the city's transport department and the Olympic Public Authority, the routes chosen for investment and the choice to build BRT corridors instead of subways were largely influenced by the Olympic authorities, who were wary of the costs and time horizon required to deliver the investments in time for the event. 
Table 3.1 Summary of new public transport investments. Rio de Janeiro, 2012-2016 ${ }^{9}$

\begin{tabular}{|c|c|c|c|c|c|c|c|c|c|c|c|c|c|}
\hline \multirow{2}{*}{ New infrastructure } & \multicolumn{8}{|c|}{$\begin{array}{l}\text { City Plans and Bids that metion each transport } \\
\text { corridor * }\end{array}$} & \multirow{2}{*}{$\begin{array}{l}\text { Length } \\
(\mathrm{Km})^{a}\end{array}$} & \multirow{2}{*}{$\begin{array}{l}\text { Number of } \\
\text { Stations } \\
\text { and } \\
\text { terminals }\end{array}$} & \multirow{2}{*}{$\begin{array}{c}\text { Total Cost } \\
\text { (U\$ Billion) } \\
\text { a }\end{array}$} & \multirow{2}{*}{$\begin{array}{c}\text { Population in } \\
\text { thousands } \\
\text { within } 1 \mathrm{Km}^{\mathrm{c}}\end{array}$} & \multirow{2}{*}{$\begin{array}{l}\text { Start Date of } \\
\text { partial or full } \\
\text { Operation }\end{array}$} \\
\hline & 1965 & 1992 & 1996 & 2005 & 2009 & 2011 & 2013 & 2015 & & & & & \\
\hline BRT Transoeste & & $\mathrm{x}$ & & & & $\mathrm{x}$ & $\mathrm{x}$ & & 58 & 63 & 0.35 & 368.7 & Jun 2012 \\
\hline BRT Transcarioca & $\mathrm{x}$ & $\mathrm{x}$ & $\mathrm{x}$ & $\mathrm{x}$ & $\mathrm{x}$ & $\mathrm{x}$ & $\mathrm{x}$ & & 39 & 47 & 0.55 & 667.1 & Oct 2014 \\
\hline BRT Transolimpica & & $\mathrm{x}$ & & & $\mathrm{x}$ & $\mathrm{x}$ & $\mathrm{x}$ & $\mathrm{x}$ & 26 & 21 & 0.73 & 171.8 & Ago 2016 \\
\hline Subway Line 4 & $\mathrm{x}$ & $\mathrm{x}$ & & $\mathrm{x}$ & & $\mathrm{x}$ & $\mathrm{x}$ & $\mathrm{x}$ & 16 & 7 & $3.11^{b}$ & 163.8 & Sep 2016 \\
\hline Light Rail System & & & & & & & $\mathrm{x}$ & $\mathrm{x}$ & 28 & 32 & $0.50^{b}$ & 66.5 & Aug 2016 \\
\hline BRT TransBrasil & & & & $\mathrm{x}$ & & $\mathrm{x}$ & $\mathrm{x}$ & & 28 & 27 & $0.48^{b}$ & 565.5 & Exp Oct 2018 \\
\hline Total & & & & & & & & & 195 & 205 & 5.72 & $1,282.7$ & - \\
\hline
\end{tabular}

Source: a. (Rio de Janeiro, 2015, 2016); b. (Mello, 2016); c. Total population living within one Km buffer around transport stops using Euclidean distance. Currency rate of $3.12 \mathrm{R} \$$ to $1 \mathrm{U} \$$.

* City plans and bids:

1965 - Doxiadis Plan

1992 - City Master Plan

1996 - City Strategic Plan

2005 - Master Plan for Urban Transport of Rio Metropolitan area

2009 - Bid file for the Olympic Games 2016

2013 - City Strategic Plan 2013-2016

2015 - Public Policy Olympics Legacy Plan

Since their opening, these new projects have already received substantial criticism from academics, grassroots movements and the media, according to whom these projects are over budget and under investigation for possible corruption (Cuadros, 2016; Fonseca, 2017; Sandy, 2016). Moreover, those Olympic projects were elaborated with little social participation and transparency (Sánchez \& Broudehoux, 2013) and they do not tackle the wider transport needs of the metropolitan area as a whole (Kassens-Noor et al., 2016; Rodrigues \& Legroux, 2015). After performing local inspections and a series of workshops and interviews with local authorities and users, the Institute for Transportation and

\footnotetext{
${ }^{9}$ These figures do not include the costs of roads nor airport investments, which predominantly cater to highly mobile high-income earners (Müller, 2015).
} 
Development Policy also observed that many BRT stations present barriers to people with physical disabilities, that buses are frequently overcrowded, and that BRT corridors on the whole are still poorly integrated with other transport modes, particularly bicycles (Hughes \& Leshner, 2013; ITDP Brasil, 2013, 2014, 2015). Although these issues are not addressed in this study, they play a central role in creating a more just and inclusive transport system that should be recognized in a broader discussion about transport legacy.

Furthermore, grassroots organizations and the press have also denounced the violation of the human rights of local communities who were evicted from their homes often with coercive and violent practices - to create space for infrastructural projects related to mega-events in the city (CPCORJ, 2015; Kommenda, 2016). Despite modifications of the transport projects to minimize the number of evictions, 2,125 families were relocated because of transport investments between 2009 and 2015, according to official figures (Rio de Janeiro, 2015). Figure 3.2 depicts the locations of the evictions enforced between 2009 and 2012, showing how affected families were largely concentrated along the routes of the transport investments. From a social justice standpoint, these evictions are in direct conflict with Rawls's first principle of justice, according to which the violation of individuals' basic rights and liberties could not be justified on the grounds of a "greater good". ${ }^{10}$

\footnotetext{
${ }^{10}$ From a Rawlsian perspective, the relocation of families in and of itself would not necessarily be considered a violation of justice as long as relocations resulted from a consensual agreement between the government and relocated families with proper compensation. However, it is difficult to determine the consensual character of transactions involving extreme asymmetries of power and, as in the case of Rio, where evictions have reportedly involved physical and psychological violence by the police (CPCORJ, 2015; Gaffney, 2016; Kommenda, 2016).
} 
Figure 3.2 Evictions in the city of Rio de Janeiro between 2009 and 2012

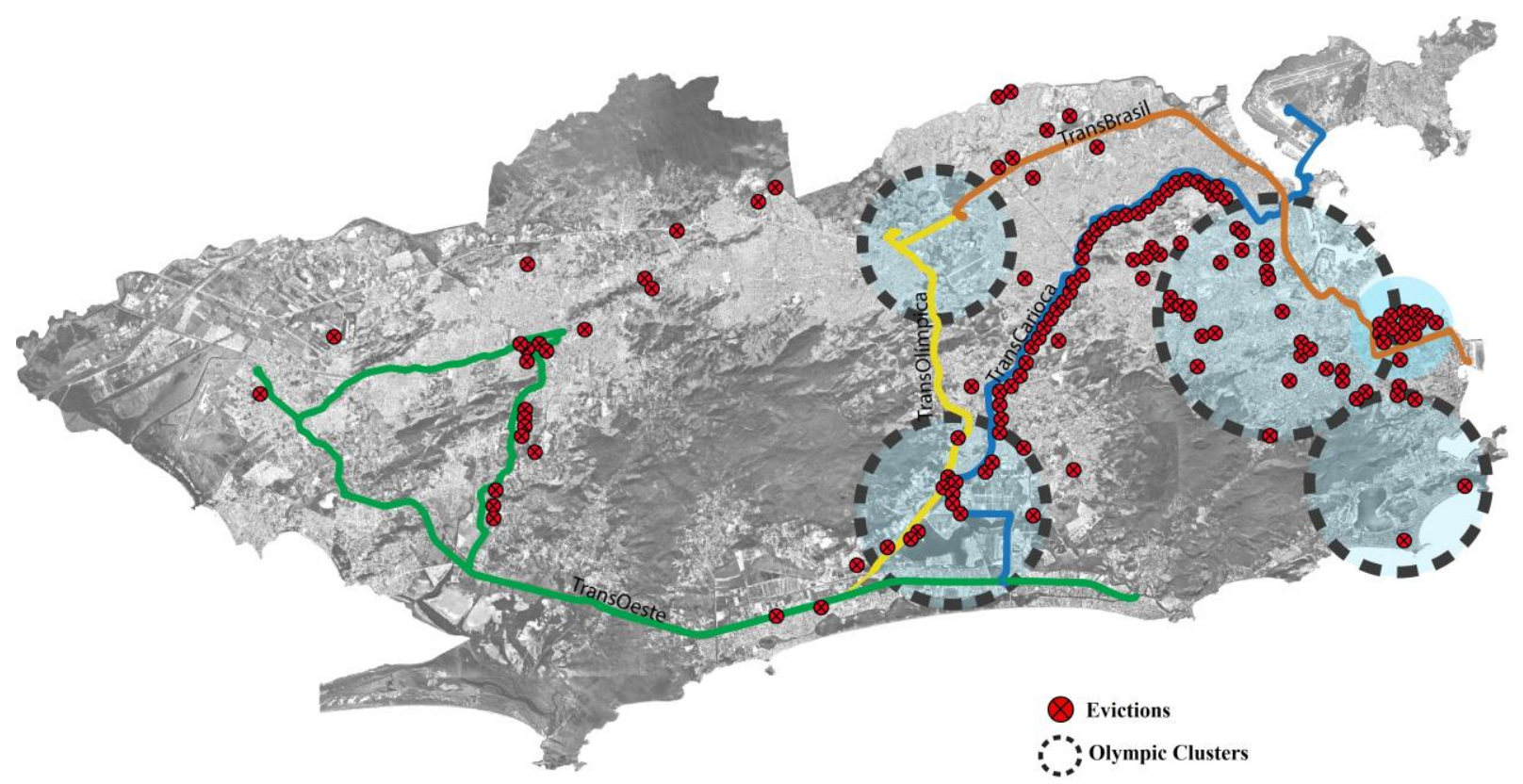

Source: Faulhaber and Nacif (2013), based on local government decrees published between January 2009 and May 2012.

A question that has received far less attention, however, is how these investments have changed the transport system of the city overall and how they have made key urban activities more or less accessible to different income groups in the city. While Brazilian public authorities and the Olympic evaluation commission claimed that the transport legacy would particularly benefit low income people who live in deprived areas in distant neighborhoods by reducing the time they spend in traffic (Brazil, 2009), others claimed that such investments were likely to exacerbate social polarization and benefit rich neighborhoods (Brownill et al., 2013; Gaffney, 2010). In the next section, the method used to address this question is explained, considering the recent changes implemented in Rio's public transport system and its network effects on transport accessibility. 


\subsection{Data and Methodology}

Accessibility is here understood as a place characteristic related to how easily a destination can be reached by different social groups. This focus allows us to grasp the broader sociospatial impacts of transport policies in terms of the access they provide to different types of services and opportunities. The analysis uses a before-and-after comparison of Rio's public transport system to capture the extent to which the transport legacy of mega-events has changed socio-spatial inequalities in access to sports venues and healthcare services in the city of Rio de Janeiro between 2014 and 2017.

Catchment area analysis was used to estimate the number of people from different income groups who can reach the relevant locations from their homes within a certain travel time threshold using only public transport and walking. I deploy a modified version of a cumulative-opportunity measure, one of the most commonly used accessibility metrics that makes very few assumptions about the nature of people's preferences and behavior (Neutens et al., 2010) and is easy both to implement and interpret (Neutens, 2015; van Wee \& Geurs, 2011). Although other conceptualizations and measurements of accessibility could have been used, they would offer less detailed insight into the specific destinations that can be reached. They generally require more data on people's observed travel behavior and they are more computationally difficult to both implement and to be interpreted; their use is left for future research. The affordability of public transport was not considered in the analysis due to data availability constraints. This is a major limitation to be addressed in future research. 


\subsubsection{Data Sources}

This study combines five data sources (Table 3.2). Demographic and socioeconomic data on Rio's resident population come from the 2010 Census (IBGE, 2010). Population count data from the Census (IBGE, 2016) were organized in a hexagonal grid of 500 by 500 meters, with 5,520 cells. The resident population in each grid cell was categorized according to income decile based on the average household income per capita of each grid cell. This was imputed from census data organized in 1,136 relatively homogeneous socioeconomic polygons known as Human Development Units (Ipea et al., 2015). The data on household income per capita collected in the census account for all members of the household and all their sources of income (including formal or informal jobs, unemployment benefits, pensions, social transfers, etc.). Although the census has some limitations in terms of capturing the upper extreme of income distribution (Souza, 2015), it is still the best data source to account for income distribution in Brazil.

Table 3.2 Data sources used in the empirical analysis.

\begin{tabular}{|c|c|c|c|}
\hline Data & Details & Source & Year \\
\hline Population - Count & Spatial distribution of population count & Population Census (IBGE) ${ }^{1}$ & 2010 \\
\hline $\begin{array}{l}\text { Population - socioeconomic } \\
\text { characteristics }\end{array}$ & $\begin{array}{l}\text { Spatial distribution of socioeconomic } \\
\text { characteristics }\end{array}$ & $\begin{array}{l}\text { Ipea et al. (2015) based on the } 2010 \\
\text { Population Census (IBGE) }\end{array}$ & 2010 \\
\hline Healthcare facilities & Location and service complexity & $\begin{array}{l}\text { Rio data portal }{ }^{3} \text { Datasus portal } \\
\text { portal }^{4}\end{array}$ & 2015 \\
\hline Street newtork & Roads and pedestrian network & Open Street Maps ${ }^{5}$ & 2017 \\
\hline Public Transport system & $\begin{array}{l}\text { Geolocated time-tables organized in GTFS } \\
\text { format }\end{array}$ & Fetranspor ${ }^{6}$ & 2011,2014 \\
\hline
\end{tabular}

Note: most of the datasets are publicly available at (1) www.ibge.gov.br (2) www.atlasbrasil.org.br (3) http://data.rio/ (4) www.tabnet.datasus.gov.br (5) www.openstreetmap.org ; (6) Federation of Passenger Transport Companies in Rio de Janeiro 
Geolocated data of healthcare facilities (Figure 3.3) and Olympic sports venues (Figure 3.4) were downloaded from Rio's open data portal. The analysis included 304 healthcare facilities providing primary and ambulatory care and hospital services free of charge through the public health system (SUS). Health care facilities are categorized in SUS according to the level of complexity of the services they provide according to the costs and technological complexity involved (Brazil, 2007). Low-complexity services include, for example, basic dental treatment, general practice and rehabilitation, while services such as diagnostic radiology, prosthesis and small surgeries are considered of medium complexity. High complexity services, in turn, include neurosurgeries, hemodialysis, intensive care and cancer treatment, among others. According to the data, some facilities provide health services at more than one level of complexity, in which case the facility was included in the accessibility analysis at both levels.

Figure 3.3 Spatial distribution of healthcare facilities by level of service complexity. Rio de Janeiro, 2015.

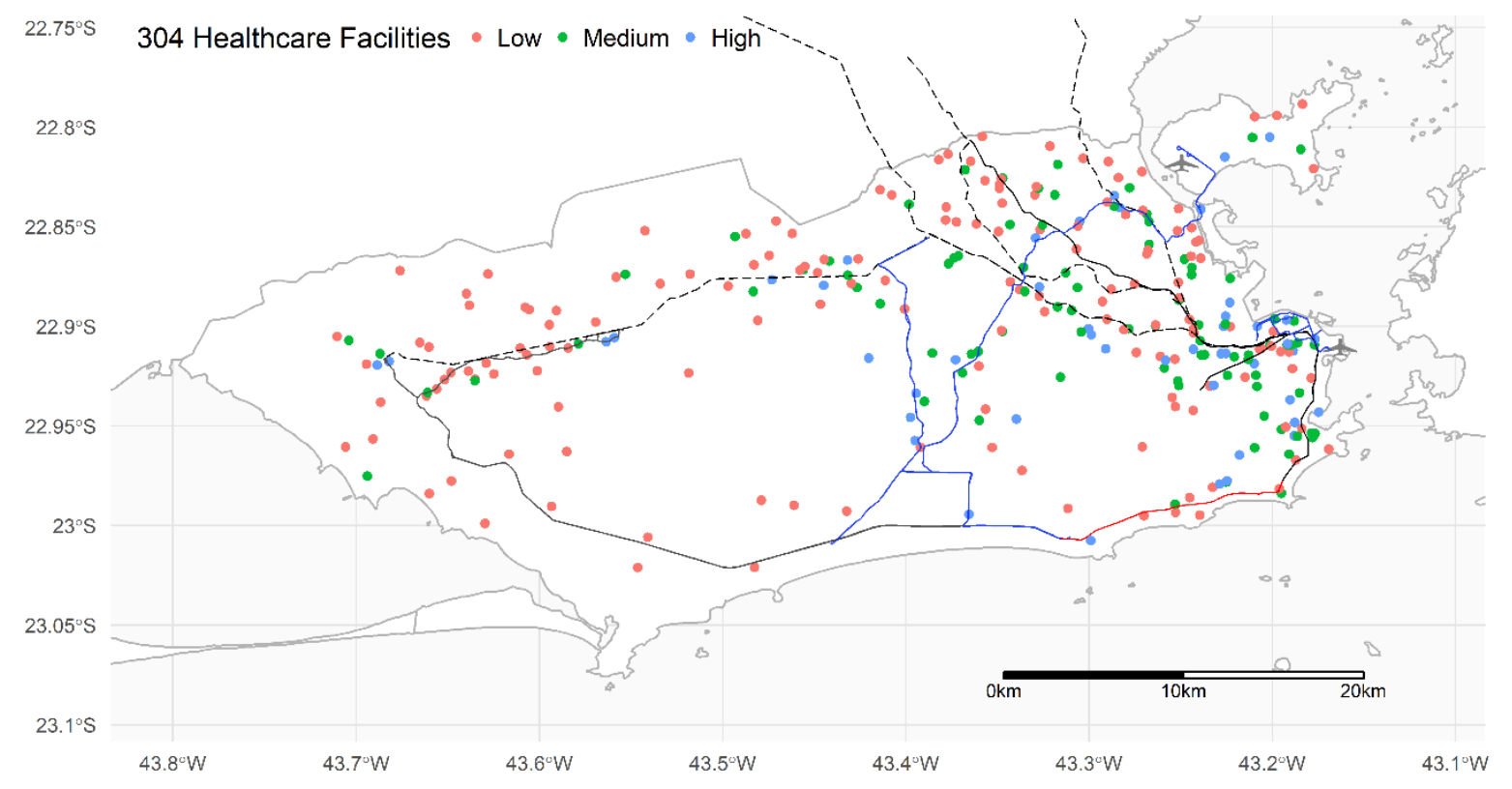


Figure 3.4 Spatial distribution of Olympic Sports Venues. Rio de Janeiro, 2016.

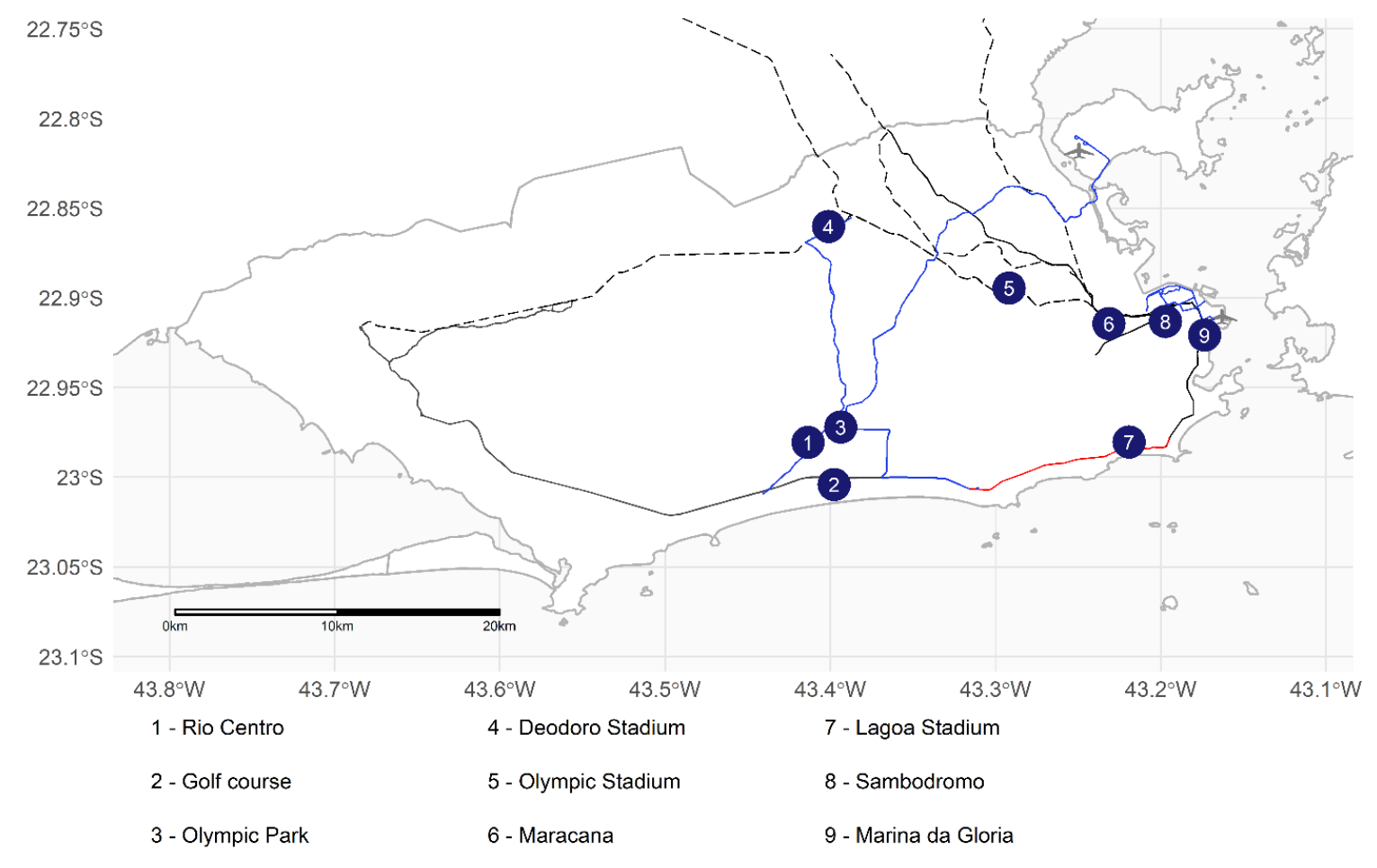

Spatial information on road networks and pedestrian infrastructure comes from OpenStreetMap, while data on Rio's public transport system comes from geolocated timetables from April 2014 and March 2017. These data are organized in General Transit Feed Specification (GTFS) format, bringing detailed geolocated information on routes, stops and timetables. An important caveat of the GTFS dataset is that it does not account for congestion levels and it may overestimate service performance in some areas and times of the day. 


\subsubsection{Catchment size and composition}

The method used in this chapter required three steps. In the first step, travel-time estimates between every pair of grid cells by public transport and walking were calculated using OpenTripPlanner (OTP), an open-source routing engine ${ }^{11}$. Several travel-time matrices were estimated departing every 20 minutes between 7 am and $7 \mathrm{pm}$ to account for fluctuations in service availability at various times of the day. These door-to-door estimates allow us to consider temporal variations in public transport services and to consider walking time from the point of origin to the transit stop, waiting time for the vehicle, actual travel time through the transport network and eventual transfers, and the walking time from the transit stop to the destination.

The second step was to combine the travel-time matrices with the geolocated data on population, sports venues and healthcare facilities. Following the equation below, the size of the population by income within the catchment area of each location was calculated for a typical working day in April 2014 and March 2017 using time thresholds of 15, 30, 60 and 90 minutes. Multiple thresholds were used because there are no universal boundaries on acceptable travel times (insofar as they exist, there will likely be difficult-to-identify differences across and within income groups and by trip purpose). The specific values selected are commonly used in accessibility analysis involving cumulative opportunity measures (Boisjoly \& El-Geneidy, 2017). As an illustration, the catchment area of highcomplexity healthcare facilities includes every person that could reach one of those facilities

${ }^{11}$ https://github.com/opentripplanner/OpenTripPlanner 
from their home by walking or public transport within a time threshold of, for example, 30 minutes.

$$
\begin{aligned}
& C_{d, i, T}=\operatorname{median}\left(\sum_{o=1}^{n} P_{i o} f\left(t_{o d r}\right)\right) \\
& f\left(t_{o d r}\right)=\left\{\begin{array}{l}
1 \text { if } t_{o d r} \leq T \\
0 \text { if } t_{\text {odr }}>T
\end{array}\right.
\end{aligned}
$$

Where:

$\mathrm{C}_{\mathrm{d} i \mathrm{~T}}$ is the catchment size of destination $\mathrm{d}$ for population of income i within time threshold $\mathrm{T}$. $\mathrm{P}_{\mathrm{i} o}$ is the number of people with income $\mathrm{i}$ in location $\mathrm{o}$ $t_{o d r}$ is the travel time in minutes between origin o and destination $d$ at departure time $r$. $\mathrm{f}\left(\mathrm{t}_{\mathrm{odr}}\right)$ is a time threshold function that varies between one and zero, depending on whether travel time $\left(t_{o d r}\right)$ is larger or smaller than time threshold $\mathrm{T}$.

In the final step, a before-and-after comparison of Rio's transport system was conducted in which the spatial distribution of the population and its income distribution, sports venues and healthcare facilities are kept constant. This assumption allowed us to isolate the effect of the new transport investments on the variations in the catchment areas (size and income composition) between 2014 and 2017. The assumption disregards changes in the spatial distribution of socio-economic groups and healthcare facilities that may have occurred over the period, but such changes tend to occur over timescales considerably exceeding those of the current analysis; changes during the 2014-2017 period are highly unlikely to have significantly affected the overall results of the current analysis.

Accessibility changes were also estimated under a quasi-counterfactual scenario in order to isolate what would have been the sole effect of the new transport investments. This scenario simulates as if all public transport services provided in April 2014 would have been 
kept constant, without any reorganization of regular bus lines or reduction in service levels. Thus, the only modifications to Rio's public transport system in this analysis were the addition of the new public transport infrastructure, i.e. the BRTs Transcarioca and Transolímpica and the new subway and light-rail lines.

A few limitations of this methods should be mentioned. First, travel-time estimates are based on information of service timetables. The misreporting of timetables and congestion levels could lead to overestimated accessibility levels. This shortcoming could be addressed by future studies by using GPS data of vehicles to generate more realistic traveltime estimates (Wessel et al., 2017). Secondly, the accessibility levels estimated in this study could be at least partially eroded by the cost of transport fares and by overcrowded and unsafe vehicles. Although these factors can significantly hinder accessibility, these issues could not be incorporated into the analysis because of data constraints. Therefore, future research could benefit from a more nuanced understanding of accessibility as a personal attribute and thus incorporate the diversity in people's abilities to use the transport systems and move around the city; such research could include aspects of affordability, age, gender, disability, etc. This would also help draw attention to an under-investigated question related to what extent transport investments driven by mega-events contribute to building a barrier-free urban environment and improve the mobility conditions of elderly and disabled people (Darcy, 2003). 


\subsection{Results}

Figure 3.5 depicts, the proportion of the city population that could reach each grid cell within 60 minutes by public transport and/or walking in 2014 and 2017. Brighter yellow colors indicate that the areas along high-capacity corridors are substantially more accessible than peripheral and less connected areas, particularly towards the northwest of Rio where a large share of the population lives. As an illustration, the Maracanã football stadium (\#7 in Figure 3.4) could be reached by approximately $48 \%$ of the city population within one hour by public transport/walking in the year 2017.

Figure 3.6 highlights how the size of catchment areas have changed in percentage points between 2014 and 2017 for both implemented and counterfactual scenarios. It shows how several areas in the city have become relatively less accessible to the population because of the streamlining of bus lines and reduction in service levels. One of the largest declines happened in between Realengo, Taquara and Oswaldo Cruz neighborhoods (clustered in dark orange). These neighborhoods were more intensely affected after two bus companies that operated in those areas went bankrupt (Borges, 2016; Zarur, 2017). Figure 3.6 also indicates that, in a quasi-counterfactual scenario where the new investments would have been implemented without the reorganization of bus lines, the new transport infrastructure would have mostly improved transport accessibility to those areas which were already relatively better connected via the subway and train systems. The analysis of catchment areas within 30, 60 and 90 minutes shows that those investments would not have improved access to peripheral areas. 
Figure 3.5 Proportion of the city population within the catchment area of 60 minutes by public transport and walking. Rio de Janeiro, 2014 and 2017.

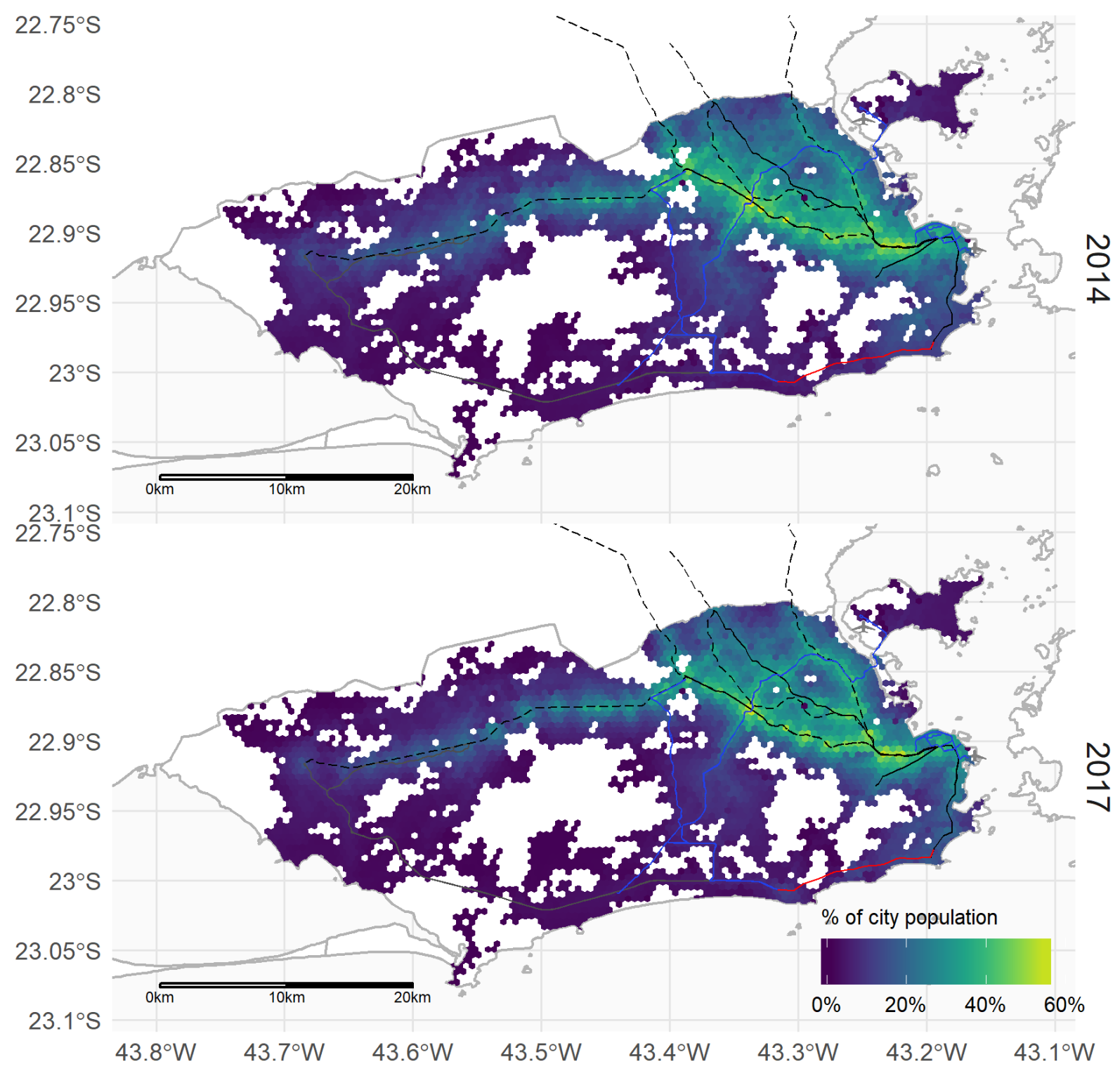


Figure 3.6 Variation in percentage points of the city population within the catchment area of 60 minutes by public transport and walking in implemented and counterfactual scenarios. Rio de Janeiro, 2014 and 2017.

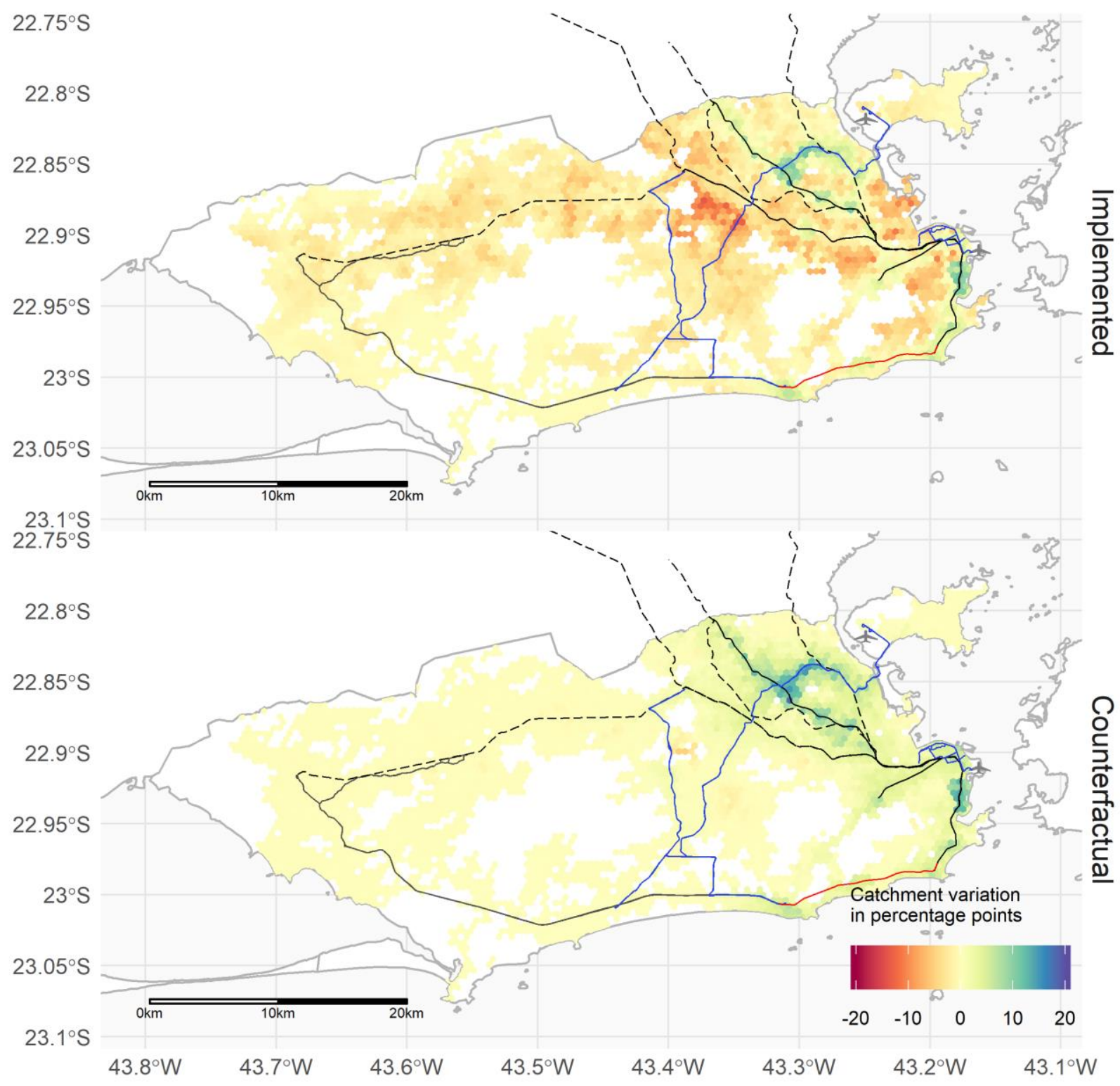




\subsubsection{Sports Venues}

Focusing more specifically on how recent transport policies have changed the population's access to Olympic Sports venues, Figures 3.7 and 3.8 show how the size and the income composition of the population within the catchment areas of those facilities have changed between 2014 and 2017, including the results for the quasi-counterfactual scenario. There is a marked variation in the size of catchment areas, reflecting how the sports venues are dispersed across the city. Venues such as the Olympic park are located in less densely populated and less connected areas, while the Olympic Stadium is located in a much denser and better-connected area. This figure also shows how the income composition of the catchment areas of Olympic sports venues is also quite varied, although higher-income groups are generally overrepresented in the catchment areas of almost every sports venue. In the most extreme cases, over $75 \%$ of the population that could reach the sports venues of the Lagoa Stadium and the Golf Court under one hour by public transport and walking belong to the two richest income deciles.

Figure 3.8 suggests that the reorganization of bus services and cuts in service levels have generally offset the new transport investments in Rio. It shows how, overall, the policies implemented in the city have reduced catchment size of every sports venue, with the exception of Marina da Gloria and the Olympic and Maracanã Stadiums. While the quasicounterfactual scenario shows that the transport infrastructure expansion alone would have increased the number of people who could access every venue, the results from both scenarios indicate that the accessibility benefits generally accrued to middle- and higherincome groups, leading to an increase in accessibility inequality across income groups. 
Figure 3.7 Population size and income composition within the catchment area of 60 minutes by public transport and walking of Olympic Sports Venues. Rio de Janeiro, 2014-2017.

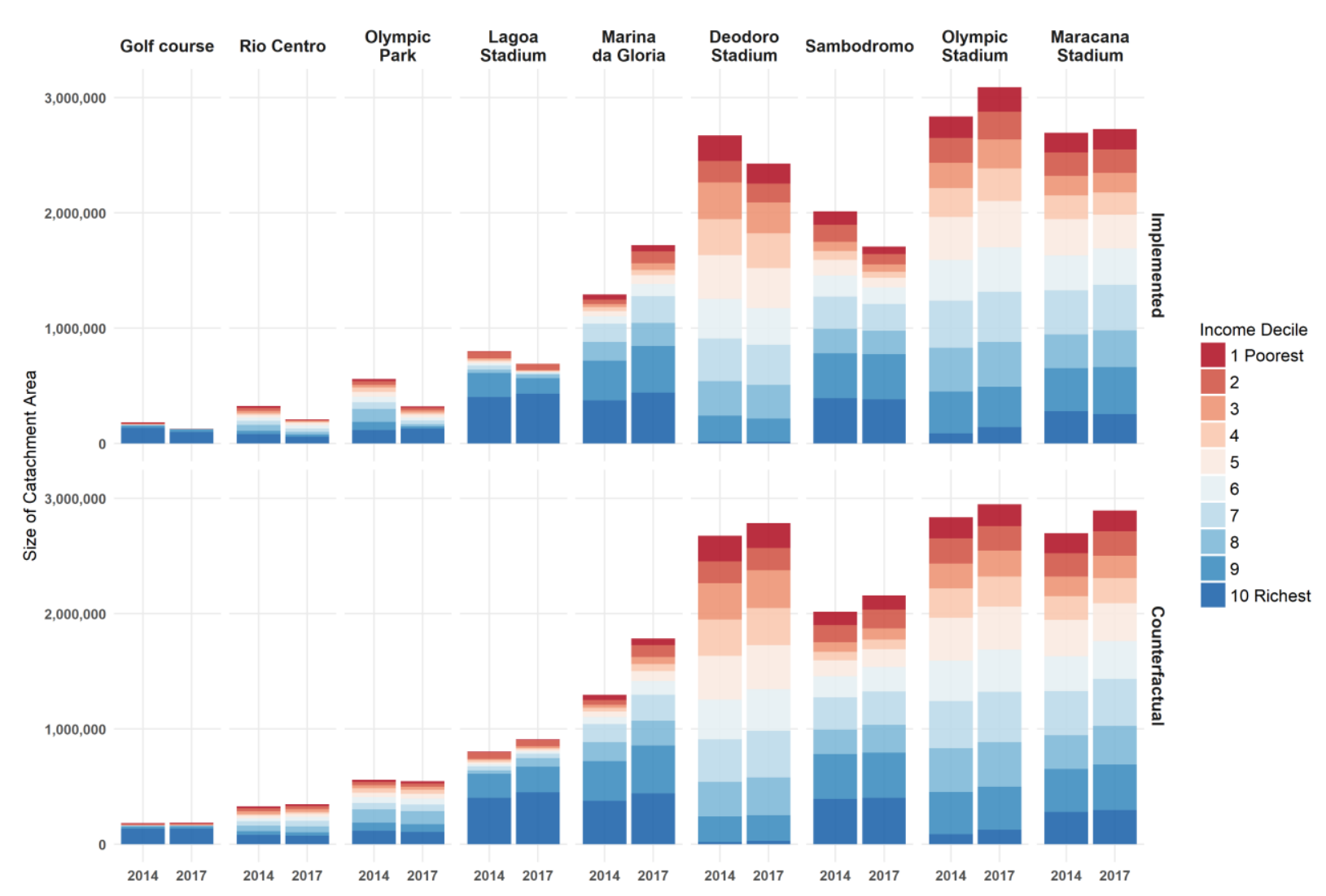

Two conclusions follow from the above. These results indicate that the potential benefits of new transport infrastructure were to a large extent offset by the subsequent reorganization of service levels, leading to a general decrease in the population's access to the Olympic sports venues. Moreover, both the changes implemented to the transport system and the new investments alone fail to meet the second Rawlsian criterion of justice because they have been unable to improve the accessibility of low-income groups, which still have lower transport access to the facilities compared to middle- and high-income groups. 
This is also in part because most of the sports venues are located either in high-income areas which were already relatively more accessible (such as Marina da Gloria and Lagoa Stadium), or in lower-income lower-density areas that remained poorly connected to the rest of the city (such as Rio Centro and Olympic Park). Although the chapter only presents figures under a time-threshold of 60 minutes due to lack of space, these general conclusions also hold under thresholds of 30 and 90 minutes.

Figure 3.8 Variation in the population size (by income groups) of the catchment areas of 60 minutes by public transport and walking of Olympic Sports Venues between 2014 and 2017. Rio de Janeiro.

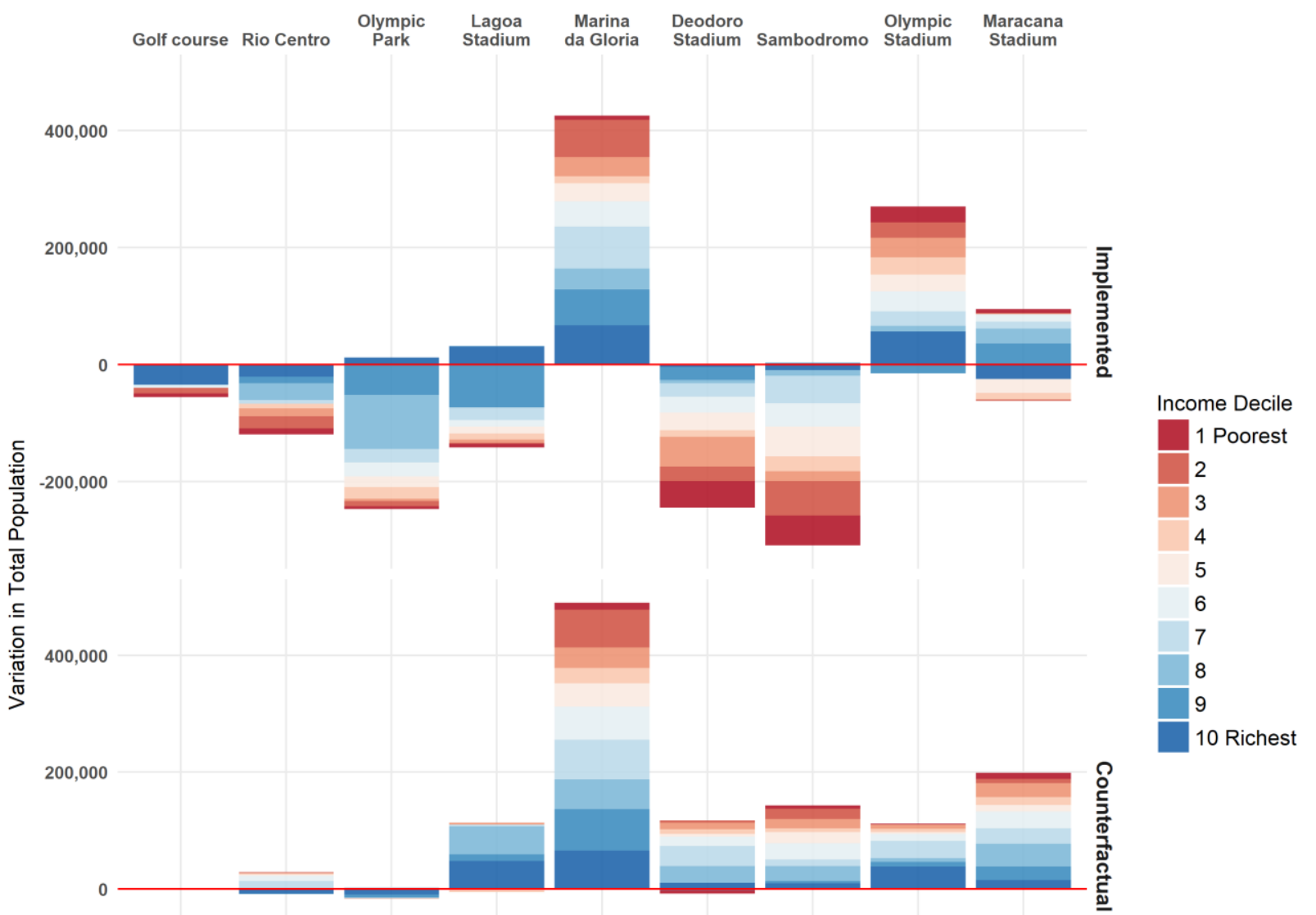




\subsubsection{Healthcare facilities}

Given the interest in analyzing the legacy of recent transport developments in Rio, it is also particularly important to understand the extent to which this cycle of investments and disinvestment have impacted people's access to essential services such as healthcare. Given a 60 -minute travel time threshold, close to $95 \%$ of the city population could reach a healthcare facility at any level of service complexity either before or after the investments. However, the conclusions change when a 30-minute threshold is used. This threshold is not only commonly used in other studies of accessibility to healthcare (Neutens, 2015) but also seems to be a more realistic value for people whose physical mobility is likely to be hindered in various ways.

Figures 3.9 and 3.10 show the how the size and the income composition of the population within a 30-minute catchment area of healthcare facilities has changed between 2014 and 2017 and how it would have changed in the quasi-counterfactual scenario. In the year 2017, approximately 5.8 million people, the equivalent of $94.5 \%$ of Rio's population, could reach at least one of the 224 facilities providing low complexity services via public transport and walking under 30 minutes. For the 93 medium-complexity and the 94 highcomplexity facilities, these figures were approximately 5 and 4.4 million people $-81 \%$ and $73 \%$ of the city population, respectively. Furthermore, the distribution across income classes was roughly even but less so for services of high level of complexity, which were more accessible to wealthier groups. ${ }^{12}$

\footnotetext{
12 It is worth noting, however, that healthcare facilities at the same level of complexity are not all interchangeable because they do not necessarily provide the same services. This chapter could thus be
} 
These relatively high levels of accessibility can, to some extent, be explained by the spatial planning of healthcare facilities in the region (Rio de Janeiro, 2014), which has been relatively successful in redistributing low- and medium-complexity healthcare facilities equally across the city of Rio. Because those healthcare facilities are fairly distributed across the city, even significant modifications in the transport systems as the ones observed in Rio would lead to relatively small changes to the catchment areas of those facilities.

Figure 3.9 Population size and income composition within a $30 \mathrm{~min}$ catchment area of healthcare facilities by service complexity. Rio de Janeiro, 2014-2017.

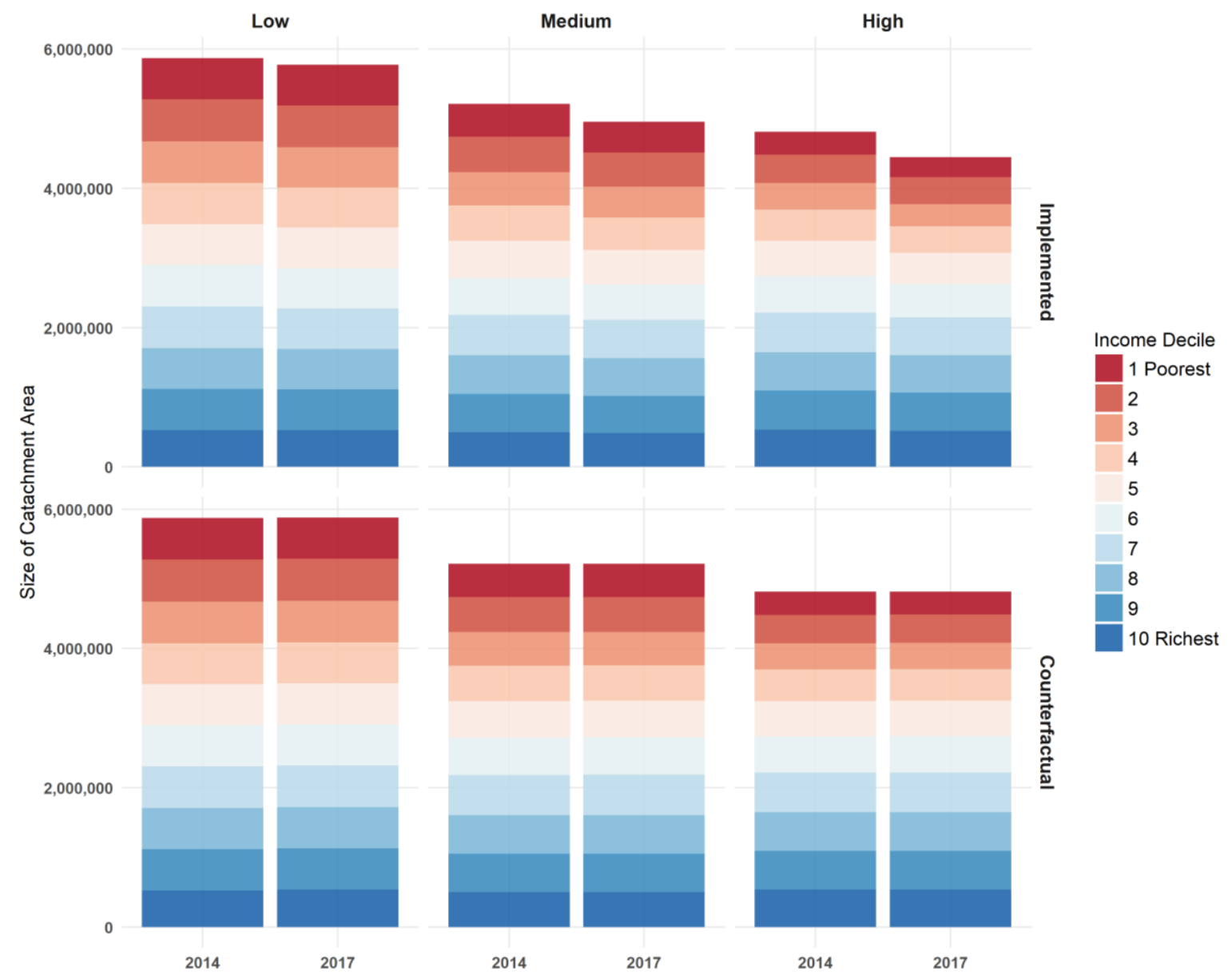

complemented by future studies providing detailed analyses of people's accessibility to particular types of treatment that demand more frequent trips to the hospital, such as hemodialysis, physical rehabilitation, etc. 
The quasi-counterfactual analysis suggests that the new investments alone would have had only a marginally positive effect, increasing by a few thousands the number of people who could reach healthcare facilities. In contrast, what was observed is that the total catchment areas of low-, medium- and high-complexity facilities have shrunk respectively by $1.6 \%, 4.9 \%$ and $7.5 \%$ between 2014 and 2017 (Figure 3.9). This reduction has resulted from the reorganization of the bus routes and particularly from a reduction in service frequency in some parts of the system, which have given rise to many complaints from users (Magalhães \& Rodrigues, 2017; O Globo, 2016; Rodrigues, 2016). Given a travel time budget of, for example, 30 minutes, lowering service frequency not only reduces people's choice of departure time but also is more likely to extend their waiting time at bus stops at the expense of travel time inside the vehicle, thus reducing the distances covered and the area that is accessible. The detrimental effect of the streamlining of the bus systems was not identified with the same intensity when considering a travel time threshold of 60 minutes. This is because the headway effect on the size of the catchment area will be smaller as the travel time budget gets larger and the waiting time at a transit stop represents a smaller share of total travel time (Ratio between waiting time and travel time).

Furthermore, Figure 3.10 suggest that the reduction in service levels have not affected all income classes in the same way. The combination of new infrastructure investments and reorganization of the bus routes have made medium- and high-complexity healthcare facilities more accessible to higher-income groups while at the same time reducing their accessibility to the poor. These analyses were also conducted considering a 15-minute threshold. This resulted in even higher levels of inequality between higher- and lower-income groups in terms of their access to healthcare facilities of medium and high 
complexity. This is largely because most of these facilities are located in relatively wealthier regions of the city.

Figure 3.10 Variation in the population size (by income) within a $30 \mathrm{~min}$ catchment area of healthcare facilities (by service complexity) between 2014 and 2017. Rio de Janeiro.

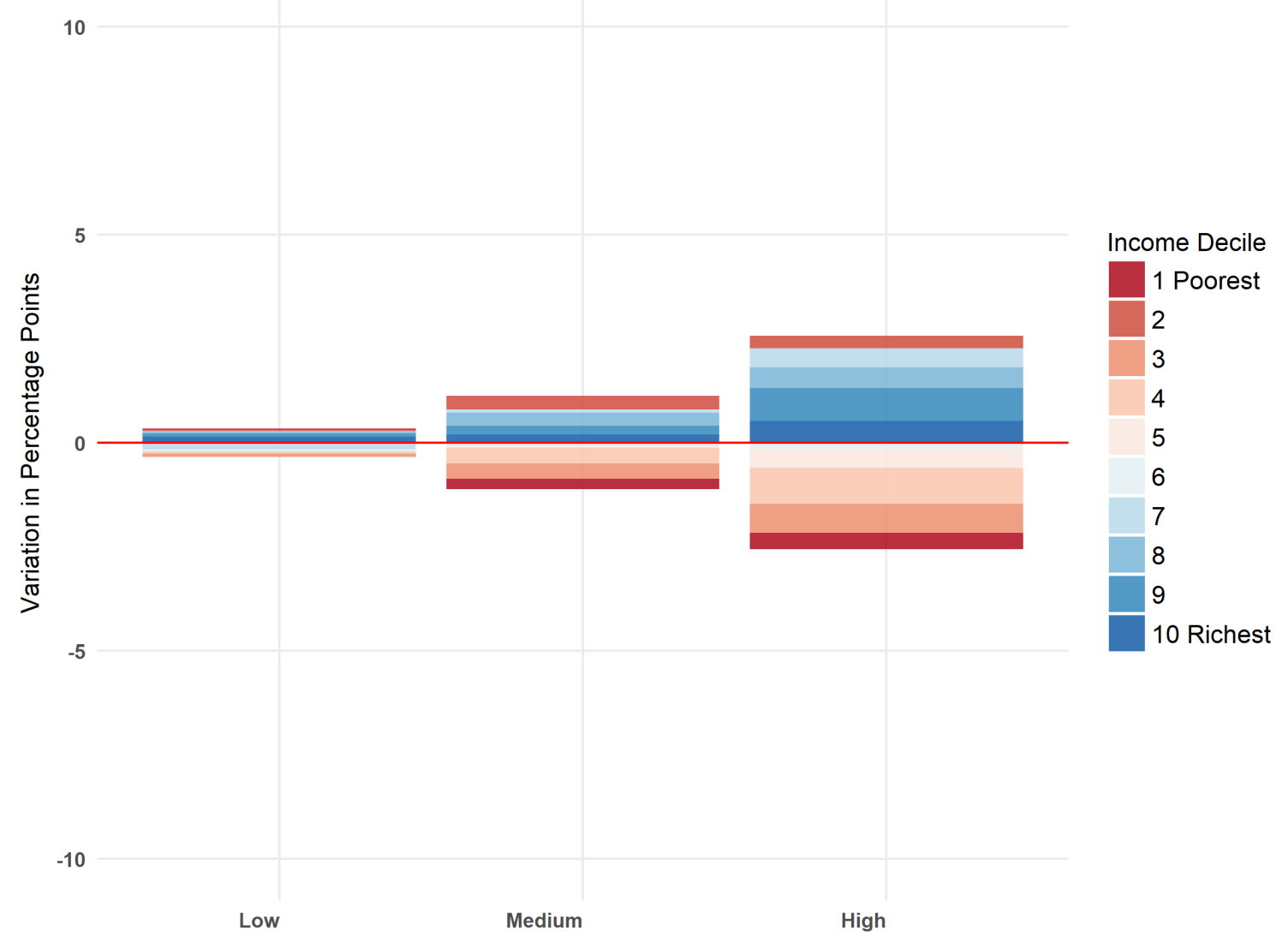

In summary, independent of income level, the population of Rio already had relatively high levels of accessibility to healthcare facilities. This is largely due to the policy-led spatial distribution of such facilities across the city, and hence the recent cycle of investments and disinvestments had only a minor effect on people's access to such facilities. The newly added transport infrastructure alone would only have marginally improved accessibility levels. In 
contrast, the new investments combined with the reorganization of the city's public transport system has actually reduced accessibility levels to medium- and high-complexity healthcare facilities, particularly for lower-income groups, and this outcome contradicts Rawls's second principle of justice. This result shows how the streamlined bus system have to some extent offset the benefits of additional transport infrastructure in a way that particularly penalizes the poor.

\subsection{Conclusions}

This chapter has sought to contribute to discussions of transport planning in the context of mega-events and of how transport legacies can help shape socio-spatial inequalities by reconfiguring urban accessibility to opportunities. Previous research has documented various issues associated with the hosting of sports mega-events in general and in Rio in particular. The lack of participatory policy and the violation of the social rights of local communities have been particularly discussed in previous studies about Rio de Janeiro (Faulhaber \& Nacif, 2013; Gaffney, 2016; Santos, 2013). This chapter complements previous research by evaluating how event-led investments in Rio and its subsequent transport policies have affected the daily transport conditions of local residents after the events, particularly investigating whether alleged transport legacies had an effect of equalizing access to opportunities.

Overall, the results indicate that the new investments in Rio's transport system have not, despite the promise in Rio's Olympic bid file, radically improved transport conditions of poor people living in the peripheries of the city (BOC, 2009; Brazil, 2009; Rio de Janeiro, 
2008). A quasi-counterfactual analysis suggests that the new infrastructure expansion alone would have increased the number of people who could access the Olympic sports venues, but they would only marginally improve people's access to healthcare facilities. Nonetheless, a before-and-after comparison of Rio's public transport system shows that the subsequent reorganization of bus routes and reductions in service levels have generally offset the potential accessibility benefits of the newly added transport infrastructure in a way that particularly penalizes the poor. Except for Marina da Gloria, the Olympic and Maracanã stadiums, all Olympic sports venues have become less accessible to the population via public transport and walking. Similarly, the catchment areas of healthcare facilities in all levels of service complexity have shrunk between 1.6\%, and 7.5\% from 2014 to 2017. Moreover, this cycle of investments and disinvestments in Rio de Janeiro's public transport system have not been able to reduce the accessibility gap between higher- and lower-income groups. The analysis of both implemented and quasi-counterfactual scenarios shows that the accessibility benefits from the transport policies implemented in Rio generally accrued to middle- and higher-income groups, reinforcing existing patterns of urban inequality.

To some extent, this is because the expansion of transport infrastructure was mostly concentrated in areas of the city that were already relatively accessible to a large part of the population, while the subsequent streamlining and reduction of bus services have mostly affected lower-income areas. This market-driven reorganization of the bus lines to accommodate the new investments did not follow a redistributive justice logic. It has actually hurt low-income groups and exacerbated inequality between wealthier and poorer populations in terms of access to medium and high-complexity health services. In different ways, it is possible to say that the Transport legacy of mega-events in Rio was not immune 
to mega-event syndrome discussed by Müller (2015). This is consistent with other urban planning regimes in Rio that, since its strategic plan in the late 1990s, have generally privileged urban development policies in wealthier areas of the city at the expense of poorer communities (Gaffney, 2015b; Ribeiro et al., 2010; Santos, 2013).

These results draw attention to the question of what would be the appropriate time and geographical scales with which to define the legacy of mega-events and of other forms of infrastructure development more broadly. As the analysis of the transport legacy in Rio illustrates, the conclusions of a project impact assessment can be significantly different depending on the way one delimits the boundary of what counts as part of a project legacy. The impact of the transport legacy of megaevents in Rio, for example, change from positive to negative depending on whether one uses a narrow understanding of legacy that only includes the recent expansion in transport infrastructure or a broader view that also incorporates the subsequent policies adopted to accommodate those investments and to cope with the economic crisis. Moreover, in the case of Rio de Janeiro, the analysis in this chapter had to focus on the city scale because of data limitations. A study conducted at the metropolitan scale would likely find much higher levels of inequality in access to opportunities, as Rio's urban periphery has relatively poorer population, lower availability of public services and transport services that have not directly benefited from the transport investments related to mega-events (Castro et al., 2015; Ribeiro, 2014). Ultimately, there is a profoundly political and normative dimension to the question of how the legacy of infrastructure development projects are defined. 
It is unrealistic to expect that new transport investments can bring equal benefits to every neighborhood in a city. From a social justice point of view, however, a Rawlsian approach would expect that transport policies would respect individuals' rights and improve the transport conditions of people in the worst situations, helping reduce inequality of access to opportunities (Pereira et al., 2017). Nonetheless, what was observed is that the transport legacy of Rio's mega-events violated both of Rawls's principles of justice, as these investments have been associated with the violation of housing rights of local communities and have brought little improvement to the transport conditions of the poor. In fact, the changes made to the city's transport system have exacerbated socio-spatial inequalities by reducing the ability of the population, particularly of low-income transit-dependent groups, to access medium and high-complexity healthcare facilities.

This chapter has only focused on the short-term impacts of transport legacy in terms of its effects on people's transport accessibility via public transport. The construction of Rio's BRTs has involved major road-widening, which is likely to improve accessibility of car users and thus exacerbate even further accessibility inequalities between the rich and the poor. Moreover, a broader view of transport legacy would be necessary to investigate other ways in which transport projects influence urban development, such as the reorganization of economic actives in urban space, reduction of traffic accidents and transport emissions, and impacts on land values. A report by the Rio city government (Rio de Janeiro, 2015), for example, indicates that some neighborhoods served by BRT Transcarioca have already observed a sharp increase in real estate prices between 2012 and 2015, which could lead to affordability issues and offset the eventual accessibility benefits received by low income families (Gaffney, 2016). Therefore, it is not entirely clear how the impact of the transport 
legacy in Rio will evolve over time and whether it will adequately correspond to future changes in the mobility needs of the population. However, even in cases where one could argue that these investments involve short-term pain that will be compensated by longerterm gains, from a Rawlsian perspective, these long-term benefits would not justify the rights violations that have been observed in Rio.

Two other broad lessons can be drawn from the study of the transport legacy of megaevents in Rio de Janeiro. One is that the case of Rio exemplifies how the apparent alignment of mega-event-related investments with long-term city plans is not a sufficient condition to create a positive legacy for local communities. The case of Rio illustrates how local governments can incorporate the realization of mega-events into their long-term strategies to promote urban development (Silvestre, 2012) and at the same time adapt existing transport projects in favor of the short-term needs of the events (Kassens-Noor et al., 2016; Santos, 2013). Moreover, new transport investments are often followed by reorganization of services to accommodate newly added infrastructure and these factors are often neglected in discussions around the impacts of new transport projects. In the case of Rio, this has been aggravated by an economic recession and fiscal crisis that have undermined the transport legacy of recent mega-events.

Finally, this evaluation of Rio's transport legacy illustrates how the legacy of megaevents can have inequitable impacts in host cities and exacerbate socio-spatial inequalities in access to opportunities, making a strong case that the debate about the impacts of urban infrastructure projects must move beyond a net-sum analysis. The evaluation of mega- 
events' impacts and transport legacies cannot be disconnected from a critical analysis of who benefits from such investments, as well as where and how these benefits are realized. 


\title{
4. Distributional effects of transport policies on inequalities in access to opportunities in Rio de Janeiro
}

\begin{abstract}
The evaluation of the social impacts of transport policies is attracting growing attention in recent years. Yet, this literature is still predominately focused on developed countries. The goal of this research is to investigate how investments in public transport networks can reshape social and geographical inequalities in access to opportunities in a developing country, using the city of Rio de Janeiro (Brazil) as a case study. Recent mega-events, including the 2014 Football World Cup and the 2016 Olympic Games, have triggered substantial investment in the city's transport system. More recently, though, bus services in Rio have been rationalized and reduced as a response to a fiscal crisis and a drop in passenger demand, giving a unique opportunity to look at the distributional effects this cycle of investment and disinvestment have had on peoples' access to educational and employment opportunities. Based on a before-and-after comparison of Rio's public transport network, this study uses a spatial regression model and cluster analysis to estimate how accessibility gains vary across different income groups and areas of the city between April 2014 and March 2017. The results show that recent cuts in service levels have offset the potential benefits of newly added public transport infrastructure in Rio. Average access by public transport to jobs and public high-schools decreased approximately $4 \%$ and $6 \%$ in the period, respectively. Nonetheless, wealthier areas had on average small but statistically significant higher gains in access to schools and job opportunities than poorer areas. These findings suggest that, contrary to the official discourses of transport legacy, recent transport policies in Rio have exacerbated rather than reduced socio-spatial inequalities in access to opportunities. The study suggests that future research should consider how the modifiable areal unit problem (MAUP) can influence the equity assessment of transport projects.
\end{abstract}




\subsection{Introduction}

Researchers have long discussed the importance of transport policies in tackling social exclusion and improving people's access to out-of-home activities (Kwan, 2000; Lucas, 2012; van Wee \& Geurs, 2011). In recent years, transport equity has been increasingly recognized as a crucial component of the sustainable mobility paradigm (Banister, 2008), attracting wider attention to the social impacts of transport policies. As a result, there has been a growing interest in the distributional effects of transport investments on socio-spatial inequalities in access to opportunities (Blair et al., 2013; Bureau \& Glachant, 2011; Foth et al., 2013).

While many researchers and transport planners in developed countries are concerned with improving accessibility (Boisjoly \& El-Geneidy, 2017; Papa et al., 2015) and equity (Karner \& Niemeier, 2013; Manaugh et al., 2015), these issues have received much less attention in the Global South (Keeling, 2008; Vasconcellos, 2001). The literature on justice in transport policy is still predominately focused on developed countries in North America and Europe, with a few notable exceptions (Bocarejo \& Oviedo, 2012; Delmelle \& Casas, 2012; Maia et al., 2016; Vermeiren et al., 2015).

The aim of this chapter is to investigate the distributional effects of transport policies recently implemented in Rio de Janeiro (Brazil), looking specifically at how those policies have changed social and spatial inequalities in access to employment and educational opportunities in the city across different income groups. Several mega-events have been hosted in Rio in the past few years, such as the 2014 Football World Cup and the 2016 Olympic Games. These events triggered substantial investment in the city's public transport 
infrastructure, including the expansion of a subway line, the construction of two new bus rapid transit (BRT) corridors and a light-rail system.

The infrastructure works associated with such events played a central role in the justification used by public authorities to host those mega-events (Kassens-Noor et al., 2016). According to various official documents, those infrastructure projects would improve people's accessibility to major sports venues in the city but they would also leave a positive legacy that would fast-track urban development and help improve transport conditions in the city, particularly for low-income people living in deprived areas (BOC, 2009; Brazil, 2009; Rio de Janeiro, 2008). Official documents like these are one of the main media used by politicians to communicate to the population what plans and priorities they have for the short and long-term development of the city. Even if one takes these official documents with skepticism (or perhaps because of it), it is extremely important to assess the extent to which the transport legacy promised in those documents are delivered to the population. Moreover, it is not clear which income groups and areas of the city have benefited from that promised legacy because these projects were followed by a reorganization of many bus lines and by cuts in service levels in response to a drop in passenger demand (see section 2). Overall, these policies have brought significant changes to the city's transport system in a relatively short period of time, giving a unique opportunity to assess its equity impacts on urban accessibility to various types of activities for different population groups.

This study estimates how access to public high-schools and formal jobs have changed for different income groups before and after the transport policies driven by mega-events in Rio de Janeiro (2014 and 2016). Employment and educational opportunities were chosen 
because of their central role for human development and in the reproduction of socioeconomic inequalities in society. In Brazil, public education is considered a basic constitutional right that should be accessible to all, regardless of personal income. Accessibility levels are calculated using geolocated timetables of Rio's public transport organized in GTFS format combined with fine-grained sociodemographic data from the population census and geolocated data on schools and jobs. The spatial association between accessibility changes and household income per capita is tested using spatial regression and cluster analysis. The investigation is conducted using multiple geographical scales and zoning schemes to test whether results are robust to the modifiable area unit problem (MAUP), i.e. whether the conclusions of the evaluation change when the data is aggregated in space using different geographical scales and areal units.

The chapter is organized as follows: Section 4.2 presents a brief review of the literature on transportation equity. Section 4.3 presents the study area of Rio de Janeiro and how its public transport network evolved between 2014 and 2017. Data and methods are presented in Section 4.4 and results presented in Section 4.5. Finally, Section 4.6 brings a discussion of the main conclusions about the case study of Rio and some lessons that can be drawn for future studies on the equity impacts of transport policies in other cities.

\subsection{Literature Review - Transportation Equity}

Equity is a multidimensional concept and it has been addressed in the transport literature in relation to various issues such as environmental externalities (Schweitzer \& Valenzuela, 2004), affordability (Eliasson, 2016; Farber et al., 2014) and the fair distribution of benefits 
from transport investments and services (Delbosc \& Currie, 2011; Foth et al., 2013). There is thus no standard definition of equity across studies that evaluate the social impacts of transport policies (Martens et al., 2012; van Wee \& Roeser, 2013).

There is, however, a growing consensus in both transport planning practice (Boisjoly \& El-Geneidy, 2017; Manaugh et al., 2015) and in the academic literature (Pereira et al., 2017; van Wee \& Geurs, 2011) that improving people's access to key destinations such as employment, healthcare, and educational opportunities should be among the primary goals of equitable transport policies; and moreover, that such policies should prioritize improving accessibility for disadvantaged groups such as the elderly, disabled and low-income people who are typically more dependent on public transport. This convergence in the literature derives from moral concerns related to the satisfaction of basic needs, the protection of disadvantaged groups and the reduction in inequalities of opportunities (Lucas et al., 2015; Pereira et al., 2017).

These moral concerns have been largely influenced by or are in line with the theory of justice as fairness proposed by John Rawls (Rawls, 1999, 2001). A core idea in this theory is that morally arbitrary factors beyond a persons' choice such as being born with a physical disability, in a poor family or ethnic group should have no bearing on people's life chances and opportunities. Rawls is particularly concerned with how institutions in society should be arranged in order to mitigate the negative effects those factors may have on people's life chances and thus minimize inequalities of opportunities that arise from arbitrary circumstances to the benefit the better-off groups and at the expense of the worse off. 
While Rawls's theory relates more directly to the definition of society's basic institutions, Rawls proposes that his high-level theory of justice ultimately should serve as a reference against which the fairness of proposed laws and policies should be assessed (Rawls, 1999, pp. 175, 253, 314-317; 2001, pp.89-90) ${ }^{13}$. Previous studies have proposed to use Rawls's principles of justice to guide and assess transport policies (Pereira et al., 2017; van Wee \& Geurs, 2011; van Wee \& Roeser, 2013) and urban planning more generally (Basta, 2015; Fainstein, 2010; McKay et al., 2012). In a recent paper, Pereira, et al. (2017) put forward an interpretation of how Rawls's theory of justice can be applied to evaluate the fairness of transport policies. According to the authors, governmental investments on transport infrastructure and services can only be considered just if they prioritize benefiting those disadvantaged groups whose transport experience is systematically undermined by unchosen personal traits and by the social circumstances into which they are born. The concern with justice thus requires researchers to move beyond descriptive cross-sectional analysis of how different groups have different levels of access to opportunities towards a better understanding of what role governmental policies can play in reducing such inequalities (Pereira et al., 2017). Another core idea in Rawls's theory of justice is the absolute priority and inviolability of people's basic rights and liberties such as the physical and psychological liberty and integrity of the person (Rawls, 2001, p.44). Accordingly, no governmental policy can be considered fair if it violates these basic rights and liberties, even

\footnotetext{
${ }^{13}$ For a different point of view, see the work of Martens(2016), who argues that Rawls' principles of justice should only be understood in relation to the basic structure of society and cannot be applied to interventions in particular domains beyond the realms of Rawls' primary goods. This interpretation seems to overlook, nonetheless, that Rawls himself argued that rational legislators should conscientiously try to follow the principles of justice to propose just laws and policies (Rawls, 1999, p.314), and that such principles should also guide governmental provision of services and public goods, which should also be identified with primary goods (Rawls, 2001, p.172).
} 
for the sake of general welfare. Although this idea might be more often embedded in the principles that guide transport policies in the developed world, it is much less so in countries in the global South, as the case of Rio de Janeiro illustrates.

\subsection{Study Area: Rio de Janeiro}

Rio de Janeiro is one of the largest and richest cities in the Global South and yet one of the most unequal (UN-HABITAT, 2010). In different ways, Rio is an exemplar of what more and more cities may become in the future, the result of rapid population growth coupled with stark socio-spatial inequalities and poor transport infrastructure where there is a strong increase in automobile use and dependence with all the negative externalities it creates (Ribeiro, 2014; UN HABITAT, 2013). Like many other cities in the Global South, Rio has a history of uneven urban development marked by spatial segregation (Préteceille \& Cardoso, 2008; Ribeiro et al., 2010) and an unequal distribution of public transport infrastructure (Câmara \& Banister, 1993). Public transportation in Rio has been found to be among the most expensive in the world (UN HABITAT, 2013), with costs being particularly expensive if not prohibitive for lower-income classes (Table 4.1). Moreover, traffic conditions have been deteriorating over the past decade, as reflected by the rise in average one-way commute time from 41.5 minutes in 2001 to 49.6 minutes in 2014 (Pereira \& Schwanen, 2013). 
Table 4.1 Affordability index of public transportation by income decile. Rio de Janeiro.

\begin{tabular}{rrrrr}
\hline & & \multicolumn{3}{c}{ Affordability index $^{\text {a }}$} \\
\cline { 3 - 4 } Income & $\begin{array}{r}\text { Average household } \\
\text { income per capita in } \\
\text { Recile } \$\end{array}$ & $\begin{array}{r}\text { Single mode or } \\
\text { integration between Bus, } \\
\text { BRT and light rail }{ }^{\mathrm{b}}\end{array}$ & $\begin{array}{r}\text { Integration between bus } \\
\text { / BRT and } \\
\text { train / subway }{ }^{\mathrm{c}}\end{array}$ & $\begin{array}{r}\text { Integration between } \\
\text { subway and train }{ }^{{ }^{2}}\end{array}$ \\
\hline 1 & 448.0 & $43 \%$ & $94 \%$ & $107 \%$ \\
2 & 732.3 & $26 \%$ & $57 \%$ & $66 \%$ \\
3 & 989.1 & $19 \%$ & $42 \%$ & $49 \%$ \\
4 & 621.8 & $31 \%$ & $68 \%$ & $77 \%$ \\
5 & 847.4 & $23 \%$ & $50 \%$ & $57 \%$ \\
6 & 532.8 & $36 \%$ & $79 \%$ & $90 \%$ \\
7 & 1699.3 & $11 \%$ & $25 \%$ & $28 \%$ \\
8 & 1217.5 & $16 \%$ & $34 \%$ & $39 \%$ \\
9 & 2934.8 & $7 \%$ & $14 \%$ & $16 \%$ \\
10 & 5448.9 & $4 \%$ & $8 \%$ & $9 \%$ \\
Average & 1550.7 & $12 \%$ & $27 \%$ & $31 \%$ \\
\hline
\end{tabular}

Source: Population Census 2010 (IBGE). Info on fare values come from https://www.cartaoriocard.com.br/rcc/institucional/tarifas, accessed on Sept. 2017

Notes: (a) percentage of income required to undertake 60 trips per month, Transport fares prices on September 2017: (b) $R \$ 3.2$, (c) $R \$ 7$, (d) $R \$ 8$.

When the city of Rio bid to host the 2014 Football World Cup and the 2016 Olympic Games, one of the key motivations of public authorities was to use those mega-events to leverage urban development and improve the city's transport conditions (Gaffney, 2010; Kassens-Noor et al., 2016; Silvestre, 2012). In preparation for the events, the city invested more than U $\$ 4.5$ billion in its public transport system (Castro et al., 2015). Most of those transport investments were included in earlier visions/plans for upgrading Rio's public transport infrastructure, what suggests that recent mega-events need to be seen as facilitating the long-term goal of the city regarding the development of previously desired infrastructure (Pereira, 2018). Some of the most significant investments included the extension of a subway line, the construction of a light-rail system and two BRT corridors that 
together stretch approximately 108 kilometers across the city, shown in Figure 1. This figure also shows the main clusters of sports venues of recent mega-events, which were generally located in consolidated urban areas and close to existing transport hubs. Alongside this new infrastructure, local authorities have also reorganized many bus lines to accommodate the newly added infrastructure and to streamline the transport system. More recently, however, a severe economic crisis led to a $70 \%$ cut in the budget of the secretary of transport (Magalhães \& Rodrigues, 2017), which coupled with a drop in the number of passengers in the public transport system (França, 2016; Rodrigues, 2017) has led the government to adopt fiscal austerity measures that affected transport services. In total, 70 bus lines were eliminated, 41 lines were rerouted or shortened and 16 new bus lines were created (G1, 2017). These measures can potentially undermine the positive effects of the new transport investments and cast doubt on which socioeconomic groups and areas in the city have benefited from the accessibility changes brought about by this cycle of investment and disinvestment. 
Figure 4.1 Spatial distribution of the population and new public transport infrastructure. Rio de Janeiro, 2017.

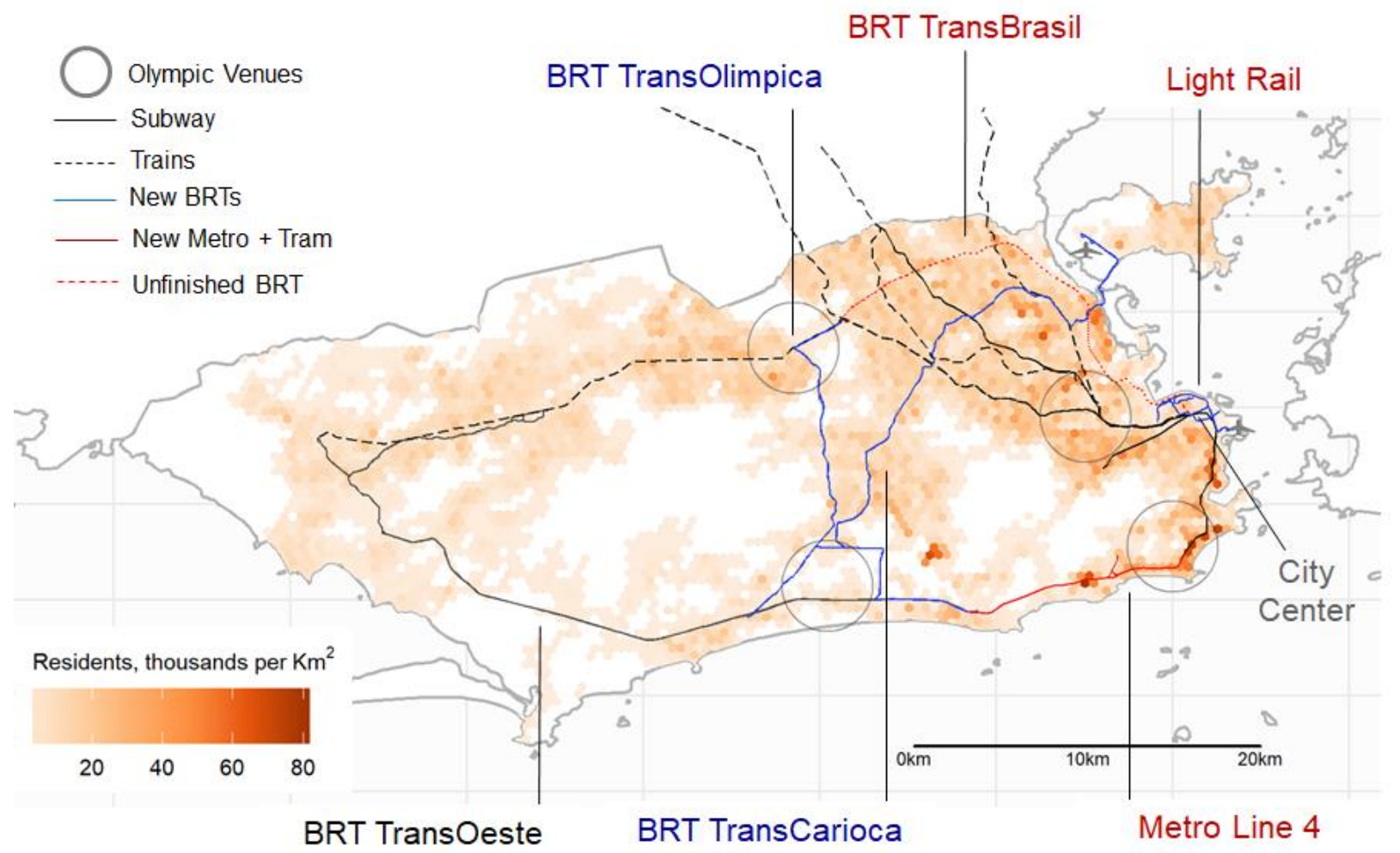

That spreading the benefits of the new transport infrastructure to Rio's local population - not just those visiting the sports events - was an integral and crucial part of the legitimization of the investments (Kassens-Noor et al., 2016). According to Rio's candidature files to host the World Cup and the Olympics, the aim of those investments was to create a high-capacity transport ring connecting key areas in the city where most of the sports competitions would take place and, above all, to benefit "low-income workers, who live in the most distant neighborhoods and spend more time in traffic." (Brazil, 2009, p.54). Nonetheless, one year after the Olympics, these investments have already been widely criticized for being over-budget and the subject of corruption investigations (Cuadros, 2016; Guimarães \& Leitão, 2017; Sandy, 2016). Academics and grassroots movements have also 
claimed that those projects were elaborated with little social participation and transparency (Legroux, 2014; Sánchez \& Broudehoux, 2013) and that many BRT stations present barriers to people with physical disabilities and poor integration with other transport modes (ITDP Brasil, 2014, 2015). Moreover, official figures indicate that those investments let to the eviction of 2,125 families between 2009 and 2015 to create space for transport infrastructure (Rio de Janeiro, 2015). According to various accounts, many these evictions involved physical and psychological violence by the police, characterizing the violation of human rights (Barbara, 2016; CPCORJ, 2015; Gaffney, 2016; Watts, 2015). Despite the utilitarian discourse that those evictions were justifiable because the transport investments would bring large benefits to a great number of people, the violation of rights and the other issues mentioned are of central importance from a social justice point view and go explicitly against a Rawlsian conception of justice (Pereira et al., 2017). Although these issues are not addressed in this study, we recognize they would need to be considered in a comprehensive equity assessment of the transport legacy left by mega-events in Rio.

Another important equity issue to consider involves the distributional effects those investments have had in improving the transport conditions of different social groups in the city. While the official rhetoric proposed prioritizing low-income groups in line with the design of equitable transport policies (Lucas \& Jones, 2012; Pereira et al., 2017; van Wee \& Geurs, 2011), the extent to which the investments have effectively improved the accessibility of low-income neighborhoods is a question that has received less attention and remains largely unanswered (Kassens-Noor et al., 2016; Rodrigues \& Legroux, 2015), and which we address in the next sections. 


\subsection{Methodology}

Accessibility is understood broadly as the ease with which a person can reach places and opportunities from a given location in space and it results from the interaction between the transport system, land use patterns, and the various constraints of individuals (van Wee \& Geurs, 2011). This chapter conducts a before-and-after comparison of Rio's transport system to estimate the change in accessibility that resulted from recent policies implemented in Rio between 2014 and 2017. The purpose is to compare the effect of those policies on accessibility changes for different social groups and areas of the city and analyze whether wealthier areas have gained more accessibility than poorer ones. The method used in this study involved five secondary data sources and two main steps as detailed below.

\subsubsection{Data Sources}

Population count data comes from the 2010 Brazilian Census, organized in a regular grid of 200x200 meters (IBGE, 2016). The resident population in each grid cell was categorized according to income decile based on the average household income per capita of each grid cell. This was imputed from the 2010 census data organized in 1,136 relatively homogeneous socioeconomic polygons known as Human Development Units (Ipea et al., 2015). The data on household income per capita collected in the census account for all members of the household and all their sources of income (including formal or informal jobs, unemployment benefits, pensions, social transfers, etc.). Although the census has some limitations in terms 
of capturing the upper extreme of income distribution (Souza, 2015), it is still the best data source to account for income distribution in Brazil. This method needs to be used with caution because it incurs ecological fallacies by disregarding socio-economic heterogeneity within Human Development Units.

Data on schools come from the School Census conducted by the Brazilian Ministry of Education, covering all of the 278 public high schools in the municipality of Rio de Janeiro in 2015. Data on formal jobs come from RAIS, a dataset organized by the Ministry of Labor and Employment. RAIS is a national register that brings the full address of all public and private institutions and the socioeconomic characteristics of their employees working in the formal labor market. In the year 2015, there were 2,914,238 formal workers employed in 227,362 institutions in Rio. In this database, workers are associated with the address of their respective workplaces. Exceptionally, some institutions with multiple offices (such as outsourcing firms or public secretaries of police, health and education) report all their employees to be working from the institution headquarters. Among the 50 largest employers in Rio, 17 institutions were found to do this and were removed from the analysis. The location of 83,589 employees working for the secretary of education could be recovered from the school census. In the end, a database covering $92.3 \%$ of all formal workers in the city was used in the study. Both datasets on schools and jobs were geolocated using the full address information available in their respective datasets.

A limitation of this study is that it does not cover job opportunities in the informal labor market because there is no data source with the addresses of informal jobs. Although a significant share of workers in Rio work in the informal labor market (approximately 36\% 
in January $2016^{14}$ ), informal jobs are relatively more accessible with shorter commute times and distances than formal jobs(Motte-Baumvol et al., 2016)(Motte-Baumvol et al., 2016) (Motte-Baumvol et al., 2016), and it is reasonable to assume that formal jobs are generally preferable given the associated labor rights and social benefits. Moreover, the 2003 household travel survey of Rio shows that the numbers of formal and informal jobs in each traffic zone are correlated at 0.78 (Pearson correlation statistically significant at 0.001 ), suggesting that the spatial distribution of formal and informal jobs in the city are not radically different.

Spatial information on road network and pedestrian infrastructure comes from OpenStreetMap. Finally, we use data on the public transport network organized in General Transit Feed Specification (GTFS) format, as provided by Fetranspor (Federation of Passenger Transport Companies in Rio de Janeiro) for the months of April 2014 and March 2017. GTFS data provides detailed geolocated information of routes, stops and timetables of the public transport system. Because the GTFS data available only covers the public transport network within the municipality of Rio de Janeiro, the accessibility analysis in this paper does not consider schools and jobs outside of the study area. This limitation might lead to an underestimation of the absolute levels accessibility in areas close to northern border of Rio. Nonetheless, this study focuses on the magnitude of relative changes in accessibility levels between 2014 and 2017, which should not be substantially affected by this data constraint.

\footnotetext{
${ }^{14}$ Source: PNAD survey, available at http://www.ipeadata.gov.br/
} 
In the before-and-after comparison of Rio's transport network conducted in this chapter, the spatial distribution of the population and its income distribution, as well as the location of schools and jobs were kept constant. This assumption allowed us to isolate the effect of the recent transport policies on the variations in accessibility levels between 2014 and 2017. This assumption obviously disregards changes in the spatial distribution of schools/jobs and redistribution of population and socio-economic groups that may have occurred over the period due the processes of displacement and gentrification. Nonetheless, previous research has shown that such phenomena are fairly stable over time in Rio, particularly over short timescales as those used in the current analysis (Lago, 2000; Ribeiro, 2014); changes during the 2010-2017 period are thus unlikely to have significantly affected the overall results of the current analysis.

\subsubsection{Estimating Accessibility levels}

A cumulative opportunity measure was used to estimate accessibility in terms of how many schools and job opportunities people could reach from their households via public transport and walking under 60 minutes. A growing number of transport agencies particularly in North America and Europe use similar accessibility analysis to compare the benefits of potential transportation investments and evaluate their social impacts (Boisjoly \& El-Geneidy, 2017). In most cases, these agencies use accessibility measures based on cumulative opportunities with time thresholds that vary between 30 and 60 minutes (ibid.). In this study, a threshold of 60 minutes was used given that Rio has relatively higher commute times when compared to international metropolitan areas (Pereira \& Schwanen, 2013). Some advantages of this 
type of accessibility measure are that it does not require prior information about people's travel behavior, it is computationally inexpensive to calculate, and it produces results that are easy to communicate to policy makers and stakeholders. This measure has limitations, though, since it assumes that all opportunities are equally desirable, regardless of the time spent on travelling; it does not take competition effects into account and it involves the selection of an arbitrary cut-off travel time (Geurs \& van Wee, 2004).

Spatial analyses like the one conducted in this study can be sensitive to the ad-hoc ways in which data are aggregated in space according to different spatial scales and zonal schemes such as census tracts or traffic analysis zones (Apparicio et al., 2008; Kwan \& Weber, 2008). This is known in the literature as the modifiable areal unit problem (MAUP). The effects of MAUP have been widely documented in urban studies and, in some occasions, researchers have found that the conclusions of spatial analysis and subsequent policy recommendations can be significantly different depending on the spatial scale and shape of areal units employed (Liao et al., 2009; Omer, 2006; Tan \& Samsudin, 2017). Nonetheless, the effects of MAUP have been largely overlooked by studies that evaluate how the accessibility benefits of transport policies are distributed across different social groups. Following the recommendation of previous studies (Horner \& Murray, 2004; Páez \& Scott, 2005), the analysis in this paper was conducted using multiple spatial scales and zoning schemes in order to test whether the results found are robust to MAUP and not a simple artefact of the ways in which data are arranged in space.

As a first step for the accessibility analysis, the municipality of Rio was divided using hexagonal grids of four different sizes, 500 meters, $1 \mathrm{~km}, 2 \mathrm{~km}$ and $4 \mathrm{~km}$ and the traffic zones 
of Rio's latest household travel survey of 2013. Following the recommendation of Stępniak and Jacobs-Crisioni (2017), the population-weighted centroids of each polygon were used as origin and destinations in order to minimize aggregation errors. Next, OpenTripPlanner ${ }^{15}$ was used to estimate various travel-time matrices by public transport and/or walking between every pair of zone centroids for each spatial grid. We used a uniform sample of departure times, calculating departures every 20 minutes between $7 \mathrm{am}$ and $7 \mathrm{pm}$ for a total of 36 departure times in that period. These travel-time matrices grasp door-to-door estimates that consider temporal variations in public transport services and incorporate walking time from the point of origin to the transit stop, waiting time for the vehicle, actual travel time through the transport network and eventual transfers, and the walking time from the transit stop to the destination. To test whether the results are robust to the modifiable areal unit problem, both accessibility estimates and spatial analysis were conducted separately for each hexagonal grid and traffic zone level.

Next, these travel-time matrices were combined with the geolocated data on population, school and jobs. Based on equation (1), we calculated the median number of opportunities (schools or jobs) that can be accessed from each grid cell via public transport in under 60 minutes across the 36 travel-time matrices for each year (2014 and 2017). In order to account for a qualitative match between socioeconomic levels of workers and jobs, estimates of access to jobs were based on an assumption of a proxy match between household income and educational qualification of jobs. For residents in households above the 5th income decile, accessibility estimates only considered employment opportunities

15 OpenTripPlanner is an open-source multimodal trip planner available at
$\underline{\underline{\text { https://github.com/opentripplanner/OpenTripPlanner }}}$


that required high or secondary education, while for households below the 5 th income decile only jobs that required secondary or primary education were considered.

$$
\begin{aligned}
& A_{o, i, T}=\operatorname{median}\left(\sum_{o=1}^{n} P_{d} f\left(t_{o d r}\right)\right) \\
& f\left(t_{o d r}\right)=\left\{\begin{array}{l}
1 \text { if } t_{o d r} \leq T \\
0 \text { if } t_{o d r}>T
\end{array}\right.
\end{aligned}
$$

Where:

$\mathrm{A}_{0 \text { i }}$ is the accessibility level at origin o for population of income i within time threshold $\mathrm{T}$.

$P_{d}$ is the number of opportunities (e.g. jobs or schools) in location $d$

$t_{o d r}$ is the travel time in minutes between origin o and destination $d$ at departure time $r$.

$\mathrm{f}\left(\mathrm{t}_{\mathrm{odr}}\right)$ is a time threshold function that varies between one and zero, depending on whether travel time $\left(t_{o d r}\right)$ is larger or smaller than time threshold $T$.

It is likely that the positive accessibility gains brought about by the new infrastructure investments in Rio have been offset by the reorganization of the bus lines and also by the austerity measures adopted including the reduction of service levels in some areas of the city. In order to measure what would have been the sole effect of the new transport investments, we have also estimated accessibility changes in a quasi-counterfactual scenario. This scenario assumes that all public transport services provided in April 2014 would have been kept constant, so the only changes to Rio's public transport system would have been the addition of the new infrastructure, i.e. the BRTs Transcarioca and Transolímpica and the new subway and light-rail lines.

Due to data availability constraints, the accessibility analysis deployed in this study has not considered issues related to affordability, safety, age, gender or disability. It is widely documented in the literature how transport disadvantages related to these issues can hinder 
people's ability to use public transportation, particularly among low-income groups (Casas, 2007; El-Geneidy et al., 2016; Ryan et al., 2015). By not considering these issues the analysis conducted in this study is likely to underestimate accessibility inequalities between highand low-income groups.

\subsubsection{Analyzing association between income and accessibility change}

The final step was to test whether there is any association between average household income per capita and the accessibility variation that occurred between 2014 and 2017, and whether this association is robust to MAUP across different spatial scales and zoning schemes. While this could be done simply by comparing the average accessibility variation for different incomes groups, statistical regression models allow us to test whether these differences are statistically significant while controlling for other confounding factors. One important cofounding factor in this case is spatial autocorrelation. It is well-known that many social, transport and land use processes are spatially dependent in the sense that the characteristics of a location are related to its neighboring areas (Anselin, 2010; Páez \& Scott, 2005). Similarly, the transport accessibility level of one location is affected by the characteristics of the transport system and land use in nearby areas. The presence of spatial dependence in the data violates basic assumptions of conventional statistical analysis, such as t-tests or person's correlation and OLS regressions, and leads to "information loss, biased and/or inefficient parameters and the possibility of seriously flawed conclusions and policy prescriptions" (Páez \& Scott, 2005, p.55). To overcome these limitations, spatial regression 
models have been commonly used by studies investigating the impacts of transport accessibility on land-use prices (Efthymiou \& Antoniou, 2013; Mitra \& Saphores, 2016; Mulley et al., 2016; Tsutsumi \& Seya, 2008), but these models have thus far found little uptake in the literature on transportation equity that evaluates the accessibility impacts of transport policies.

In order to control for spatial autocorrelation in the data, a spatial regression model was used to estimate whether wealthier areas were able to attract more accessibility gains from the transport policies implemented in Rio between 2014 and 2017. Other variables can influence where new transport infrastructure is likely to be built and consequently which locations have higher accessibility gains from new investments. Areas with greater densities of population and economic activities, for example, are likely to have higher transport demand and make transport projects more economically viable (Kutz, 2003). Topography is another relevant variable that puts physical barriers for construction, impacting construction costs and influencing where surface transportation modes are likely to go (ibid.). In order to control for these factors, the regression model includes local level control variables for topography, population and job or school density. The authors acknowledge, though, that the specification of the regression is ad-hoc rather than informed by a full theoretical framework. The baseline model without spatial effects is written as: 


$$
\begin{gathered}
\log \left(\mathrm{R}_{i o}\right)=\beta_{0}+\beta_{1} \log \left(\mathrm{I}_{i}\right)+\beta_{2} \log \left(\mathrm{P}_{i}\right)+\beta_{3} \log \left(\mathrm{O}_{o i}\right)+\beta_{4} \log \left(\mathrm{E}_{i}\right)+\varepsilon_{i} \\
\mathrm{R}_{i o}=\frac{A_{i o T}^{2017}}{A_{i o T}^{2014}}
\end{gathered}
$$

Where:

$\mathrm{R}_{i o}$ is the relative change in accessibility level from polygon i to opportunities of type o between 2014 and 2017

$A_{i o T}^{2017}$ is the number of opportunities of type o that could be accessed from origin i under traveltime threshold $\mathrm{T}$ in the year 2017

o opportunities of type jobs or schools

$I_{i}$ is the average household income per capita in polygon $\mathrm{i}$

$\mathrm{P}_{i}$ is the population density in polygon $\mathrm{i}$

$\mathrm{O}_{i o}$ is the density of jobs or number of schools in polygon $\mathrm{i}$

$\mathrm{E}_{i}$ is the average terrain elevation in meters of polygon $\mathrm{i}$

Variation in accessibility was measured as the ratio between accessibility levels in 2017 and 2014. This approach means that changes in accessibility have proportionally lower impact in those areas that already had higher accessibility in 2014, in line with decreasing marginal returns. In other words, it implies that for a person living in an area with access to 100 jobs, an increase of, for example, 50 jobs add more to this person's utility than for a person who already had access to 1000 jobs.

The spatial dependence underlying the baseline model was evaluated using the Lagrange multiplier test following standard methods used in the literature (Elhorst, 2010; LeSage, 2008), which indicated a spatial lag regression to be the most appropriate model. The Lagrange test indicated stronger preference for the spatial lag specification but did not 
reject the error model. This suggests that either the spatial lag, Durbin or spatial autocorrelation (SAC) models could be appropriate. The spatial Durbin model (SDM) was chosen because it gave the best results minimizing the Akaike Information Criterion (AIC) and the autocorrelation in the OLS residuals. The SDM specification controls for spatial autocorrelation in both the dependent and the independent variables, and it is an appropriate model choice because permutation tests for Moran's I indicated spatial autocorrelation in the dependent as well as in the independent variables of the baseline model. That specification allows estimation of how strongly the accessibility gain in polygon $i$ is associated not only with the local characteristics (including income) of $i$ but also with the characteristics and accessibility gains in the neighboring polygons of $i$. Because the Durbin model includes a spatial lag in both set of variables, one advantage of this model is that it produces coefficient estimates that are unbiased even if there is one or more relevant omitted variables in the regression equation (Elhorst, 2010; LeSage, 2008). This advantage of the Durbin model minimizes the issue that the regression is not informed by a full theoretical framework and that other cofounding variables might be absent in the model. Polygons were defined as neighbors if they share at least one boundary point using a standard queen contiguity matrix.

This spatial Durbin model calculates the average global spatial association between income and changes in accessibility for the entire city. Nonetheless, it is possible that the strength and direction of this association may vary across space. To complement the global analysis, we also estimate the local correlation between those two variables using the local indicator of spatial association (LISA). The bivariate LISA analysis is an extension of its univariate version (Anselin et al., 2002) and it measures the correlation between one 
variable in an area and the average of another variable in its neighbors. In practice, this analysis is a useful technique to identify clusters of areas with high and low income that gained and lost access to opportunities. For this local correlation measure, a queen contiguity matrix was used to define neighboring areas. Pseudo p-values were estimated with a thousand random simulations in each round.

\subsection{Results}

\subsubsection{Descriptive results}

Figure 4.2 presents the spatial distribution of income groups in the city of Rio according to different spatial scales and zoning schemes. It shows how lower-income families are mainly located in the north and particularly northwest areas of Rio while higher-income groups live mainly along the coast in the southwest close to the city center where most of the economic activity is concentrated. This figure also illustrates how spatial analysis at coarser resolutions can lead to information loss. With the aggregation of household income per capita one loses valuable detail regarding the spatial heterogeneity of the data and, in the most extreme cases, the income decile classification of some areas changes from poor to rich and vice-versa. 
Figure 4.2 Spatial distribution of population classified by deciles of household income per capita. Rio de Janeiro, 2010.
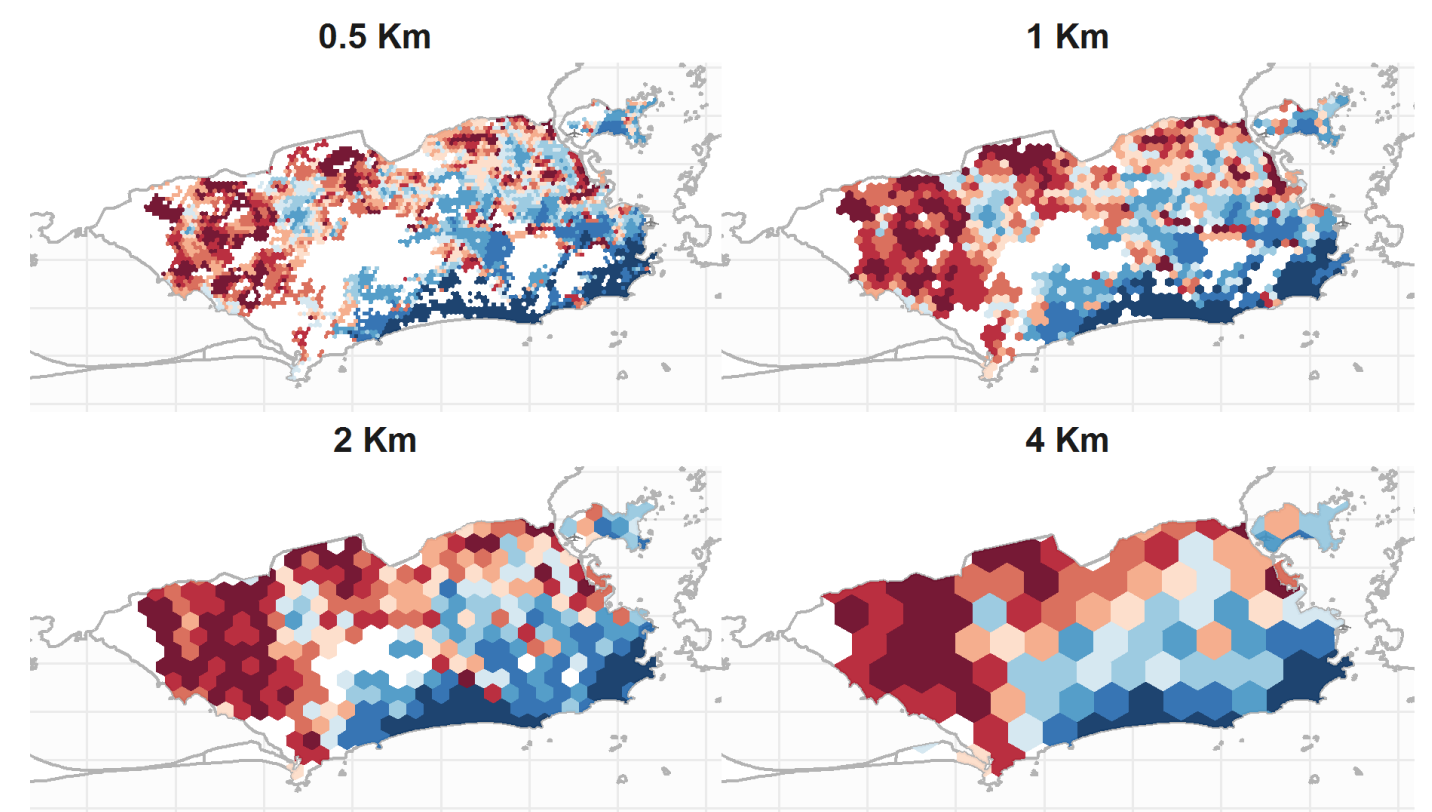

Traffic zones

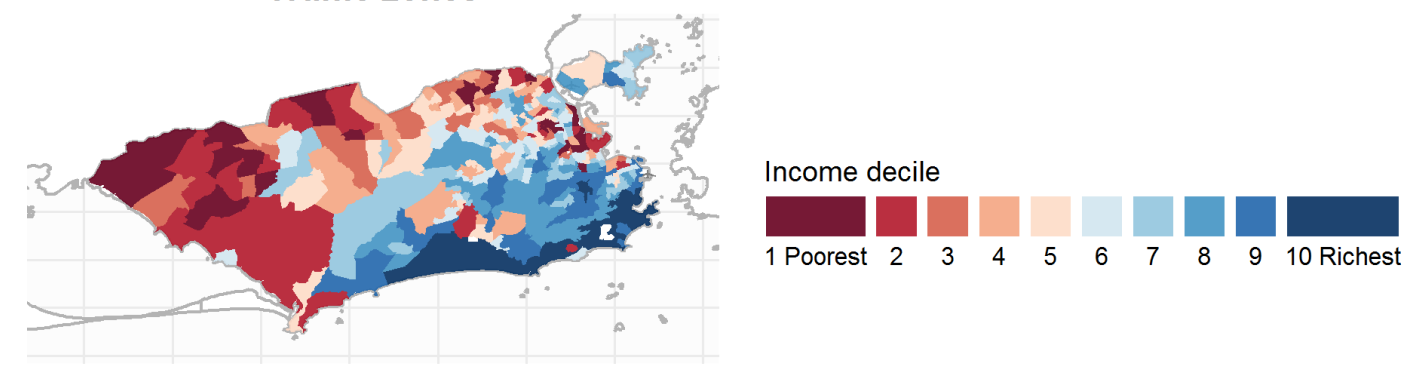

Source: 2010 Population Census (IBGE). Note: white areas in the municipality of Rio represent polygons with no population, jobs nor schools.

The next two figures illustrate for the year 2017 how median access to formal jobs and public schools by public transport varies substantially across space. For both types of opportunities, it becomes clear that accessibility levels are greater along the train and subway lines and part of the new Transcarioca BRT line. These figures also draw attention to the way spatial inequalities in accessibility are largely shaped by the unequal distribution of land use activities. The historical development of Rio, with high concentration of 
employment opportunities close to the city center helps explain, for example, why residents in the west region of the city have such low levels of access to opportunities. To some extent, this issue has been minimized by the spatial planning of public schools, which has been relatively successful in allocating public high-schools more evenly across Rio. Moreover, these figures also show how spatial analyses at a higher resolution allows for accessibility estimates with more spatial detail, making the influence of transport corridors on spatial accessibility more visible.

Figure 4.3 Median proportion of formal jobs accessible within 1 hour by public transport and walking between 7am and 7pm. Rio de Janeiro, 2017.
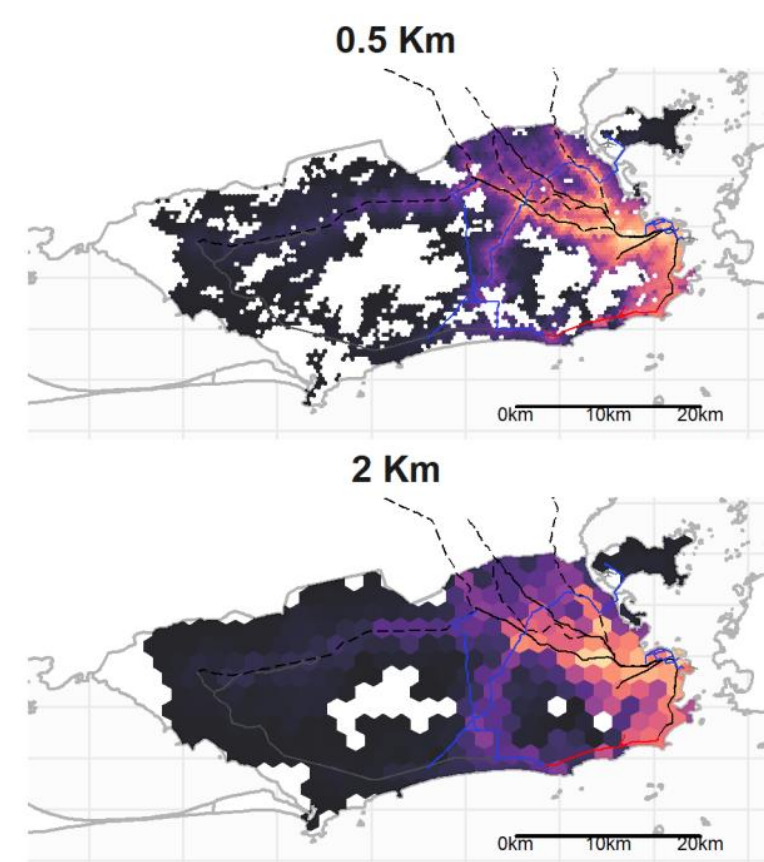

Traffic zones

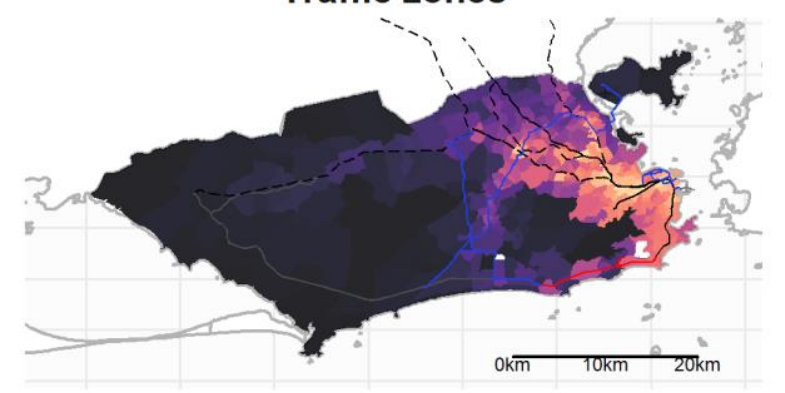

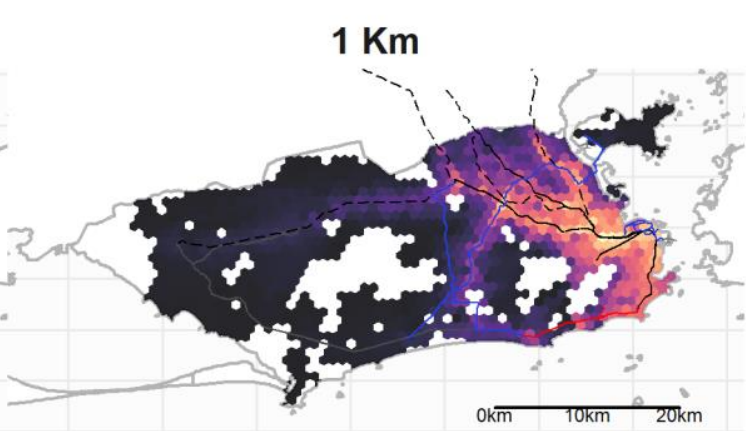
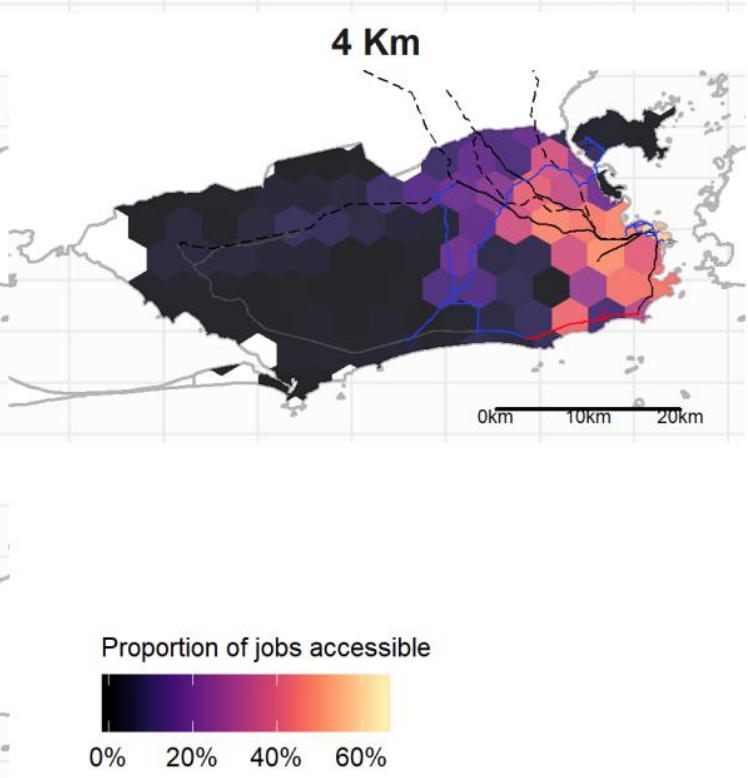
Figure 4.4 Median proportion of public high-schools accessible within 1 hour by public transport and walking between 7am and 7pm. Rio de Janeiro, 2017.

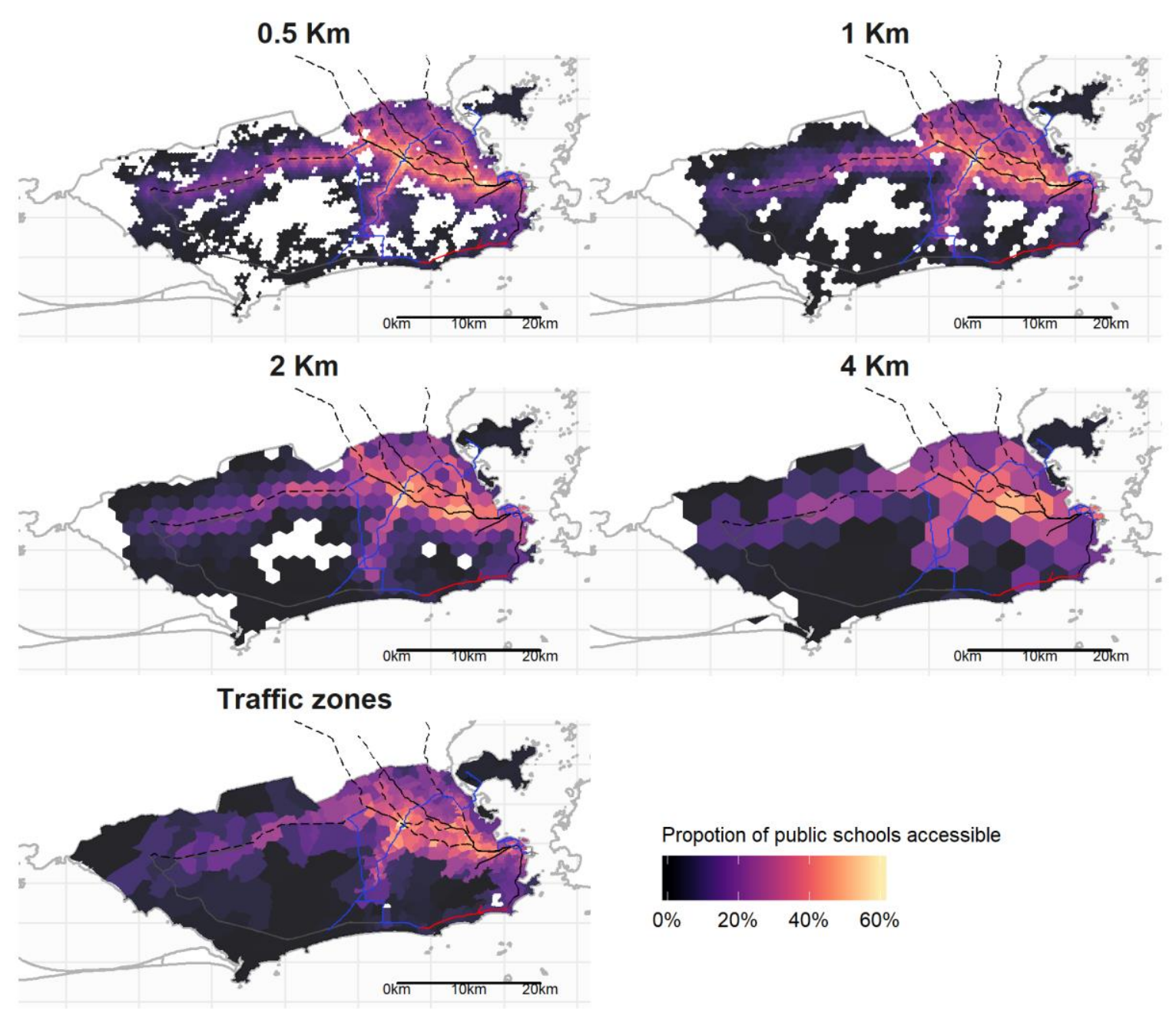

The summary results suggest that average access to jobs and schools by public transport dropped approximately $-4.5 \%$ and $-6.1 \%$ between 2014 and 2017 in the city of Rio. Using a quasi-counterfactual scenario to isolate what would have been the sole effect of the new infrastructure investments, the analysis shows that between 2014 and 2017 average access to jobs and schools would have increased approximately $13.4 \%$ and $11.7 \%$ respectively. These findings suggest that the rationalization of bus lines and recent cuts in 
service levels have played an important role in offsetting the positive impacts of the new transport infrastructure.

Nevertheless, these are only average results that might hide heterogeneity in the data, and it is important to analyze how accessibility changes varied by income groups and areas of the city. A crucial issue to consider from a social justice point of view is not only the level of inequality in access to opportunities but more importantly to what extent new policies contribute to reducing such inequalities, particularly by improving the access of lowerincome groups. In 2014, the level of access to jobs were $84 \%$ larger for the richest $20 \%$ than for the poorest $20 \%$. What happened in the implemented scenario is that the new infrastructure expansion, combined with the reorganization of many bus lines and by cuts in service levels, raised that inequality to $116 \%$. The analysis of the counter-factual scenario indicates that the infrastructure investments alone would have increased this difference to $92 \%$ in the year 2017. These results add to the evidence that the accessibility benefits from the recent cycle of investments and disinvestments in Rio generally accrued to middle- and higher-income groups and reinforced rather than reduced socio-spatial inequalities in access to opportunities.

Figures 5 and 6 compare for each scale of analysis how the number of jobs and schools accessible have changed between 2014 (horizontal axis) and 2017 (vertical axis) in both implemented and quasi-counterfactual scenarios. In these figures, each dot represents a grid cell where dot size varies according to population size and color indicates its income classification. Dots located above the diagonal line have seen an improvement in accessibility by public transport. From a simple visual analysis, these results look consistent across 
different spatial scales and zoning schemes, and suggest that the recent policies implemented in Rio had a limited and ambiguous impact on people's access to employment and educational opportunities. The distribution of various dots above and below the diagonal line indicate that the transport policies had more substantial effects both positively and negatively for those areas from which people already had access to between $20 \%$ and $50 \%$ of all jobs in the city. This is somewhat expected given that most of the changes to the network have occurred in areas which were already better connected in 2014. Regarding access to schools, there are substantially more dots below the line, reflecting that access to schools has been affected more adversely than job access by the policies implemented (Figure 6). Figures 5 and 6 also show the distribution of accessibility gains in the quasicounterfactual scenario. The income composition and distribution of dots above the diagonal line is very similar in both scenarios, reflecting the job and school accessibility gains that resulted from the newly added infrastructure. There is a marked contrast, however, in the distribution of dots below the diagonal line, which gives a clearer picture of how the reduction in services levels between 2014 and 2017 reduced people's access to jobs and schools, offsetting the benefits of recent transport investments in the period.

An important component of an equity evaluation of the policies implemented in Rio is the identification of those income groups in the city that have benefited the most from the recent cycle of transport investments and disinvestments. Although a simple visual analysis of Figures 5 and 6 suggests that most gains in access to jobs and schools have accrued to richer areas (shown in blue), the answer to this question demands a more robust statistical analysis. 
Figure 4.5 Proportion of formal jobs accessible from each grid cell via public transport and walking under 1 hour in the years 2014 ( $\mathrm{X}$ axis) and 2017 (Y axis) in implemented and counterfactual scenarios. Rio de Janeiro.

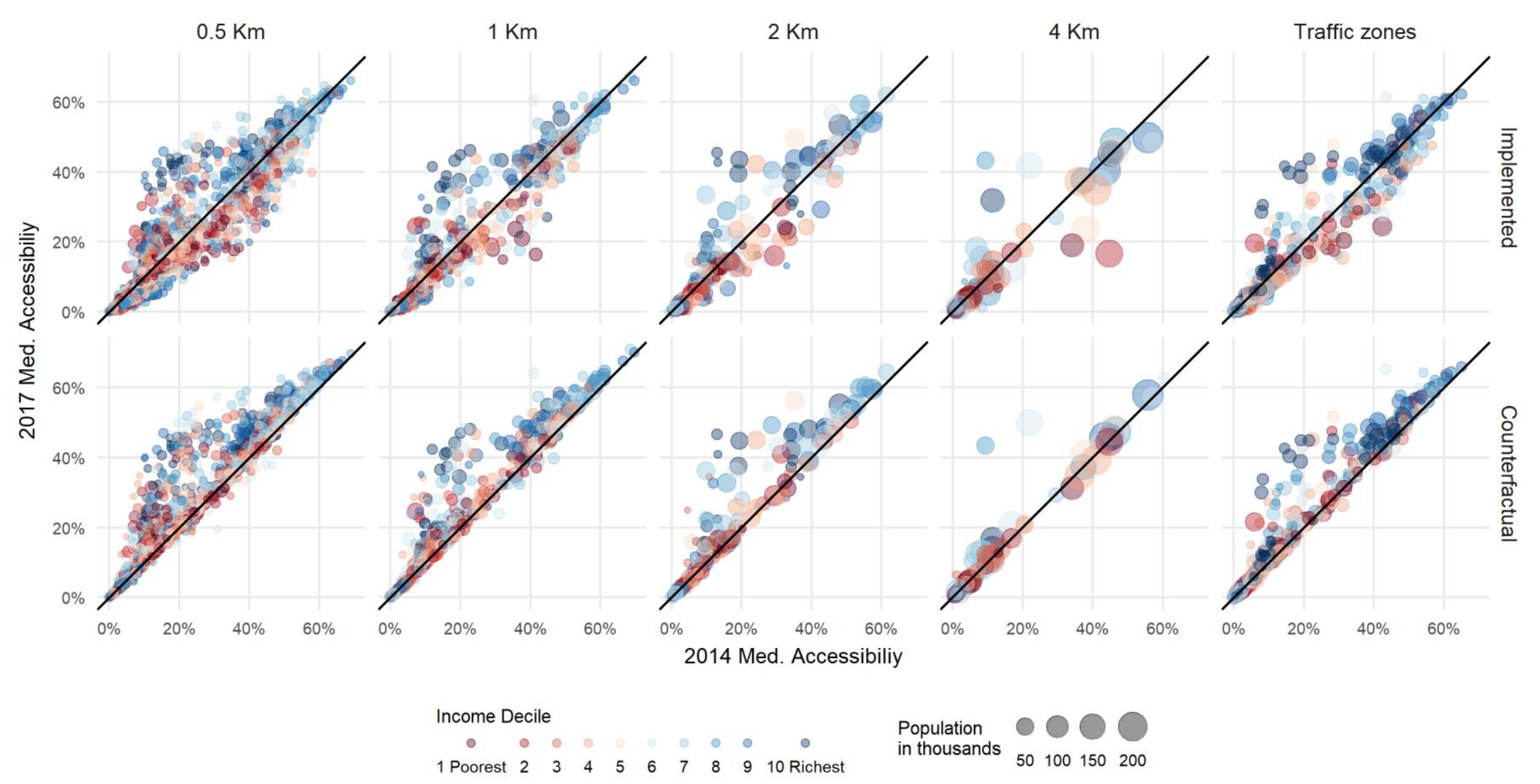


Figure 4.6 Proportion of public high-schools accessible from each grid cell via public transport and walking under 1 hour in the years 2014 (X axis) and 2017 (Y axis) in implemented and counterfactual scenarios. Rio de Janeiro.

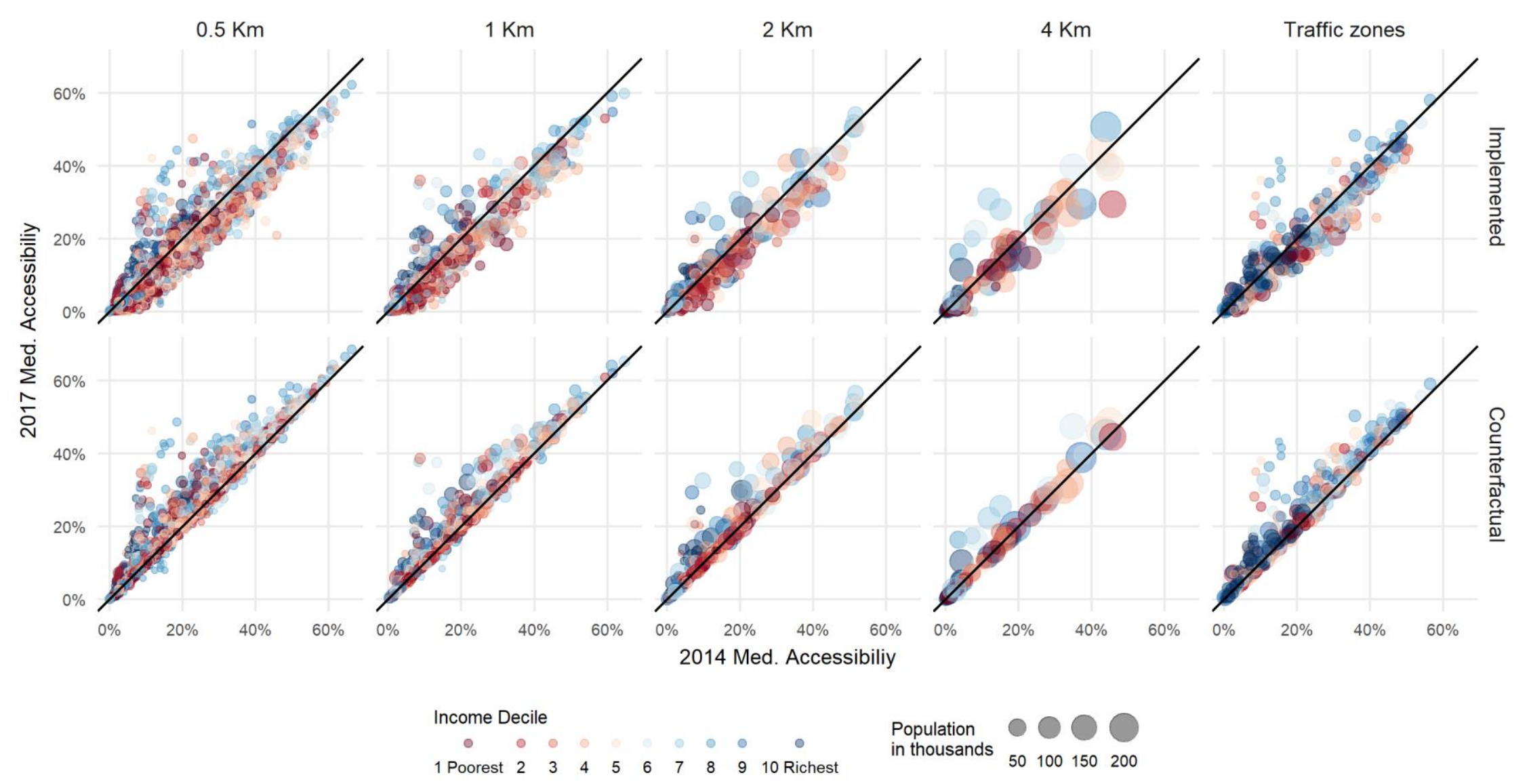




\subsubsection{Global association between income and accessibility change}

The association between average household income per capita and the accessibility variation that occurred between 2014 and 2017 was tested using a spatial regression model. This model provides a more robust analysis, indicating whether the differences in accessibility gains by income levels are statistically significant while controlling for other confounding factors, including spatial autocorrelation in the data. Moreover, it allows us to test whether the distributive effects of recent transport policies are sensitive to the modifiable areal unit problem (MAUP), what cannot be captured only by looking at the descriptive analysis presented thus far.

Tables 2 and 3 report the results of the spatial Durbin regression model, measuring how changes in access to jobs/schools between 2014 and 2017 are associated with household income per capita in 2010. The results show a small but positive association between income and variation in access to opportunities. However, both the strength and statistical significance of this association vary across multiple spatial scales and zonings. Using $0.5 \mathrm{~km}$ hexagonal grid, for example, a $1 \%$ higher income is associated with an increase of $0.08 \%$ in the number of schools accessible by public transport. This effect is twice as large when the analysis is conducted based on traffic zones $-0.16 \%$ (table 2 ). When analyzing the changes in access to job opportunities (table 3), the results only showed to be statistically significant for the analysis based on traffic zones. These results suggest a moderate association where a $1 \%$ higher income is associated with an increase of $0.21 \%$ in the number of jobs accessible by public transport. For both regressions on jobs and school opportunities, the spatial lag (rho) was not statistically significant when using the hexagonal grid of $4 \mathrm{~km}$. 
The statistical significance of the control variables used in the model also varied in an inconsistent way. Nonetheless, the direction of the associations shows that recent policies in Rio had on average larger accessibility benefits in those areas with higher population and job densities, and lower accessibility gains in communities located on hilly areas.

Table 4.2 Total effects of spatial Durbin model showing association with gains in access to public high-schools under various spatial scales and zoning schemes.

\begin{tabular}{llllll}
\hline Dependent Variable: $\log ($ ratio) & $\mathbf{0 . 5} \mathbf{~ K m}$ & $\mathbf{1 ~ K m}$ & $\mathbf{2 ~ K m}$ & $\mathbf{4 ~ K m}$ & $\begin{array}{l}\text { Traffic } \\
\text { Zones }\end{array}$ \\
\hline $\log ($ income) & $0.08^{*}$ & 0.12 & 0.16 & $0.16^{*}$ & $0.16^{* *}$ \\
& $(0.04)$ & $(0.06)$ & $(0.09)$ & $(0.08)$ & $(0.06)$ \\
$\log$ (pop.dens) & $0.08^{* * *}$ & 0.01 & 0.08 & 0.06 & $0.19^{* * *}$ \\
& $(0.02)$ & $(0.04)$ & $(0.06)$ & $(0.07)$ & $(0.04)$ \\
I(schools) & 0.03 & $0.37^{*}$ & 0.03 & -0.01 & -0.09 \\
& $(0.40)$ & $(0.17)$ & $(0.08)$ & $(0.03)$ & $(0.07)$ \\
$\log ($ elevation) & $-0.08^{* *}$ & -0.08 & -0.10 & 0.04 & -0.08 \\
& $(0.03)$ & $(0.05)$ & $(0.06)$ & $(0.07)$ & $(0.05)$ \\
rho & $0.88^{* * *}$ & $0.78^{* * *}$ & $0.54 * * *$ & -0.00 & $0.57^{* * *}$ \\
& $(0.01)$ & $(0.02)$ & $(0.06)$ & $(0.15)$ & $(0.05)$ \\
\hline Pseudo R2 & 0.76 & 0.53 & 0.28 & 0.10 & 0.37 \\
Num. obs. & 3485 & 1068 & 313 & 96 & 390 \\
Parameters & 11 & 11 & 11 & 11 & 11 \\
Log Likelihood & 282.63 & -338.74 & -177.51 & -59.06 & -124.82 \\
AIC (Linear model) & 4124.87 & 1389.65 & 432.85 & 138.13 & 355.41 \\
AIC (Spatial model) & -543.26 & 699.49 & 377.01 & 140.13 & 271.64 \\
LR test: statistic & 4670.13 & 692.16 & 57.84 & 0.00 & 85.77 \\
LR test: p-value & 0.00 & 0.00 & 0.00 & 0.99 & 0.00 \\
\hline
\end{tabular}

Notes: AIC, Akaike information criterion. Standard errors are in parentheses; ${ }^{* * *} \mathrm{p}<0.001,{ }^{* *} \mathrm{p}<$ $0.01,{ }^{*} \mathrm{p}<0.05$ 
Table 4.3 Total effects of spatial Durbin model showing association with gains in access to formal jobs under various spatial scales and zoning schemes.

\begin{tabular}{llllll}
\hline Dependent Variable: $\log ($ ratio $)$ & $\mathbf{0 . 5} \mathbf{~ K m}$ & $\mathbf{1 ~ K m}$ & $\mathbf{2 ~ K \mathbf { m }}$ & $\mathbf{4 ~ K m}$ & $\begin{array}{l}\text { Traffic } \\
\text { Zones }\end{array}$ \\
\hline $\log ($ income) & 0.06 & 0.10 & 0.10 & 0.07 & $0.21^{* * *}$ \\
& $(0.04)$ & $(0.06)$ & $(0.09)$ & $(0.11)$ & $(0.06)$ \\
$\log$ (popdens) & 0.05 & 0.01 & 0.01 & 0.03 & $0.11^{* * *}$ \\
& $(0.03)$ & $(0.19)$ & $(0.05)$ & $(0.09)$ & $(0.04)$ \\
$\log ($ jobdens) & $0.03^{*}$ & $0.04^{*}$ & $0.08^{*}$ & 0.12 & 0.05 \\
& $(0.01)$ & $(0.02)$ & $(0.04)$ & $(0.08)$ & $(0.03)$ \\
$\log ($ elevation) & $-0.06^{*}$ & -0.06 & 0.01 & -0.07 & 0.00 \\
& $(0.03)$ & $(0.04)$ & $(0.07)$ & $(0.08)$ & $(0.05)$ \\
rho & $0.89^{* * *}$ & $0.77^{* * *}$ & $0.47^{* * *}$ & -0.26 & $0.55^{* * *}$ \\
& $(0.01)$ & $(0.02)$ & $(0.06)$ & $(0.15)$ & $(0.05)$ \\
\hline Pseudo R2 & 0.79 & 0.55 & 0.31 & 0.18 & 0.40 \\
Num. obs. & 3580 & 1109 & 335 & 104 & 397 \\
Parameters & 11 & 11 & 11 & 11 & 11 \\
Log Likelihood & 609.77 & -321.20 & -211.70 & -114.87 & -74.72 \\
AIC (Linear model) & 3765.24 & 1372.53 & 491.95 & 252.46 & 254.65 \\
AIC (Spatial model) & -1197.54 & 664.39 & 445.39 & 251.73 & 171.43 \\
LR test: statistic & 4964.78 & 710.14 & 48.56 & 2.73 & 85.21 \\
LR test: p-value & 0.00 & 0.00 & 0.00 & 0.10 & 0.00 \\
\hline
\end{tabular}

Notes: AIC, Akaike information criterion. Standard errors are in parentheses; ${ }^{* * *} \mathrm{p}<0.001,{ }^{* *} \mathrm{p}<$ $0.01,{ }^{*} \mathrm{p}<0.05$

Under a quasi-counterfactual scenario, the results of the spatial Durbin regression model (Tables 4 and 5) indicate that the direction of the association between income and accessibility gains remains positive, but the magnitude of the effects is generally smaller, and the significance of some spatial scales also change. Overall, it also shows that even if there had been no reorganization of bus lines and austerity measures, wealthy areas in the city would still have benefited more from the new transport infra-structure than poor areas. 
Table 4.4 Total effects of spatial Durbin model showing association with gains in access to public high-schools in quasi-counterfactual scenario under various spatial scales and zoning schemes.

\begin{tabular}{llllll}
\hline Dependent Variable: $\log ($ ratio $)$ & $\mathbf{0 . 5} \mathbf{~ K m}$ & $\mathbf{1 ~ K m}$ & $\mathbf{2 ~ K m}$ & $\mathbf{4 ~ K m}$ & $\begin{array}{l}\text { Traffic } \\
\text { Zones }\end{array}$ \\
\hline $\log ($ income) & $0.04^{*}$ & $0.08^{* * *}$ & $0.12^{* * *}$ & 0.06 & -0.01 \\
& $(0.02)$ & $(0.02)$ & $(0.04)$ & $(0.04)$ & $(0.05)$ \\
$\log$ (popdens) & 0.01 & 0.01 & 0.05 & 0.01 & -0.00 \\
& $(0.01)$ & $(0.01)$ & $(0.03)$ & $(0.03)$ & $(0.03)$ \\
I(schools) & -0.08 & -0.01 & -0.05 & -0.00 & -0.10 \\
& $(0.11)$ & $(0.06)$ & $(0.05)$ & $(0.02)$ & $(0.06)$ \\
$\log ($ elevation) & -0.02 & -0.02 & -0.01 & -0.00 & -0.08 \\
& $(0.01)$ & $(0.02)$ & $(0.03)$ & $(0.03)$ & $(0.05)$ \\
rho & $0.86^{* * *}$ & $0.76^{* * *}$ & $0.62^{* * * *}$ & -0.03 & $0.74^{* * * *}$ \\
& $(0.01)$ & $(0.02)$ & $(0.05)$ & $(0.15)$ & $(0.04)$ \\
\hline Pseudo R2 & 0.70 & 0.51 & 0.38 & 0.14 & 0.46 \\
Num. obs. & 3546 & 1087 & 322 & 98 & 391 \\
Parameters & 11 & 11 & 11 & 11 & 11 \\
Log Likelihood & 2840.01 & 621.76 & 89.51 & 2.96 & 102.44 \\
AIC (Linear model) & -1666.14 & -538.23 & -62.63 & 14.11 & 15.05 \\
AIC (Spatial model) & -5658.01 & -1221.51 & -157.02 & 16.08 & -182.87 \\
LR test: statistic & 3993.87 & 685.28 & 96.39 & 0.03 & 199.92 \\
LR test: p-value & 0.00 & 0.00 & 0.00 & 0.86 & 0.00 \\
\hline
\end{tabular}

Notes: AIC, Akaike information criterion. Standard errors are in parentheses; ${ }^{* * *} \mathrm{p}<0.001,{ }^{* *} \mathrm{p}<$ $0.01,{ }^{*} \mathrm{p}<0.05$

In summary, spatial regression analyses show that the direction of the relationship between income and accessibility change remains positive across spatial scale and zoning schemes. However, the magnitude and statistical significance of results are sensitive to the spatial scale and zoning scheme of choice. Ideally, the conclusions of policy evaluations should not be dependent on the ad-hoc ways in which the data are spatially aggregated (Kwan \& Weber, 2008). This stability in the results is not observed in Rio and this case study illustrates the importance of using sensitivity analysis in the evaluation of transport policies. 
It is worth mentioning, though, that according to Log Likelihood and AIC tests (Tables 4.2 to 4.5), the regressions conducted using hexagonal grids of $0.5 \mathrm{~km}, 1 \mathrm{~km}$ and traffic zones had the best fit to the data, showing to be more appropriate for the spatial analysis.

Table 4.5 Total effects of spatial Durbin model showing association with gains in access to formal jobs in quasi-counterfactual scenario under various spatial scales and zoning schemes.

\begin{tabular}{llllll}
\hline Dependent Variable: $\log ($ ratio $)$ & $\mathbf{0 . 5} \mathbf{~ K m}$ & $\mathbf{1 ~ K m}$ & $\mathbf{2 ~ K m}$ & $\mathbf{4 ~ K m}$ & $\begin{array}{l}\text { Traffic } \\
\text { Zones }\end{array}$ \\
\hline $\log ($ income) & 0.04 & $0.06^{*}$ & $0.12^{*}$ & 0.02 & 0.02 \\
& $(0.02)$ & $(0.03)$ & $(0.05)$ & $(0.05)$ & $(0.06)$ \\
$\log$ (popdens) & -0.00 & 0.01 & 0.02 & 0.01 & 0.01 \\
& $(0.03)$ & $(0.02)$ & $(0.04)$ & $(0.04)$ & $(0.04)$ \\
$\log ($ jobdens) & 0.01 & 0.00 & -0.00 & 0.03 & -0.02 \\
& $(0.01)$ & $(0.01)$ & $(0.02)$ & $(0.03)$ & $(0.04)$ \\
$\log ($ elevation) & -0.01 & 0.00 & 0.00 & -0.02 & -0.04 \\
& $(0.01)$ & $(0.02)$ & $(0.05)$ & $(0.04)$ & $(0.05)$ \\
rho & $0.90^{* * *}$ & $0.81^{* * *}$ & $0.68 * *$ & 0.02 & $0.75^{* * *}$ \\
& $(0.01)$ & $(0.02)$ & $(0.05)$ & $(0.14)$ & $(0.04)$ \\
\hline Pseudo R2 & 0.77 & 0.60 & 0.42 & 0.34 & 0.44 \\
Num. obs. & 3580 & 1109 & 335 & 104 & 397 \\
Parameters & 11 & 11 & 11 & 11 & 11 \\
Log Likelihood & 3473.09 & 675.74 & 95.07 & -3.75 & 107.72 \\
AIC (Linear model) & -1933.29 & -431.60 & -26.21 & 27.51 & 11.38 \\
AIC (Spatial model) & -6924.18 & -1329.47 & -168.15 & 29.49 & -193.44 \\
LR test: statistic & 4992.89 & 899.87 & 143.94 & 0.02 & 206.82 \\
LR test: p-value & 0.00 & 0.00 & 0.00 & 0.90 & 0.00 \\
\hline
\end{tabular}

Notes: AIC, Akaike information criterion. Standard errors are in parentheses; ${ }^{* * *} \mathrm{p}<0.001,{ }^{* *} \mathrm{p}<$ $0.01,{ }^{*} \mathrm{p}<0.05$ 


\subsubsection{Local association between income and accessibility change}

While, the spatial Durbin model gives global results for the entire city, it is important to identify which areas in Rio gained or lost access to opportunities, and how the association between accessibility gains and income varies across space. Figures 4.7 and 4.8 show bivariate cluster maps of the local association between household income per capita and the variation in access to jobs and schools observed between 2014 and 2017. Spatial clusters colored light-green are the sweet spot from a transport equity point of view as they represent areas of relatively lower income population that had relatively higher accessibility gains. In contrast, red clusters show locations where higher accessibility gains accrued to higher-income groups. Darker green areas are also problematic as they represent clusters of low-income areas which lost accessibility in the period. This high/low classification of clusters is defined based on the mean of each variable.

The cluster analysis shows for example how the new light-rail system in the city center had little effect on people's access to schools and jobs. This is partially explained by its small network which is still not properly connected to the rest of the public transport system. On the other hand, the new subway line in the south has mostly improved access to opportunities for higher-income groups (red clusters). The analyses at higher resolution $(0.5 \mathrm{~km}, 1 \mathrm{~km}$ and traffic zones), nonetheless, indicate that the new subway line has also improved accessibility levels of two poor favelas, Vidigal and Rocinha shown in light green. Again, the results demonstrate how analyses at coarse scales lead to information loss and potential issues of ecological fallacy and aggregation error. 
Figure 4.7 Bivariate LISA based spatial clusters showing the local association between average household income per capita and gains in access to formal job opportunities by public transport between 2014 and 2017. Rio de Janeiro.

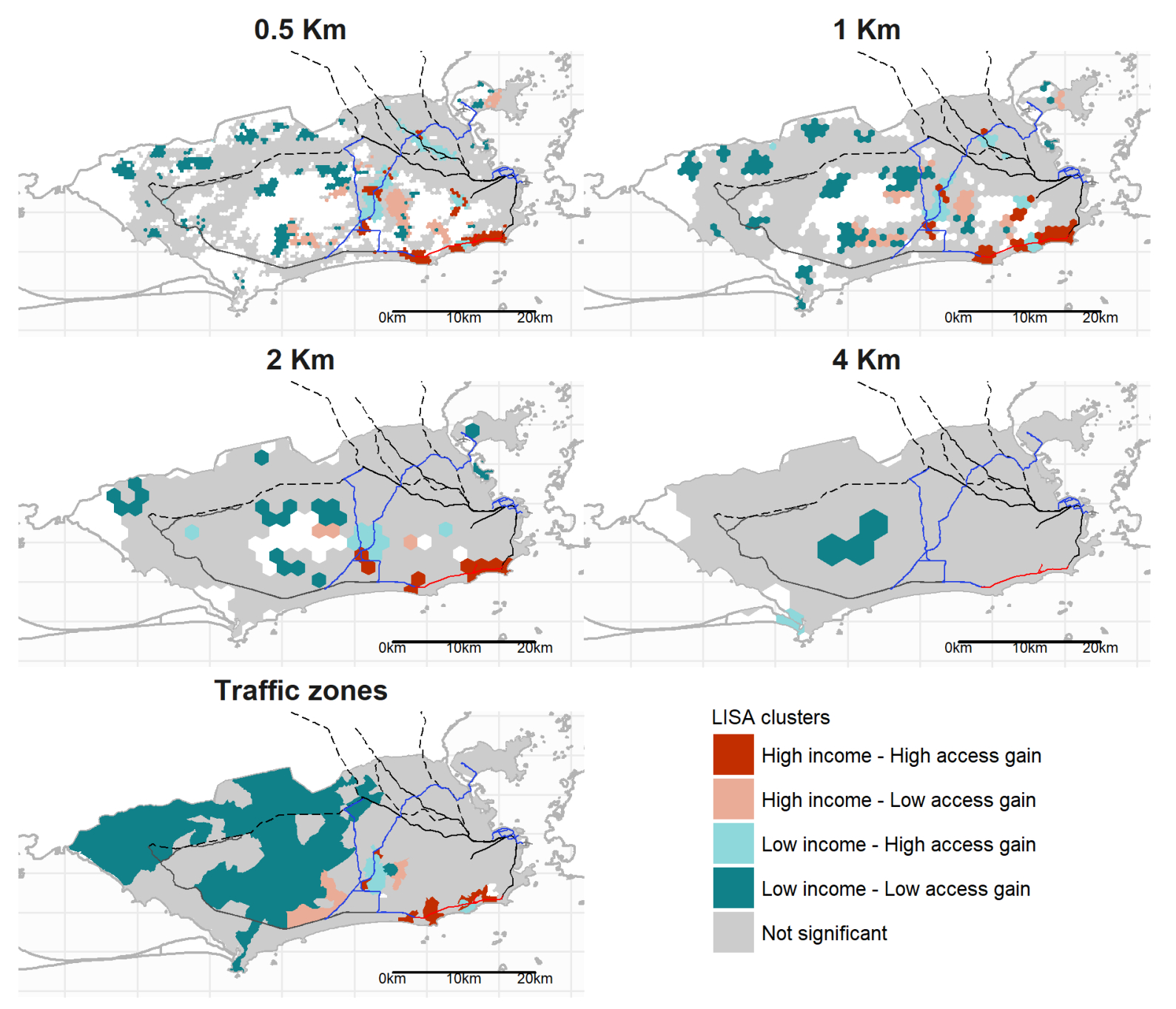

Furthermore, there are a few clusters of both high- and low-income people that have gained access due to the new Transcarioca BRT line and its connection to the subway line. The Transolímpica BRT, on the other hand, has had no significant effect on people's access to either schools or employment opportunities. This is closely related to the fact that the passenger demand in Transolímpica is only at $41 \%$ of the demand originally projected for 
the investment, which has led the company that runs this corridor to close some stations (Magalhães \& Rodrigues, 2017). Finally, there are various clusters of low-income areas that experienced a decrease in accessibility in the urban fringes in the west region of the city. This likely the result of worsening traffic conditions combined with service cuts in those areas.

Figure 4.8 Bivariate LISA based spatial clusters showing the local association between average household income per capita and gains in access to public high-schools by public transport between 2014 and 2017. Rio de Janeiro.

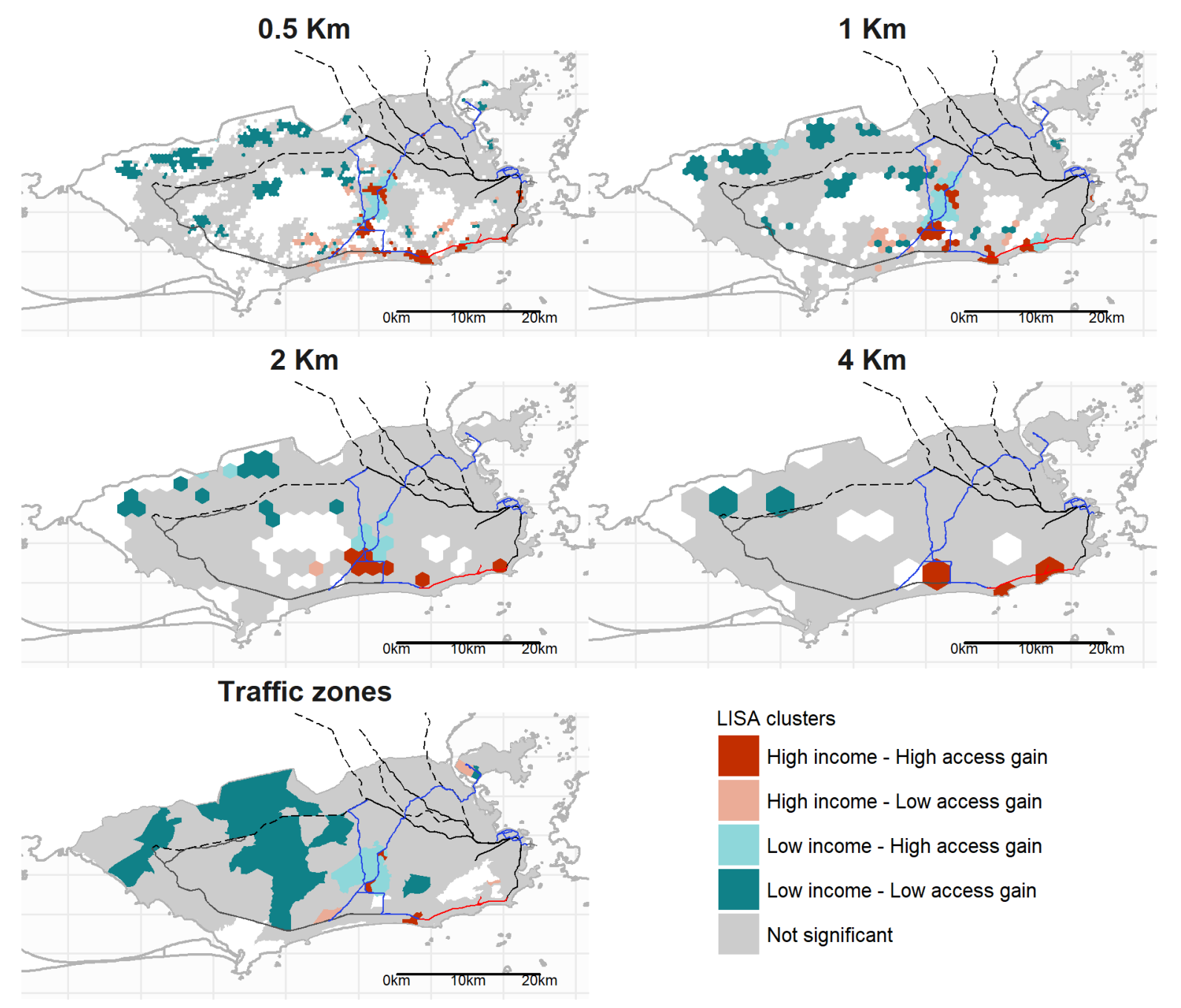




\subsection{Conclusion}

This chapter has evaluated, on multiple spatial scales, the public transport policies recently implemented in Rio de Janeiro to assess their distributional effects on people's access to schools and employment opportunities. Overall, the results show that infrastructure investments related to the 2014 World Cup and the 2016 Olympic Games, combined with cuts in service levels were followed by a small loss in average accessibility levels in Rio. A quasi-counterfactual analysis indicates that the reorganization of bus lines and reduction in services have offset the potential benefits of new transport infrastructure and were just as important as the new investments in reshaping accessibility levels. Moreover, the results show that wealthier areas had on average small but statistically significant higher gains in access to opportunities between 2014 and 2017 than poorer areas. Contrary to the official discourses of transport legacy, there has been little accessibility improvement in the most deprived areas, which are doubly disadvantaged with low income and low accessibility.

It is unrealistic to demand that new transport investments equally benefit every neighborhood in a city. From a social justice point of view, however, the least one would expect is that such governmental policies would improve the transport conditions of people in the worst-off position and not reinforce inequality (Pereira et al., 2017). Nonetheless, the findings of this study indicate that the transport legacy of recent mega-events in Rio are in direct conflict with the Rawlsian principles of justice. If anything, these policies have violated basic rights with the forced eviction of families and further exacerbated socio-spatial inequalities in access to employment and educational opportunities. 
The case of Rio exemplifies how the uneven nature of urban and transport development tends to create place-based advantages for higher income groups that are hard to tackle even with large infrastructure investments. Reducing socio-spatial inequalities in people's access to opportunities is a challenging long-term task which can only have limited results without a full integration between transport and land use planning. The findings of this study are specific to this case study of Rio and how recent policies interacted with the city's spatial patterning of land-use and social classes. Nonetheless, the austerity measures adopted in Rio's public transport systems might resonate well with the experience of local authorities elsewhere, particularly in developing countries, which often have to invest and manage their transport systems under severe budgetary constraints. Moreover, the method used in this chapter relies mostly on datasets that are organized in standardized formats and commonly available for different cities in the world, allowing for the replicability of this research method to transport projects in other urban contexts.

This chapter advances previous studies that analyze the social effects of transport policies by taking spatial autocorrelation into account and by showing that the conclusions of the equity assessment of transportation policies are sensitive to MAUP as these conclusions can vary depending on the spatial scale and aerial units of analysis. In the casestudy of Rio, while the direction of the association between accessibility gains and income remains positive in every analysis, the magnitude and statistical significance of this association changed considerably when using different spatial schemes. This finding reinforces the importance of sensitivity analysis in this type of evaluation. It also shows how the analysis based on traffic zones captured the geography of poverty and wealth and its relation to uneven access to opportunities. The statistical tests indicated that the $05 . \mathrm{Km}, 1$ 
Km grids and the traffic zones were best attuned to capture the socio-spatial differences of the changes in accessibility brought about by recent policies. However, it is unclear whether these spatial scales and zonings would still be appropriate if one used different regression specifications or measured accessibility differently. It may well be possible that there are particular scales that are more or less appropriate to analyze accessibility to different types of activities - such as local grocery stores or healthcare services.

This chapter has focused on physical accessibility and its limitations need careful attention in future studies. The analysis of access to employment opportunities does not consider jobs in the informal labor market, an issue that may be particularly important in other cities in the Global South given the size of the gray economy in these cities. Secondly, this analysis has not considered the influence of personal characteristics such as physical disabilities, age or gender and how they can hinder people's ability to use public transportation. As noted in section 4.3, the question of affordability is particularly relevant in Rio, where public transport costs can be prohibitive to low-income families. Moreover, the results presented are based on timetables of services. These timetables are not fully reliable given the incidence of traffic accidents and non-recurrent congestion levels in Rio. Future research would benefit from instead using GPS data of vehicles, which would render more accurate travel times for accessibility estimates (Wessel et al., 2017). Finally, future research is also needed to examine the long-term economic and social consequences of such transport developments for Rio's metropolitan area, for example in terms of air quality, reallocation of jobs, real estate appreciation and gentrification. 
A lesson that can be drawn from the case of Rio de Janeiro is that policy makers should incorporate accessibility scenario analysis in the early phases of transport planning to give a more complete picture of who benefits from new investments and subsequent changes in service levels. While it is a common practice to evaluate transportation projects based on cost-benefit analysis, transport planners seldom take into consideration the impact a project could have on the population's access to out-of-home activities.

Finally, the case of Rio de Janeiro is not an exception when it comes to the way in which official rhetoric seeks to justify transport projects based on promised benefits to society as a whole and to low-income groups in particular. It serves as a cautionary tale about how the potential benefits of new infrastructure projects can be undermined when these projects are seen in isolation from rest of the city and its transport system, and when governments do not sustain the level of spending necessary to maintain and run services at affordable prices. The recent experience of Rio with the transport investments related to mega-events illustrates how governments have significant capacity to reshape inequalities of access and opportunities in cities through the provision of public transport services and investments but often do not deliver what was promised. 


\section{Future accessibility impacts of transport policy scenarios: equity and sensitivity to travel time thresholds for Bus Rapid Transit expansion in Rio de} Janeiro

\section{Abstract}

The accessibility impacts of transport projects ex-post implementation are generally evaluated using cumulative opportunity measures based on a single travel time threshold. Fewer studies have explored how ex-ante accessibility appraisal of transport plans can be used to evaluate policy scenarios and their impacts for different social groups or examined whether the results of project appraisals are sensitive to the time threshold of choice. This chapter analyzes how different scenarios of full and partial implementation of the TransBrasil BRT project in Rio de Janeiro (Brazil) will likely impact the number of jobs accessible to the population of different income levels under various travel time thresholds of 30, 60, 90 and 120 minutes. Compared to a partial operation scenario, the full implementation of TransBrasil that extends this corridor into the city center would lead to higher accessibility gains due to network effects of connecting this BRT to other transport modes. Nonetheless, the size of the accessibility impacts of the proposed BRT as well as its distribution across income classes would significantly change depending on the time threshold chosen for the accessibility analysis. Considering cut-off times of 30 or 60 minutes, both scenarios of TransBrasil would lead to higher accessibility impacts in general and particularly for low-income groups, moving Rio towards a more equitable transportation system. However, under longer thresholds of 90 and 120 minutes, an evaluation of this project would find much smaller accessibility gains more evenly distributed by income levels. The chapter highlights how time threshold choice in cumulative opportunity measures can have important but overlooked implications for policy evaluation and it calls for further research on the modifiable temporal unit problem (MTUP) in future transport and mobility studies. 


\subsection{Introduction}

Over the past decade, there has been growing concern over the equity impacts of public transport investments (Ciommo \& Shiftan, 2017; Lucas, 2012), particularly of Bus Rapid Transit (BRT) projects, which are increasingly being adopted worldwide (Delmelle \& Casas, 2012; Venter et al., 2017). This is largely reflected in the growing number of academic studies and transport agency reports assessing how projects impact local communities and particularly vulnerable groups in terms of their access to out-of-home activities, such as employment and educational opportunities (Karner \& Niemeier, 2013; Manaugh et al., 2015). Most of these studies measure accessibility levels using cumulative opportunity measures of accessibility (Boisjoly \& El-Geneidy, 2017; Papa et al., 2015), which allow estimating, for example, the number of jobs accessible to a population group under an adhoc travel time threshold of say 60 minutes (Geurs \& van Wee, 2004). As a rule, however, these studies only consider a single cutoff time value and have thus far overlooked whether the conclusions/results are sensitive to different travel time thresholds. This issue is directly related to the modifiable temporal unit problem (MTUP) (Cheng \& Adepeju, 2014), which has been largely overlooked in the transportation literature (see section 5.2).

Moreover, while most of these studies focus on the ex-post assessment of the accessibility impacts of transport investments, there is a growing need to understand how researchers and policymakers can conduct ex-ante accessibility appraisal of transport plans to anticipate their likely accessibility impacts across different social groups (Guthrie et al., 2017; van Wee \& Geurs, 2011). The dearth of ex-ante evaluations is particularly significant in developing countries, where the accessibility and equity impacts of transport plans are 
5. Future accessibility impacts of transport policy scenarios: equity and sensitivity to travel time thresholds for Bus Rapid Transit expansion in Rio de Janeiro

often overlooked by local authorities (Blanco et al., 2018; Vasconcellos, 2001, 2014) and where the challenges of transportation are likely to grow due to rapid urbanization under conditions of inadequate transport infrastructure (UN-HABITAT, 2010).

Using a cumulative opportunity measure of accessibility, this chapter examines a major BRT project in a developing country to illustrate how ex-ante scenario analysis can be used to anticipate the likely accessibility impacts of transport plans for different income groups across space. It also investigates whether the conclusions of the analysis are robust when using different travel time thresholds. The study analyzes the TransBrasil project in Rio de Janeiro (Brazil), a 32-km long BRT corridor that was planned alongside other major public transport investments in preparation for the 2016 Olympic Games. Despite its strategic role in integrating Rio's public transport system and connecting high-density lowincome neighborhoods to the city center, the TransBrasil BRT remains unfinished because of legal disputes and fiscal issues. Only a part of the project is currently under construction and a fiscal crisis that recently hit the local government has raised serious uncertainties about whether this BRT is ever going to be finished (see section 5.3).

This chapter estimates the likely future impacts of the TransBrasil corridor on the number of jobs accessible to the population via public transport, measuring how accessibility gains vary across space and income classes and to what extent these are affected by the choice of travel time threshold (30, 60, 90 and 120 minutes from door to door). Combining population census and land use data with geolocated timetables of Rio's public transport network, the chapter assesses how two scenarios of the BRT plan - full and partial implementation of the project - will increase the number of formal jobs that people from 
5. Future accessibility impacts of transport policy scenarios: equity and sensitivity to travel time thresholds for Bus Rapid Transit expansion in Rio de Janeiro

different income levels and areas of the city can reach from their homes via public transport and walking. The study uses a spatial regression analysis to estimate if there is association between household income per capita and the accessibility gains brought by the proposed BRT project, and test whether this association is robust to MTUP across different travel-time thresholds.

The remainder of this chapter is organized as follows: the next section presents a short review of the literature on transportation equity and accessibility. Section 5.3 presents the study area of Rio de Janeiro and its unfinished BRT project. Data and methods are presented in section 5.4 and results presented in section 5.5. Section 5.6 presents the conclusions.

\subsection{Transportation equity and accessibility}

There is extensive literature on how transport investments can reshape people's access to out-of-home activities and improve wellbeing (Banister \& Hickman, 2006; Lucas, 2012). Previous studies have conducted ex-ante accessibility analysis to examine how people's access to jobs by car or public transport can be affected by future transport and land-use scenarios (Anderson et al., 2013; Geurs \& va Eck, 2003; Tilahun \& Fan, 2014). Some studies have also focused specifically on different scenarios of alternative public transport projects, looking at their accessibility impacts across racial/ethnic and income groups (El-Geneidy et al., 2011; Farber \& Grandez, 2017; Manaugh \& El-Geneidy, 2012; Niehaus et al., 2016). In recent decades, transport authorities, mainly in European and North American cities, have started using this type of accessibility analysis to evaluate their policies (Boisjoly \& El- 
Geneidy, 2017; Papa et al., 2015) with particular concerns regarding the different social impacts of their projects on population groups (Karner \& Niemeier, 2013; Manaugh et al., 2015).

While there is no consensus among transport authorities or academics about what makes a transport investment equitable, an egalitarian-prioritarian view of justice like the one developed by John Rawls $(1999,2001)$ is increasingly influential among academics (Lucas et al., 2015; Martens, 2012; Pereira et al., 2017; van Wee \& Roeser, 2013) and local transport authorities (Karner \& Niemeier, 2013; Manaugh et al., 2015). According to this view, a 'fair' transport policy prioritizes improving the accessibility conditions of people from disadvantaged groups. These include various social groups whose capabilities to use a transport system to access out-of-home activities and participate in society (or develop a fulfilling life) are systematically undermined by morally arbitrary factors such as being born in a poor family, having a disability, or belonging to a particular gender or racial/ethnic category (Pereira et al., 2017).

There are various methods of measuring accessibility to discuss equity impacts of transport policies (Martens \& Golub, 2012; Neutens et al., 2010; van Wee \& Geurs, 2011). Cumulative opportunity measures are among the most commonly used among academic researchers (Fan et al., 2012; Golub \& Martens, 2014; Manaugh \& El-Geneidy, 2012), funding agencies (Scholl et al., 2016) and transport agencies (Boisjoly \& El-Geneidy, 2017) to analyze the accessibility and social impacts of transportation investments. Some advantages of this type of accessibility measure are that it does not require prior information about people's travel behavior, is computationally inexpensive and produces results that are easy to 
communicate to policymakers and stakeholders. This makes it a particularly attractive measure to inform decision-making. It also has limitations, however, since it assumes that all opportunities are equally desirable, regardless of the time spent traveling; it does not take competition effects into account; it accounts neither for the space-time constraints on people activity-travel behavior nor the possibility of trip-chaining; and it involves the selection of an arbitrary cutoff travel time (Geurs \& van Wee, 2004; Neutens et al., 2010). As a rule, previous studies have used a single time threshold that varies between 30 and 60 minutes, depending on the geographical context or type of land use activity, such as schools or job opportunities. One exception is the study of Palmateer et al. (2016), who analyzed the accessibility impacts of an arterial bus rapid transit service in Minneapolis-Saint Paul (USA) under cutoff time values of 10, 20, 30, 40, 50 and 60 minutes. The authors found that average accessibility benefits gradually increase up to thresholds between 30 and 40 minutes and then decline. However, the authors did not investigate whether the equity effects of the BRT are sensitive to travel times.

As a rule, researchers and practitioners have generally overlooked how the choice of the cutoff travel time can influence the estimates of accessibility inequalities and the equity assessment of transport policies. Most of the cited studies in this section, for example, evaluate the accessibility impacts of transport investments and devise policy recommendations based on accessibility analysis that considers a single cutoff time value (Boisjoly \& El-Geneidy, 2016; Fan et al., 2012; Golub \& Martens, 2014; Manaugh \& ElGeneidy, 2012). By doing this, these studies disregard how the evaluation of transport projects and subsequent policy recommendations could vary depending on an ad-hoc definition of time thresholds. This issue relates to the boundary effect in the modifiable 
5. Future accessibility impacts of transport policy scenarios: equity and sensitivity to travel time thresholds for Bus Rapid Transit expansion in Rio de Janeiro

temporal unit problem (MTUP) (Cheng \& Adepeju, 2014; Huang \& Wong, 2015), which is the temporal analogue of the modifiable area unit problem (MAUP). The MAUP effect has been extensively explored in the geographical literature (Apparicio et al., 2008; Tan \& Samsudin, 2017) and it draws attention to how the conclusions of spatial analysis are often sensitive to the ad-hoc ways in which spatial data are aggregated according to different geographical scales and zonal schemes. Although the chapter 4 of this thesis and various other studies have examined how transport accessibility estimates can be sensitive to the MAUP (Kwan \& Weber, 2008; Omer, 2006; Ortega et al., 2012; Zhang \& Kukadia, 2005), these studies have generally overlooked the effects of MTUP and whether the arbitrary choice of cutoff time values has any influence on the evaluation of the accessibility impacts of transport projects and whether such impacts are equitably distributed across income groups.

\subsection{Study area: Rio de Janeiro}

The city of Rio Janeiro has approximately 6 million inhabitants, just over half of the population residing in its metropolitan region. Like many other cities in the Global South, Rio is the result of decades of rapid population growth and fragmented urban development (UNHABITAT, 2010). This gave rise to a city with high levels of urban segregation (Ribeiro et al., 2010), uneven provision of infrastructure (Câmara \& Banister, 1993; Ribeiro, 2014) and poor transport conditions (Motte-Baumvol et al., 2016; Pereira \& Schwanen, 2013).

Since the late 1990s, local authorities have incorporated into the city's urban plans the goal of making Rio a stage for international mega-events, having successfully hosted the 2007 Pan American Games, 2014 FIFA World Cup and 2016 Olympic Games (Gaffney, 2010; 
5. Future accessibility impacts of transport policy scenarios: equity and sensitivity to travel time thresholds for Bus Rapid Transit expansion in Rio de Janeiro

Kassens-Noor et al., 2016). This event-led planning agenda has triggered substantial investments in the city's transport system, particularly between 2012 and 2017, including a subway extension, a light rail system in the city center and four new BRT corridors (Figure 5.1). These transport investments were promoted as one of the main legacies of recent sports mega-events. According to local authorities, the new transport projects would collectively help the city overcome its socially fragmented urban development and reduce commute times, particularly to and from the poorest marginalized neighborhoods (Brazil, 2009). According to data of the 2013 household travel survey of Rio, commute trips by public transport and walking within the city used to take 57 minutes on average.

Figure 5.1 Medium and large capacity transport corridors. Rio de Janeiro, 2017.

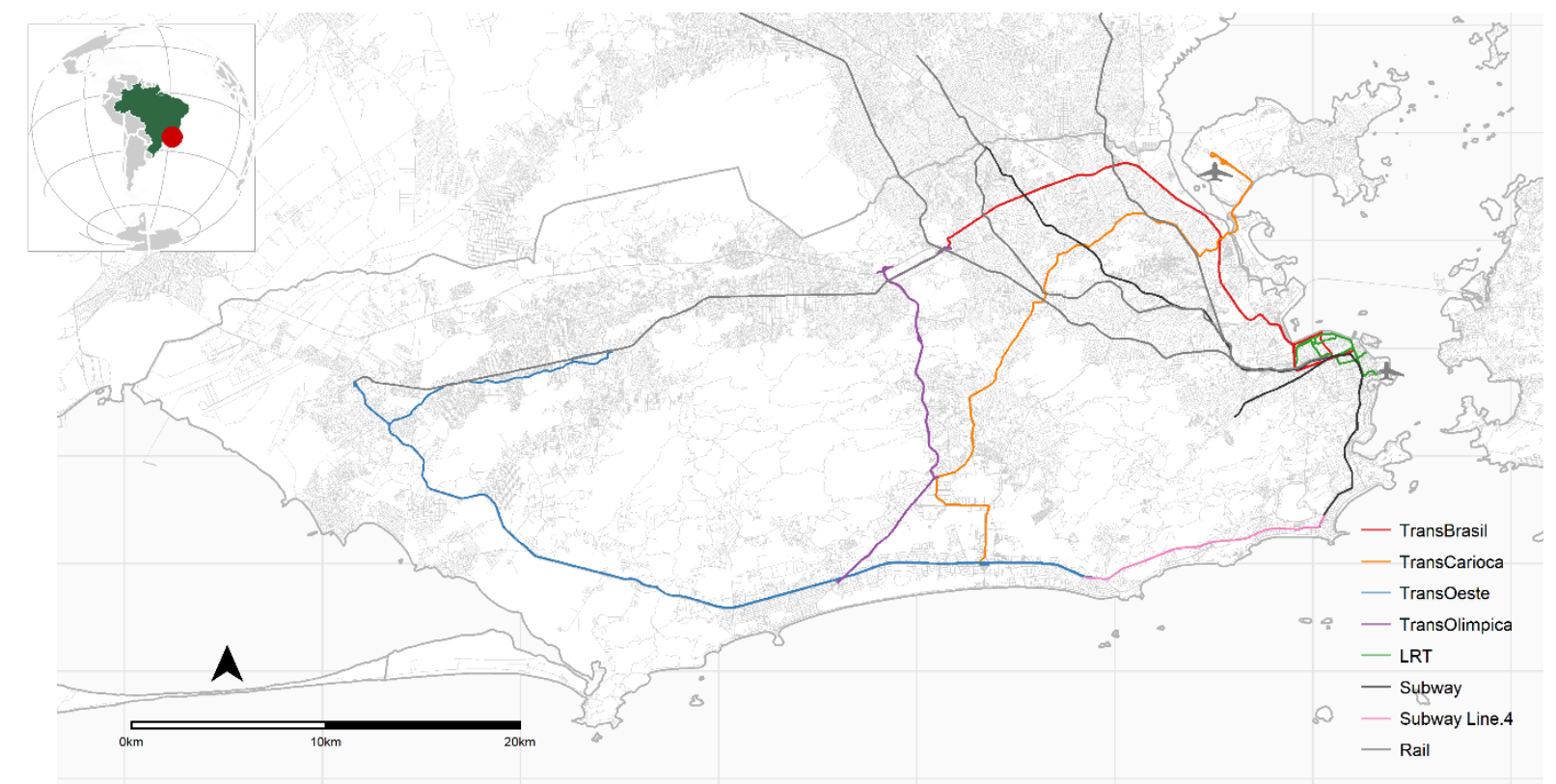

The TransBrasil BRT (red line in Figure 5.1) is perhaps one of the most important pieces of infrastructure amid this promised transport legacy of mega-events in Rio. At a cost of approximately US\$ 500 million, the project has 26 stations and length of $32 \mathrm{~km}$, running from the city center where most of the employment opportunities are concentrated to one 
of the most densely populated regions with lowest income levels in the city. It was proposed with a crucial role of integrating the city's public transport network. The TransBrasil corridor is planned to have two terminals where it integrates with city and metropolitan bus lines, and it should have integrated stations with the Transolímpica BRT as well as the commuter rail and subway systems. According to official estimates, TransBrasil is expected to be the BRT corridor with the highest demand in the city, carrying 800 thousand passengers per day (Logit, 2014).

However, while all the other mega-event related investments in Rio's transport network were fully or partially operational before the 2016 Olympic Games, the TransBrasil BRT remains unfinished as of this writing (Sept 2018). The construction work on TransBrasil was suspended for over nine months between 2016 and 2017 because of legal disputes with construction companies. Although contractors have restarted building a section of the project (between Deodoro and Caju stations - Figure 5.2), there is no perspective for when this section is going to be finished. Local authorities have recognized there is even greater uncertainty whether the full project (reaching downtown) will ever become fully operational (Candida, 2017; Lisboa, 2017), and this would create a first/last-mile problem for people moving in and out of the city center (Givoni, 2016). Moreover, the city of Rio has been hit by a severe economic crisis since 2016 , which has led to a $70 \%$ cut in the municipal transport agency's budget (Magalhães \& Rodrigues, 2017) and a significant drop in passenger demand due to rising unemployment rates (França, 2016; Rodrigues, 2017). Because of this situation, various bus companies claim they are facing a difficult fiscal situation. Indeed, seven companies went bankrupt between 2015 and 2017 and 12 others are threatening to do so, 
5. Future accessibility impacts of transport policy scenarios: equity and sensitivity to travel time thresholds for Bus Rapid Transit expansion in Rio de Janeiro

which could affect feeder lines and undermine people's access to the BRT services (Zarur, 2017; Zuazo et al., 2017).

There is a high level of uncertainty about whether the TransBrasil corridor will be completed. A prospective study that assesses the likely accessibility impacts of this BRT can offer additional information about the relevance of this project to the city's transport system. To the best of my knowledge, however, no study has thus far estimated the accessibility benefits of TransBrasil or its differential effects for various income groups. The next section describes the data and methods used to estimate the accessibility impacts of this BRT corridor.

Figure 5.2 Detail of the TransBrasil BRT corridor. Rio de Janeiro, 2017.

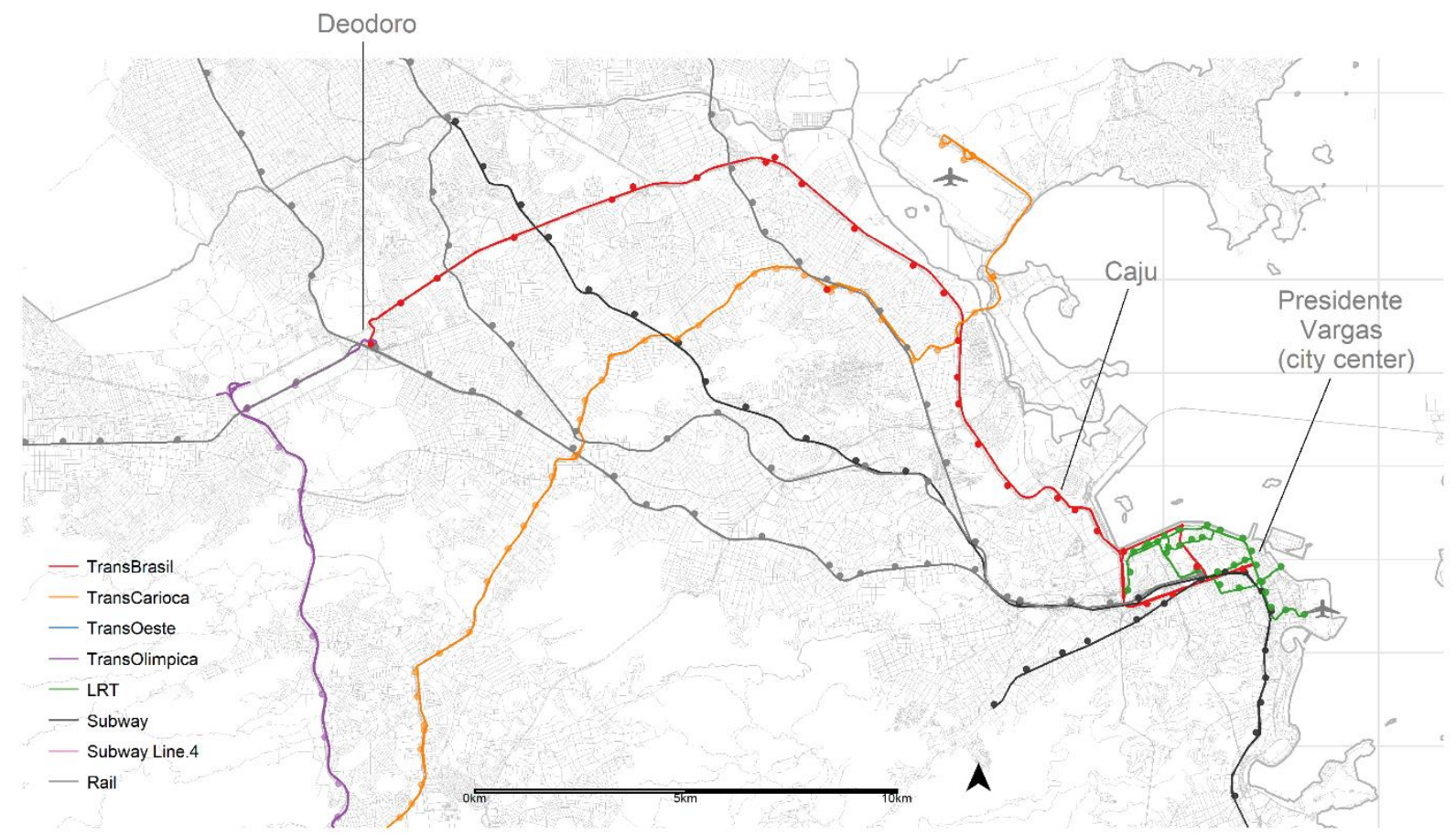

Note: As of the writing of this chapter, the BRT section between Deodoro and Caju stations is under construction and expected to be completed by October 2018 (RJTV, 2018). Local authorities have not given any estimate of when construction work of the section between Caju and Presidente Vargas will start. 


\subsection{Methodology}

A cumulative opportunity measure is used to estimate the likely impact of the TransBrasil BRT project on the number of formal jobs accessible by the population of different income levels via public transport and walking within various time-thresholds. Accessibility levels are estimated under a business-as-usual baseline without the TransBrasil corridor and then compared to two scenarios of partial and full operation of the BRT. The data sources and methods used in this study are detailed below.

\subsubsection{Data Sources}

Population count data comes from the 2010 Brazilian Census (IBGE, 2016) and were organized in a hexagonal grid of 500 by 500 meters with 5,520 cells. The choice of 500 meters allows a high-resolution accessibility analysis without compromising computational tractability. A hexagon grid was used to reduce sampling bias from edge effects and because it is more suitable than rectangular grid to analyze spatial phenomena in which nearest neighborhood and connectivity are important (Birch et al., 2007). The resident population in each grid cell was categorized according to income decile based on the average household income per capita of each grid cell. This was imputed from census data organized into 1,136 relatively homogeneous socioeconomic polygons known as Human Development Units (Ipea et al., 2015). The data on household income per capita collected in the census account for all members of the household and all their sources of income (including formal and informal jobs, unemployment benefits, pensions, social transfers, etc.). Although the census has some limitations in terms of capturing the upper extreme of income distribution (Souza, 2015), it 
5. Future accessibility impacts of transport policy scenarios: equity and sensitivity to travel time thresholds for Bus Rapid Transit expansion in Rio de Janeiro

is still the best data source to account for income distribution in Brazil. These data on income needs to be used with caution because it incurs ecological fallacies by disregarding socioeconomic heterogeneity within Human Development Units.

Data on formal jobs come from RAIS, a national register organized by the Ministry of Labor and Employment that has full addresses of all public and private establishments and the socioeconomic characteristics of their employees working in the formal labor market i.e. with a formal labor contract and social security contributions. In 2015, there were 2,914,238 formal workers employed in 227,362 establishments in Rio. In this database, workers are associated with the address of their respective workplaces. Exceptionally, some institutions with multiple offices/branches (such as outsourcing firms or public entities police, health and education) report all their employees to be working from the institutional headquarters. Among the 50 largest employers in Rio, 17 entities were found to do this and were removed from the analysis. The location of 83,589 employees working for the municipal education secretariat could be recovered from the school census. In the end, a database covering $92.3 \%$ of all formal workers in the city was used. This procedure should not substantially change the results of this study because the jobs excluded from the database are distributed in different locations in Rio and correspond to only a small fraction of formal jobs in the city.

Due to the unavailability of a data source with the addresses of jobs in the informal labor market, this study does not consider informal jobs. Although a significant share of workers in Rio self-declared to work in the informal labor market (approximately 36\% in 
5. Future accessibility impacts of transport policy scenarios: equity and sensitivity to travel time thresholds for Bus Rapid Transit expansion in Rio de Janeiro

January $2016^{16}$ ), the 2003 household travel survey of Rio shows that the numbers of formal and informal jobs in each traffic zone are correlated at 0.78 (Pearson correlation, statistically significant at 0.001). This suggests that the spatial distribution of formal and informal jobs in the city is not radically different, so that the lack of data on informal jobs should not radically change the relative distribution of accessibility estimates using cumulative opportunity measures.

Spatial information on road network and pedestrian infrastructure comes from OpenStreetMap. Finally, data on the public transport network was provided by Fetranspor (Federation of Passenger Transport Companies in Rio de Janeiro). The dataset is organized in General Transit Feed Specification (GTFS) format and it provides a snapshot of the scheduled services for May 2017, with detailed geolocated information of routes, stops and timetables of the public transport system.

\subsubsection{Simulating the TransBrasil BRT project}

In order to analyze the future accessibility impacts of the TransBrasil corridor, a GTFS data feed representing the scheduled services of this BRT was created using the official data presented in the latest revised operational plan of the project (Logit, 2014). According to this plan, 12 services would run in the TransBrasil corridor and 7 services would run between the TransBrasil and Transcarioca BRT corridors, including both regular routes that stop at various stations and express routes that only stop at a few stations. The sequence of stops in

\footnotetext{
${ }^{16}$ Source: National Household Sample Survey (PNAD/IBGE), available at http://www.ipeadata.gov.br/.
} 
each of these services is presented in Appendix I. In the accessibility analysis, the full operation scenario considered all stops in Appendix I, while the partial operation scenario only considered the stops between Deodoro and Caju stations, which is the section of the project currently under construction. The plan also presents some operational characteristics of these services during the morning peak time, including total length, travel time, average speed, frequency and headways. These characteristics were also used to create a GTFS representation of the project and they are summarized in Appendix II.

Following this 2014 revised plan of TransBrasil (Logit, 2014), eight regular bus routes would have significant overlap with the new BRT and the intention was to cease their operation. Five of these routes were still present in GTFS files of May 2017 and removed from the analysis in this study. Moreover, the plan also identified 77 regular bus routes in the city of Rio to have partial overlap with the proposed BRT, recommending these routes to be shortened and turned into feeder lines. The document, however, does not provide enough information on how these routes should be modified, so they were kept unchanged for the purpose of this study. This means that the final GTFS dataset used still presents partial overlap between TransBrasil BRT and existing bus routes, which may have resulted in inflated accessibility estimates. This limitation deserves more attention and is discussed in the results section.

\subsubsection{Accessibility Analysis}

Accessibility levels have been estimated using a cumulative opportunity measure that indicates the number of formal jobs accessible by the population of different income levels 
via public transport and walking under a certain cutoff travel time. Because this type of accessibility measure inevitably involves setting a travel time threshold (Section 5.2), sensitivity analysis has been undertaken to assess the extent to which accessibility levels are affected by the choice of travel time cutoff value $(30,60,90$ and 120 minutes).

The study estimates the number of jobs accessible from every hexagonal grid cell of 500 meters via public transport and walking. OpenTripPlanner ${ }^{17}$ was used to estimate travel time matrices by public transport and/or walking between every pair of centroids of hexagonal cells. Population-weighted centroids of each polygon have been used as origins and destinations in order to minimize aggregation errors (Stępniak \& Jacobs-Crisioni, 2017). The study of Boisjoly \& El-Geneidy (2016) has found that accessibility levels measured at 8am are representative of the relative accessibility at other time periods the day in Toronto. In this chapter, though, various travel time matrices have been calculated for a typical business day, departing every 15 minutes between 7 a.m. and 9 a.m. in order to take into account possible variations in accessibility due to temporal variations in service levels and departure times. These travel time matrices contain door-to-door estimates that consider walking time from the point of origin to the public transport stop, waiting time for the vehicle, actual travel time through the transport network, waiting time during transfers, and the walking time from the transport stop to the final destination.

These travel time matrices have been combined with the geolocated data on population and jobs. Based on equation (1), the median number of jobs that can be accessed

\footnotetext{
17 OpenTripPlanner is an open-source multimodal trip planner available at https://github.com/opentripplanner/OpenTripPlanner.
} 
from each grid cell via public transport and walking across the various travel time matrices have been calculated for the business-as-usual baseline and for both partial and full operation scenarios. In an attempt to reduce qualitative mismatch between workers' socioeconomic position and available employment, job accessibility levels were adjusted on the basis of household income per grid cell and educational qualifications for the jobs. For residents in grid cells above the 5th income decile, accessibility estimates only considered employment opportunities that required high or secondary education, while for grid cells below the 5th income decile only jobs that required secondary or primary education were considered.

$$
\begin{aligned}
& A_{o, i, T}=\operatorname{median}\left(\sum_{o=1}^{n} P_{d} f\left(t_{o d r}\right)\right) \\
& f\left(t_{o d r}\right)= \begin{cases}1 & \text { if } t_{o d r} \leq T \\
0 & \text { if } t_{o d r}>T\end{cases}
\end{aligned}
$$

Where:

$A_{o i T}$ is the accessibility level at origin $o$ for population of income $i$ within time threshold $T$;

$P_{d}$ is the number of formal jobs in location $d$;

$t_{o d r}$ is the travel time in minutes between origin $o$ and destination $d$ at departure time $\mathrm{r}$; and $f\left(t_{o d r}\right)$ is a time threshold function that varies between one and zero, depending on whether travel time $\left(t_{o d r}\right)$ is longer or shorter than time threshold $T$.

Previous studies have shown that people's ability to use public transportation and hence their accessibility levels are dependent on affordability (El-Geneidy et al., 2016), disability (Casas, 2007), age (Ryan et al., 2015) or gender (Akyelken, 2017). The accessibility analysis conducted in this study did not consider these issues due to data availability constraints and is thus likely to underestimate accessibility inequalities (Neutens et al., 
5. Future accessibility impacts of transport policy scenarios: equity and sensitivity to travel time thresholds for Bus Rapid Transit expansion in Rio de Janeiro

2010). Another limitation of this analysis is that is does not consider the long-term effect that the new BRT project might have on the relocation of job opportunities and population. Such land-use impacts of a transportation investment are difficult to model and take time to materialize. If the accessibility gains brought about by construction of TransBrasil attract more jobs to locate closer to the BRT stations, it is likely that the results of this study will underestimate the long-term accessibility benefits of this proposed BRT corridor. Because this chapter seeks to isolate the short-term impact of the BRT project on accessibility levels, data on the spatial distribution of jobs and population have been kept constant in the analysis. Moreover, previous studies have shown that the spatial distribution of jobs in socioeconomic groups has remained fairly stable over the past two decades in Rio (Lago, 2000; Ribeiro, 2014).

\subsubsection{Analyzing association between income and accessibility change}

The final step was to analyze whether there is any association between people's income levels and the accessibility gains brought about by the proposed transport project upon implementation. Previous studies have conducted similar investigations using conventional statistical analysis (Fan et al., 2012; Foth et al., 2013). However, transport and land use processes are marked by spatial dependence, meaning that the accessibility levels of a location are related to its neighboring areas (Páez \& Scott, 2005). This spatial dependence in the data violates basic assumptions of standard regression analysis and leads to biased parameters and possibly flawed conclusions and policy prescriptions (Páez \& Scott, 2005). 
To take spatial dependence into account, this study uses a spatial regression model to estimate whether wealthier areas in 2010 will benefit by the accessibility gains from the implementation of the TransBrasil corridor. The baseline model without spatial effects is written as:

$$
\begin{gathered}
\log \left(\mathrm{R}_{i o}\right)=\beta_{0}+\beta_{1} \log \left(\mathrm{I}_{i}\right)+\beta_{2} \log \left(\mathrm{P}_{i}\right)+\beta_{3} \log \left(\mathrm{O}_{o i}\right)+\beta_{4} \log \left(\mathrm{E}_{i}\right)+\varepsilon_{i} \\
\mathrm{R}_{i o}=\frac{A_{i o T}^{S}}{A_{i o T}^{b}}
\end{gathered}
$$

Where:

$R_{i o}$ is the relative change in accessibility level from polygon $i$ to opportunities of type $o$ between baseline and scenario $s$ of partial or full operation;

$A_{i o T}^{\mathrm{S}}$ is the number of opportunities of type $o$ that could be accessed from origin $i$ under travel time threshold $T$ in scenario $s$ of partial or full operation;

$I_{i}$ is the average household income per capita in polygon $i$;

$P_{i}$ is the population density in polygon $i$;

$O_{i o}$ is the density of jobs in polygon $i$; and

$E_{i}$ is the average terrain elevation in meters of polygon $i$.

The purpose of this regression analysis is to test for associations between people's income levels and the likely accessibility gains brought about by the TransBrasil BRT project. Another motivation for such analysis is to test whether the assessment of the distributive effects of the new transport project is robust to the modifiable temporal unit problem (MTUP). Other variables influence where new transport infrastructure is likely to be built and consequently which locations derive higher accessibility gains from new investments. Areas with greater job and population densities, for example, are likely to have higher transport demand and make transport projects more economically viable (Kutz, 2003). 
5. Future accessibility impacts of transport policy scenarios: equity and sensitivity to travel time thresholds for Bus Rapid Transit expansion in Rio de Janeiro

Topography is another relevant variable that puts geographical barriers for construction and which has direct influence over construction costs and where surface transportation modes are likely to go (ibid.). In order to control for these factors, the regression model included information on local population and job densities as well as terrain elevation in the independent variables.

Variation in accessibility was measured as the ratio between accessibility levels with and without the new BRT. This approach means that changes in accessibility have proportionally lower impact in those areas that already had higher accessibility before the TransBrasil, in line with decreasing marginal returns. In other words, it implies that for a person living in an area with access to 100 jobs, an increase of, say, 50 jobs would add more to this person's utility than for a person who already had access to 1000 jobs.

The spatial dependence underlying the baseline model was evaluated using the Lagrange multiplier test, following standard methods used in the literature (Elhorst, 2010; LeSage, 2008). The Lagrange test indicated stronger preference for the spatial lag specification but also found the spatial lag and error models to be significant, which suggests that the spatial lag, Durbin or spatial autocorrelation (SAC) models could all be appropriate. Moving forward with a strategy of model determination, spatial Durbin model (SDM) was chosen because it gave the best results for the Akaike Information Criterion (AIC) and minimized and autocorrelation in the OLS residuals.

The SDM specification assumes there is spatial autocorrelation in the both dependent variable $y$ and explanatory variables $x$. This allows estimation of how strongly the accessibility gain in polygon $i$ is associated not only with the land use characteristics 
5. Future accessibility impacts of transport policy scenarios: equity and sensitivity to travel time thresholds for Bus Rapid Transit expansion in Rio de Janeiro

(including income) of $i$ but also with the land use characteristics and accessibility gains in

the neighboring polygons of $i$. Because the Durbin model includes a spatial lag in both set of variables, it produces coefficient estimates that are unbiased even if one or more relevant explanatory variables are omitted from the regression equation (Elhorst, 2010; LeSage, 2008). This is an important advantage given that only a limited set of independent variables is considered in the current analysis (see above). Polygons were defined as neighbors if they share at least one boundary point using a standard queen contiguity matrix. ${ }^{18}$

\subsection{Results}

Constructing the TransBrasil project either partially or in full will generate moderate to substantial average gains in accessibility, although the magnitude of these gains and the number of people who benefits from them differs depending on the travel time threshold selected for the accessibility analysis. Table 5.1 below summarizes the impact the TransBrasil BRT project could have on people's access to employment opportunities under various travel time thresholds. These results suggest, for example, that the full construction of this BRT could benefit approximately 800 thousand people (13.7\% of Rio's population), with an average increase of $13.3 \%$ in job accessibility under a travel time of 30 minutes. Under 60 minutes, 3.6 million people (58.5\% of the city's population) would be able to reach

\footnotetext{
${ }^{18}$ Various contiguity and spatial weight matrices were tested, including queen, rook, $K$-nearest neighbors (from 2 to 20), neighborhood contiguity with travel time thresholds (from 10 to 90 minutes every ten 10 minutes) and a weight matrix based on the inverse of travel times via public transport between polygons. The queen type of contiguity matrix captured the spatial dependence in the data most successfully, returning the highest value of Moran's I test for spatial autocorrelation in the OLS residuals.
} 
5. Future accessibility impacts of transport policy scenarios: equity and sensitivity to travel time thresholds for Bus Rapid Transit expansion in Rio de Janeiro

on average $11.3 \%$ more jobs under the full construction scenario than in the business-asusual baseline.

Table 5.1 Summary of the impact of the TransBrasil BRT project on people's access to job opportunities within various travel time thresholds under partial and full operation scenarios. Rio de Janeiro.

\begin{tabular}{|c|c|c|c|c|c|c|}
\hline \multirow{2}{*}{ Scenario } & & & \multicolumn{4}{|c|}{ Travel time threshold (minutes) } \\
\hline & & & 30 & 60 & 90 & 120 \\
\hline \multirow{3}{*}{ Full operation } & \multicolumn{2}{|c|}{ Average accessibility change $*$} & $13.3 \%$ & $11.3 \%$ & $4.2 \%$ & $2.4 \%$ \\
\hline & \multirow{2}{*}{$\begin{array}{l}\text { Population who gained } \\
\text { access to jobs }\end{array}$} & $\begin{array}{l}\text { Absolute } \\
\text { (in millions) }\end{array}$ & 0.8 & 3.6 & 4.8 & 4.3 \\
\hline & & $\begin{array}{l}\% \text { relative to } \\
\text { city population }\end{array}$ & $13.7 \%$ & $58.5 \%$ & $78.5 \%$ & $71.0 \%$ \\
\hline \multirow{3}{*}{ Partial operation } & \multicolumn{2}{|c|}{ Average accessibility change $*$} & $10.8 \%$ & $4.9 \%$ & $2.3 \%$ & $2.0 \%$ \\
\hline & \multirow{2}{*}{$\begin{array}{l}\text { Population who gained } \\
\text { access to jobs }\end{array}$} & $\begin{array}{l}\text { Absolute } \\
\text { (in millions) }\end{array}$ & 0.7 & 3.2 & 4.6 & 3.8 \\
\hline & & $\begin{array}{l}\% \text { relative to } \\
\text { city population }\end{array}$ & $12.0 \%$ & $52.0 \%$ & $76.1 \%$ & $62.2 \%$ \\
\hline
\end{tabular}

* Population-weighted mean increase in the number of jobs accessible via public transport and walking within specified travel time threshold.

For every cutoff time, the accessibility impacts of the full operation scenario of TransBrasil would be larger than the partial construction of the project. However, average gains in accessibility become consistently smaller for longer time thresholds in both scenarios. This is because the BRT becomes accessible to increasingly distant areas as longer cutoff times are considered. The population living in distant areas, however, would need to spend a larger portion of their travel time budget to reach a BRT station, which leaves less 
time to travel inside the BRT corridor and benefit from its speed and connectivity. It is thus expected that people living in areas further away from the new BRT will have smaller benefits from TransBrasil. Consequently, when the accessibility impact of a new project is measured using longer time thresholds, the results include areas further afield in which the population has relatively smaller accessibility gains, which lowers the overall average gain in accessibility. These results show that the accessibility impacts of TransBrasil would be mostly limited to shorter travel time thresholds and that the proposed BRT would add little accessibility to what people already have in longer trips.

Another interesting result in Table 5.1 is that the number of people who would have any accessibility gain due to the new BRT gradually increases when considering longer time thresholds up to 90 minutes and then declines for 120 minutes. To understand why this happens, it is important to bear in mind that cumulative opportunity measures only grasp accessibility changes when travel times between origin-destination pairs are pushed across the time threshold in question. In the 120-minutes maps, for example, accessibility gains for specific origins only show up if there are destinations that used to take longer than 120 minutes to reach but now take less due to the new transport project. Even though travel times to other destinations might be improved as well, say from 100 to 80 minutes, these changes will not appear on a 120-minute threshold map, but they will appear on the 90minute map. This is what happened to some specific locations that are colored in the 90minute map but not in the 120-minute maps of Figure 5.3 (below). The population living in those areas was already relatively well served by the public transport network, so the proposed BRT would only marginally improve their accessibility under a 90-minute cutoff time. With a 120-minute threshold, however, that population could already access most of 
the employment opportunities in the eastern side of the city without the TransBrasil corridor, so the construction of this BRT would not effectively reduce their travel times to job opportunities in the west side of the city, located further away.

Accessibility gains brought about the proposed BRT will be higher in the surrounding areas of the new corridor but will not be limited to them due to network connectivity effects. Figure 5.3 illustrates the spatial distribution of accessibility gains promoted by the TransBrasil project in its partial and full scenarios. Under shorter travel times, accessibility gains are, as expected, larger along the new BRT. In some of these areas, for example, the number of jobs accessible under 60 minutes would more than double compared to the business-as-usual baseline. Nonetheless, the accessibility impacts of TransBrasil are more than local. Particularly when longer time thresholds are considered, accessibility gains become smaller and more spatially distributed towards the west side of Rio, which is generally less populated and economically developed. Figure 5.3 also points to how accessibility gains spread further along other major transport corridors, illustrating an important network effect of how the proposed BRT would be connected to Rio's public transport system.

The full construction of TransBrasil can bring higher accessibility impacts to a larger share of the population than the partial operation scenario (see Figure 5.4, which zooms in by a factor close to two compared to the results of Figure 5.3 to present these results with more spatial detail). This will happen in part because the complete construction of TransBrasil will make it easier for people living in the north region to reach the city center, where most of the job opportunities are concentrated. This final stretch into the city center 
5. Future accessibility impacts of transport policy scenarios: equity and sensitivity to travel time thresholds for Bus Rapid Transit expansion in Rio de Janeiro

will significantly increase the connectivity of the proposed BRT to the rest of Rio's transport network via the light-rail, commuter rail and subway systems. This will also benefit people living in the southern part of the city, who will be able to connect to the new BRT in the city center and thus more easily access the job opportunities along the TransBrasil corridor towards the north.

It is worth noting that due to limitations of data availability, it is not possible to measure the accessibility impacts of the TransBrasil project outside the boundaries of the city of Rio (shown in dark gray in Figures 5.3 and 5.4). Nonetheless, the figures suggest that accessibility gains from this BRT will likely spill over/extend to neighboring municipalities, which have relatively poorer populations and lower availability of transport services. In this sense, had these municipalities been incorporated into the analysis, then the TransBrasil BRT would have had even more progressive effects by increasing job accessibility to poorer population groups in other municipalities. 
5. Future accessibility impacts of transport policy scenarios: equity and sensitivity to travel time thresholds for Bus Rapid Transit expansion in Rio de Janeiro

Figure 5.3 Figure 5.3 Variation in the proportion of formal jobs accessible within various travel time thresholds via public transport and walking under full (A) and partial (B) operation scenarios of the TransBrasil BRT project. Rio de Janeiro.

(A)

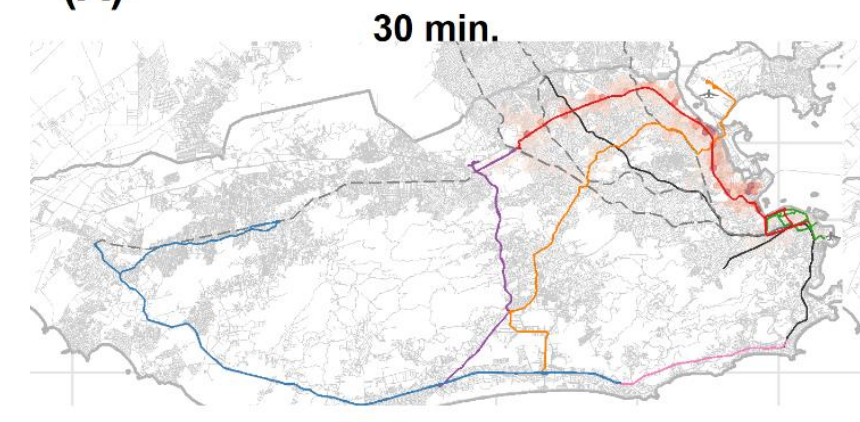

(B)

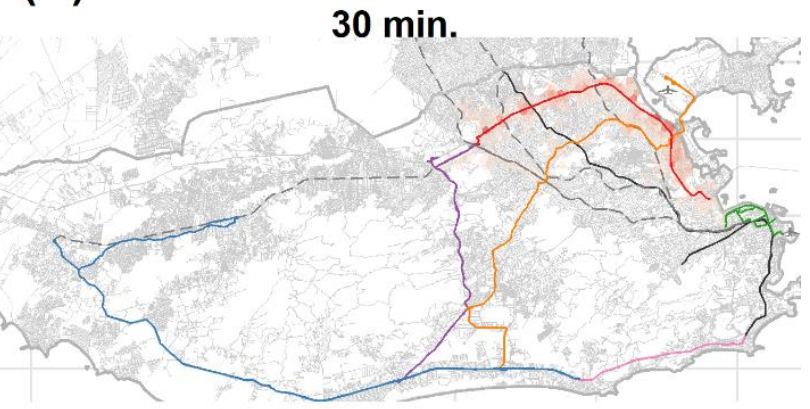

$60 \mathrm{~min}$.

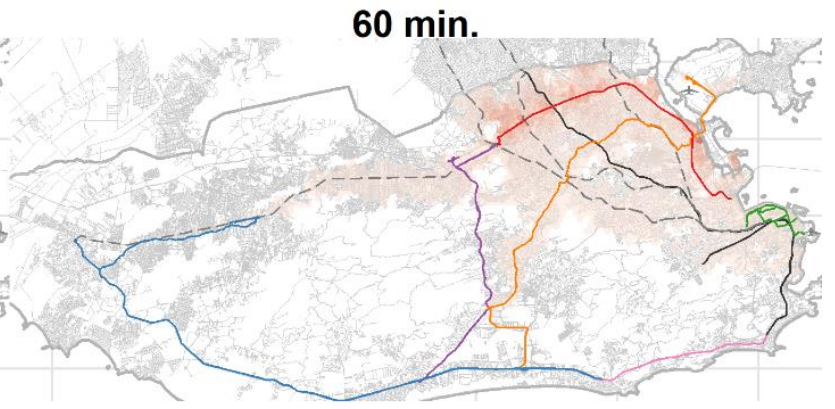

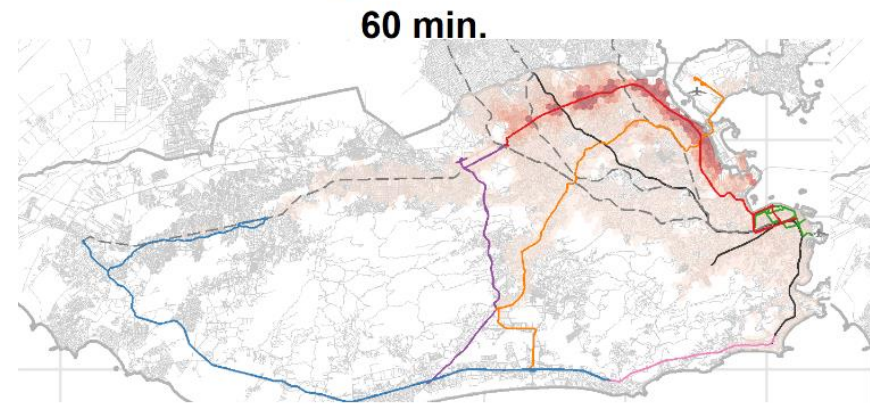

$90 \mathrm{~min}$.

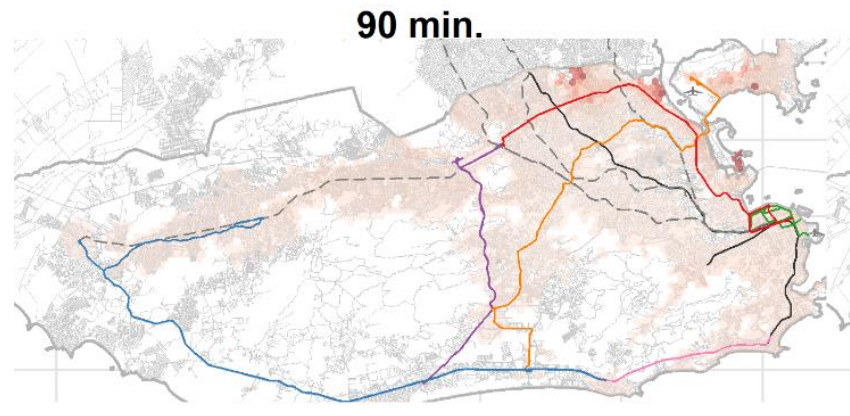

$120 \mathrm{~min}$.

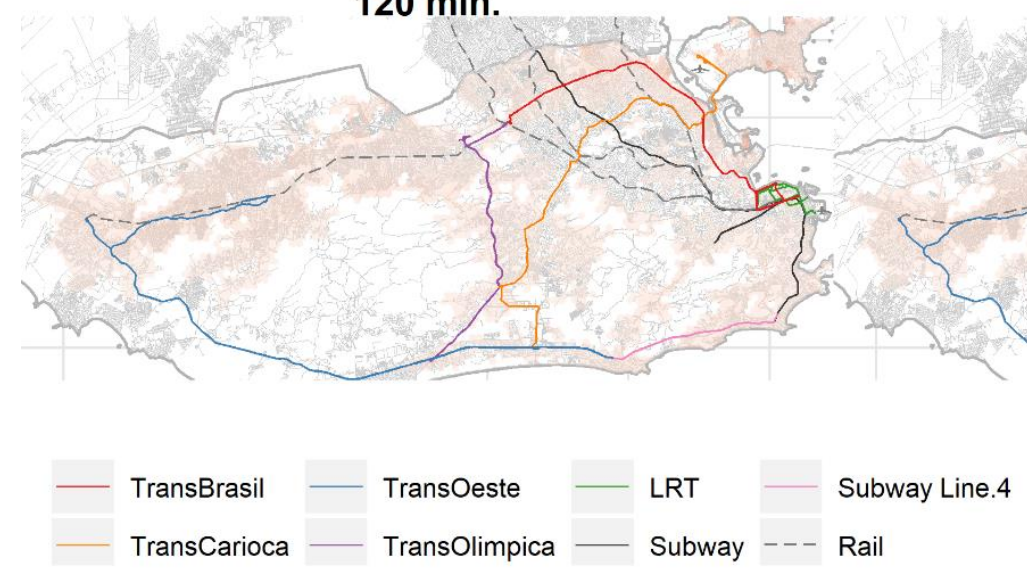

$90 \mathrm{~min}$.

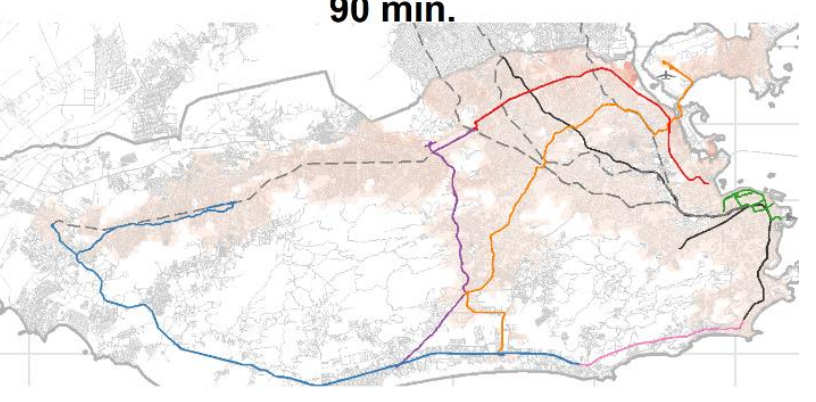

$120 \mathrm{~min}$.
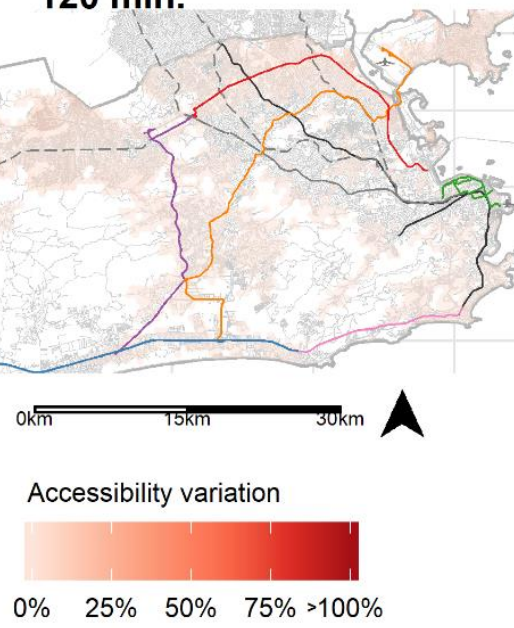
Figure 5.4 Detail of the variation in the proportion of formal jobs accessible within various travel time thresholds via public transport and walking under full (A) and partial (B) operation scenarios of the TransBrasil BRT project. Rio de Janeiro.

(A)
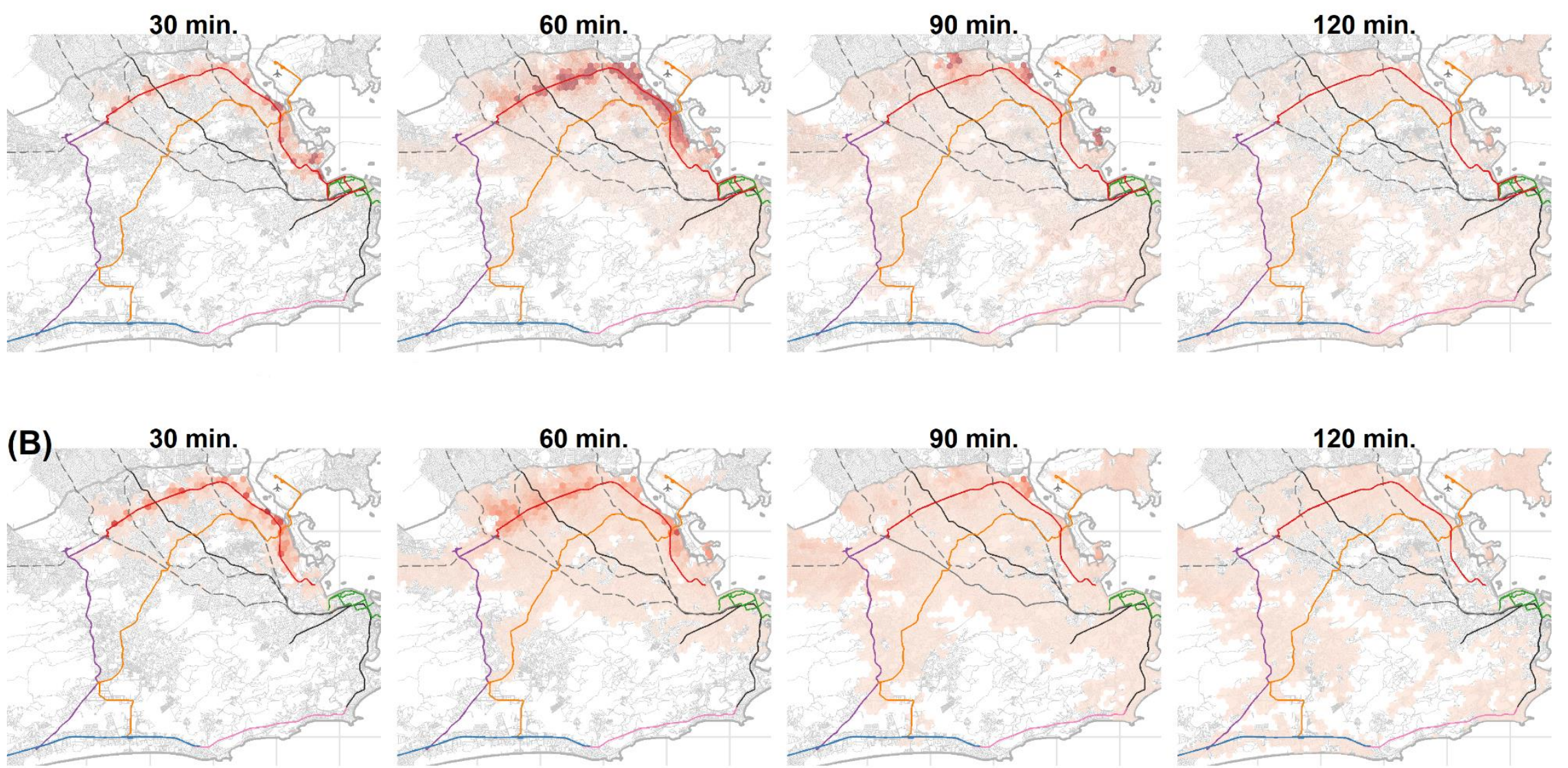

$$
\begin{array}{llll}
\text { TransBrasil } & \text { TransOeste } & \text { LRT } & \text { Subway Line.4 } \\
\text { TransCarioca } & \text { TransOlimpica }- \text { Subway }--- & \text { Rail }
\end{array}
$$
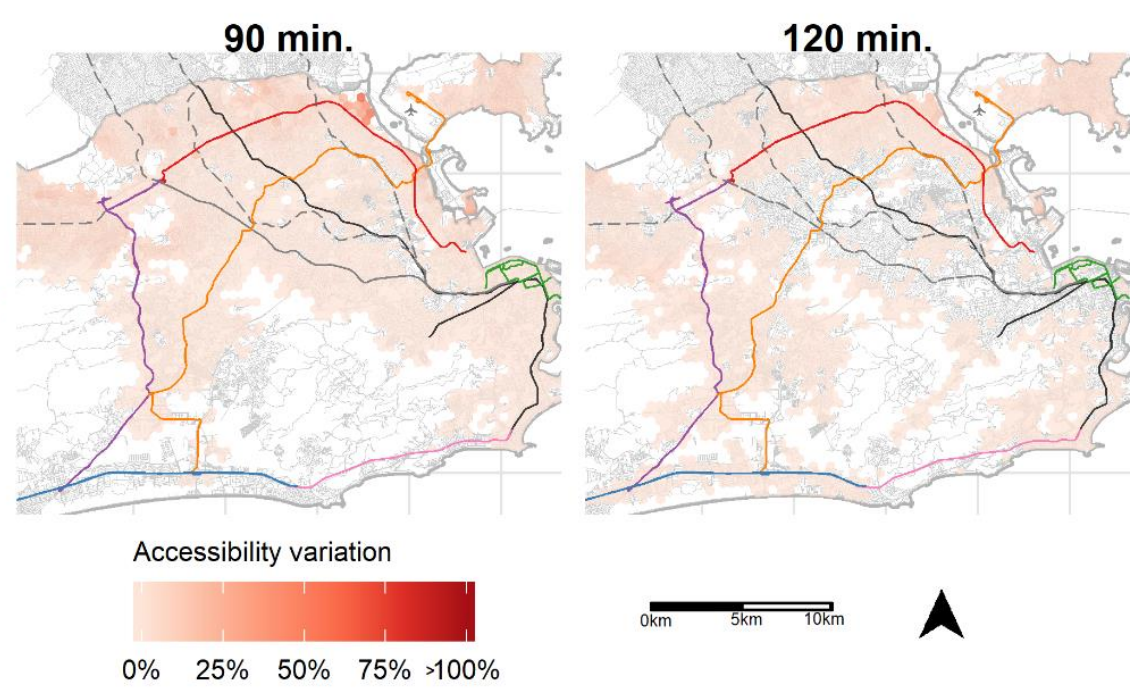
A central question to consider from a transportation equity point of view is to what extent the implementation of the proposed transport investment will contribute to reducing inequality of access to opportunities, particularly by improving the access of lower-income groups. The results show that both partial and full scenarios will have progressive effects i.e. they will bring larger accessibility benefits to lower- than to higher-income groups, particularly under shorter travel time thresholds. Figure 5.5 shows box plots of job accessibility gains by income deciles given travel time limits of 30, 60, 90 and 120 minutes. It indicates that TransBrasil will bring higher accessibility gains to lower income classes, but also that the magnitude of these gains differs considerably depending on the travel time limit. With a 60-minute threshold, for example, the complete implementation of the BRT will increase job accessibility in the city by $11.3 \%$ on average, while the two poorest income groups will experience a $23 \%$ average rise in their accessibility to employment opportunities. To a large extent, this is because of the layout of this corridor, which cuts across various low-income neighborhoods with high population density and improves their connection to areas of high job concentration, particularly in the city center. Figure 5.5 also shows how the magnitude of the accessibility impacts promoted by TransBrasil gradually declines for longer travel time thresholds, and this decline is particularly noticeable for lower income deciles. The TransBrasil corridor will have more progressive effects when considering a threshold of 30 minutes. It gradually becomes more neutral when longer travel times are considered but it is still slightly progressive at a threshold of 120 minutes. In other words, the progressive redistribution of accessibility brought about by the TransBrasil project cannot be considered in isolation from the cutoff time value that is used in the cumulative opportunity analysis. 
5. Future accessibility impacts of transport policy scenarios: equity and sensitivity to travel time thresholds for Bus Rapid Transit expansion in Rio de Janeiro

The boxplots also illustrate how, compared to the partial implementation of the TransBrasil corridor, the full implementation would bring relatively higher accessibility gains to larger numbers of people. This can be seen in the rise of average accessibility indicated by the colored dots - which would be particularly more pronounced for lowerincome classes once the project is fully implemented. The horizontal bar inside the boxplots of Figure 5.5 represents the median accessibility within each income group. Median accessibility levels would generally decrease from partial to full operation scenario. This is because under the full operation scenario, the accessibility impacts of the new BRT would extend to a larger number of people in areas further afield, as seen in Figures 5.3. However, because these areas have relatively smaller accessibility gains, the expansion of the BRT's area of influence increases the number of beneficiaries at the same time as it drives the median gains in accessibility down. 
5. Future accessibility impacts of transport policy scenarios: equity and sensitivity to travel time thresholds for Bus Rapid Transit expansion in Rio de Janeiro

Figure 5.5 Distribution of gains in job accessibility via public transport and walking by income groups under partial and full operation scenarios given various travel time thresholds. Rio de Janeiro.

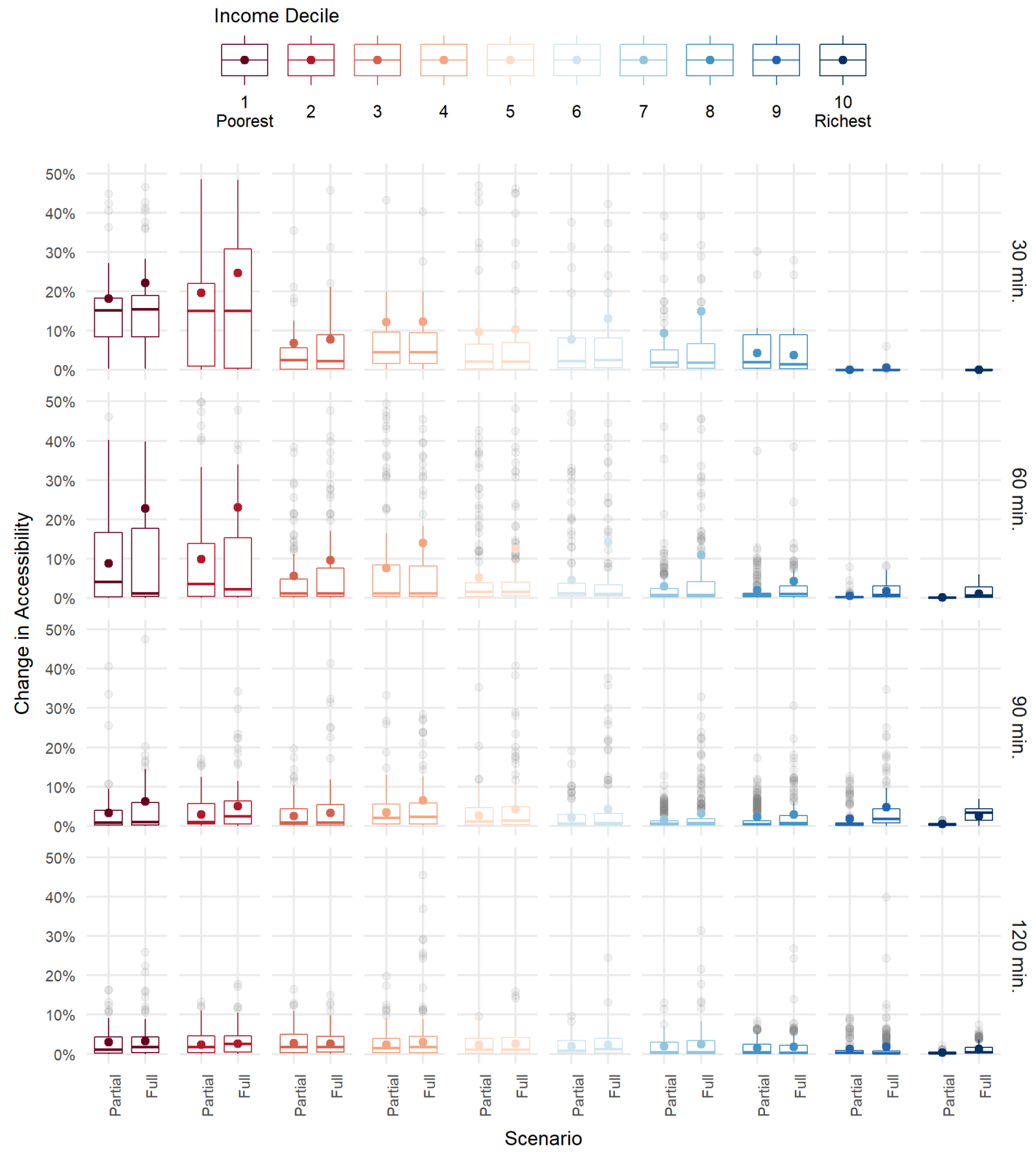

Note: Chart only considers the grid cells where there will be a change in accessibility levels caused by the partial and full implementation of the BRT project. 
While a simple visual analysis suggests that most gains in access to jobs would accrue to poorer areas (shown in reddish colors), a more robust statistical analysis is necessary to test whether these differences are statistically significant and whether the results vary according to different travel-time thresholds or if they are robust to MTUP. Tables 5.2 and 5.3 report the total effects of the spatial Durbin regression model, measuring how household income per capita in 2010 is associated with the future changes in accessibility to jobs brought by the full and partial construction of the TransBrasil BRT. For both scenarios, regression results show a small but negative association between accessibility gains and income levels, suggesting that on average lower-income groups would have larger accessibility benefits from the new BRT than wealthier groups. Considering a threshold of 60 minutes under the full operation scenario, for example, the results indicate that a $1 \%$ increase in average household income per capita is associated with an approximate $0.047 \%$ smaller accessibility gain. To put this result into perspective, every additional $\mathrm{U} \$ 100$ dollars in household income per capita (equivalent to $\mathrm{R} \$ 325$ Brazilian Reais, close to one-third of national minimum wage) is associated with a $1 \%$ smaller accessibility gain on average. According to the results in Tables 5.2 and 5.3, the total effects are consistently smaller in the partial than in the full operation scenario, which suggests that extending this BRT into the city center would make this project more progressive.

Although the direction of association between gains in accessibility and income level is consistently negative, the magnitude of this association varies considerably when using different cutoff time values. In the full operation scenario, for example, this effect is 3 times larger under the 30-minute threshold compared to 120 minutes (Table 5.3). The strength of the association between income and accessibility gains tends to decline for time thresholds 
5. Future accessibility impacts of transport policy scenarios: equity and sensitivity to travel time thresholds for Bus Rapid Transit expansion in Rio de Janeiro

longer than 60 minutes. This confirms that the TransBrasil BRT promotes greater accessibility gains for low- than for high-income groups, particularly when shorter travel times are considered. It also indicates a transition from more progressive to neutral effects as longer travel times are considered. These results indicate more broadly that evaluations of the distributional effects of transport accessibility based on cumulative opportunity measures are sensitive to the modifiable temporal unit problem (MTUP).

Table 5.2 Total effects of spatial Durbin model showing association with gains in access to formal jobs given various travel time thresholds under full operation scenario of TransBrasil BRT.

\begin{tabular}{lllll}
\hline & $\mathbf{3 0} \mathbf{~ m i n .}$ & $\mathbf{6 0} \mathbf{~ m i n}$. & $\mathbf{9 0} \mathbf{~ m i n}$. & $\mathbf{1 2 0} \mathbf{~ m i n}$. \\
\hline $\log$ (income) & $-0.014^{* * *}$ & $-0.047^{* *}$ & $-0.016^{* *}$ & -0.005 \\
& $(0.004)$ & $(0.016)$ & $(0.006)$ & $(0.003)$ \\
$\log$ (popdens) & $-0.007^{*}$ & $-0.024^{*}$ & $-0.011^{*}$ & 0.002 \\
& $(0.003)$ & $(0.011)$ & $(0.005)$ & $(0.002)$ \\
$\log$ (jobdens) & $0.007^{* * *}$ & $0.023^{* * *}$ & $0.010^{* * *}$ & 0.000 \\
& $(0.002)$ & $(0.006)$ & $(0.002)$ & $(0.001)$ \\
$\log ($ elevation) & $-0.008^{* *}$ & $-0.021^{*}$ & -0.005 & -0.000 \\
& $(0.003)$ & $(0.011)$ & $(0.004)$ & $(0.002)$ \\
rho & $0.739^{* * *}$ & $0.947^{* * *}$ & $0.891^{* * *}$ & $0.849^{* * *}$ \\
& $(0.013)$ & $(0.004)$ & $(0.007)$ & $(0.009)$ \\
\hline Pseudo R2 & 0.457 & 0.845 & 0.767 & 0.668 \\
Num. obs. & 3571 & 3580 & 3581 & 3581 \\
Parameters & 11 & 11 & 11 & 11 \\
Log Likelihood & 6047.286 & 5891.710 & 7463.830 & 9632.171 \\
AIC (Linear model) & -10094.363 & -5478.946 & -9851.494 & -15352.707 \\
AIC (Spatial model) & -12072.572 & -11761.421 & -14905.660 & -19242.343 \\
LR test: statistic & 1980.208 & 6284.475 & 5056.166 & 3891.636 \\
LR test: p-value & 0.000 & 0.000 & 0.000 & 0.000 \\
\hline
\end{tabular}

Notes: AIC $=$ Akaike information criterion; standard errors are in parentheses; ${ }^{* * *}=\mathrm{p}<0.001,{ }^{* *}=\mathrm{p}<0.01,{ }^{*}$ $=\mathrm{p}<0.05$. 
5. Future accessibility impacts of transport policy scenarios: equity and sensitivity to travel time thresholds for Bus Rapid Transit expansion in Rio de Janeiro

Table 5.3 Total effects of spatial Durbin model showing association with gains in access to formal jobs given various travel time thresholds under partial operation scenario of TransBrasil BRT.

\begin{tabular}{lllll}
\hline & 30 min. & $\mathbf{6 0}$ min. & $\mathbf{9 0 ~ m i n .}$ & $\mathbf{1 2 0 ~} \mathbf{~ m i n}$. \\
\hline $\log ($ income) & $-0.012^{* * *}$ & $-0.021^{* * *}$ & $-0.012^{* * *}$ & $-0.007^{* * *}$ \\
& $(0.003)$ & $(0.005)$ & $(0.003)$ & $(0.002)$ \\
$\log$ (popdens) & $-0.005^{*}$ & -0.003 & -0.004 & $0.003^{*}$ \\
& $(0.002)$ & $(0.003)$ & $(0.002)$ & $(0.002)$ \\
$\log$ (jobdens) & $0.005^{* * *}$ & $0.007^{* * *}$ & $0.005^{* * *}$ & -0.000 \\
& $(0.001)$ & $(0.002)$ & $(0.001)$ & $(0.001)$ \\
$\log$ (elevation) & $-0.006^{*}$ & $-0.007^{*}$ & -0.000 & 0.001 \\
& $(0.002)$ & $(0.004)$ & $(0.002)$ & $(0.001)$ \\
rho & $0.759^{* * *}$ & $0.892^{* * *}$ & $0.893^{* * *}$ & $0.905^{* * *}$ \\
& $(0.012)$ & $(0.007)$ & $(0.007)$ & $(0.006)$ \\
\hline Pseudo R2 & 0.471 & 0.770 & 0.747 & 0.811 \\
Num. obs. & 3571 & 3580 & 3581 & 3581 \\
Parameters & 11 & 11 & 11 & 11 \\
Log Likelihood & 7145.605 & 8249.277 & 10118.013 & 11681.540 \\
AIC (Linear model) & -12202.389 & -11565.116 & -15555.503 & -17660.196 \\
AIC (Spatial model) & -14269.210 & -16476.554 & -20214.026 & -23341.081 \\
LR test: statistic & 2068.821 & 4913.438 & 4660.523 & 5682.884 \\
LR test: p-value & 0.000 & 0.000 & 0.000 & 0.000 \\
\hline
\end{tabular}

Notes: AIC $=$ Akaike information criterion; standard errors are in parentheses; ${ }^{* * *}=\mathrm{p}<0.001,{ }^{* *}=\mathrm{p}<0.01,{ }^{*}$ $=\mathrm{p}<0.05$.

In summary, these results suggest that the implementation of the TransBrasil BRT can significantly improve the access to job opportunities for a large share of Rio's population, and particularly for lower-income groups. However, these results vary substantially depending on what time threshold is chosen for the analysis. While the implementation of this new BRT would have more progressive and higher accessibility impacts under shorter travel times (30 and 60 minutes), it will have more neutral effects with smaller impact with longer time thresholds (90 and 120 minutes). Moreover, the full implementation of the 
5. Future accessibility impacts of transport policy scenarios: equity and sensitivity to travel time thresholds for Bus Rapid Transit expansion in Rio de Janeiro

TransBrasil corridor will promote greater accessibility gains compared to its partial construction, and extending this BRT into the city center will make this project slightly more progressive from a distributional point of view. Finally, the TransBrasil corridor stands out as a far more equitable investment that promotes larger accessibility gains for lower-income groups when compared to the accessibility impacts of the other recent transport investments in Rio de Janeiro analyzed in chapters 3 and 4 of this thesis.

\subsection{Conclusions}

This study has presented an ex-ante evaluation of how different scenarios of a major BRT project currently under development in Rio de Janeiro may impact employment accessibility of different income groups and how these results vary when using different travel time thresholds. The findings indicate that the full implementation of the TransBrasil corridor will promote greater accessibility gains compared to its partial construction and extending this BRT into the city center will make this project slightly more progressive from a distributional point of view. From a Rawlsian perspective, both scenarios would move Rio de Janeiro towards a more equitable transportation system because they increase accessibility levels across all income groups, but they prioritize improving accessibility for disadvantaged groups. While it would be unrealistic to expect every neighborhood in a city to have the same level of access to job opportunities, the results of this chapter suggest that the construction of this BRT would at least reduce inequalities in access to opportunities by increasing accessibility levels of poorer communities that are more transit-dependent. From this angle, 
any of the scenarios of the TransBrasil corridor will stand out as a far more equitable investment than the other recent transport investments in Rio de Janeiro (chapters 3 and 4).

Nonetheless, the results also reveal that the size of the accessibility impacts of the TransBrasil project as well as its distribution across income groups vary substantially depending on the time threshold chosen for the cumulative opportunity accessibility analysis. While the implementation of this new BRT will have more progressive and higher accessibility impacts under shorter travel times (30 and 60 minutes), it will have more neutral effects with smaller impact with longer time thresholds (90 and 120 minutes). This result draws attention to a broader question about the extent to which the conclusions of equity assessments of transportation projects are dependent on the travel time threshold used in accessibility analysis. It points to how some methodological choices such as this one can have important but little discussed implications for policy evaluation. It is important to ask whether analyses using various time thresholds lead to differences in results that would be sufficiently large to suggest substantial modifications in the transport policy proposed. In the case of the TransBrasil BRT, the size of average accessibility gains could vary five-fold while the magnitude of the association between those gains and income levels could vary three-fold depending on the cutoff time considered. This can have important implications for decision making if these results are incorporated in some sort of cost benefit analysis or multi-criteria analysis. This, however, is a study of a particular project and city, and it is reasonable to expect that the sensitivity of results to cutoff time values varies according to the complexity of the transport network and the characteristics of the transport intervention and the city under analysis. The findings of this chapter suggest that future research on the equity appraisal of transportation projects conducted by researchers and local authorities 
should pay attention to MTUP and include sensitivity analysis and look more carefully at distributional effects on low-income groups.

Although an alternative to circumvent this issue would be to use other accessibility measures that are not based on a single cutoff time values - e.g., log-sum or gravitational metrics - these measures also rely on parameters defined ad-hoc, such as distance/time decay factors that are known to greatly influence accessibility estimates (Stępniak \& Rosik, 2017). According to Kwan \& Weber (2008), space-time accessibility measures are not sensitive to the spatial MAUP, but further investigation will be necessary to examine whether this type of metric can also overcome the modifiable temporal unit problem . In any case, the alternative accessibility measures have other limitations, such as being data-hungry and less transparent/easy to communicate to policymakers. Just as there is no single best method to measure accessibility (Neutens et al., 2010; van Wee \& Geurs, 2011), there is no single universal threshold that is appropriate for every transportation project, trip purpose, social group and urban context. This case study of the city of Rio de Janeiro illustrates why sensitivity analysis should be incorporated more often in future research in order to test whether the conclusions of such evaluations are robust to different travel time thresholds.

A limitation of the analysis presented in this study is that it was circumscribed to the city limits of Rio de Janeiro due to lack of data for outlying municipalities of the metropolitan area. Nonetheless, the accessibility benefits of the TransBrasil project are likely to spill over to nearby municipalities and thus benefit relatively poorer populations and people with lower availability of public services and transport services. This issue deservers further attention in future studies inasmuch as it touches on questions related to the planning and 
financing of transport projects that are under the responsibility of a single municipality but have wider accessibility impacts, crossing borders in metropolitan regions such as Rio de Janeiro that lack integrated governance of the public transport network. Another limitation of this chapter is that it focuses on the short-term impacts of the new BRT project in terms of its impacts on people's physical accessibility via public transport. While this approach allows isolating the likely accessibility impacts of transportation projects, it overlooks the long-term feedback between transport investments and reorganization of land use patterns as well as other changes to the public transport system that generally follow the expansion of infrastructures such as BRT corridors. Other efforts are necessary to gain a more comprehensive understanding of the long-term equity impacts of transport projects in terms of health, travel costs and road safety. Other research questions that deserve careful attention from future studies include the long-term effects of transport investments on real estate values (Jun, 2012; Stokenberga, 2014), gentrification processes (Gaffney, 2016) and issues of governance and participatory decision-making which are also of key importance for the co-production of fair transport policies (Boisjoly \& Yengoh, 2017; Fainstein, 2010).

This study illustrated how ex-ante accessibility analysis can be used to evaluate the equity and accessibility impacts of different transport project scenarios in their early planning stages using open-source software and standardized datasets. A similar method can be used easily in ex-post studies, which should be conducted to compare and validate the results of ex-ante evaluations and to control for the effects of population and job changes over time. The same type of analysis used here can also be replicated in other contexts with a few adaptations to the local context. The method applied here can be a valuable tool to facilitate accessibility-based planning at the level of individual projects by evaluating their 
5. Future accessibility impacts of transport policy scenarios: equity and sensitivity to travel time thresholds for Bus Rapid Transit expansion in Rio de Janeiro

accessibility impacts when integrated to the public transport system as a whole. It allows for project scenario analysis that captures the accessibility impacts of transport investment alternatives in a disaggregated manner for different social groups and across space at the local, city and regional level at various time scales. This method could also be significantly enhanced by recent developments in accessibility modeling that are opening up new possibilities to improve public participation of local communities in accessibility-based transport planning through digital interactive tools and collaborative scenario building (Stewart, 2017). 
5. Future accessibility impacts of transport policy scenarios: equity and sensitivity to travel time thresholds for Bus Rapid Transit expansion in Rio de Janeiro

Appendix I - Stop sequence of the services planned to run in the TransBrasil BRT corridor

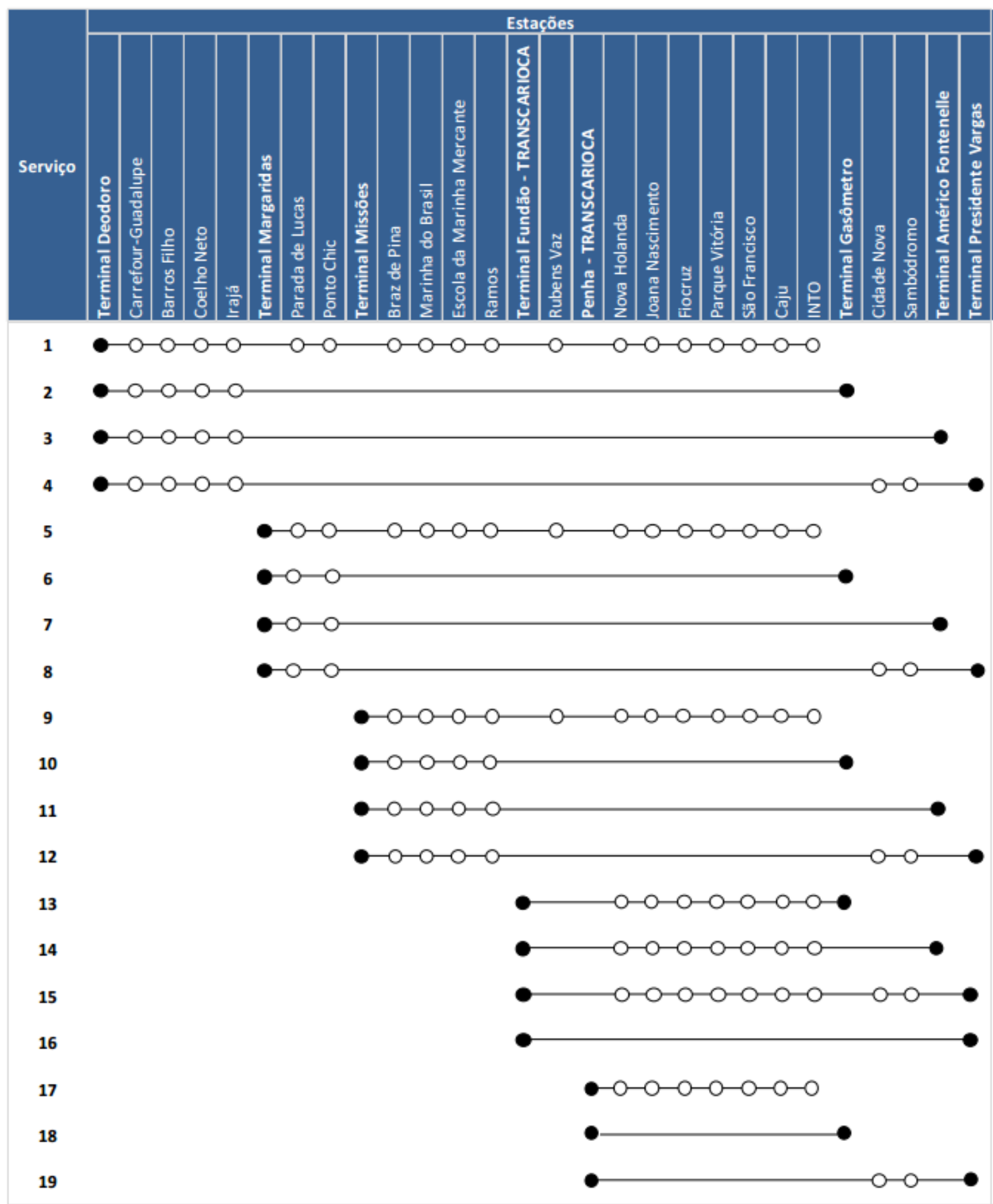

Source: Logit (2014, p.42) 


\begin{tabular}{|c|c|c|c|c|c|c|}
\hline \# & Route service name & $\begin{array}{l}\text { Total length } \\
\qquad(\mathbf{K m}) *\end{array}$ & $\begin{array}{l}\text { Travel time } \\
\text { (minutes)* }\end{array}$ & $\begin{array}{c}\text { Average } \\
\text { speed } \\
(\mathbf{K m} / \mathbf{h}) *\end{array}$ & $\begin{array}{c}\text { Frequency } \\
\text { (morning } \\
\text { peak) }\end{array}$ & $\begin{array}{l}\text { Headway } \\
\text { (min' sec") }\end{array}$ \\
\hline 1 & Terminal Deorodo - I.N.T.O. (Parador) & 50.0 & 98 & 30.6 & 72 & $0^{\prime} 45^{\prime \prime}$ \\
\hline 2 & Terminal Deorodo - Terminal Gasômetro (Semi-Direto/ Direto) & 51.5 & 94 & 32.8 & 12 & $5^{\prime} 00^{\prime \prime}$ \\
\hline 3 & Terminal Deorodo - Terminal Américo Fontenelle (Semi-Direto/ Direto) & 56.5 & 104 & 32.6 & 6 & $10^{\prime} 00^{\prime \prime}$ \\
\hline 4 & Terminal Deorodo - Terminal Presidente Vargas (Semi-Direto/ Direto) & 62.0 & 115 & 32.3 & 36 & $1^{\prime} 50^{\prime \prime}$ \\
\hline 5 & Terminal Margaridas - I.N.T.O. (Parador) & 32.8 & 72 & 27.3 & 60 & $1^{\prime} 00^{\prime \prime}$ \\
\hline 6 & Terminal Margaridas - Terminal Gasômetro (Semi-Direto/ Direto) & 35.6 & 70 & 30.5 & 12 & $5^{\prime} 00^{\prime \prime}$ \\
\hline 7 & Terminal Margaridas - Terminal Américo Fontenelle (Semi-Direto) & 40.6 & 80 & 30.5 & 5 & $12^{\prime} 00^{\prime \prime}$ \\
\hline 8 & Terminal Margaridas - Terminal Presidente Vargas (Semi-Direto/ Direto) & 46.1 & 90 & 30.7 & 30 & $2^{\prime} 00^{\prime \prime}$ \\
\hline 9 & Terminal Missões - I.N.T.O. (Parador) & 26.4 & 60 & 26.4 & 53 & $1^{\prime} 10^{\prime \prime}$ \\
\hline 10 & Terminal Missões - Terminal Gasômetro (Semi-Direto/ Direto) & 28.5 & 60 & 28.5 & 15 & $4^{\prime} 00^{\prime \prime}$ \\
\hline 11 & Terminal Missões - Terminal Américo Fontenelle (Semi-Direto) & 33.5 & 70 & 28.7 & 10 & $6^{\prime} 00^{\prime \prime}$ \\
\hline 12 & Terminal Missões - Terminal Presidente Vargas (Semi-Direto/ Direto) & 39.0 & 80 & 29.3 & 40 & 1'30" \\
\hline 13 & Terminal Fundão - Terminal Gasômetro (Parador) & 19.8 & 54 & 22.0 & 12 & $5^{\prime} 00^{\prime \prime}$ \\
\hline 14 & Terminal Fundão - Terminal Américo Fontenelle (Parador) & 24.8 & 64 & 23.3 & 11 & $5^{\prime} 30^{\prime \prime}$ \\
\hline 15 & Terminal Fundão - Terminal Presidente Vargas (Parador) & 30.8 & 78 & 23.7 & 25 & $2 \cdot 25 "$ \\
\hline 16 & Terminal Fundão - Terminal Presidente Vargas (Direto) & 30.8 & 72 & 25.7 & 4 & $15^{\prime} 00^{\prime \prime}$ \\
\hline 17 & Terminal Penha - I.N.T.O. (Parador) & 23.2 & 62 & 22.4 & 50 & 1'15" \\
\hline 18 & Terminal Penha - Terminal Gasômetro (Direto) & 25.2 & 64 & 23.6 & 8 & 7'30" \\
\hline 19 & Terminal Penha - Terminal Presidente Vargas (Direto) & 35.8 & 88 & 24.4 & 24 & 2'30" \\
\hline
\end{tabular}

Source: Logit (2014, p.44-45). * Values refer to both-way trip. 


\section{Conclusion}

\subsection{Thesis Summary}

Questions of transport accessibility have long been a central topic in transport studies. The evaluation of the accessibility impacts of transport policies has been attracting growing attention in recent years as equity is increasingly recognized as a priority for urban and transport planning. The growing interest in the implications of transportation projects for social and spatial inequalities means that a more theoretically grounded understanding of justice is needed to inform both policy planning and evaluation (Lucas et al., 2015; van Wee \& Geurs, 2011). To date, most of the research on this topic has paid little attention to theories of distributive justice. The first aim of this thesis was to contribute to the literature by proposing a theoretical framework that can help guide the assessment of the distributive effects of transportation policy outcomes in terms of how they shape inequalities in accessibility. In the first part, chapter 2 reviewed the literature on transportation equity and some of the most influential theories of justice from modern political philosophy. Building a dialogue between Rawls's theory of justice and capability approaches, this chapter put forward a theoretical framework to analyze the distributive effects of transportation policies on accessibility to opportunities. This concern with the accessibility impacts of transport policies is particularly important from an equity point of view for at least two reasons. First, accessibility has an instrumental role for people to satisfy their basic needs and develop their capabilities. Second, the idea of accessibility helps to draw out the spatial dimension in moral concerns over freedom of choice and equality of opportunities. These are central concerns 
of political philosophers, who have not traced out the spatial implications of these concerns so far.

A spatial consideration of freedom of choice and equality of opportunity needs to consider the dialectical relationship with the production of urban space and historical context (Soja, 2010), something that cannot be explained with the concept of accessibility alone. Nonetheless, the idea of spatial accessibility has played an important role in the works of various authors who previously tried to spatialize distributive theories of justice, including Rawls's theory (Dawkins, 2017; Galster, 2017; Harvey, 2009; Smith, 2000). While these studies have largely focused on equalization of the distribution of resources across spatial units (e.g., neighborhoods or regions), the framework developed in this thesis focuses on the role of governmental policies in expanding people's capability to access opportunities and reducing inequalities of accessibility via the prioritization of disadvantaged groups.

According to the theoretical framework proposed in this thesis, transport accessibility can be better understood as a combined human capability to (a) use mobile technologies and transport systems, and (b) reach desired places and opportunities. This is an important departure from the work of authors like Martens, for example, who conceives of transport accessibility as "personal resource" (Martens, 2016). Compared to other theoretically oriented literature on accessibility (Geurs \& van Wee, 2004; Lucas, 2012), the proposed conceptualization extends previous research by using the capabilities approach as a theoretical framework to understand how accessibility levels result from an interaction not only between transport systems and land use patterns, but also with individual characteristics and cultural norms. This framing of accessibility as capability (detailed in 
chapter 2) helps articulate how personal characteristics including preferences and skills interact with the social and built environment to enhance or restrict a person's ability to convert available resources into access to desired opportunities. By doing so, this conceptualization brings to light a more nuanced understanding of how interpersonal differences in accessibility levels are influenced by factors that are morally arbitrary, such as coming from a poor family, being elderly, disabled or of a certain gender or ethnic group, or even being struck by bad luck (illness, accident or temporary unemployment). These factors are morally arbitrary because they result from natural and social contingencies, and whether they put people in a relatively disadvantaged position given their specific social context is beyond anyone's control. It is widely accepted across various theories of justice that such factors should have no bearing on people's life chances and opportunities (Kymlicka, 2002). The conceptualization of accessibility as capability helps draw attention to how urban and transport policies are often set up in ways that lead those morally arbitrary factors to have detrimental effects on people's access to opportunities. While this conceptualization of accessibility brings a more nuanced theoretical understanding of accessibility, it also raises important empirical and policy challenges, as discussed in the next section.

The theoretical framework proposed in chapter 2 then draws on Rawls's two principles of justice to guide the fair allocation of governmental investments in transport infrastructure and services to improve people's accessibility. Following the first principle, transport projects can only be considered fair if their implementation respects people's basic rights and liberties, such as the physical and psychological liberty and integrity of the person. Contrary to a utilitarian argument, the violation of such rights and liberties cannot be justified on the grounds of the 'greater good' of improving accessibility levels of large 
numbers of people. Following the second principle, transport policies should prioritize improving the accessibility levels of disadvantaged groups whose transport conditions are systematically undermined by those morally arbitrary factors, and thus contribute to reducing inequality of opportunities. The theoretical framework proposed in this chapter thus urges researchers and practitioners to move beyond descriptive cross-sectional analysis of accessibility inequalities and to reflect on how governmental policies should be arranged to promote fairer and more inclusive cities and mobility systems. Compared to previous transport studies that engage with Rawls's theory (Khisty, 1996; Marlin, 1989; Tyler, 2006; van Wee \& Geurs, 2011), this thesis provides a thorough discussion of how Rawls's principles of justice can be applied to the distribution of accessibility benefits of transport policies and by shifting the focus from the distribution of transport goods and resources to accessibility as capability.

The second aim of this thesis was to demonstrate how the proposed theoretical framework can be applied to a case study in a developing country and offer important policy insights. In chapters 3, 4 and 5, the framework was applied in a selective way, focusing on the Rawlsian interpretation of what constitutes a fair transport policy. This was due to the difficulties of operationalizing the concept of accessibility as capability with the available data. These difficulties raise important questions for future investigations, as discussed in the next section. The theoretical framework was used to evaluate the distributive effects of transport policies on inequalities of access to various types of opportunities in Rio de Janeiro. In recent years, Rio has significantly expanded its public transport infrastructure in preparation to host mega-events, including the 2014 FIFA Football World Cup and the 2016 Olympic Games. This included a new light rail system, the expansion of a high-capacity 
subway line and three new BRT corridors, which altogether were promised to improve the transport conditions of low-income neighborhoods and become one of the main legacies of those mega-events. Nonetheless, one of the proposed BRT projects has not been built and the implementation of the other projects was followed by an economic crisis shortly after the 2016 Olympics, leading to a cutback in service levels in many areas of the city.

Even though this thesis was mainly focused on the accessibility impacts of the recent transport policies implemented in Rio, the negative effects of evictions/displacements that these projects had on the local community did not go unnoticed. It is not surprising that lowincome people are the ones who most often face home eviction due to urban development policies based on the organization of mega-events (Davis, 2011; Porter et al., 2009; Silvestre \& de Oliveira, 2012) and on the expansion of transport infrastructure in general (Ahmed et al., 2008; Patel et al., 2002). In the case of Rio de Janeiro presented in chapter 3, the transport investments related to mega-events led to the eviction of 2,125 households between 2009 and 2012, many of which involved human rights violations with physical and psychological violence by the police (CPCORJ, 2015; Gaffney, 2015a; Kommenda, 2016). Although Rawls's first principle of justice of respecting people's basic rights and liberties may be more commonly respected by policymakers in developed countries, the case of Rio shows that this is often not the case in the Global South. The displacement of low-income communities to create space for new transport investments is not an exception of projects to host megaevents like in Rio (Kassens-Noor \& Kayal, 2016; Melo, 2017; Stewart \& Rayner, 2016), although the magnitude of the investments related to these events can lead to much larger number of households affected. Displacement of poor communities is more often the norm than the exception, and it is consistent with urban planning regimes and institutionalized 
practices of transport planning that spare wealthier areas of the city from construction projects to the detriment of poorer communities. Because land costs related to home evictions are an important variable included in the bottom line of infrastructure projects, these projects are typically built where land prices are lower, leading to disproportionate impacts on poorer neighborhoods (Sanchez et al., 2003). This is a similar dynamic to the one observed in conventional project appraisal methods that implicitly favor transport investments that primarily benefit higher income groups, because of the ways in which the monetary valuation of travel time savings is commonly considered in cost-benefit analysis (Mackie et al., 2001; Martens \& Ciommo, 2017; van Wee, 2012).

The accessibility impacts of the transport legacy of mega-events in Rio were analyzed in the three empirical chapters of the thesis. In chapters 3 and 4, ex-post evaluations of the transport investments implemented in Rio were conducted using complementary perspectives by looking at accessibility from both activity place and individual perspectives. Based on catchment area analysis, chapter 3 showed how transport policies recently implemented in the city affected the number of people from different income levels who could access Olympic sports venues and healthcare facilities by public transport. In turn, Chapter 4 showed how the policies implemented in Rio changed the number of schools and jobs opportunities that people from different income levels could be reach via public transport and walking. Both studies included a before-and-after comparison of Rio's transport network (2014-2017), considering the accessibility effects of the recent expansion of transport infrastructure as well as the reduction in bus service levels that followed the economic crisis that hit the city after the Olympics. Additionally, these chapters included quasi-counterfactual analyses that allowed to empirically separate the effects of newly 
added infrastructure from the reorganization and cuts in transport services caused by the recent economic meltdown in the city. Finally, chapter 5 illustrated how the accessibility methods used in the previous chapters can also be deployed in the ex-ante evaluation of transport policy scenarios still in their early planning stages. In this chapter, I complemented the evaluation of the transport legacy of mega-events in Rio by examining the likely distributive effects of the as-yet unfinished TransBrasil BRT project on access to job opportunities.

The findings of these chapters suggest that, had the city not been hit by the economic crisis, the transport investments implemented in Rio between 2014 and 2017 would have only marginally improved people's access to healthcare facilities. Nonetheless, the expansion of transportation infrastructure alone would have significantly increased the number of people who could access the Olympic sports venues, and the number of schools and jobs accessible to the population. However, the subsequent rationalization of bus routes and reduction in service levels aggravated by the economic crisis have generally offset the shortterm accessibility benefits from Rio's transport legacy in a way that particularly penalizes the poor. As a result, most sports venues and high-complexity healthcare facilities have become less accessible via public transport and average access to jobs and schools dropped by approximately $4.5 \%$ and $6.1 \%$ between 2014 and 2017. In any scenario, these results contradict the official promises of Rio's transport legacy and point to a distribution of accessibility benefits that can be considered inequitable from a Rawlsian point of view. The accessibility benefits from the recent cycle of investments and disinvestments in Rio generally accrued to middle- and higher-income groups and reinforced rather than reduced socio-spatial inequalities in access to opportunities. While in 2014, the level of access to jobs 
were $84 \%$ larger for the richest $20 \%$ than for the poorest $20 \%$, this difference rose to $116 \%$ in 2017. In contrast to the findings of chapters 3 and 4, the results of chapter 5 indicate that the planned TransBrasil BRT project will stand out as a far more equitable investment than the transport policies implemented in the 2014-2017 period. The evaluation of the future accessibility impacts of the proposed BRT corridor suggests that it will promote significantly larger accessibility gains for lower-income groups than for wealthier families, thus helping to reduce inequalities in access to employment opportunities. From a Rawlsian standpoint, this is a much more desirable policy outcome than what happened with the other recent policies implemented in Rio. This is largely because, compared to the other transport investments, the future layout of the TransBrasil BRT is much more effective in connecting low-income neighborhoods with high population density to areas of high employment concentration, particularly in the city center.

Together, these chapters provide important insights about the implications of the legacy of mega-events and transport inequalities. On the one hand, it is fair to say that the mega-events agenda of Rio de Janeiro helped the city leverage substantial investments to expand its urban and transportation infrastructure. On the other hand, the apparent alignment of this relative abundance of resources with the long-term developmental goals of Rio has clearly been an insufficient condition to create a positive legacy for poorer communities. The one BRT project that could lead to substantial accessibility gains to lowincome families became a low priority during the preparation for the mega-events. Moreover, the fact that those transport investments remained limited within the administrative boundaries of the municipality of Rio de Janeiro indicates how the transport planning in the region in recent years has been influenced by the short-term needs of the 
events. It points to how the state of Rio de Janeiro missed the opportunity to use the political momentum around recent mega-events to deliver transport investments that could better integrate the large poor communities living in the peripheral municipalities and overcome the fragmentation of metropolitan planning.

The findings of chapters 3 and 4 also draw attention to how the subsequent reorganization and cuts in transport services intensified inequalities in access to opportunities in Rio. The reduced investments in Rio de Janeiro's public transport network after the 2016 Olympics have offset the short-term accessibility benefits from recent infrastructure expansion, with particularly detrimental effects on the accessibility levels of poor neighborhoods. These changes in service levels were in part a result of a market-driven reorganization of bus lines/companies in response to a reduction in passenger demand due to the rise of unemployment in the city, but they were also partially planned by the local government to accommodate the newly added infrastructure and streamline the transport system. These findings point to the ways in which network configurations get reworked under a market-oriented approach, drawing attention to how the political-economy of infrastructure shapes the social fragmentation and splintering of urban spaces (Graham, 2000; Graham \& Marvin, 2001). While the construction of new transport infrastructure attracts extensive media attention is discursively constituted as the legacy of mega-events, much less attention has been paid to what happened to the level of transport services across the city after the events had ended. The study of Rio illustrates how the accessibility impact of a reorganization of service levels can be as big as the impact resulting from an expansion of physical infrastructure. In order to deliver a positive legacy, future policies need to look beyond the spatial allocation of new infrastructure and its connection to land use and the 
rest of the transport network. Careful attention also needs to be paid to whether the service levels are sustained and how the subsequent reorganization of feeder lines impacts people's access to opportunities, particularly among disadvantaged communities.

Finally, the third aim of this thesis was to investigate whether the equity assessment of transport projects and their impacts on people's accessibility are sensitive to the temporal and spatial scales of accessibility analysis. This aim was addressed in chapters 4 and 5 , where careful empirical analyses were conducted to measure the accessibility impacts of Rio's mega-event transport legacy, respectively, at multiple spatial scales and zoning schemes, and under various travel-time thresholds (30,60, 90 and 120 minutes). Together, the findings of chapters 4 and 5 show that the equity assessments of transportation projects based on cumulative opportunity metrics are subject to both the modifiable areal unit problem (MAUP) and the modifiable temporal unit problem (MTUP). Both the size of the accessibility impacts of the analyzed policies in Rio as well as their distribution across income groups and statistical significance vary substantially depending on spatial scales and aerial units of analysis and on what time threshold is chosen for the cumulative-opportunity measure. While previous studies have documented how the ad-hoc ways in which data are organized in space can influence the conclusions of empirical analyses and subsequent policy recommendations, (Kwan \& Weber, 2008), far less attention has been paid to how those conclusions can be affected by the temporal dimension of data (Coltekin et al., 2011). This thesis thus extends the work of other researchers, who have previously considered only the effect of MAUP on accessibility analysis but overlooked the implication of MUTP, and it found that both issues can affect the equity assessment of transport projects. 
These findings raise important implications/questions for research and policy. They suggest that the conclusions of equity assessments of projects based on cumulative opportunity measures depend on the methodological choices regarding how the data are spatially organized and the cutoff travel time used in the accessibility analysis. In other words, they suggest that the most common practice adopted by academic studies and transport agencies when evaluating the accessibility impacts of transportation projects can lead to misleading or partial conclusions if these methodological choices are made uncritically. There is currently no standard approach to deal with MTUP nor MAUP. One way to minimize MTUP when working with cumulative opportunity measures could be to estimate accessibility levels under various travel-time thresholds and then calculate the weighted average accessibility of different income groups considering all of those thresholds. Although this approach avoids the arbitrariness involved in choosing a single time threshold, it still requires some ad-hoc decision on which and how many cut-off points should be considered. Two common approaches to deal with MAUP are to use an 'optimal zoning scheme' that would capture the underlying processes that are being investigated (Openshaw, 1977), or to work with disaggregate/point data in continuous surfaces and avoid using aggregated data (Fotheringham \& Wong, 1991). As noted by Fotheringham and Wong (1991), however, it seems unlikely that a truly objective optimal zoning scheme can be formulated. Moreover, the use of disaggregate/point data is not a viable solution for many types of analyses and it merely introduces other sorts of error, such as inaccuracy, and distortion (Openshaw, 1996). An alternative approach to mitigated uncertainties generated by MAUP is to move towards scale-independent accessibility metrics that that are not influenced by how data are organized with respect to space (Kwan \& Schwanen, 2018). In 
transport accessibility analysis, the work of Kwan and Weber (2008) has demonstrated this can be achieved with more sophisticated space-time accessibility measures, but further research is needed to investigate whether this type of accessibility metric could also overcome the modifiable temporal unit problem (MTUP). In any case, space-time accessibility analysis also requires high-resolution space-time data that is often not readily available. The case study of the city of Rio illustrates how, in the absence of such detailed data, it is important to conduct sensitivity analysis to make sure the conclusions of project evaluations are not simply artifacts resulting from ad-hoc methodological choices.

In summary, this thesis has moved beyond descriptive analysis of accessibility inequalities and it has developed a distributive justice framework that articulates a moral argument against which to judge the fairness of transport policies. It has applied this framework to analyze the equity impacts of transport policies in a major city of an emerging economy, a context which has received significantly less attention from the literature on transportation equity than European and North American cities. The empirical application of the proposed framework, even if partial, helps illustrate how the framework is flexible enough to accommodate universalist concerns about the protection of basics rights and promotion of equality of opportunities without losing sight of context-specific issues regarding the particularities of the urban context and the policies under scrutiny. The empirical chapters of this thesis have stablished that, overall, the transport policies implemented in Rio de Janeiro between 2014 and 2017 have had inequitable outcomes. These policies have violated the basic rights and liberties of local communities and increased social and spatial inequalities in access to opportunities, going against both of Rawls's principles of justice. The yet to be completed TransBrasil BRT project can be an exception to 
this outcome because the likely accessibility benefits of this corridor will be more progressively distributed, favoring lower-income groups. Furthermore, the empirical chapters have also demonstrated how the equity assessment of transport projects and their impacts on people's accessibility are sensitive to methodological choices regarding the temporal and spatial scales of accessibility analysis when using cumulative opportunity measures, something that have gone unnoticed in the academic and policy literatures.

\subsection{Reflections on emerging issues}

In this section I reflect on a few issues that emerged during my doctoral research and on the potential research avenues they open. One important limitation of this thesis is that the theoretical framework proposed in chapter 2 could only be partially applied in the subsequent empirical chapters. While the case study of the transport legacy of mega-events in Rio de Janeiro was largely guided through my own interpretation of Rawls's theory of justice, the empirical analysis put aside much of the discussion that could have emerged from adopting a capabilities approach lens. The first and most important reason for this lies in the challenges of measuring accessibility that arise from a more comprehensive understanding of accessibility as capability. If on the one hand the framing of accessibility as capability brings more conceptual nuance and richer understandings of personal accessibility, on the other hand it raises serious challenges about how to operationalize accessibility metrics in a way that accounts for those nuances. These challenges result largely from the difficulty in capturing how the interaction between the social and built environments and certain personal characteristics - such as physical and mental fitness, motor and cognitive skills - 
affect people's different capabilities that are necessary to use certain transport modes and navigate the transport system. This type of information is not collected in conventional transport surveys, which ends up limiting the possibility of developing more refined measurements of individual accessibility. Moreover, the qualitative methods and questionnaire surveys used in the literature to capture these types of information and discuss questions of capability related to transportation (Nordbakke, 2013; Ryan et al., 2015; Yang \& Day, 2016) would be either too costly or unpractical to apply in large urban areas like Rio without significant loss of spatial granularity.

This issue suggests that future research that aims to deepen the understanding of transport accessibility as a human capability will have to overcome a major challenge of data collection. This will probably require lots of resources and/or creativity to go beyond the limits imposed by conventional transport surveys and to capture for large population samples other factors that shape individuals' accessibility, such as their cognitive and embodied competencies, time constraints, social and cultural norms. Once these types of information are available, future studies will be better equipped to investigate, for example, how and to what extent different levels of accessibility relate to travel needs, travel practices and well-being under a capability framework. This will likely require researchers to develop empirical analyses based on more sophisticated accessibility measures that can better capture how interpersonal differences in accessibility are influenced by the interaction between personal characteristics and the social and built environments. Place-based accessibility measures are not up to this task. Good candidates include a range of peoplebased accessibility measures (Kwan, 1998; Neutens et al., 2010), such as activity based accessibility (Nahmias-Biran \& Shiftan, 2016) and space-time accessibility measures (Kwan 
\& Weber, 2008). Even these measures, however, might not go far enough in capturing for example how social-cultural context and social expectations shape people's travel-horizons (Wixey et al., 2003).

The second reason why the capabilities approach has been sidestepped in the empirical analysis of this thesis was that it would require a deeper political debate about basic capabilities, a debate which falls beyond the scope of this research. If one recalls the theoretical framework proposed in chapter 2, some of the core ideas in the capabilities approach suggest that a research agenda on transportation equity should go beyond egalitarian concerns for reducing inequalities of opportunity. It should also involve sufficientarian concerns related to a minimum necessary level of accessibility to key destinations so that people can satisfy their basic needs and exercise basic rights, such as going to school, receiving healthcare, and voting in elections. What the ideas of basic capability and sufficientarian concern more broadly imply is that people are in some way considered to be socially excluded if their accessibility level falls below a certain minimum acceptable threshold (Lucas et al., 2015). Thus, a deeper discussion of capabilities in transport studies requires not only a more refined method to measure accessibility as a capability. First, it also requires the definition of which capabilities should be considered as basic capabilities, those without which "life [is] not worthy of human dignity" (Nussbaum, 2011, p.31). And second, it requires the definition of what should be an acceptable minimum threshold of access to those basic capabilities. Even among capability scholars, however, there is an unresolved debate about whether researchers and policymakers would be legitimate actors to decide on a list of basic capabilities and what would be the minimum acceptable thresholds. 
One element that makes this discussion particularly complex is that there will hardly be a single threshold universally adopted, and any threshold will be highly dependent on the heterogeneity of people's needs and acceptable cultural norms and living standards across societies. A related issue is the extent to which these thresholds should consider personal preferences and choices - for example, when a person has voluntarily chosen to live in a location with low accessibility (van Wee, 2016) - and whether it is always possible to distinguish voluntary from involuntary low accessibility levels. Moreover, the operationalization of such minimum thresholds would probably be different according to trip purposes and transport modes. It could take many forms, including options based on a minimum number of accessible opportunities, or based on at least one opportunity that is accessible given some minimum service parameters of reliability, safety, frequency etc. or under a maximum range of acceptable travel cost (either monetary or in terms of time or distance) (Hananel \& Berechman, 2016; Smith et al., 2012), or some combination of these. One challenge here is to develop a new type of metric that captures more than physical accessibility and takes into account individuals' abilities, constraints, priorities, time, needs, experiences, and so forth. Another challenge for defining minimum accessibility thresholds is to move beyond an operational limitation of most accessibility metrics that measure the attractiveness of a given location based solely in quantitative terms. This requires one to consider, for example, that the satisfaction of people's needs is influenced not only by how many opportunities are accessible, but also by the qualitative characteristics of those opportunities (e.g. school quality) and of the trip to access them (e.g. a passenger's comfort and perceived safety in public transport). When it comes to the discussion on minimum accessibility thresholds, there is no one-size-fits-all approach and future research on this 
topic will have to argue why certain methods and accessibility measures are more or less appropriate to the specific research contexts, questions and basic capabilities under analysis.

Advances in the transportation equity debate need to go beyond technical aspects of measuring accessibility. Scholars working on this topic should engage more directly with normative questions about which activities should be considered essential and what an "adequate" level of accessibility to those activities means. Ultimately, this is as much a political decision as it is a moral issue, one that deeply reflects the vision of a just city and mobility system each society aspires to build. In the pursuit of this vision, a democratic society needs to seriously consider the role of participatory planning in the building of legitimate political processes/decisions. However, it also requires acknowledging that the recognition of rights and prioritization of policies are themselves the result of historical struggles and power imbalances between social groups with different visions of what constitutes a just city.

\subsection{Future Research}

The research presented in this thesis could be expanded in different directions. One that immediately follows from a limitation of this thesis is the need to deepen the understanding of transport accessibility as a human capability. From a theoretical standpoint, a promising research avenue would be to explore the links between the idea of accessibility as capability and theories of practice (Watson, 2012). Little attention has been paid to how practice theory and the capabilities approach can inform one another in transport studies. Nonetheless, the growing literature on practice theory could provide valuable conceptual tools to discuss how 
structures of social practices and mobility systems condition people's accessibility capability and mobility functioning, what could cast light on the (dis)connections between different levels of accessibility and travel behavior patterns in various cultural contexts.

Another research avenue would be to explore the similarities and differences between the idea of accessibility as capability and the broader concept of motility, originally developed by Kaufmann (2004). There are important commonalities between these two concepts, but new studies are needed to discuss the differences and complementarities between them and to explore how the notion of motility itself can have value as a policy objective and help advance the debate on transport justice (Shliselberg \& Givoni, 2018). Like the notion of accessibility as capability, the concept of motility brings a nuanced understanding of the various factors that influence a persons' capacity to be mobile, including physical capacities, social conditions of access to existing transportation systems, and acquired skills. Nonetheless, the concept of motility goes further than the idea of accessibility in different ways. For example, the concept of motility draws attention to the fact that a person's potential to be mobile is also shaped by her plans, aptitudes, habits and aspirations (Kaufmann et al., 2017), something that is largely overlooked in the transport accessibility literature. These 'plans' are influenced by social context and social expectations and they play a key role in shaping the extent to which people are willing to mobilize their skills and resources to appropriate the accessibility potential that might be available to them and convert it in actual mobility. In this sense, the concept of motility is related to but broader than the issue of 'adaptive preferences', a concept that is discussed in capabilities studies (Nussbaum, 2006; Shin, 2011) and which refers to how people sometimes adjust their preferences/ambitions to conform to what social/cultural norms define as normal or 
acceptable for someone like them. A deeper engagement with the motility concept could help bring more behavioral realism into the transportation equity literature and raise important questions regarding choice and agency in future research concerned with inequalities in accessibility and travel behavior. Moreover, while the notion of accessibility as capability is rooted in liberal political philosophy, the concept of motility could allow more flexibility for future investigations on transportation equity to build closer dialogues with other strands of justice theory (e.g. feminist, communitarian) and overcome some of the limitations of liberal theories of distributive justice. Finally, the mobilization of the ideas of accessibility as capability and motility to discuss transport justice still needs to overcome significant empirical constraints, despite recent advances in the operationalization of these concepts (Flamm \& Kaufmann, 2006; Kaufmann et al., 2017; Ryan et al., 2015; Yang \& Day, 2016). Nonetheless, there are good reasons to mobilize these concepts to advance the theoretical debate of the transportation equity literature, which should inform future data collection in order to overcome the constraints imposed by the current practices of data gathering.

Other research directions include finding better ways to incorporate justice concerns in transportation planning and evaluation beyond looking at the distribution of accessibility impacts as explored in this thesis. Recent developments in accessibility modeling are opening new possibilities to improve participation of local communities in accessibilitybased transport planning through digital interactive tools and collaborative scenario building (Stewart, 2017). Nonetheless, more research is required to understand if and to what extent these new technologies can effectively help communities overcome asymmetries in political voice or if these technologies will end up reinforcing the ability of some groups to influence political processes more than others. Moreover, many questions 
about how to incorporate accessibility evaluations and ethical concerns into wider evaluation frameworks such as cost-benefit analysis (CBA) and multi-criteria analysis (MCA) remain open (Thomopoulos \& Grant-Muller, 2013; van Wee, 2016; van Wee \& Roeser, 2013). Despite recent efforts to incorporate equity concerns in CBA and MCA (Martens \& Ciommo, 2017; Taleai et al., 2014), it remains unclear whether utilitarian reasoning could be satisfactorily reconciled with both prioritarian and sufficientarian concerns, or whether the incorporation of equity in planning practices would require a more radical departure from those traditional appraisal approaches, and if so, how this new radical approach would look like.

This thesis and most of the transport geography literature try to objectively measure accessibility levels assuming that such metrics hold some relationship with or will help improve personal levels of wellbeing, activity participation etc. Further research is necessary to evaluate the extent to which objective accessibility gains promoted by transport policies influence subjectively experienced well-being and whether they actually improve social outcomes and reduce social exclusion. There is a substantial literature on the interplay of well-being, geographical context and travel behavior (De Vos et al., 2013; Schwanen \& Wang, 2014). However, there is still little understanding of the extent to which urban and transport policies can influence subjective well-being through marginal increases in accessibility to opportunities and travel time savings. This strand of investigation would need a much better understanding of how and to what extent objective measures of accessibility relate to subjectively perceived accessibility levels and to what extent they correspond to activity participation. These questions have thus far received relatively little attention in the literature and remain largely unanswered (Cascetta et al., 2013; Curl et al., 2015; Fransen et 
al., 2018). Future studies could investigate, for example, how the association between activity participation levels and perceived and objectively measured accessibility varies across the population and to what extent this variation is affected by the built environment, the transport system and people's sociodemographic characteristics and competencies (e.g. skills and abilities). Further in-depth research could also be conducted with individuals who experience some form of dissonance (e.g. low level of subjective accessibility but high objective accessibility). This type of investigation could shed light on how travel behavior is influenced by factors such as geographical and social context, personal attitudes and preferences, and possibly open new questions related to the role of transportation in social exclusion.

Moreover, while the academic literature has often recognized that increasing physical mobility and accessibility are cause and effect of social mobility (Chetty et al., 2014; Kaufmann et al., 2004; Kronlid, 2008; Lucas, 2012), only a few studies have developed robust identification strategies to measure how accessibility gains from transport policies have impacted employment and educational outcomes (Cervero et al., 2002; Dawkins et al., 2015; Muralidharan \& Prakash, 2017). Implicit in most of this literature, and to some extent in the empirical chapters of this thesis, is this idea that promoting greater access to opportunities for disadvantaged groups will in the long run improve their social and economic outcomes and contribute to reducing inequalities. Nonetheless, there is still little understanding of how much of people's social mobility is determined by their geographical context and public transport accessibility levels amid a myriad of other variables. Much more research is needed to understand to what extent and under which circumstances urban and transport policies can effectively improve those chances, particularly for disadvantaged groups. 
Another interesting avenue of research would be to reflect on how questions of transportation equity related to accessibility will be impacted by the future changes in the transport planning sector driven by automation and shared mobility systems. In the coming decades, the transport industry will increasingly rely on algorithms to support the planning, management and allocation of autonomous vehicles and mobility services, for example with the use of artificial intelligence and big data predictive modeling to develop flexible routing and scheduling of services (Shaheen et al., 2018). There is a growing awareness of the ways in which big data and algorithms often reflect the biases underlying broader social and political processes (Crawford, 2013; Kwan, 2016; Veale \& Ribas, 2017). The lack of critical reflection and algorithmic transparency raises the risk of decision-making processes that inadvertently reflect those biases and end up reinforcing injustices. In the transportation sector, algorithmic discrimination has already been documented, for example, with the racial bias underlying Amazon's delivery system in North American cities (Ingold \& Soper, 2016). While much of the current research on autonomous vehicles and shared mobility systems focuses on how to make them commercially viable, future research will be needed to understand how these changes in technology and governance will reshape who gets access, when, and how, and what implications they might have for questions of equity, public health and environmental justice. Much of this research could already benefit from ongoing discussions on the ethics behind the use of big data and algorithms in the governance of emerging smart cities (Brauneis \& Goodman, 2017; Kitchin, 2016) and autonomous vehicles (Mladenovic \& McPherson, 2016; Papa \& Ferreira, 2018; Shariff et al., 2017).

Furthermore, questions of intergenerational justice have been largely overlooked in this thesis and in the transportation equity literature more generally and should receive 
more attention in future research. Equity among generations is regarded as integral to the definition of sustainability (Holden et al., 2018) and it generally relates to the impacts and consequences of some decisions made by present generations that may affect future generations (Bullard, 2003; van Wee \& Roeser, 2013). It involves, for example, how present decisions on funding transport infrastructure carry costs to future generations (Banister, 1994; Jonsson, 2008) and also the environmental burden that is left to future generations by present travel behavior (Greene \& Wegener, 1997; Holden et al., 2013). Questions of intergenerational justice will become increasingly important as the depletion of oil resources and climate change compel societies to rethink urban and mobility systems in a transition to a low-carbon future (Newell \& Mulvaney, 2013). To some extent, this debate is being incorporated in an emerging literature on mobility transitions (Temenos et al., 2017). Nonetheless, the idea of intergenerational justice raises important and broader questions of environmental justice between generations not only at the local level, but also on a global scale, which have received little attention in the literature on transportation equity and mobility transitions (Nixon \& Schwanen, 2018). These questions should receive much more attention in future research. The challenge of building just mobility transitions will require further critical investigation of who the winners and losers are from emerging initiatives and policies towards low-carbon mobility systems, now and in the future.

While this thesis focused on the distributive aspects of transportation equity, there is more to justice than just distribution. Much research still needs to be done to address the distributive implications of governmental policies while critically examining the political processes and institutional context that determine those distributive patterns (Davoudi \& Brooks, 2014; Young, 1990). This calls for further efforts to expand the social justice agenda 
in urban and transport studies and develop theoretical frameworks that accommodate equity with concerns related to democracy and diversity within the realm of urban and transport policies and beyond them (Fainstein, 2010).

While the literature on transportation equity has traditionally focused on the political processes and outcomes of government policies, more attention should be paid to grassroots movements outside formal institutional settings. This is the case, for example, of the paper of Verlinghieri and Venturini (2017), who analyzed how urban social movements that frame their struggle around the ideas of the 'right to the city' and 'the right to mobility' played a central role in the wave of protests that swept through Brazil in 2013. Another example is the research of Nixon and Schwanen (2018), who show that community initiatives working to provide or enhance infrastructures for cycling and walking in the cities of London and São Paulo are motivated by complex and multi-scalar conceptions of justice that are not fully captured by the recent literature on transport and mobilities justice. A broader understanding of justice will require researchers to look at the role of these community-led initiatives in the creation of more inclusive cities and mobility systems, particularly as they can complement or challenge existing government policies, or because they fill a gap where there is a lack of governmental action.

As researchers deepen this agenda, questions about social conflicts and the politics of space come to the fore. This is largely because the notion of a polycentric democracy entails multiple political actors with competing visions and claims about what a "good city" should be and how urban commons such as public spaces and public transportation should be organized. The research on the role of grassroots movements in the promotion of more just 
and inclusive cities raises a question about whether it is possible and desirable to develop a theory of the 'just city' detached from a theory of the 'good city' (Amin, 2006; Fainstein, 2010; Marcuse et al., 2009; Smith, 1997). For liberal philosophers like Rawls and Sen, a theory of justice should be independent from the normative debate of what a good life should be. Because individuals often do not share one another's ideals of what a good life is, liberal philosophers argue that the state should not enforce a particular conception of the good life on people but provide them with the conditions to pursue their own (justice-respecting) way of life. Contrasting perspectives, however, can be found in the critical scholarship on spatial, feminist and communitarian theories of justice (Fraser, 2003; Harvey, 2013; Kymlicka, 2002) and in the literature on the right to the city and self-management (Purcell, 2014), which have not been discussed in this thesis but which could bring important insights into this discussion in future investigations.

\subsection{Policy recommendations}

The set of studies presented in this thesis provide insights and guidance to researchers and policymakers who are interested in the equity assessment of transportation projects and their accessibility impacts, and to those particularly working with transport planning in Rio de Janeiro. Better methods of accessibility modeling and spatial data analysis like the ones deployed in this study can help policymakers make better decisions. If these methods are incorporated alongside traditional practices of transport project appraisal such as CBA, this can lead to incremental but important improvements in the ability of decision makers to assess the accessibility impacts of transport projects, either ex-post or ex-ante. Even in those 
contexts where the process of transport planning and decision making is dominated by politicized power, better analytical methods have an important role to play in informing advocacy groups and grassroots movements and in increasing accountability on the distributional effects of transport policies.

All the analyses presented in this thesis were conducted using open-source software, so the main bottlenecks for reproducing these types of analyses in other contexts are the availability of human capital and good quality data. This means a wider institutionalized culture of open data could help local authorities and social organizations to incorporate the types of analyses presented in this thesis into their project evaluation practices. This points to the need for an effort from urban development and transport agencies to systematically collect, store and share the data on land use and transport systems in their regions. Social organizations and academic groups have also demonstrated they can contribute to the collection and dissemination of public transport data, including on informal transport services, which often operate below the radar of local authorities (Eros et al., 2014; Williams et al., 2015).

My experience with the research in Rio revealed how challenging it can be to access the GTFS and GPS data of a transport system in a city where there is poor integration of transport policies and data management at the metropolitan scale. A lesson for transport agencies elsewhere is that they should make the intellectual property rights of the transport data belong to local authorizes, and not to the transport service operators like it is the case in Rio. Transport agencies should also institutionalize the practice of keeping historical GPS and GTFS data feeds from previous years, which could be a valuable resource for long-term 
analysis and planning. The equity and accessibility analysis of transport systems could also be enhanced if information of ridership and fare revenues were made publicly available by transport agencies. Moreover, local authorities in Rio and elsewhere should more actively collect other types of information about factors that affect passengers' well-being and ability to use the transport system, including information about passengers with physical disabilities and passengers who have experienced harassment and other types of violence in the transport system. In different ways, the experience of Rio points to different ways in which transport agencies elsewhere could improve their practices of data collection, management and sharing.

Another policy recommendation that can be drawn from the empirical analysis of this thesis is that local governments should better integrate transport and land use planning in order to more effectively improve people's access to opportunities, particularly among disadvantaged communities. Although this is not exactly an original policy recommendation, the case study of Rio de Janeiro aptly illustrates some of the benefits of this integration. That case has shown that given a particular city and transport system, levels of accessibility to opportunities differ depending on the type of land use activity considered and respond differently to changes in the transport network. In Rio, the notion of accessibility to essential services has been explicitly embedded in the spatial planning of schools and health services, leading these activities to be much more spatially distributed across the city than employment opportunities, for example. This explains in large part why accessibility levels to schools and healthcare facilities were found to be substantially higher and more equally distributed than access to jobs in the city. It also explains why accessibility to schools and healthcare facilities were much less affected by the cuts in services that occurred in Rio de 
Janeiro. In other words, the integration between transport, land use and social policies can not only promote higher levels of access to opportunities, but also help make accessibility more resilient to eventual downgrades and disruptions to the transport network and service levels.

The empirical chapters of this thesis also serve as a cautionary tale about how the expansion of transport infrastructure is not sufficient to improve people's accessibility if new investments are not followed by corresponding improvements in service levels. New infrastructure investments often entail the reorganization of existing services and require higher government spending to maintain and run the added services. The findings of this thesis also illustrate for transport agencies that the reorganization of bus lines in terms of routes, frequency, etc. can in some cases be as effective as new infrastructure expansion in reshaping accessibility levels. These factors should not be neglected in discussions around the impacts of transportation projects, and the case of Rio has shown how such factors can be deeply affected by unexpected economic problems and the austerity measures that follow, with particularly negative consequences for the poor.

This thesis echoes the recommendations from other studies that planning authorities should incorporate justice concerns and accessibility studies in the evaluation of the impacts of transportation projects and consider their distributional effects. Although equity and accessibility analysis are gradually becoming common practices in developed countries (Boisjoly \& El-Geneidy, 2017; Manaugh et al., 2015; Papa et al., 2015), transport planning is still predominantly guided by four-step demand modeling and cost-benefit analysis, which are known to overlook accessibility benefits and distributional issues (Martens, 2016; van 
Wee, 2012). The study of the transport legacy of mega-events in Rio has shown that even celebrated projects and large investments do not necessarily deliver the expected accessibility benefits to low-income communities, which are typically more dependent on public transport. The empirical research of this thesis has illustrated how accessibility analysis can help inform transport policies with both ex-post assessment of transport projects and ex-ante simulation of the accessibility impacts of different project scenarios in the early phases of transport planning.

Finally, this thesis has shown that methodological choices regarding the temporal and spatial scales of accessibility analysis commonly used in the literature to assess the equity impacts of transportation projects can have important but little discussed implications for policy evaluation. Most the of the accessibility evaluations of transport projects conducted by academics and transport authorities are based on cumulative opportunity measures, mainly because they are easy to communicate and have few data requirements (Boisjoly \& El-Geneidy, 2017; Papa et al., 2015). As a rule, however, these evaluations are based on accessibility estimates that are calculated using a single spatial scale and zoning scheme and a single travel-time threshold, usually between 30 and 60 minutes. Previous studies have found that accessibility estimates are susceptible to the modifiable area unit problem (MAUP) (Omer, 2006; Ortega et al., 2012) and its analogue the modifiable temporal unit problem (MTUP) (Palmateer et al., 2016). This thesis extends previous work by demonstrating how these two types of problems can affect the equity assessment of the distributive impacts of transport policies on accessibility inequalities. Arguably, there is no single method that is best for every transportation project, trip purpose, social group and urban context. The findings of this thesis thus suggest that future evaluations of the 
distributive effects of transport policies on accessibility should conduct sensitivity analysis to test whether results are robust to different choices of time threshold, spatial scales and zoning schemes. Ideally, sensitivity analysis should also consider different methods to measure accessibility levels so that researchers can evaluate the tradeoff between scientific soundness of accessibility metrics and the ease of communicating the results (van Wee, 2016). The use of sensitivity analysis in the evaluation of the accessibility impacts of a transport project, however, generates a greater number of results, which might be harder to communicate to policymakers and others who lack the in-depth technical knowledge to make sense of the different results. Another important point here is to prevent advocates of a certain position from opportunistically choosing the results that support their arguments. One alternative would be to gather the results from different data or parameter configurations and communicate them as bandwidths that reflect the level of uncertainty about the estimated accessibility impacts. This alternative also does not exclude the possibility of having various research teams to conduct their evaluations independently.

These are a few possible directions in which the research presented is thesis could be expanded to meet the demand for better transportation policies. The prospects of urban growth and the persistent challenges of uneven urban development, particularly in the Global South, are indicative of the growing importance that integrated urban and transport planning will have in the development of more just cities and inclusive urban mobility systems. While the intention with this thesis was not to offer a blueprint of what a just transport policy should look like, I hope this work has provided some useful insights about how distributive justice concerns can be incorporated into the planning and evaluation of transport policies. 


\section{References}

Abe, M. A. (1975). Distributional Equity and Optimal Pricing of Urban Transport. Journal of Transport Economics and Policy, 9(2), 178-185.

Ahmed, Q. I., Lu, H., \& Ye, S. (2008). Urban transportation and equity: A case study of Beijing and Karachi. Transportation Research Part A: Policy and Practice, 42(1), 125-139. doi:10.1016/j.tra.2007.06.004

Akyelken, N. (2017). Mobility-Related Economic Exclusion: Accessibility and Commuting Patterns in Industrial Zones in Turkey. Social Inclusion, 5(4), 175-182.

Amin, A. (2006). The Good City. Urban Studies, 43(5-6), 1009-1023. doi:10.1080/00420980600676717

Anderson, P., Levinson, D., \& Parthasarathi, P. (2013). Accessibility Futures. Transactions in GIS, 17(5), 683-705. doi:10.1111/tgis.12024

Andranovich, G., \& Burbank, M. J. (2011). Contextualizing Olympic Legacies. Urban Geography, 32(6), 823-844. doi:10.2747/0272-3638.32.6.823

Andranovich, G., Burbank, M. J., \& Heying, C. H. (2001). Olympic Cities: Lessons Learned from Mega-Event Politics. Journal of Urban Affairs, 23(2), 113-131. doi:10.1111/07352166.00079

Anselin, L. (2010). Thirty years of spatial econometrics. Papers in Regional Science, 89(1), 325. doi:10.1111/j.1435-5957.2010.00279.x

Anselin, L., Syabri, I., \& Smirnov, O. (2002). Visualizing multivariate spatial correlation with dynamically linked windows. In New Tools for Spatial Data Analysis: Proceedings of the Specialist Meeting (p. 61801). Santa Barbara: Center for Spatially Integrated Social Science (CSISS), University of California. Retrieved from https://pdfs.semanticscholar.org/bfc5/e6683bf0d4d6ea197d95309d0545e8969e6 4.pdf

Apparicio, P., Abdelmajid, M., Riva, M., \& Shearmur, R. (2008). Comparing alternative approaches to measuring the geographical accessibility of urban health services: 
Distance types and aggregation-error issues. International Journal of Health Geographics, 7(1), 7. doi:10.1186/1476-072X-7-7

Appleyard, D., \& Lintell, M. (1972). The Environmental Quality of City Streets: The Residents' Viewpoint. Journal of the American Institute of Planners, 38(2), 84-101. doi:10.1080/01944367208977410

Armstrong, C. (2000). Philosophical Interpretation in the Work of Michael Walzer. Politics, 20(2), 87-92. doi:10.1111/1467-9256.00116

Armstrong, G., Hobbs, D., \& Lindsay, I. (2011). Calling the Shots The Pre-2012 London Olympic Contest. Urban Studies, 48(15), 3169-3184. doi:10.1177/0042098011422397

Attoh, K. A. (2012). The Transportation Disadvantaged and the Right to the City in Syracuse, New York. The Geographical Bulletin; Ypsilanti, 53(1), 1-19.

Baade, R. A. (1996). Professional Sports as Catalysts for Metropolitan Economic Development. Journal of Urban Affairs, 18(1), 1-17. doi:10.1111/j.14679906.1996.tb00361.x

Baade, R. A., \& Matheson, V. A. (2004). The Quest for the Cup: Assessing the Economic Impact of the World Cup. Regional Studies, 38(4), 343-354. doi:10.1080/03434002000213888

Banister, D. (1994). Equity and acceptability questions in internalising the social costs of transport, Internalising the social costs of transport. In OECD \& ECMT (Eds.), Internalising the Social Costs of Transport (pp. 153-175). Paris: OECD.

Banister, D. (2002). Transport Planning (2 edition.). London u.a.: Spon: Routledge.

Banister, D. (2008). The sustainable mobility paradigm. Transport Policy, 15(2), 73-80. doi:10.1016/j.tranpol.2007.10.005

Banister, D. (2018). Inequality In Transport. Alexandrine Press.

Banister, D., \& Hickman, R. (2006). How to design a more sustainable and fairer built environment: transport and communications. Intelligent Transport Systems, IEE Proceedings, 153(4), 276-291. doi:10.1049/ip-its:20060009

Barat, J. (1990). Rio de Janeiro Mass Transportation System: The Social Role Played by the Metro Lines. International Journal of Social Economics, 17(9), 25-40. doi:10.1108/EUM0000000000454 
Barbara, V. (2016, July 1). Brazil's Olympic Catastrophe. The New York Times. Retrieved from https://www.nytimes.com/2016/07/03/opinion/sunday/brazils-olympiccatastrophe.html

Barry, B. (1965). Political argument. London: Routledge \& Kegan Paul.

Basta, C. (2015). From justice in planning toward planning for justice: A capability approach. Planning Theory, 1473095215571399. doi:10.1177/1473095215571399

Benenson, I., Martens, K., Rofé, Y., \& Kwartler, A. (2011). Public transport versus private car GIS-based estimation of accessibility applied to the Tel Aviv metropolitan area. Annals of Regional Science, 47(3), 499-515. doi:10.1007/s00168-010-0392-6

Beyazit, E. (2011). Evaluating Social Justice in Transport: Lessons to be Learned from the Capability Approach. Transport Reviews, 31(1), 117-134. doi:10.1080/01441647.2010.504900

Bills, T., Sall, E., \& Walker, J. (2012). Activity-Based Travel Models and Transportation Equity Analysis. Transportation Research Record: Journal of the Transportation Research Board, 2320, 18-27. doi:10.3141/2320-03

Birch, C. P. D., Oom, S. P., \& Beecham, J. A. (2007). Rectangular and hexagonal grids used for observation, experiment and simulation in ecology. Ecological Modelling, 206(3), 347-359. doi:10.1016/j.ecolmodel.2007.03.041

Blair, N., Hine, J., \& Bukhari, S. M. A. (2013). Analysing the impact of network change on transport disadvantage: a GIS-based case study of Belfast. Journal of Transport Geography, 31, 192-200. doi:10.1016/j.jtrangeo.2013.06.015

Blanco, J., Lucas, K., Schafran, A., ... Apaolaza, R. (2018). Contested mobilities in the Latin American context. Journal of Transport Geography. doi:10.1016/j.jtrangeo.2018.01.006

BOC. (2009). Rio de Janeiro's Candidature File to host the 2016 Olympic and Paralympic Games (No. 1, 2 and 3). Brazilian Olympic Committee. Retrieved from http://www.rio2016.com/en/organising-committee/transparency/documents

Bocarejo, J. P., \& Oviedo, D. (2012). Transport accessibility and social inequities: a tool for identification of mobility needs and evaluation of transport investments. Journal of Transport Geography, 24, 142-154. doi:10.1016/j.jtrangeo.2011.12.004 
Boisjoly, G., \& El-Geneidy, A. (2016). Daily fluctuations in transit and job availability: A comparative assessment of time-sensitive accessibility measures. Journal of Transport Geography, 52, 73-81. doi:10.1016/j.jtrangeo.2016.03.004

Boisjoly, G., \& El-Geneidy, A. M. (2017). How to get there? A critical assessment of accessibility objectives and indicators in metropolitan transportation plans. Transport Policy, 55, 38-50. doi:10.1016/j.tranpol.2016.12.011

Boisjoly, G., \& Yengoh, G. T. (2017). Opening the door to social equity: local and participatory approaches to transportation planning in Montreal. European Transport Research Review, 9(3), 43. doi:10.1007/s12544-017-0258-4

Booth, C., \& Richardson, T. (2001). Placing the public in integrated transport planning. Transport Policy, 8(2), 141-149. doi:10.1016/S0967-070X(01)00004-X

Borges, B. (2016, December 5). Auto Viação Bangu decreta falência no Rio. Retrieved October 5 , 2017, from http://noticias.band.uol.com.br/cidades/rio/noticias/100000806203/auto-viacaobangu-decreta-falencia-apos-semana-turbulenta

Boschmann, E. E., \& Kwan, M.-P. (2008). Toward Socially Sustainable Urban Transportation: Progress and Potentials. International Journal of Sustainable Transportation, 2(3), 138-157. doi:10.1080/15568310701517265

Brauneis, R., \& Goodman, E. P. (2017). Algorithmic Transparency for the Smart City (SSRN Scholarly Paper No. ID 3012499). Rochester, NY: Social Science Research Network. Retrieved from https://papers.ssrn.com/abstract=3012499

Brazil. (2007). Assistência de Média e Alta Complexidade no SUS (No. 9). Brasília: Conselho Nacional de Secretários de Saúde. Retrieved from http://bvsms.saude.gov.br/bvs/publicacoes/colec_progestores_livro9.pdf

Brazil. (2009). Caderno de Legados Urbano e Ambiental. Rio 2016 Cidade Candidata. Sport Ministry. Retrieved from http://www.esporte.gov.br/arquivos/rio2016/cadernoLegadosUrbanoAmbiental.p df

Brenner, N., \& Schmid, C. (2014). The 'Urban Age' in Question. International Journal of Urban and Regional Research, 38(3), 731-755. doi:10.1111/1468-2427.12115 
Broudehoux, A.-M. (2007). Spectacular Beijing: The Conspicuous Construction of an Olympic Metropolis. Journal of Urban Affairs, 29(4), 383-399. doi:10.1111/j.14679906.2007.00352.x

Brownill, S., Keivani, R., \& Pereira, G. (2013). Olympic legacies and city development strategies in London and Rio; beyond the carnival mask? International Journal of Urban Sustainable Development, 5(2), 111-131. doi:10.1080/19463138.2013.840637

Bullard, R. D. (2003). Addressing Urban Transportation Equity in the United States. Fordham Urban Law Journal, 31, 1183.

Burbank, M. J., Andranovich, G., \& Heying, C. H. (2002). Mega-Events, Urban Development, and Public Policy. Review of Policy Research, 19(3), 179-202. doi:10.1111/j.15411338.2002.tb00301.x

Bureau, B., \& Glachant, M. (2011). Distributional effects of public transport policies in the Paris Region. Transport Policy, 18(5), 745-754. doi:10.1016/j.tranpol.2011.01.010

Câmara, P., \& Banister, D. (1993). Spatial inequalities in the provision of public transport in Latin American cities. Transport Reviews, 13(4), 351-373. doi:10.1080/01441649308716857

Candida, S. (2017, April 11). Perguntas e respostas sobre a retomada das obras do BRT Transbrasil. O Globo. Retrieved from https://oglobo.globo.com/rio/perguntasrespostas-sobre-retomada-das-obras-do-brt-transbrasil-21189095

Casas, I. (2007). Social exclusion and the disabled: An accessibility approach. Professional Geographer, 59(4), 463-477. doi:10.1111/j.1467-9272.2007.00635.x

Cascetta, E., Cartenì, A., \& Montanino, M. (2013). A New Measure of Accessibility based on Perceived Opportunities. Procedia - Social and Behavioral Sciences, 87, 117-132. doi:10.1016/j.sbspro.2013.10.598

Cass, N., Shove, E., \& Urry, J. (2005). Social exclusion, mobility and access. The Sociological Review, 53(3), 539-555. doi:10.1111/j.1467-954X.2005.00565.x

Castro, D. G., Gaffney, C., Novaes, P. R., ... Santos Junior, O. A. dos (Eds.). (2015). Rio de Janeiro: os impactos da Copa do Mundo 2014 e das Olimpíadas 2016 (1st ed.). Rio de Janeiro: Letra Capital,. 
Cervero, R. (2013). Linking urban transport and land use in developing countries. Journal of Transport and Land Use, 6(1), 7-24. doi:10.5198/jtlu.v6i1.425

Cervero, R., Sandoval, O., \& Landis, J. (2002). Transportation as a Stimulus of Welfare-toWork Private versus Public Mobility. Journal of Planning Education and Research, 22(1), 50-63. doi:10.1177/0739456X0202200105

Chakraborty, J. (2006). Evaluating the environmental justice impacts of transportation improvement projects in the US. Transportation Research Part D: Transport and Environment, 11(5), 315-323. doi:10.1016/j.trd.2006.06.003

Chalkley, B., \& Essex, S. (1999). Urban development through hosting international events: a history of the Olympic Games. Planning Perspectives, 14(4), 369-394. doi:10.1080/026654399364184

Chappelet, J.-L. (2012). Mega Sporting Event Legacies: A Multifaceted Concept. Papeles de Europa, 0(25), 76-86. doi:10.5209/rev_PADE.2012.n25.41096

Chappelet, J.-L., \& Junod, T. (2006). A tale of 3 Olympic cities: What can Turin learn from the Olympic legacy of other Alpine cities. Major Sport Events as Opportunity for Development. Valencia: Valencia Summit Proceedings.

Cheng, T., \& Adepeju, M. (2014). Modifiable Temporal Unit Problem (MTUP) and Its Effect on Space-Time Cluster Detection. PLOS ONE, 9(6), e100465. doi:10.1371/journal.pone.0100465

Chetty, R., Hendren, N., Kline, P., \& Saez, E. (2014). Where is the land of Opportunity? The Geography of Intergenerational Mobility in the United States. The Quarterly Journal of Economics, qju022. doi:10.1093/qje/qju022

Church, A., Frost, M., \& Sullivan, K. (2000). Transport and social exclusion in London. Transport Policy, 7(3), 195-205. doi:10.1016/S0967-070X(00)00024-X

Ciommo, F. D., \& Shiftan, Y. (2017). Transport equity analysis. Transport Reviews, 37(2), 139151. doi:10.1080/01441647.2017.1278647

Collins, A., Flynn, A., Munday, M., \& Roberts, A. (2007). Assessing the Environmental Consequences of Major Sporting Events: The 2003/04 FA Cup Final. Urban Studies, 44(3), 457-476. doi:10.1080/00420980601131878 
Collins, A., Jones, C., \& Munday, M. (2009). Assessing the environmental impacts of mega sporting events: Two options? Tourism Management, 30(6), 828-837. doi:10.1016/j.tourman.2008.12.006

Coltekin, A., Sabbata, S. D., Willi, C., ... Lacayo, M. (2011). Modifiable Temporal Unit Problem. Presented at the ISPRS/ICA workshop "Persistent problems in geographic visualization" (ICC2011), Paris. Retrieved from https://www.academia.edu/20157829/Modifiable_Temporal_Unit_Problem

Cook, N., \& Butz, D. (2015). Mobility Justice in the Context of Disaster. Mobilities, O(0), 1-20. doi:10.1080/17450101.2015.1047613

Cornelissen, S., Bob, U., \& Swart, K. (2011). Towards redefining the concept of legacy in relation to sport mega-events: Insights from the 2010 FIFA World Cup. Development Southern Africa, 28(3), 307-318. doi:10.1080/0376835X.2011.595990

Costa, M. A., Santos, M. A., Rahy, I. S., ... Silva, L. F. F. T. da. (2015). Caracterização e Quadros de Análise Comparativa da Governança Metropolitana no Brasil: análise comparativa das funções públicas de interesse comum (Componente 2) - RM do Rio de Janeiro (Relatório de Pesquisa). Rio de Janeiro: Institute for Applied Economic Research Ipea. $\quad$ Retrieved from http://www.ipea.gov.br/portal/index.php?option=com_content\&view=article\&id=2 6361

CPCORJ. (2015). Rio 2016 Olympics: The Exclusion Games - Mega-Events and Human Rights Violations in Rio de Janeiro Dossier. Rio de Janeiro: Comitê popular Copa e Olimpíadas Rio - World Cup and Olympics Popular Committee of Rio de Janeiro. Retrieved from https://comitepo pulario.files.wordpress.com/2016/03/dossiecomiterio2015_eng1.pdf

Crawford, K. (2013, April 1). The Hidden Biases in Big Data. Retrieved February 11, 2018, from https://hbr.org/2013/04/the-hidden-biases-in-big-data

Cresswell, T. (2006). The right to mobility: The production of mobility in the courtroom. Antipode, 38(4), 735-754. doi:10.1111/j.1467-8330.2006.00474.x

Cresswell, T. (2010). Towards a politics of mobility. Environment and Planning D: Society and Space, 28(1), 17 - 31. doi:10.1068/d11407 
Cuadros, A. (2016, August 1). The Broken Promise of the Rio Olympics. The Atlantic. Retrieved from http://www.theatlantic.com/international/archive/2016/08/building-barra-rioolympics-brazil/493697/

Curl, A., Nelson, J. D., \& Anable, J. (2015). Same question, different answer: A comparison of GIS-based journey time accessibility with self-reported measures from the National Travel Survey in England. Computers, Environment and Urban Systems, 49, 86-97. doi:10.1016/j.compenvurbsys.2013.10.006

Currie, G. (2010). Quantifying spatial gaps in public transport supply based on social needs. Journal of Transport Geography, 18(1), 31-41. doi:10.1016/j.jtrangeo.2008.12.002

Currie, G., Richardson, T., Smyth, P., ... Stanley, J. (2010). Investigating links between transport disadvantage, social exclusion and well-being in Melbourne - Updated results. Research in Transportation Economics, 29(1), 287-295. doi:10.1016/j.retrec.2010.07.036

Currie, G., \& Shalaby, A. (2012). Synthesis of Transport Planning Approaches for the World's Largest Events. Transport Reviews, 32(1), 113-136. doi:10.1080/01441647.2011.601352

Darcy, S. (2003). The politics of disability and access: the Sydney 2000 Games experience. Disability \& Society, 18(6), 737-757. doi:10.1080/0968759032000119497

Davis, L. K. (2011). International Events and Mass Evictions: A Longer View. International Journal of Urban and Regional Research, 35(3), 582-599. doi:10.1111/j.14682427.2010.00970.x

Davoudi, S., \& Brooks, E. (2014). When does unequal become unfair? Judging claims of environmental injustice. Environment and Planning A, 46(11), 2686-2702. doi:10.1068/a130346p

Dawkins, C. J. (2017). Putting Equality in Place: The Normative Foundations of Geographic Equality of Opportunity. Housing Policy Debate, 27(6), 897-912. doi:10.1080/10511482.2016.1205646

Dawkins, C. J., Jeon, J. S., \& Pendall, R. (2015). Vehicle Access and Exposure to Neighborhood Poverty: Evidence from the Moving to Opportunity Program. Journal of Regional Science, 55(5), 687-707. doi:10.1111/jors.12198 
De Vos, J., Schwanen, T., Van Acker, V., \& Witlox, F. (2013). Travel and Subjective Well-Being: A Focus on Findings, Methods and Future Research Needs. Transport Reviews, 33(4), 421-442. doi:10.1080/01441647.2013.815665

Death, C. (2011). 'Greening' the 2010 FIFA World Cup: Environmental Sustainability and the Mega-Event in South Africa. Journal of Environmental Policy \& Planning, 13(2), 99117. doi:10.1080/1523908X.2011.572656

Delbosc, A., \& Currie, G. (2011). Using Lorenz curves to assess public transport equity. Journal of Transport Geography, 19(6), 1252-1259. doi:10.1016/j.jtrangeo.2011.02.008

Delmelle, E. C., \& Casas, I. (2012). Evaluating the spatial equity of bus rapid transit-based accessibility patterns in a developing country: The case of Cali, Colombia. Transport Policy, 20, 36-46. doi:10.1016/j.tranpol.2011.12.001

Dijst, M., Jong, T. de, \& Eck, J. R. van. (2002). Opportunities for Transport Mode Change: An Exploration of a Disaggregated Approach. Environment and Planning B: Planning and Design, 29(3), 413-430. doi:10.1068/b12811

Dworkin, R. (1981a). What is equality? Part 1: Equality of welfare. Philosophy \& Public Affairs, 10(3), 185-246.

Dworkin, R. (1981b). What Is Equality? Part 2: Equality of Resources. Philosophy and Public Affairs Princeton, NJ, 10(4), 283-345.

Dworkin, R. (2000). Sovereign virtue: the theory and practice of equality. Cambridge, Mass. ; London: Harvard University Press.

Efthymiou, D., \& Antoniou, C. (2013). How do transport infrastructure and policies affect house prices and rents? Evidence from Athens, Greece. Transportation Research Part A: Policy and Practice, 52, 1-22. doi:10.1016/j.tra.2013.04.002

El-Geneidy, A., Cerdá, A., Fischler, R., \& Luka, N. (2011). Evaluating the Impacts of Transportation Plans Using Accessibility Measures. Canadian Journal of Urban Research, 20(1), 81-104.

El-Geneidy, A., Levinson, D., Diab, E., ... Loong, C. (2016). The cost of equity: Assessing transit accessibility and social disparity using total travel cost. Transportation Research Part A: Policy and Practice, 91, 302-316. doi:10.1016/j.tra.2016.07.003 
Elhorst, J. P. (2010). Applied Spatial Econometrics: Raising the Bar. Spatial Economic Analysis, 5(1), 9-28. doi:10.1080/17421770903541772

Eliasson, J. (2016). Is congestion pricing fair? Consumer and citizen perspectives on equity effects. Transport Policy, 52, 1-15. doi:10.1016/j.tranpol.2016.06.009

Eros, E., Mehndiratta, S., Zegras, C., ... Ochoa, M. (2014). Applying the General Transit Feed Specification to the Global South. Transportation Research Record: Journal of the Transportation Research Board, 2442, 44-52. doi:10.3141/2442-06

Essex, S., \& Chalkley, B. (2004). Mega-sporting events in urban and regional policy: a history of the Winter Olympics. Planning Perspectives, 19(2), 201-204. doi:10.1080/0266543042000192475

Estache, A., \& Gómez-Lobo, A. (2005). Limits to competition in urban bus services in developing countries. Transport Reviews, 25(2), 139-158. doi:10.1080/0144164042000289654

Fainstein, S. S. (2010). The just city. Ithaca: Cornell University Press.

Fan, Y., Guthrie, A. E., \& Levinson, D. M. (2012). Impact of light rail implementation on labor market accessibility: A transportation equity perspective. Journal of Transport and $\begin{array}{llll}\text { Land Use, 5(3). } & \text { Retrieved }\end{array}$ https://www.jtlu.org/index.php/jtlu/article/view/240

Farber, S., Bartholomew, K., Li, X., ... Nurul Habib, K. M. (2014). Assessing social equity in distance based transit fares using a model of travel behavior. Transportation Research Part A: Policy and Practice, 67, 291-303. doi:10.1016/j.tra.2014.07.013

Farber, S., \& Grandez, M. (2017). Transit accessibility, land development and socioeconomic priority: A typology of planned station catchment areas in the Greater Toronto and Hamilton Area. Journal of Transport and Land Use, 10(1). doi:10.5198/jtlu.2017.980

Farrington, J. H. (2007). The new narrative of accessibility: its potential contribution to discourses in (transport) geography. Journal of Transport Geography, 15(5), 319-330. doi:10.1016/j.jtrangeo.2006.11.007

Farrington, J. H., \& Farrington, C. (2005). Rural accessibility, social inclusion and social justice: towards conceptualisation. Journal of Transport Geography, 13(1), 1-12. doi:10.1016/j.jtrangeo.2004.10.002 
Faulhaber, L., \& Nacif, C. L. (2013). Rio Maravilha: desapropriações, remoções e reforço do padrão de organização espacial centro-periferia. Anais: Encontros Nacionais da $\begin{array}{llll}\text { ANPUR, } & \text { 15(0). } & \text { Retrieved }\end{array}$ http://unuhospedagem.com.br/revista/rbeur/index.php/anais/article/view/4222

Feitelson, E. (2002). Introducing environmental equity dimensions into the sustainable transport discourse: issues and pitfalls. Transportation Research Part D: Transport and Environment, 7(2), 99-118. doi:10.1016/S1361-9209(01)00013-X

Fincher, R., \& Iveson, K. (2012). Justice and Injustice in the City. Geographical Research, 50(3), 231-241. doi:10.1111/j.1745-5871.2011.00742.x

Flamm, M., \& Kaufmann, V. (2006). Operationalising the Concept of Motility: A Qualitative Study. Mobilities, 1(2), 167-189. doi:10.1080/17450100600726563

Flyvbjerg, B., \& Stewart, A. (2012). Olympic Proportions: Cost and Cost Overrun at the Olympics 1960-2012 (SSRN Scholarly Paper No. ID 2238053). Rochester, NY: Social Science Research Network. Retrieved from http://papers.ssrn.com/abstract=2238053

Fonseca, P. (2017, August 3). Brazil police arrest ex-Rio infrastructure head in Olympics graft probe. Reuters. Retrieved from https://www.reuters.com/article/us-brazilcorruption-olympics-idUSKBN1AJ2NY

Forkenbrock, D. J., \& Schweitzer, L. A. (1999). Environmental justice in transportation planning. Journal of the American Planning Association, 65(1), 96-111.

Foth, N., Manaugh, K., \& El-Geneidy, A. M. (2013). Towards equitable transit: examining transit accessibility and social need in Toronto, Canada, 1996-2006. Journal of Transport Geography, 29, 1-10. doi:10.1016/j.jtrangeo.2012.12.008

Fotheringham, A. S., \& Wong, D. W. S. (1991). The Modifiable Areal Unit Problem in Multivariate Statistical Analysis. Environment and Planning A, 23(7), 1025-1044. doi:10.1068/a231025

França, R. (2016, December 11). Ônibus perdem passageiros durante a crise. $O$ Globo. Retrieved from https://oglobo.globo.com/rio/onibus-perdem-passageiros-durantecrise-20625497

Fransen, K., Farber, S., Deruyter, G., \& De Maeyer, P. (2018). A spatio-temporal accessibility measure for modelling activity participation in discretionary activities. Travel Behaviour and Society, 10, 10-20. doi:10.1016/j.tbs.2017.09.002 
Fraser, N. (1995). Recognition or Redistribution? A Critical Reading of Iris Young's Justice and the Politics of Difference*. Journal of Political Philosophy, 3(2), 166-180. doi:10.1111/j.1467-9760.1995.tb00033.x

Fraser, N. (2003). Redistribution or recognition?: a political-philosophical exchange. London: Verso.

G1. (2017, February 6). Confira as novas mudanças de linhas de ônibus no Rio. Retrieved January 15, 2017, from http://g1.globo.com/rio-dejaneiro/noticia/2016/02/confira-novas-mudancas-de-linhas-de-onibus-no-rio.html

Gaffney, C. (2010). Mega-events and socio-spatial dynamics in Rio de Janeiro, 1919-2016. Journal of Latin American Geography, 9(1), 7-29. doi:10.1353/lag.0.0068

Gaffney, C. (2013). Between Discourse and Reality: The Un-Sustainability of Mega-Event Planning. Sustainability, 5(9), 3926-3940. doi:10.3390/su5093926

Gaffney, C. (2015a). Gentrifications in pre-Olympic Rio de Janeiro. Urban Geography, 0(0), 122. doi:10.1080/02723638.2015.1096115

Gaffney, C. (2015b). The mega-event city as neo-liberal laboratory: the case of Rio de Janeiro. Percurso Acadêmico, 0(0), 217-237.

Gaffney, C. (2016). Gentrifications in pre-Olympic Rio de Janeiro. Urban Geography, 37(8), 1132-1153. doi:10.1080/02723638.2015.1096115

Galster, G. (2017). The Geography of Opportunity 20 Years Later. Housing Policy Debate, 27(6), 941-943. doi:10.1080/10511482.2016.1216745

Geurs, K., Boon, W., \& van Wee, B. (2009). Social Impacts of Transport: Literature Review and the State of the Practice of Transport Appraisal in the Netherlands and the United Kingdom. Transport Reviews, 29(1), 69-90. doi:10.1080/01441640802130490

Geurs, K., \& va Eck, J. R. R. (2003). Evaluation of Accessibility Impacts of Land-Use Scenarios: The Implications of Job Competition, Land-Use, and Infrastructure Developments for the Netherlands. Environment and Planning B: Planning and Design, 30(1), 69-87. doi:10.1068/b12940

Geurs, K., \& van Wee, B. (2004). Accessibility evaluation of land-use and transport strategies: review and research directions. Journal of Transport Geography, 12(2), 127-140. doi:10.1016/j.jtrangeo.2003.10.005

Givoni, M. (2016). Winning the Last Mile. Built Environment, 42(4), 517-522. 
Glaister, S., Starkie, D., \& Thompson, D. (1990). The Assessment: Economic Policy for Transport. Oxford Review of Economic Policy, 6(2), 1-21. doi:10.1093/oxrep/6.2.1

Gold, J. R., \& Gold, M. M. (2008). Olympic Cities: Regeneration, City Rebranding and Changing Urban Agendas. Geography Compass, 2(1), 300-318. doi:10.1111/j.17498198.2007.00080.x

Gold, J. R., \& Gold, M. M. (2011). Olympic cities : city agendas, planning and the world's games, 1896-2016 (2nd ed.). London: Routledge.

Golub, A., \& Martens, K. (2014). Using principles of justice to assess the modal equity of regional transportation plans. Journal of Transport Geography, 41, 10-20. doi:10.1016/j.jtrangeo.2014.07.014

Graham, S. (2000). Constructing premium network spaces: reflections on infrastructure networks and contemporary urban development. International Journal of Urban and Regional Research, 24(1), 183-200. doi:10.1111/1468-2427.00242

Graham, S., \& Marvin, S. (2001). Splintering urbanism: networked infrastructures, technological mobilities and the urban condition. London: Routledge.

Gratton, C., \& Preuss, H. (2008). Maximizing Olympic Impacts by Building Up Legacies. The International Journal of the History of Sport, 25(14), 1922-1938. doi:10.1080/09523360802439023

Gratton, C., Shibli, S., \& Coleman, R. (2005). Sport and Economic Regeneration in Cities. Urban Studies, 42(5-6), 985-999. doi:10.1080/00420980500107045

Greene, D. L., \& Wegener, M. (1997). Sustainable transport. Journal of Transport Geography, 5(3), 177-190. doi:10.1016/S0966-6923(97)00013-6

Guimarães, A., \& Leitão, L. (2017). Ex-secretário de obras de Paes é preso em desmembramento da Lava Jato no Rio. G1. Retrieved from http://g1.globo.com/riode-janeiro/noticia/pf-cumpre-mandados-em-mais-um-desmembramento-da-lavajato-no-rio.ghtml

Guthrie, A., Fan, Y., \& Das, K. V. (2017). Accessibility Scenario Analysis of a Hypothetical Future Transit Network: Social Equity Implications of a General Transit Feed Specification-Based Sketch Planning Tool. Transportation Research Record: Journal of the Transportation Research Board, 2671, 1-9. doi:10.3141/2671-01 
Hananel, R., \& Berechman, J. (2016). Justice and transportation decision-making: The $\begin{array}{lllll}\text { capabilities } & \text { approach. } & \text { 78-85. }\end{array}$ doi:10.1016/j.tranpol.2016.04.005

Harvey, D. (2009). Social justice and the city. Athens: University of Georgia Press. Retrieved from http://site.ebrary.com/id/10405168

Harvey, D. (2013). Rebel Cities: From the Right to the City to the Urban Revolution (2 edition.). London; New York: Verso Books.

Hausman, D. M., \& McPherson, M. S. (2006). Economic analysis, moral philosophy, and public policy (2nd ed..). New York ; Cambridge: Cambridge University Press.

Hay, A. (1993). Equity and welfare in the geography of public transport provision. Journal of Transport Geography, 1(2), 95-101. doi:10.1016/0966-6923(93)90003-I

Hay, A., \& Trinder, E. (1991). Concepts of equity, fairness, and justice expressed by local transport policymakers. Environment and Planning C: Government and Policy, 9(4), 453 - 465. doi:10.1068/c090453

Hefner, J. (1972). Efficiency, equity and pricing in mass transit system. The Review of Black Political Economy, 2(3), 38-44. doi:10.1007/BF03040606

Hensher, D. A., \& Brewer, A. M. (2002). Going for gold at the Sydney Olympics: How did transport perform? Transport Reviews, 22(4), 381-399. doi:10.1080/01441640110121112

Herdy, F. H. (2012). Dos planos urbanísticos ao projeto Rio 2016: a mobilidade urbana nas leituras de cidade. Universidade Federal Fluminense, Niterou.

Hernandez, D. (2017). Uneven mobilities, uneven opportunities: Social distribution of public transport accessibility to jobs and education in Montevideo. Journal of Transport Geography. doi:10.1016/j.jtrangeo.2017.08.017

Hess, D. B. (2005). Access to Employment for Adults in Poverty in the Buffalo-Niagara Region. Urban Studies, 42(7), 1177-1200. doi:10.1080/00420980500121384

Hickman, R., Bonilla, D., Givoni, M., \& Banister, D. (2015). Handbook on transport and development. Cheltenham: Edward Elgar.

Hiller, H. H. (2000). Mega-events, Urban Boosterism and Growth Strategies: An Analysis of the Objectives and Legitimations of the Cape Town 2004 Olympic Bid. International 
Journal of Urban and Regional Research, 24(2), 449-458. doi:10.1111/14682427.00256

Hiller, H. H. (2006). Post-event Outcomes and the Post-modern Turn: The Olympics and Urban Transformations. European Sport Management Quarterly, 6(4), 317-332. doi:10.1080/16184740601154458

Hodgson, F. C., \& Turner, J. (2003). Participation not consumption: the need for new participatory practices to address transport and social exclusion. Transport Policy, 10(4), 265-272. doi:10.1016/j.tranpol.2003.08.001

Holden, E., Linnerud, K., \& Banister, D. (2013). Sustainable passenger transport: Back to Brundtland. Transportation Research Part A: Policy and Practice, 54, 67-77. doi:10.1016/j.tra.2013.07.012

Holden, E., Linnerud, K., Banister, D., ... Wierling, A. (2018). The imperatives of sustainable development: needs, justice, limits. London: Routledge, Taylor \& Francis Group.

Horne, J., \& Manzenreiter, W. (2006). An introduction to the sociology of sports mega-events. The Sociological Review, 54, 1-24. doi:10.1111/j.1467-954X.2006.00650.x

Horner, M. W., \& Murray, A. T. (2004). Spatial Representation and Scale Impacts in Transit Service Assessment. Environment and Planning B: Planning and Design, 31(5), 785797. doi:10.1068/b3046

Huang, Q., \& Wong, D. W. S. (2015). Modeling and Visualizing Regular Human Mobility Patterns with Uncertainty: An Example Using Twitter Data. Annals of the Association of American Geographers, 105(6), 1179-1197. doi:10.1080/00045608.2015.1081120 Hughes, C., \& Leshner. (2013). Impact Analysis of Transoeste Bus Rapid Transit System in Rio de Janeiro. Rio de Janeiro: ITDP Brasil.

IBGE. (2016). Grade Estatística 2010. Retrieved from http://mapas.ibge.gov.br/interativos/grade.html

Ingold, D., \& Soper, S. (2016). Amazon Doesn't Consider the Race of Its Customers. Should It? Retrieved February 11, 2018, from http://www.bloomberg.com/graphics/2016amazon-same-day/

Ipea. (2016). ipeadata. Retrieved from http://www.ipeadata.gov.br/

Ipea, UNPD, \& FJP. (2015). Atlas do desenvolvimento humano nas regiões metropolitanas brasileiras. Retrieved November 20, 2015, from http://www.atlasbrasil.org.br/ 
ITDP Brasil. (2013). Workshop de Planejamento Urbano no entorno da estação do BRT Transbrasil em Bonsucesso. Rio de Janeiro: ITDP Brasil.

ITDP Brasil. (2014). Análise do Fluxo de Pedestres nas Estações do BRT Transbrasil. Rio de Janeiro: ITDP Brasil. Retrieved from http://itdpbrasil.org.br/wpcontent/uploads/2014/11/Pedestrian-Flow-Analysis-Transbrasil_FINAL.pdf

ITDP Brasil. (2015). Análise de Impacto do BRT TransCarioca na Mobilidade Urbana do Rio de Janeiro. Rio de Janeiro: ITDP Brasil. Retrieved from https://www.itdp.org/wpcontent/uploads/2015/04/ITDP-Brasil_An\%C3\%A1lise-Impacto-BRT-

TransCarioca_em-PT_vers\%C3\%A3o-WEB-para-site.pdf

Jaramillo, C., Lizárraga, C., \& Grindlay, A. L. (2012). Spatial disparity in transport social needs and public transport provision in Santiago de Cali (Colombia). Journal of Transport Geography, 24, 340-357. doi:10.1016/j.jtrangeo.2012.04.014

Jones, C. (2001). A level playing field? Sports stadium infrastructure and urban development in the United Kingdom. Environment and Planning A, 33(5), 845-861. doi:10.1068/a33158

Jonsson, R. D. (2008). Analysing sustainability in a land-use and transport system. Journal of Transport Geography, 16(1), 28-41. doi:10.1016/j.jtrangeo.2007.02.006

Jun, M.-J. (2012). Redistributive effects of bus rapid transit (BRT) on development patterns and property values in Seoul, Korea. Transport Policy, 19(1), 85-92. doi:10.1016/j.tranpol.2011.09.003

Kain, J. F. (1968). Housing Segregation, Negro Employment, and Metropolitan Decentralization. The Quarterly Journal of Economics, 82(2), 175-197. doi:10.2307/1885893

Kaplan, S., Popoks, D., Prato, C. G., \& Ceder, A. (2014). Using connectivity for measuring equity in transit provision. Journal of Transport Geography, 37, 82-92. doi:10.1016/j.jtrangeo.2014.04.016

Karlström, A., \& Franklin, J. P. (2009). Behavioral adjustments and equity effects of congestion pricing: Analysis of morning commutes during the Stockholm Trial. Transportation Research Part A: Policy and Practice, 43(3), 283-296. doi:10.1016/j.tra.2008.09.008 
Karner, A., \& Niemeier, D. (2013). Civil rights guidance and equity analysis methods for regional transportation plans: a critical review of literature and practice. Journal of Transport Geography, 33, 126-134. doi:10.1016/j.jtrangeo.2013.09.017

Kasimati, E. (2003). Economic aspects and the Summer Olympics: a review of related research. International Journal of Tourism Research, 5(6), 433-444. doi:10.1002/jtr.449

Kassens-Noor, E. (2010). Sustaining the Momentum. Transportation Research Record: Journal of the Transportation Research Board, 2187, 106-113. doi:10.3141/2187-14

Kassens-Noor, E. (2012). Planning Olympic Legacies: Transport Dreams and Urban Realities. Routledge.

Kassens-Noor, E. (2013). Transport Legacy of the Olympic Games, 1992-2012. Journal of Urban Affairs, 35(4), 393-416. doi:10.1111/j.1467-9906.2012.00626.x

Kassens-Noor, E., Gaffney, C., Messina, J., \& Phillips, E. (2016). Olympic Transport Legacies: Rio de Janeiro's Bus Rapid Transit System. Journal of Planning Education and Research, 0739456X16683228. doi:10.1177/0739456X16683228

Kassens-Noor, E., \& Kayal, P. (2016). India's new globalization strategy and its consequences for urban development: the impact of the 2010 Commonwealth Games on Delhi's transport system. International Planning Studies, 21(1), 34-49. doi:10.1080/13563475.2015.1114448

Kaufmann, V., Bergman, M. M., \& Joye, D. (2004). Motility: mobility as capital. International Journal of Urban and Regional Research, 28(4), 745-756. doi:10.1111/j.03091317.2004.00549.x

Kaufmann, V., Dubois, Y., \& Ravalet, E. (2017). Measuring and typifying mobility using motility. Applied Mobilities, O(0), 1-16. doi:10.1080/23800127.2017.1364540

Kawabata, M., \& Shen, Q. (2007). Commuting inequality between cars and public transit: The case of the San Francisco Bay Area, 1990-2000. Urban Studies, 44(9), 1759-1780. doi:10.1080/00420980701426616

Keeling, D. J. (2008). Latin America's Transportation Conundrum. Journal of Latin American Geography, 7(2), 133-154. doi:10.1353/lag.0.0005

Kellerman, A. (2012). Potential Mobilities. Mobilities, 7(1), 171-183. doi:10.1080/17450101.2012.631817 
Kenyon, S., Lyons, G., \& Rafferty, J. (2002). Transport and social exclusion: investigating the possibility of promoting inclusion through virtual mobility. Journal of Transport Geography, 10(3), 207-219. doi:10.1016/S0966-6923(02)00012-1

Khisty, C. (1996). Operationalizing Concepts of Equity for Public Project Investments. Transportation Research Record, 1559(1), 94-99. doi:10.3141/1559-12

Kitchin, R. (2016). The ethics of smart cities and urban science. Phil. Trans. R. Soc. A, 374(2083), 20160115. doi:10.1098/rsta.2016.0115

Klein, D. B., Moore, A. T., \& Reja, B. (2003). Curb Rights Eliciting Competition and Entrepreneurship in Urban Transit (SSRN Scholarly Paper No. ID 473441). Rochester, NY: Social Science Research Network. Retrieved from http://papers.ssrn.com/abstract $=473441$

Kommenda, N. (2016, August 2). How evictions have laid bare Rio's real Olympic legacy. The Guardian. Retrieved from http://www.theguardian.com/sport/nginteractive/2016/aug/02/how-evictions-have-laid-bare-rios-real-olympic-legacy

Kronlid, D. (2008). Mobility as Capability. In T. P. Uteng \& T. Cresswell (Eds.), Gendered Mobilities (pp. 15-34). Aldershot: Ashgate.

Kutz, M. (2003). Handbook of Transportation Engineering (1 edition.). New York: McGrawHill Professional.

Kwan, M.-P. (1998). Space-Time and Integral Measures of Individual Accessibility: A Comparative Analysis Using a Point-based Framework. Geographical Analysis, 30(3), 191-216. doi:10.1111/j.1538-4632.1998.tb00396.x

Kwan, M.-P. (2000). Gender differences in space-time constraints. Area, 32(2), 145-156. doi:10.1111/j.1475-4762.2000.tb00125.x

Kwan, M.-P. (2016). Algorithmic Geographies: Big Data, Algorithmic Uncertainty, and the Production of Geographic Knowledge. Annals of the American Association of Geographers, 106(2), 274-282. doi:10.1080/00045608.2015.1117937

Kwan, M.-P., \& Schwanen, T. (2018). Context and Uncertainty in Geography and GIScience: Advances in Theory, Method, and Practice. Annals of the American Association of Geographers, O(0), 1-3. doi:10.1080/24694452.2018.1457910 
Kwan, M.-P., \& Weber, J. (2008). Scale and accessibility: Implications for the analysis of land use-travel interaction. Applied Geography, 28(2), 110-123. doi:10.1016/j.apgeog.2007.07.002

Kwok, R. C. W., \& Yeh, A. G. O. (2004). The Use of Modal Accessibility Gap as an Indicator for Sustainable Transport Development. Environment and Planning A: Economy and Space, 36(5), 921-936. doi:10.1068/a3673

Kymlicka, W. (2002). Contemporary political philosophy : an introduction (2nd ed.). Oxford: Oxford University Press.

Lago, L. C. do. (2000). Desigualdades e segregação na metrópole: o Rio de Janeiro em tempo de crise. Observatório IPPUR/UFRJ-FASE. Retrieved from http://web.observatoriodasmetropoles.net/new/images/abook_file/desigualdade_ metropolerj_lucianalago.pdf

Langmyhr, T. (1997). Managing equity: The case of road pricing. Transport Policy, 4(1), 2539. doi:10.1016/S0967-070X(96)00031-5

Legroux, J. (2014). From discourse to reality: impacts of Rio's "transportation revolution" on socio-spatial justice. In L. C. de Q. Ribeiro, The Metropolis of Rio de Janeiro: a space in transition (1st ed., pp. 343-372). Rio de Janeiro: Letra Capital.

Leopkey, B., \& Parent, M. M. (2012). Olympic Games Legacy: From General Benefits to Sustainable Long-Term Legacy. The International Journal of the History of Sport, 29(6), 924-943. doi:10.1080/09523367.2011.623006

LeSage, J. P. (2008). An Introduction to Spatial Econometrics. Revue d'économie Industrielle, (123), 19-44. doi:10.4000/rei.3887

Levinson, D. (2002). Identifying winners and losers in transportation. Transportation Research Record: Journal of the Transportation Research Board, 1812(1), 179-185.

Levinson, D. (2010). Equity Effects of Road Pricing: A Review. Transport Reviews, 30(1), 3357. doi:10.1080/01441640903189304

Liao, C.-H., Hsueh-Sheng, C., \& Tsou, K.-W. (2009). Explore the spatial equity of urban public facility allocation based on sustainable development viewpoint. Presented at the 14th International conference on urban planning and regional development in the information society, Spain, Sitges. Retrieved from http://realcorp.at/archive/CORP2009_48.pdf 
Lisboa, V. (2017). Prefeitura do Rio retoma obras do BRT Transbrasil. Agência Brasil Últimas Notícias Do Brasil e Do Mundo. Rio de Janeiro. Retrieved from http://agenciabrasil.ebc.com.br/geral/noticia/2017-04/rio-retoma-obras-docorredor-expresso-de-onibus-articulados

Litman, T. (2002). Evaluating Transportation Equity. World Transport Policy \& Practice, 8(2), $50-65$.

Liu, M., Mao, B., Huang, Y., ... Chen, S. (2008). Comparison of Pre- \& Post-Olympic Traffic: A Case Study of Several Roads in Beijing. Journal of Transportation Systems Engineering and Information Technology, 8(6), 67-72. doi:10.1016/S1570-6672(09)60006-4

Logit. (2014). Relatorio Final: Revisão do Estudo TransBrasil - Área Central. São Paulo: Logit. Retrieved from http://www.rio.rj.gov.br/web/pmus/documentos

Lucas, K. (2012). Transport and social exclusion: Where are we now? Transport Policy, 20, 105-113. doi:10.1016/j.tranpol.2012.01.013

Lucas, K. (2018). Editorial for special issue of European transport research review: transport poverty and inequalities. European Transport Research Review, 10(1), 17. doi:10.1007/s12544-018-0288-6

Lucas, K., \& Jones, P. (2012). Social impacts and equity issues in transport: an introduction. Journal of Transport Geography, 21, 1-3. doi:10.1016/j.jtrangeo.2012.01.032

Lucas, K., Mattioli, G., Verlinghieri, E., \& Guzman, A. (2016). Transport poverty and its adverse social consequences. Proceedings of the Institution of Civil Engineers - Transport, 169(6), 353-365. doi:10.1680/jtran.15.00073

Lucas, K., van Wee, B., \& Maat, K. (2015). A method to evaluate equitable accessibility: combining ethical theories and accessibility-based approaches. Transportation, 1-18. doi:10.1007/s11116-015-9585-2

Mackie, P. J., Jara-Díaz, S., \& Fowkes, A. S. (2001). The value of travel time savings in evaluation. Transportation Research Part E: Logistics and Transportation Review, 37(2-3), 91-106. doi:10.1016/S1366-5545(00)00013-2

Magalhães, L. E., \& Rodrigues, R. (2017, June 6). Sistema BRT completa 5 anos sem motivos para comemorar. O Globo. Retrieved from https://oglobo.globo.com/rio/sistema-brtcompleta-5-anos-sem-motivos-para-comemorar-21439782 
Maia, M. L., Lucas, K., Marinho, G., ... de Lima, J. H. (2016). Access to the Brazilian City-From the perspectives of low-income residents in Recife. Journal of Transport Geography, 55, 132-141. doi:10.1016/j.jtrangeo.2016.01.001

Manaugh, K., Badami, M. G., \& El-Geneidy, A. M. (2015). Integrating social equity into urban transportation planning: A critical evaluation of equity objectives and measures in transportation plans in North America. Transport Policy, 37, 167-176. doi:10.1016/j.tranpol.2014.09.013

Manaugh, K., \& El-Geneidy, A. (2012). Who Benefits from New Transportation Infrastructure? Using Accessibility Measures to Evaluate Social Equity in Public Transport Provision. In K. Martens, K. Geurs, K. Krizek, \& A. Reggiani (Eds.), Accessibility Analysis and Transport Planning: Challenges for Europe and North America. Cheltenham, UK; Northampton, MA: Edward Elgar. Retrieved from http://www.kevinmanaugh.com/resources/Transit_plan_equity.pdf

Manderscheid, K., Schwanen, T., \& Tyfield, D. (2014). Introduction to Special Issue on 'Mobilities and Foucault.' Mobilities, 9(4), 479-492. doi:10.1080/17450101.2014.961256

Mao, B. (2008). Analysis on Transport Policies of Post-Olympic Times of Beijing. Journal of Transportation Systems Engineering and Information Technology, 8(6), 138-145. doi:10.1016/S1570-6672(09)60011-8

Marcuse, P., Connolly, J., Navy, J., ... Steil, J. (2009). Searching for the just city : debates in urban theory and practice. London; New York: Routledge.

Marlin, R. (1989). Rawlsian justice and community planning. International Journal of Applied Philosophy, 4(4), 36-43.

Martens, K. (2011). Substance precedes methodology: on cost-benefit analysis and equity. Transportation, 38(6), 959-974. doi:10.1007/s11116-011-9372-7

Martens, K. (2012). Justice in transport as justice in accessibility: applying Walzer's 'Spheres of Justice' to the transport sector. Transportation, 39(6), 1035-1053. doi:10.1007/s11116-012-9388-7

Martens, K. (2016). Transport Justice: Designing fair transportation systems. New York, NY: Routledge. 
Martens, K., \& Ciommo, F. D. (2017). Travel time savings, accessibility gains and equity effects in cost-benefit analysis. Transport Reviews, 37(2), 152-169. doi:10.1080/01441647.2016.1276642

Martens, K., \& Golub, A. (2012). A justice-theoretic exploration of accessibility measures. In K. Geurs, K. J. Krizek, A. Reggiani, \& Network on European Communications and Transport Activity Research (Eds.), Accessibility analysis and transport planning: challenges for Europe and North America (pp. 195-210). Cheltenham: Edward Elgar.

Martens, K., Golub, A., \& Robinson, G. (2012). A justice-theoretic approach to the distribution of transportation benefits: Implications for transportation planning practice in the United States. Transportation Research Part A: Policy and Practice, 46(4), 684-695. doi:10.1016/j.tra.2012.01.004

Matela, I. P. (2017). Transport Management: The Renovation of the Road Pact. In L. C. D. Q. Ribeiro, Urban Transformations in Rio de Janeiro (pp. 287-302). Springer, Cham. doi:10.1007/978-3-319-51899-2_16

McKay, S., Murray, M., \& Macintyre, S. (2012). Justice as Fairness in Planning Policy-Making. International Planning Studies, 17(2), 147-162. doi:10.1080/13563475.2012.672798

Meijers, E., Hoekstra, J., Leijten, M., ... Spaans, M. (2012). Connecting the periphery: distributive effects of new infrastructure. Journal of Transport Geography, 22, 187198. doi:10.1016/j.jtrangeo.2012.01.005

Mello, K. (2016, April 6). Alerj aprova empréstimo para conclusão da Linha 4 do Metrô do Rio. Rio de Janeiro. Retrieved from http://g1.globo.com/rio-dejaneiro/noticia/2016/04/alerj-aprovada-emprestimo-para-conclusao-da-linha-4do-metro-do-rio.html

Melo, E. S. O. (2017). Exerting State Power in Core and Semi- peripheral Countries: land clearance and domination strategies in London, Rio de Janeiro and Johannesburg (PhD). Oxford Brookes University, Oxford, UK.

Miller, D. (1999). Principles of social justice. Cambridge, Mass; London: Harvard University Press.

Miller, H. J. (2006). Social exclusion in space and time. In K. Axhausen (Ed.), Moving through Nets: The Social and Physical Aspects of Travel (pp. 353-380). London: Elsevier. 
Minis, I., \& Tsamboulas, D. A. (2008). Contingency Planning and War Gaming for the Transport Operations of the Athens 2004 Olympic Games. Transport Reviews, 28(2), 259-280. doi:10.1080/01441640701628685

Minnaert, L. (2012). An Olympic legacy for all? The non-infrastructural outcomes of the Olympic Games for socially excluded groups (Atlanta 1996-Beijing 2008). Tourism Management, 33(2), 361-370. doi:10.1016/j.tourman.2011.04.005

Mitra, S. K., \& Saphores, J.-D. M. (2016). The value of transportation accessibility in a least developed country city - The case of Rajshahi City, Bangladesh. Transportation Research Part A: Policy and Practice, 89, 184-200. doi:10.1016/j.tra.2016.05.002

Mladenovic, M. N., \& McPherson, T. (2016). Engineering Social Justice into Traffic Control for Self-Driving Vehicles? Science and Engineering Ethics, 22(4), 1131-1149. doi:10.1007/s11948-015-9690-9

Motte-Baumvol, B., Aguilera, A., Bonin, O., \& Nassi, C. D. (2016). Commuting patterns in the metropolitan region of Rio de Janeiro. What differences between formal and informal jobs? Journal of Transport Geography, 51, 59-69. doi:10.1016/j.jtrangeo.2015.10.019

Motte-Baumvol, B., \& Nassi, C. D. (2012). Immobility in Rio de Janeiro, beyond poverty. Journal of Transport Geography, 24, 67-76. doi:10.1016/j.jtrangeo.2012.06.012

Mullen, C. (2012). Mobility (transport). In R. F. Chadwick, Encyclopedia of applied ethics (2nd ed., Vol. 3, pp. 137-144). London: Academic Press.

Mullen, C., Tight, M., Whiteing, A., \& Jopson, A. (2014). Knowing their place on the roads: What would equality mean for walking and cycling? Transportation Research Part A: Policy and Practice, 61, 238-248. doi:10.1016/j.tra.2014.01.009

Müller, M. (2015). The Mega-Event Syndrome: Why So Much Goes Wrong in Mega-Event Planning and What to Do About It. Journal of the American Planning Association, 81(1), 6-17. doi:10.1080/01944363.2015.1038292

Mulley, C., Ma, L., Clifton, G., ... Burke, M. (2016). Residential property value impacts of proximity to transport infrastructure: An investigation of bus rapid transit and heavy rail networks in Brisbane, Australia. Journal of Transport Geography, 54, 41-52. doi:10.1016/j.jtrangeo.2016.05.010 
Muralidharan, K., \& Prakash, N. (2017). Cycling to School: Increasing Secondary School Enrollment for Girls in India. American Economic Journal: Applied Economics, 9(3), 321-350. doi:10.1257/app.20160004

Murray, A. T., \& Davis, R. (2001). Equity in regional service provision. Journal of Regional Science, 41(4), 577-600.

Nahmias-Biran, B., \& Shiftan, Y. (2016). Towards a more equitable distribution of resources: Using activity-based models and subjective well-being measures in transport project evaluation. Transportation Research Part A: Policy and Practice, 94, 672-684. doi:10.1016/j.tra.2016.10.010

Neutens, T. (2015). Accessibility, equity and health care: review and research directions for transport geographers. Journal of Transport Geography, 43, 14-27. doi:10.1016/j.jtrangeo.2014.12.006

Neutens, T., Schwanen, T., Witlox, F., \& Maeyer, P. D. (2010). Equity of urban service delivery: a comparison of different accessibility measures. Environment and Planning A, 42(7), 1613 - 1635. doi:10.1068/a4230

Newell, P., \& Mulvaney, D. (2013). The political economy of the 'just transition.' The Geographical Journal, 179(2), 132-140. doi:10.1111/geoj.12008

Niehaus, M., Galilea, P., \& Hurtubia, R. (2016). Accessibility and equity: An approach for wider transport project assessment in Chile. Research in Transportation Economics, 59, 412422. doi:10.1016/j.retrec.2016.05.003

Nixon, D., \& Schwanen, T. (2018). Emergent and Integrated Justice: Lessons from Community Initiatives to Improve Infrastructures for Walking and Cycling. In D. Butz \& N. Cookk, Mobilities, Mobility Justice \& Social Justice. Abingdon: Routledge.

Nordbakke, S. (2013). Capabilities for mobility among urban older women: barriers, strategies and options. Journal of Transport Geography, 26, 166-174. doi:10.1016/j.jtrangeo.2012.10.003

Nordbakke, S., \& Schwanen, T. (2015). Transport, unmet activity needs and wellbeing in later life: exploring the links. Transportation, 1-23. doi:10.1007/s11116-014-9558-x

Nozick, R. (2003). Anarchy, state, and Utopia. [electronic resource]. Oxford: Blackwell.

Nussbaum, M. C. (2006). Frontiers of justice: disability, nationality, species membership. Cambridge, Massachusetts: The Belknap Press. Retrieved from https://ezproxy- 
prd.bodleian.ox.ac.uk/login?url=http://search.ebscohost.com/login.aspx?direct=tru e\&scope $=$ site $\& d b=$ nlebk\&AN $=282347$

Nussbaum, M. C. (2011). Creating capabilities: the human development approach. Cambridge, Mass.: Belknap Press of Harvard University Press.

O Globo. (2016). Falhas na racionalização das linhas de ônibus. Editorial - 20/02/2016. O Globo. Retrieved from http://oglobo.globo.com/opiniao/falhas-na-racionalizacaodas-linhas-de-onibus-18712277

Omer, I. (2006). Evaluating accessibility using house-level data: A spatial equity perspective. Computers, Environment and Urban Systems, 30(3), 254-274. doi:10.1016/j.compenvurbsys.2005.06.004

Ong, P. M. (2002). Car ownership and welfare-to-work. Journal of Policy Analysis and Management, 21(2), 239-252. doi:10.1002/pam.10025

Openshaw, S. (1977). Optimal Zoning Systems for Spatial Interaction Models. Environment and Planning A: Economy and Space, 9(2), 169-184. doi:10.1068/a090169

Openshaw, S. (1996). Developing GIS-relevant zone-based spatial analysis methods. In P. Longley \& M. Batty (Eds.), Spatial Analysis: Modelling in a GIS Environment (pp. 5573). New York: John Wiley and Sons. Retrieved from http://www.geog.leeds.ac.uk/papers/96-7/

Ortega, E., López, E., \& Monzón, A. (2012). Territorial cohesion impacts of high-speed rail at different planning levels. Journal of Transport Geography, 24, 130-141. doi:10.1016/j.jtrangeo.2011.10.008

Oviedo, D., \& Dávila, J. (2016). Transport, urban development and the peripheral poor in Colombia - Placing splintering urbanism in the context of transport networks. Journal of Transport Geography, 51, 180-192. doi:10.1016/j.jtrangeo.2016.01.003

Paddison, R. (1993). City Marketing, Image Reconstruction and Urban Regeneration. Urban Studies, 30(2), 339-349. doi:10.1080/00420989320080331

Páez, A., Mercado, R. G., Farber, S., ... Roorda, M. (2010). Relative Accessibility Deprivation Indicators for Urban Settings: Definitions and Application to Food Deserts in Montreal. Urban Studies, 47(7), 1415-1438. doi:10.1177/0042098009353626

Páez, A., \& Scott, D. M. (2005). Spatial statistics for urban analysis: A review of techniques with examples. GeoJournal, 61(1), 53-67. doi:10.1007/s10708-005-0877-5 
Palmateer, C., Owen, A., \& Levinson, D. M. (2016). Accessibility Evaluation of the Metro Transit A-Line (Report). Accessibility Observatory, University of Minnesota. Retrieved from http://conservancy.umn.edu/handle/11299/180900

Papa, E., \& Ferreira, A. (2018). Sustainable Accessibility and the Implementation of Automated Vehicles: Identifying Critical Decisions. Urban Science, 2(1), 5. doi:10.3390/urbansci2010005

Papa, E., Silva, C., Brömmelstroet, M. te, \& Hull, A. (2015). Accessibility instruments for planning practice: a review of European experiences. Journal of Transport and Land Use, $0(0)$. Retrieved from https://www.jtlu.org/index.php/jtlu/article/view/585

Patel, S., d'Cruz, C., \& Burra, S. (2002). Beyond evictions in a global city: people-managed resettlement in Mumbai. Environment and Urbanization, 14(1), 159-172. doi:10.1177/095624780201400113

Pereira, R. H. M. (2018). Transport legacy of mega-events and the redistribution of accessibility to urban destinations. Cities, 81, 45-60. doi:10.1016/j.cities.2018.03.013

Pereira, R. H. M. (2018). Future accessibility impacts of transport policy scenarios: equity and sensitivity to travel time thresholds for Bus Rapid Transit expansion in Rio de Janeiro. Open Science Framework Preprints. doi:10.31219/osf.io/sut7r

Pereira, R. H. M., \& Schwanen, T. (2013). Commute Time in Brazil (1992-2009): differences between metropolitan areas, by income levels and gender (Texto para Discussão No. 1813a). Brasília: Institute for Applied Economic Research - Ipea. Retrieved from http://repositorio.ipea.gov.br/handle/11058/964

Pereira, R. H. M., Schwanen, T., \& Banister, D. (2017). Distributive justice and equity in transportation. Transport Reviews, 37(2), 170-191. doi:10.1080/01441647.2016.1257660

Pereira, R. H. M., Banister, D., Schwanen, T., \& Wessel, N. (2017). Distributional effects of transport policies on inequalities in access to opportunities in Rio de Janeiro. SocArXiv. doi:10.31235/osf.io/cghx2

Pillay, U., \& Bass, O. (2008). Mega-events as a Response to Poverty Reduction: The 2010 FIFA World Cup and its Urban Development Implications. Urban Forum, 19(3), 329-346. doi:10.1007/s12132-008-9034-9 
PNUD, Ipea, \& FJP. (2013). Índice de Desenvolvimento Humano Municipal Brasileiro. Brasília: PNUD, Ipea, FJP. Retrieved from http://atlasbrasil.org.br/2013/pt/home/

Porter, G. (2014). Transport Services and Their Impact on Poverty and Growth in Rural SubSaharan Africa: A Review of Recent Research and Future Research Needs. Transport Reviews, 34(1), 25-45. doi:10.1080/01441647.2013.865148

Porter, L., Jaconelli, M., Cheyne, J., ... Wagenaar, H. (2009). Planning Displacement: The Real Legacy of Major Sporting Events. Planning Theory \& Practice, 10(3), 395-418. doi:10.1080/14649350903229828

Preston, J., \& Rajé, F. (2007). Accessibility, mobility and transport-related social exclusion. Journal of Transport Geography, 15(3), 151-160. doi:10.1016/j.jtrangeo.2006.05.002

Préteceille, E., \& Cardoso, A. (2008). Río de Janeiro y Sao Paulo: ¿ciudades duales? comparación con Paris. Ciudad y Territorio: Estudios Territoriales, (158), 617-640.

Preuss, H. (2007). The Conceptualisation and Measurement of Mega Sport Event Legacies. Journal of Sport \& Tourism, 12(3-4), 207-228. doi:10.1080/14775080701736957

Prytherch, D. L. (2012). Legal Geographies-Codifying the Right-Of-Way: Statutory Geographies of Urban Mobility and The Street. Urban Geography, 33(2), 295-314. doi:10.2747/0272-3638.33.2.295

Pucher, J. (1981). Equity in Transit Finance: Distribution of Transit Subsidy Benefits and Costs Among Income Classes. Journal of the American Planning Association, 47(4), 387-407. doi:10.1080/01944368108976521

Pucher, J. (1982). Discrimination in Mass Transit. Journal of the American Planning Association, 48(3), 315-326. doi:10.1080/01944368208976181

Purcell, M. (2002). Excavating Lefebvre: The right to the city and its urban politics of the inhabitant. GeoJournal, 58(2-3), 99-108. doi:10.1023/B:GEJ0.0000010829.62237.8f

Purcell, M. (2014). Possible Worlds: Henri Lefebvre and the Right to the City. Journal of Urban Affairs, 36(1), 141-154. doi:10.1111/juaf.12034

R Core Team. (2018). R: A language and environment for statistical computing. Vienna, Austria: R Foundation for Statistical Computing. Retrieved from https://www.Rproject.org/ 
Raco, M. (2014). Delivering Flagship Projects in an Era of Regulatory Capitalism: State-led Privatization and the London Olympics 2012. International Journal of Urban and Regional Research, 38(1), 176-197. doi:10.1111/1468-2427.12025

Rawls, J. (1999). A theory of justice (revised edition.). Cambridge, Mass.: Belknap Press of Harvard University Press.

Rawls, J. (2001). Justice as fairness : a restatement. Cambridge, Mass; London: Harvard University Press.

Rezende, V., \& Leitão, G. (2003). Plano Piloto para a Barra da Tijuca e Baixada de Jacarepaguá, a avaliação dos ideais modernistas após três décadas. In XVII Congresso Brasileiro de Arquitetos, Rio de Janeiro. Retrieved from http://xa.yimg.com/kq/groups/21776930/1339371762/name/PET+plano+piloto+ Barra+Baixada+Jaca+EAU-UFF.pdf

Ribeiro, L. C. de Q. (Ed.). (2014). The Metropolis of Rio de Janeiro: a space in transition (1st ed.). Rio de Janeiro: Letra Capital.

Ribeiro, L. C. de Q. (2017). Urban Transformations in Rio de Janeiro: Development, Segregation, and Governance. Springer.

Ribeiro, L. C. de Q., Rodrigues, J. M., \& Corrêa, F. S. (2010). Segregação residencial e emprego nos grandes espaços urbanos brasileiros. Cadernos Metrópole. ISSN (impresso) 15172422; (eletrônico) 2236-9996, 12(23). Retrieved from http://revistas.pucsp.br/index.php/metropole/article/view/5921

Ricciardi, A. M., Xia, J., \& Currie, G. (2015). Exploring public transport equity between separate disadvantaged cohorts: a case study in Perth, Australia. Journal of Transport Geography, 43, 111-122. doi:10.1016/j.jtrangeo.2015.01.011

Rietveld, P., Rouwendal, J., \& van der Vlist, A. (2007). Equity Issues in the Evaluation of Transport Policies and Transport Infrastructure Projects. In M. S. van Geenhuizen, A. Reggiani, \& P. Rietveld (Eds.), Policy analysis of transport networks (pp. 19-36). Aldershot: Ashgate.

Rio de Janeiro. (1996). Strategic Plan for the City of Rio de Janeiro - Rio Forever Rio. Rio de Janeiro: City Hall of Rio de Janeiro.

Rio de Janeiro. (2005). Plano diretor de transporte urbano da região metropolitana do Rio de Janeiro. Relatório 2 - analise de estudos e planos existentes. Revisão 2. Rio de Janeiro: 
Governo do Estado. Secretaria de Estado de Transportes. Retrieved from http://download.rj.gov.br/documentos/10112/1474054/DLFE59250.pdf/Relatorio02AnaliseEstudosExistentes.pdf

Rio de Janeiro. (2008). Plano de Legado Urbano e Ambiental: Olimpíadas Rio 2016. Rio de Janeiro: Comitê Especial de Legado Urbano - Secretaria Municipal de Urbanismo. Retrieved from http://www.rio.rj.gov.br/web/smu/exibeconteudo?article$\mathrm{id}=138922$

Rio de Janeiro. (2014). Atualização do Plano Diretor de Regionalização - 2012 / 2013. Secretaria Estadual de Saúde do Estado do Rio de Janeiro. Retrieved from http://www.saude.rj.gov.br/component/docman/?task=doc_download\&gid=9794\& Itemid $=1214$

Rio de Janeiro. (2015). Explaining Rio de Janeiro habitational policy. Rio de Janeiro: City Hall of Rio de Janeiro. Retrieved from https://drive.google.com/file/d/0B1x0_cNhKxbDb094M1hraGVNekU/view

Rio de Janeiro. (2016). Rio 2016: Jogos Olímpicos e legado - Cadernos de políticas públicas. Rio de Janeiro: City Hall of Rio de Janeiro.

Ritchie, J. R. B. (1984). Assessing the Impact of Hallmark Events: Conceptual and Research Issues. Journal of Travel Research, 23(1), 2-11. doi:10.1177/004728758402300101

RJTV. (2018, January 23). "Mãos à Obra" prende cinco pessoas investigadas por receber propina da Transbrasil. Rio de Janeiro, Brasil. Retrieved from https://globoplay.globo.com/v/6441668/

Robbins, D., Dickinson, J., \& Calver, S. (2007). Planning transport for special events: a conceptual framework and future agenda for research. International Journal of Tourism Research, 9(5), 303-314. doi:10.1002/jtr.639

Robeyns, I. (2003). Sen's Capability Approach and Gender Inequality: Selecting Relevant $\begin{array}{llll}\text { Capabilities. } & \text { Feminist } & \text { Economics, } & \text { 9(2-3), }\end{array}$ doi:10.1080/1354570022000078024

Robeyns, I. (2005). The Capability Approach: a theoretical survey. Journal of Human Development, 6(1), 93-117. doi:10.1080/146498805200034266

Roche, M. (1994). Mega-events and urban policy. Annals of Tourism Research, 21(1), 1-19. doi:10.1016/0160-7383(94)90002-7 
Rodrigues, J. M. (2013). Transformações urbanas e crise da mobilidade urbana no Brasil: hipóteses sobre o caso do Rio de Janeiro no contexto dos megaeventos. E-Metropolis: Revista Eletrônica de Estudos Urbanos e Regionais, 4(14), 38-51.

Rodrigues, J. M., \& Legroux, J. (2015). A questão da mobilidade urbana na Região Metropolitana do Rio de Janeiro: reflexões a partir dos projetos de infraestrutura para megaeventos esportivos. In D. G. Castro et al. (Ed.), Rio de Janeiro. Os impactos da copa do mundo 2014 e das Olimpíadas 2016 (1st ed.). Rio de Janeiro: Letra Capital.

Rodrigues, M. (2016). Após 5 meses, usuários reprovam racionalização de ônibus no Rio 03/03/2016. G1 Rio Globo.Com. Retrieved from http://g1.globo.com/rio-dejaneiro/noticia/2016/03/apos-5-meses-usuarios-reprovam-racionalizacao-deonibus-no-rio.html

Rodrigues, R. (2017, June 28). Metrô faz oferta promocional após queda de 14,5\% nas viagens - Jornal 0 Globo. Retrieved from https://oglobo.globo.com/rio/metro-fazoferta-promocional-apos-queda-de-145-nas-viagens-21527565

Rosenbloom, S., \& Altshuler, A. (1977). Equity Issues in Urban Transportation. Policy Studies Journal, 6(1), 29-40. doi:10.1111/j.1541-0072.1977.tb01163.x

Rubalcaba-Bermejo, L., \& Cuadrado-Roura, J. R. (1995). Urban Hierarchies and Territorial Competition in Europe: Exploring the Role of Fairs and Exhibitions. Urban Studies, 32(2), 379-400. doi:10.1080/00420989550013149

Ryan, J., Wretstrand, A., \& Schmidt, S. M. (2015). Exploring public transport as an element of older persons' mobility: A Capability Approach perspective. Journal of Transport Geography, 48, 105-114. doi:10.1016/j.jtrangeo.2015.08.016

Sager, T. (2006). Freedom as Mobility: Implications of the Distinction between Actual and Potential Travelling. Mobilities, 1(3), 465-488. doi:10.1080/17450100600902420

Sánchez, F., \& Broudehoux, A.-M. (2013). Mega-events and urban regeneration in Rio de Janeiro: planning in a state of emergency. International Journal of Urban Sustainable Development, 5(2), 132-153. doi:10.1080/19463138.2013.839450

Sanchez, T. W., Stolz, R., \& Ma, J. S. (2003). Moving to equity: addressing inequitable effects of transportation policies on minorities. Cambridge, MA: Civil Rights Project at Harvard University and Center for Community Change. Retrieved from goo.gl/n18BZY

Sandel, M. J. (1984). Liberalism and its critics. New York: New York University Press. 
Sandel, M. J. (2009). Justice: what's the right thing to do? (1st ed..). New York: Farrar, Straus and Giroux.

Sandy, M. (2016, March 24). The Rio Olympics Could Be the Next Victim of Brazil's Corruption Scandal. Time. Retrieved from http://time.com/4271376/brazil-corruption-scandalolympics /

Santos, G., Behrendt, H., Maconi, L., ... Teytelboym, A. (2010). Part I: Externalities and economic policies in road transport. Research in Transportation Economics, 28(1), 245. doi:10.1016/j.retrec.2009.11.002

Santos, G., \& Rojey, L. (2004). Distributional impacts of road pricing: The truth behind the myth. Transportation, 31(1), 21-42. doi:10.1023/B:PORT.0000007234.98158.6b

Santos, R. R. de 0. (2013, September 30). O planejamento da cidade é o planejamento dos jogos? O megaevento olímpico como instrumento de (re)ordenação do território carioca (text). Universidade de São Paulo, São Paulo. Retrieved from http://www.teses.usp.br/teses/disponiveis/16/16139/tde-06012014-160038/

Scholl, L., Bouillon, C. P., Oviedo, D., ... Jansson, M. (2016). Urban Transport and Poverty: Mobility and Accessibility Effects of IDB-supported BRT Systems in Cali and Lima. Washington, DC: Inter-American Development Bank.

Schwanen, T., \& Wang, D. (2014). Well-Being, Context, and Everyday Activities in Space and Time. Annals of the Association of American Geographers, 104(4), 833-851. doi:10.1080/00045608.2014.912549

Schweitzer, L., \& Valenzuela, A. (2004). Environmental Injustice and Transportation: The Claims and the Evidence. Journal of Planning Literature, 18(4), 383-398. doi:10.1177/0885412204262958

Sen, A. (1979). Equality of what? The Tanner Lectures on Human Values, 1, 353-369.

Sen, A. (1999). Development as freedom. New York: Anchor books.

Sen, A. (2005). Human Rights and Capabilities. Journal of Human Development, 6(2), 151166. doi:10.1080/14649880500120491

Sen, A. (2009). The idea of justice. Cambridge, Mass: Belknap Press of Harvard Univ. Press.

Serebrisky, T., Gómez-Lobo, A., Estupiñán, N., \& Muñoz-Raskin, R. (2009). Affordability and Subsidies in Public Urban Transport: What Do We Mean, What Can Be Done? Transport Reviews, 29(6), 715-739. doi:10.1080/01441640902786415 
Seto, K. C., Güneralp, B., \& Hutyra, L. R. (2012). Global forecasts of urban expansion to 2030 and direct impacts on biodiversity and carbon pools. Proceedings of the National Academy of Sciences, 109(40), 16083-16088. doi:10.1073/pnas.1211658109

Shaheen, S., Totte, H., \& Stocker, A. (2018). Future of Mobility White Paper. California, USA: California Department of Transportation. Retrieved from https://escholarship.org/uc/item/68g2h1qv

Shariff, A., Bonnefon, J.-F., \& Rahwan, I. (2017). Psychological roadblocks to the adoption of self-driving vehicles. Nature Human Behaviour, 1(10), 694. doi:10.1038/s41562-017$0202-6$

Sheller, M. (2013). The islanding effect: post-disaster mobility systems and humanitarian logistics in Haiti. Cultural Geographies, 20(2), 185-204. doi:10.1177/1474474012438828

Sheller, M. (2016). Uneven Mobility Futures: A Foucauldian Approach. Mobilities, 11(1), 1531. doi:10.1080/17450101.2015.1097038

Shin, H. (2011). Spatial Capability for Understanding Gendered Mobility for Korean Christian Immigrant Women in Los Angeles Spatial Capability for Understanding Gendered Mobility for Korean Christian Immigrant Women in Los Angeles. Urban Studies, 48(11), 2355-2373. doi:10.1177/0042098010388955

Shin, H. B., \& Li, B. (2013). Whose games? The costs of being "Olympic citizens" in Beijing. Environment and Urbanization, 0956247813501139. doi:10.1177/0956247813501139

Shliselberg, R., \& Givoni, M. (2018). Motility as a policy objective. Transport Reviews, 38(3), 279-297. doi:10.1080/01441647.2017.1355855

Short, J. R. (2008). Globalization, cities and the Summer Olympics. City, 12(3), 321-340. doi:10.1080/13604810802478888

Silva, M. A. V. da, \& Portugal, L. da S. (2016). Location factors affecting trip generation during megaevents. Proceedings of the Institution of Civil Engineers - Municipal Engineer, 114. doi:10.1680/jmuen.16.00014

Silvestre, G. (2012). An Olympic city in the making : Rio de Janeiro mega-event strategy 19932016. IOC Olympic Studies Centre. Retrieved from http://doc.rero.ch/record/32218 
Silvestre, G., \& de Oliveira, N. G. (2012). The revanchist logic of mega-events: community displacement in Rio de Janeiro's West End. Visual Studies, 27(2), 204-210. doi:10.1080/1472586X.2012.677506

Smith, A. (2009). Theorising the Relationship between Major Sport Events and Social Sustainability. Journal of Sport \& Tourism, 14(2-3), 109-120. doi:10.1080/14775080902965033

Smith, D. M. (1997). Back to the Good Life: Towards an Enlarged Conception of Social Justice. Environment and Planning D: Society and Space, 15(1), 19-35. doi:10.1068/d150019

Smith, D. M. (2000). Social Justice Revisited. Environment and Planning A: Economy and Space, 32(7), 1149-1162. doi:10.1068/a3258

Smith, N., Hirsch, D., \& Davis, A. (2012). Accessibility and capability: the minimum transport needs and costs of rural households. Journal of Transport Geography, 21, 93-101. doi:10.1016/j.jtrangeo.2012.01.004

Soja, E. W. (2010). Seeking spatial justice. Minneapolis: University of Minnesota Press.

Souza, P. H. G. F. de. (2015). Income distribution according to Brazilian household surveys: harmonization and comparison of Census, PNAD and POF data. Revista Brasileira de Estudos de População, 32(1), 165-188. doi:10.1590/S0102-30982015000000009

Steinbrink, M., Haferburg, C., \& Ley, A. (2011). Festivalisation and urban renewal in the Global South: socio-spatial consequences of the 2010 FIFA World Cup. South African Geographical Journal, 93(1), 15-28. doi:10.1080/03736245.2011.567827

Stępniak, M., \& Jacobs-Crisioni, C. (2017). Reducing the uncertainty induced by spatial aggregation in accessibility and spatial interaction applications. Journal of Transport Geography, 61, 17-29. doi:10.1016/j.jtrangeo.2017.04.001

Stępniak, M., \& Rosik, P. (2017). The Role of Transport and Population Components in Change in Accessibility: the Influence of the Distance Decay Parameter. Networks and Spatial Economics. doi:10.1007/s11067-017-9376-8

Stewart, A. F. (2017). Mapping transit accessibility: Possibilities for public participation. Transportation Research Part A: Policy and Practice, 104, 150-166. doi:10.1016/j.tra.2017.03.015 
Stewart, A., \& Rayner, S. (2016). Planning mega-event legacies: uncomfortable knowledge for host cities. Planning Perspectives, 31(2), 157-179. doi:10.1080/02665433.2015.1043933

Stokenberga, A. (2014). Does Bus Rapid Transit Influence Urban Land Development and Property Values: A Review of the Literature. Transport Reviews, 34(3), 276-296. doi:10.1080/01441647.2014.902404

Taleai, M., Sliuzas, R., \& Flacke, J. (2014). An integrated framework to evaluate the equity of urban public facilities using spatial multi-criteria analysis. Cities, 40, 56-69. doi:10.1016/j.cities.2014.04.006

Tan, P. Y., \& Samsudin, R. (2017). Effects of spatial scale on assessment of spatial equity of urban park provision. Landscape and Urban Planning, 158, 139-154. doi:10.1016/j.landurbplan.2016.11.001

Temenos, C., Nikolaeva, A., Schwanen, T., ... Sheller, M. (2017). Theorizing Mobility Transitions: An Interdisciplinary Conversation. Transfers, 7(1), 113-129. doi:10.3167/TRANS.2017.070109

Thomopoulos, N., \& Grant-Muller, S. (2013). Incorporating equity as part of the wider impacts in transport infrastructure assessment: an application of the SUMINI approach. Transportation, 40(2), 315-345. doi:10.1007/s11116-012-9418-5

Thomopoulos, N., Grant-Muller, S., \& Tight, M. R. (2009). Incorporating equity considerations in transport infrastructure evaluation: Current practice and a proposed methodology. Evaluation and Program Planning, 32(4), 351-359. doi:10.1016/j.evalprogplan.2009.06.013

Tilahun, N., \& Fan, Y. (2014). Transit and job accessibility: an empirical study of access to competitive clusters and regional growth strategies for enhancing transit accessibility. Transport Policy, 33, 17-25. doi:10.1016/j.tranpol.2014.02.002

Tomlinson, A. (2014). Olympic legacies: recurrent rhetoric and harsh realities. Contemporary Social Science, 9(2), 137-158. doi:10.1080/21582041.2014.912792

Tonkiss, F. (2013). Cities by design: the social life of urban form. Cambridge: Polity.

Trinder, E., Hay, A., Dignan, J., ... Skorupski, J. (1991). Concepts of equity, fairness, and justice in British transport legislation, 1960 - 88. Environment and Planning C: Government and Policy, 9(1), 31 - 50. doi:10.1068/c090031 
Tsutsumi, M., \& Seya, H. (2008). Measuring the impact of large-scale transportation projects on land price using spatial statistical models. Papers in Regional Science, 87(3), 385401. doi:10.1111/j.1435-5957.2008.00192.x

Tyler, N. (2006). Capabilities and Radicalism: Engineering Accessibility in the 21st century. Transportation Planning and Technology, 29(5), 331-358. doi:10.1080/03081060600917629

UN HABITAT. (2013). Planning and Design for Sustainable Urban Mobility: Global Report on Human Settlements 2013. London: Routledge: UN HABITAT. Retrieved from http://www.unhabitat.org/pmss/listItemDetails.aspx?publicationID=3503

UN-HABITAT. (2010). State of the World's Cities 2010/2011-Cities for All: Bridging the Urban Divide (p. 244). UN-HABITAT. Retrieved from http://unhabitat.org/books/state-ofthe-worlds-cities-20102011-cities-for-all-bridging-the-urban-divide/

United Nations. (2015). Transforming our world: the 2030 Agenda for Sustainable Development (Resolution adopted by the General Assembly No. A/RES/70/1). New York.

Retrieved from http://www.un.org/ga/search/view_doc.asp?symbol=A/RES/70/1\&Lang=E

Uteng, T. P., \& Cresswell, T. (2008). Gendered mobilities. Aldershot: Ashgate.

van Wee, B. (2011). Transport and Ethics [electronic resource] : Ethics and the Evaluation of Transport Policies and Projects. Cheltenham: Edward Elgar Pub.

van Wee, B. (2012). How suitable is CBA for the ex-ante evaluation of transport projects and policies? A discussion from the perspective of ethics. Transport Policy, 19(1), 1-7. doi:10.1016/j.tranpol.2011.07.001

van Wee, B. (2016). Accessible accessibility research challenges. Journal of Transport Geography, 51, 9-16. doi:10.1016/j.jtrangeo.2015.10.018

van Wee, B., \& Geurs, K. (2011). Discussing equity and social exclusion in accessibility evaluations. European Journal of Transport and Infrastructure Research, 11(4). Retrieved from http://www.ejtir.tbm.tudelft.nl/issues/2011_04/abstracts/2011_04_01.asp

van Wee, B., Hagenzieker, M., \& Wijnen, W. (2014). Which indicators to include in the ex ante evaluations of the safety effects of policy options? Gaps in evaluations and a 
discussion based on an ethical perspective. Transport Policy, 31, 19-26. doi:10.1016/j.tranpol.2013.11.002

van Wee, B., \& Rietveld, P. (2013). Using value of statistical life for the ex ante evaluation of transport policy options: a discussion based on ethical theory. Transportation, 40(2), 295-314. doi:10.1007/s11116-012-9425-6

van Wee, B., \& Roeser, S. (2013). Ethical Theories and the Cost-Benefit Analysis-Based Ex Ante Evaluation of Transport Policies and Plans. Transport Reviews, 33(6), 743-760. doi:10.1080/01441647.2013.854281

Vanwynsberghe, R., Surborg, B., \& Wyly, E. (2013). When the Games Come to Town: Neoliberalism, Mega-Events and Social Inclusion in the Vancouver 2010 Winter Olympic Games. International Journal of Urban and Regional Research, 37(6), 20742093. doi:10.1111/j.1468-2427.2012.01105.x

Vasconcellos, E. A. de. (2001). Urban transport, environment, and equity: the case for developing countries. London, UK ;Sterling, VA: Earthscan.

Vasconcellos, E. A. de. (2005). Transport metabolism, social diversity and equity: The case of São Paulo, Brazil. Journal of Transport Geography, 13(4), 329-339. doi:10.1016/j.jtrangeo.2004.10.007

Vasconcellos, E. A. de. (2014). Políticas de transporte no Brasil: a construção da mobilidade excludente. MANOLE.

Veale, M., \& Ribas, F. (2017). Data Management and Use: Case Studies of Technologies and Governance. London: The Royal Society and the British Academy. Retrieved from http://www.homepages.ucl.ac.uk/ ucqnmve/papers/RSCaseStudies.pdf

Venter, C., Jennings, G., Hidalgo, D., \& Pineda, A. F. V. (2017). The equity impacts of bus rapid transit: A review of the evidence and implications for sustainable transport. International Journal of Sustainable Transportation, o(0), 1-13. doi:10.1080/15568318.2017.1340528

Verlinghieri, E., \& Venturini, F. (2017). Exploring the right to mobility through the 2013 mobilizations in Rio de Janeiro. Journal of Transport Geography. doi:10.1016/j.jtrangeo.2017.09.008

Vermeiren, K., Verachtert, E., Kasaija, P., ... Van Rompaey, A. (2015). Who could benefit from a bus rapid transit system in cities from developing countries? A case study from 
Kampala, Uganda. Journal of Transport Geography, 47, 13-22. doi:10.1016/j.jtrangeo.2015.07.006

Viegas, J. M. (2001). Making urban road pricing acceptable and effective: searching for quality and equity in urban mobility. Transport Policy, 8(4), 289-294. doi:10.1016/S0967070X(01)00024-5

Villaça, F. (1998). Espaço intra-urbano no Brasil. Studio Nobel.

Wachs, M., \& Kumagai, K. (1973). Physical accessibility as a social indicator. Socio-Economic Planning Sciences, 7(5), 437-456. doi:10.1016/0038-0121(73)90041-4

Walzer, M. (1983). Spheres of justice : a defense of pluralism and equality. New York: Basic Books.

Watson, M. (2012). How theories of practice can inform transition to a decarbonised transport system. Journal of Transport Geography, 24, 488-496. doi:10.1016/j.jtrangeo.2012.04.002

Watts, J. (2015, June 3). Forced evictions in Rio favela for 2016 Olympics trigger violent $\begin{array}{llll}\text { clashes. The Guardian. } & \text { Retrieved }\end{array}$ http://www.theguardian.com/world/2015/jun/03/forced-evictions-vilaautodromo-rio-olympics-protests

Weed, M., Coren, E., Fiore, J., ... Dowse, S. (2015). The Olympic Games and raising sport participation: a systematic review of evidence and an interrogation of policy for a demonstration effect. European Sport Management Quarterly, 15(2), 195-226. doi:10.1080/16184742.2014.998695

Welch, T. F. (2013). Equity in transport: The distribution of transit access and connectivity among affordable housing units. Transport Policy, 30, 283-293. doi:10.1016/j.tranpol.2013.09.020

Wessel, N., Allen, J., \& Farber, S. (2017). Constructing a routable retrospective transit timetable from a real-time vehicle location feed and GTFS. Journal of Transport Geography, 62, 92-97. doi:10.1016/j.jtrangeo.2017.04.012

Whitson, D., \& Horne, J. (2006). Part 2 The Glocal Politics of Sports Mega-Events: Underestimated costs and overestimated benefits? Comparing the outcomes of sports mega-events in Canada and Japan. The Sociological Review, 54, 71-89. doi:10.1111/j.1467-954X.2006.00654.x 
Williams, S., White, A., Waiganjo, P., ... Klopp, J. (2015). The digital matatu project: Using cell phones to create an open source data for Nairobi's semi-formal bus system. Journal of Transport Geography, 49, 39-51. doi:10.1016/j.jtrangeo.2015.10.005

Winston, C. (2000). Government Failure in Urban Transportation. Fiscal Studies, 21(4), 403425. doi:10.1111/j.1475-5890.2000.tb00030.x

Wixey, S., Jones, P., Lucas, K., \& Aldridge, M. (2003). Measuring accessibility as experienced by different socially disadvantaged groups (Working Paper 2 - Social Groups User Needs Survey Findings). London: Transport Studies Group - University of Westminster.

Xu, Y., \& Gonzalez, M. C. (2016). Collective benefits in traffic during mega events via the use of information technologies. ArXiv:1607.08203 [Physics]. Retrieved from http://arxiv.org/abs/1607.08203

Yang, X., \& Day, J. (2016). Operationalizing the Capabilities Approach for Urban Policy Evaluation: The Travel Welfare Impacts of Government Job Resettlement. Geography Research Forum, 35(0), 113-137.

Young, I. M. (1990). Justice and the Politics of Difference. Princeton University Press.

Young, I. M. (2001). Equality of Whom? Social Groups and Judgments of Injustice. Journal of Political Philosophy, 9(1), 1-18. doi:10.1111/1467-9760.00115

Zarur, C. (2017). Empresa de ônibus do Rio fecha por causa da crise. Retrieved October 5, 2017, from https://extra.globo.com/noticias/rio/empresa-de-onibus-do-rio-fechapor-causa-da-crise-21258317.html

Zhang, L., \& Zhao, S. X. (2009). City branding and the Olympic effect: A case study of Beijing. Cities, 26(5), 245-254. doi:10.1016/j.cities.2009.05.002

Zhang, M., \& Kukadia, N. (2005). Metrics of Urban Form and the Modifiable Areal Unit Problem. Transportation Research Record: Journal of the Transportation Research Board, 1902, 71-79. doi:10.3141/1902-09

Zuazo, P., Goulart, G., \& Rodrigues, R. (2017, December 29). Sistema de transporte no Rio anda para trás. Extra Online. Rio de Janeiro, Brasil. Retrieved from https://extra.globo.com/noticias/rio/sistema-de-transporte-no-rio-anda-para-tras22237449.html 